\title{
THE INFLUENCE OF THERMAL BARRIER COATING SURFACE ROUGHNESS ON SPARK-IGNITION ENGINE PERFORMANCE AND EMISSIONS
}

\author{
by
}

\author{
Silvio Memme
}

A thesis submitted in conformity with the requirements for the degree of Master of Applied Sciences

\section{Mechanical and Industrial Engineering University of Toronto}

C Copyright by Silvio Memme 2012 


\begin{abstract}
The Influence of Thermal Barrier Coating Surface Roughness on Spark Ignition Engine Performance and Emissions

\author{
Silvio Memme \\ Master of Applied Science \\ Mechanical and Industrial Engineering \\ University of Toronto
}

2012

The effects on heat transfer of piston crown surface finish and use of a metal based thermal barrier coating (TBC) on the piston crown were studied in an SI engine. Measured engine parameters such as power, fuel consumption, emissions and cylinder pressure were used to identify the effects of the coating and its surface finish. Two piston coatings were tested: a baseline copper coating and a metal TBC. Reducing surface roughness of both coatings increased in-cylinder temperature and pressure as a result of reduced heat transfer through the piston crown. These increases resulted in small improvements in both power and fuel consumption, while also having measurable effect on emissions. Oxides of nitrogen emissions were increased while total hydrocarbon emissions were decreased. Improvements attributed to the TBC were found to be small, but statistically significant. At an equivalent surface finish, the TBC performed better than the baseline copper finish.
\end{abstract}




\section{Acknowledgements}

I would first and foremost like to thank Professor James Wallace for everything he has provided me with in the past three years. His ability to maintain things in perspective and to always be a reassuring voice when things seemed insurmountable made it a joy to work with him. His guidance has been greatly appreciated and will not be forgotten.

I would also like to thank those who have made these past two years about more than just the trials and tribulations of the project itself. My labmates Mark, Charles, Robert, Reza, Farhan and Justin were always there to brainstorm, chat and laugh with. Thank you for your help with the project and for helping me keep my sanity. A special thanks also goes out to Osmond Sargeant and Terry Zak, as without their expertise (and uncanny ability to solve the unsolvable and repair the irreparable), I most definitely would not have been able to complete this project. I would like to thank Sheila Baker for always greeting me with a smile (and consoling me after she gave me the inevitable bad news) and Nick for keeping me company those late nights and never letting me give up. I also want to thank Ryan, Gord, Jeff, Fred and Tai in the machine shop; they were always happy to guide me through my many endeavours and made the shop feel like home. Finally, many thanks to Larry Pershin for his help with the coatings used in the project and the Centre for Advanced Coating Technologies for use of their facilities.

I would be remised not to thank those who truly made this possible: my family. My loving parents and sister were always there to listen and to give me support in my times of need, and for this I will always be thankful. 


\section{Contents}

Chapter 1 Introduction ..................................................................................

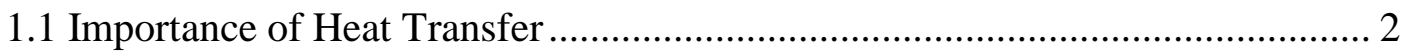

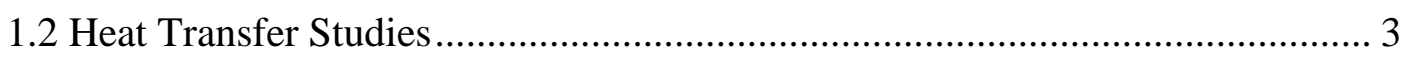

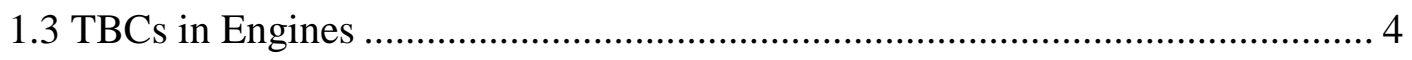

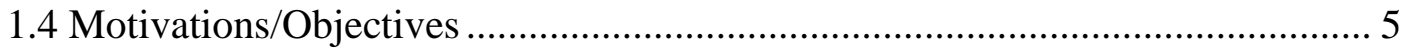

Chapter 2 Literature Review .......................................................................

2.1 Thermal Barrier Coatings .......................................................................... 7

2.1.1 TBCs in Diesel Engines ................................................................... 9

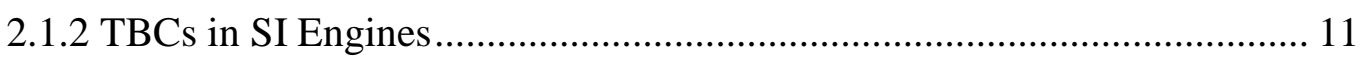

2.1.3 Summary: TBCs in Engines................................................................... 15

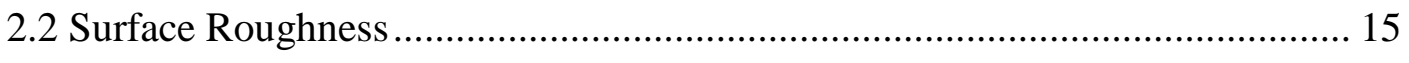

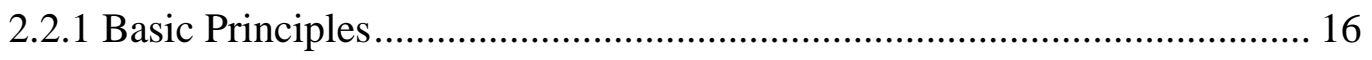

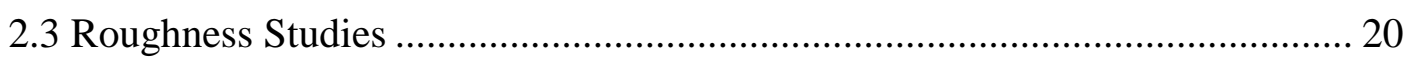

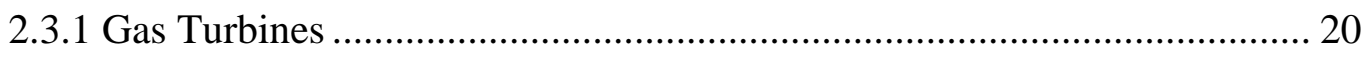

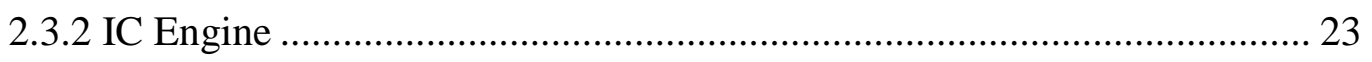

2.3.3 Summary: Roughness Studies............................................................... 24

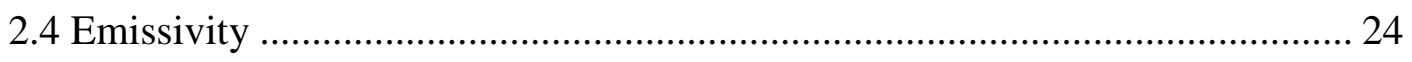

2.4.1 Emissivity Studies............................................................................. 25

2.4.2 Radiation in Engines ....................................................................... 25

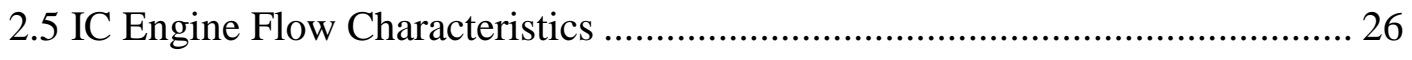

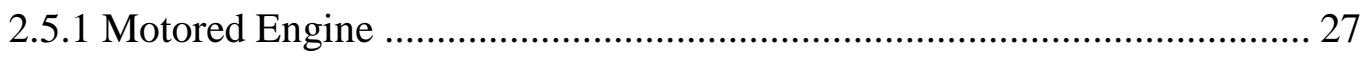

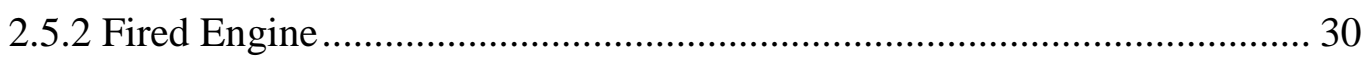

2.5.3 Roughness Effects on Convective Heat Transfer in CFR Engine ............. 32 


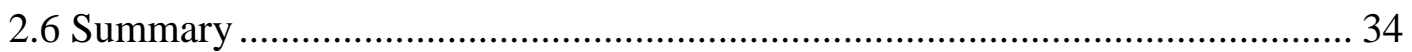

Chapter 3 Experimental Setup and Procedures ............................................... 37

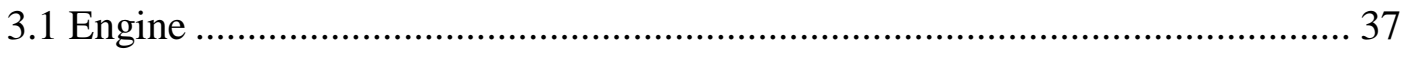

3.1.1 Engine Modifications ................................................................................ 38

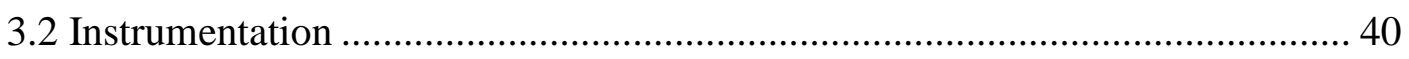

3.2.1 Temperature and Pressure Measurement ................................................... 40

3.2.2 Speed and Torque …………………………………....................... 40

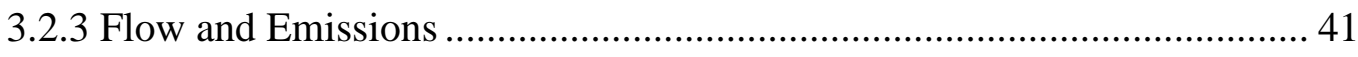

3.3 Data Acquisition System............................................................................ 42

3.4 Proposed Engine Testing Procedure ................................................................ 43

3.4.1 Surface Roughness Measurements …………………………………….... 43

3.4.2 Surface - Flow Interactions ................................................................. 45

3.5 Modified Engine Testing Procedure ................................................................ 46

3.5.1 Modified Test Matrix ................................................................................. 47

Chapter 4 Thermocouple Development ........................................................... 48

4.1 Heat Transfer Analysis Basics ........................................................................ 48

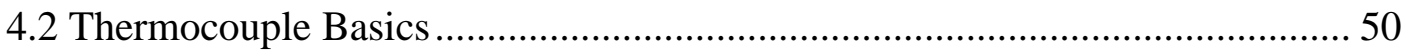

4.2.1 Thermocouple Design Requirements........................................................ 52

4.2.2 Past Surface Thermocouple Designs ……………………………….... 52

4.3 Surface Thermocouple Design and Construction .............................................. 57

4.4 Surface Thermocouple Finite Element Analysis …………………………….... 59

4.4.1 Basic Model Parameters …………………………………………….... 59

4.4.2 Wire and Coating Optimization ............................................................... 62

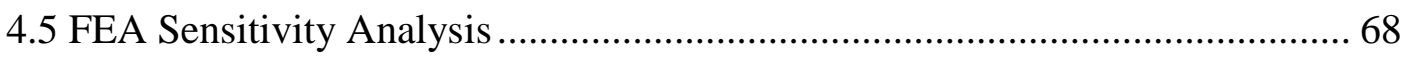

4.6 In-Depth Thermocouple Development ……………......................................... 70 
4.7 Surface Thermocouple FEA Summary .................................................... 72

Chapter 5 Experimental Thermocouple Testing .............................................. 74

5.1 Thermocouple Test Plug Design and Construction ........................................ 74

5.2 Plug Thermocouple Calibration .................................................................. 77

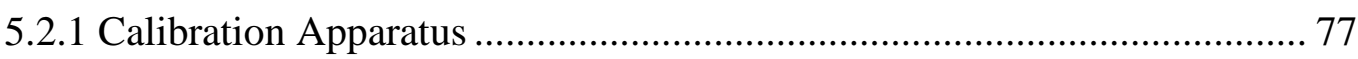

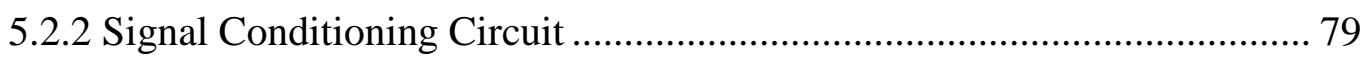

5.2.3 Calibration Procedure ….................................................................... 79

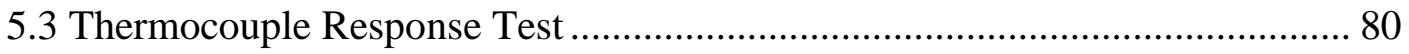

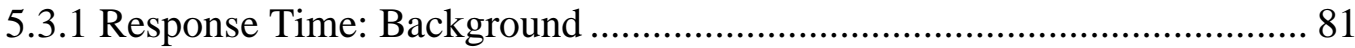

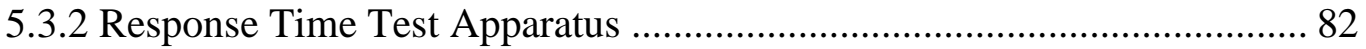

5.3.3 Response Time Results ................................................................ 82

5.3.4 Summary: Thermocouple Response Time ........................................... 86

5.4 Thermocouple Test Conditions and Results .............................................. 86

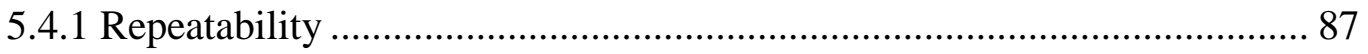

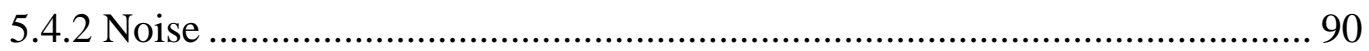

5.5 Thermocouple Development Summary ................................................... 91

Chapter 6 Piston Testing Setup and Methodology ......................................... 92

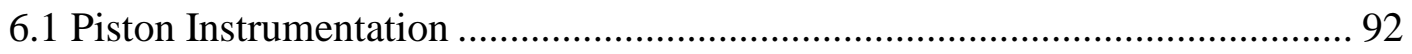

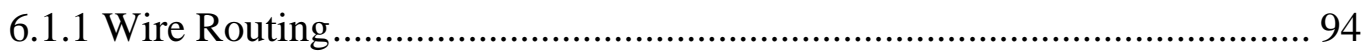

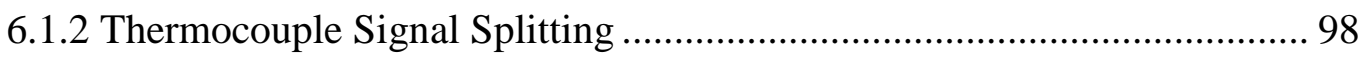

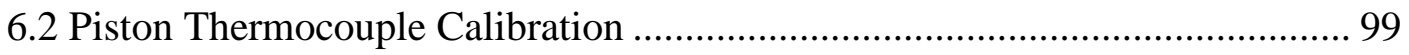

6.2.1 Preliminary Plug Calibration .......................................................... 100

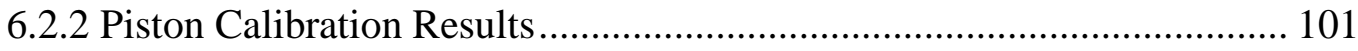

6.3 Data Processing ................................................................................... 102

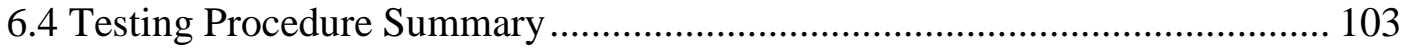


Chapter 7 Piston Surface Roughness Test Results ...................................... 105

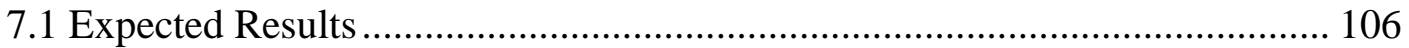

7.2 Engine Performance Metrics......................................................................... 110

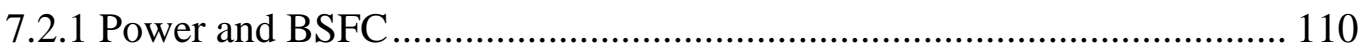

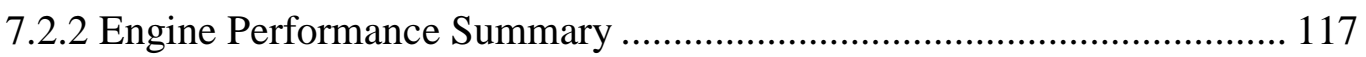

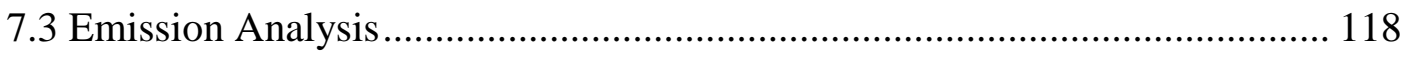

7.3.1 Review of Engine Exhaust Emissions ………………………………..... 119

7.3.2 Carbon Monoxide (CO) ………………………..................................... 121

7.3.3 Total Hydrocarbons (THC) ................................................................. 123

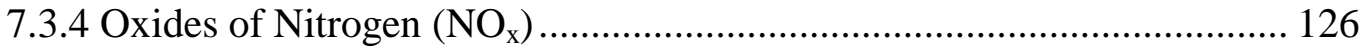

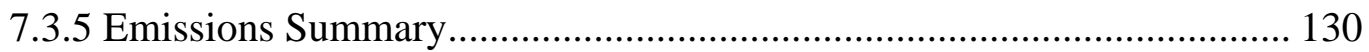

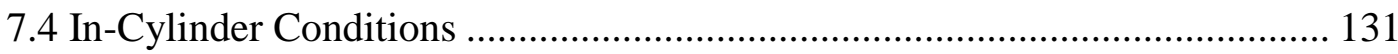

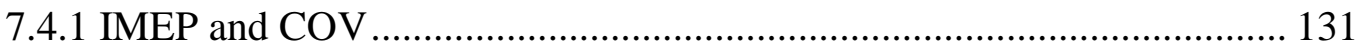

7.4.2 Peak Pressure and Angle of Occurrence .................................................... 134

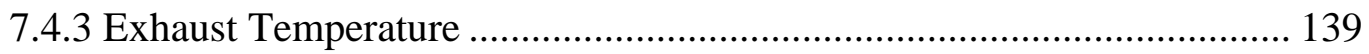

7.5 Piston Surface Roughness Test Results Summary .......................................... 141

Chapter 8 Conclusions and Recommendations .......................................... 143

8.1 Effects of Surface Roughness ....................................................................... 144

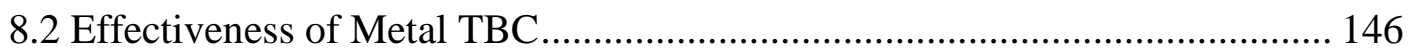

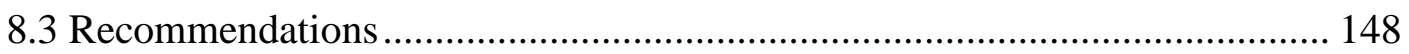

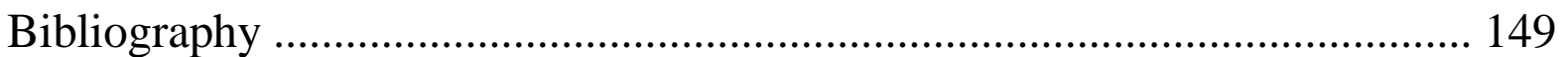

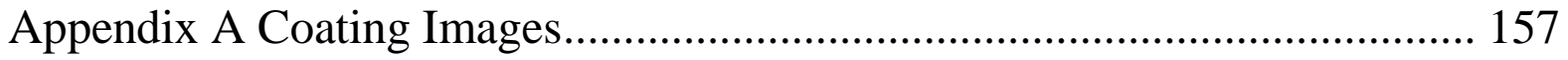

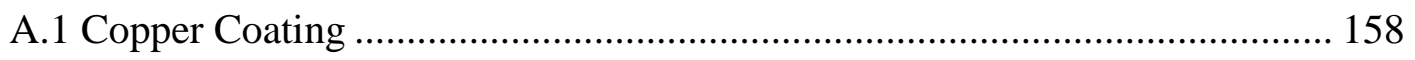

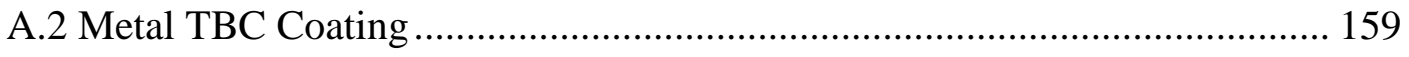

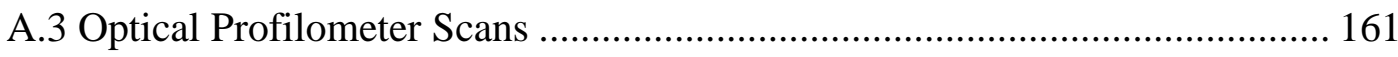

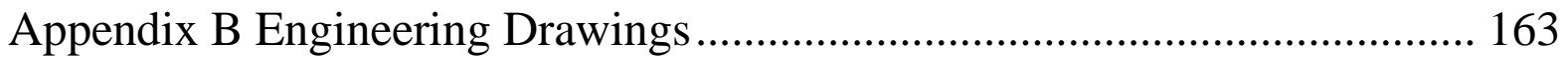


Appendix C Analog Filter Circuit Design ………………………………….... 169

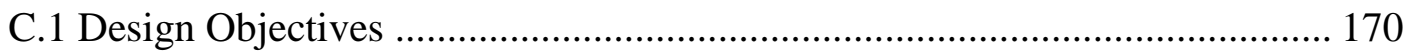

C.2 Circuit Design Features ............................................................................... 170

C.3 Circuit Development Testing Results........................................................... 171

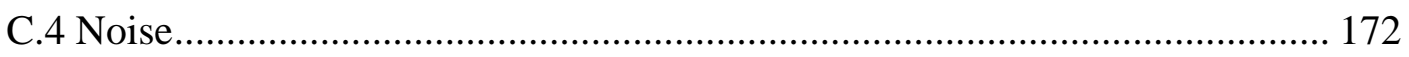

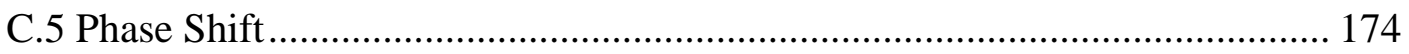

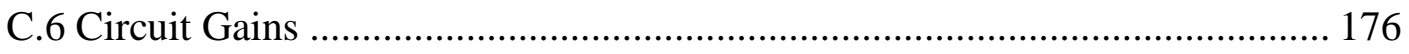

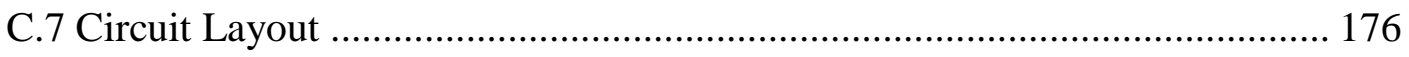

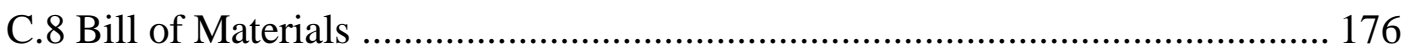

Appendix D Thermocouple Calibration - Circuit Setup.................................. 179

Appendix E Thermocouple Response Time Laser Test ................................ 181

E.1 Half Rise Time Technique....................................................................... 181

Appendix F MATLAB Code Descriptions ................................................... 185

Appendix G Piston Surface Temperature Measurement Overview ............... 189

G.1 Surface Temperature and Heat Flux Measurements ........................................ 189

G.2 Wire Failure Photographs .......................................................................... 192 


\section{List of Tables}

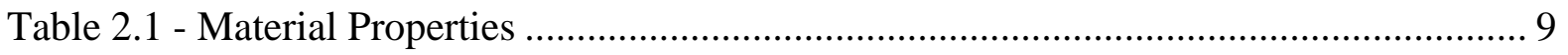

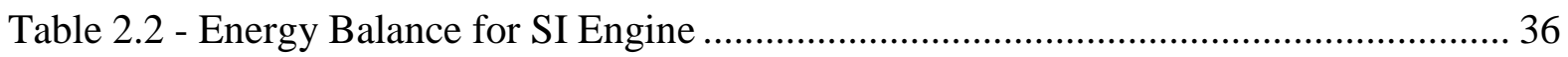

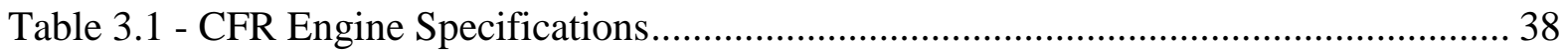

Table 3.2 -Coating Surface Roughness Measurements $\left(R_{a}\right.$ values in $\left.\mu \mathrm{m}\right)$.......................... 44

Table 3.3 - Engine Test Conditions for Piston Surface Roughness Tests ........................... 45

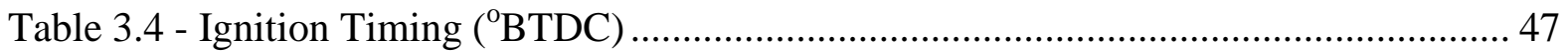

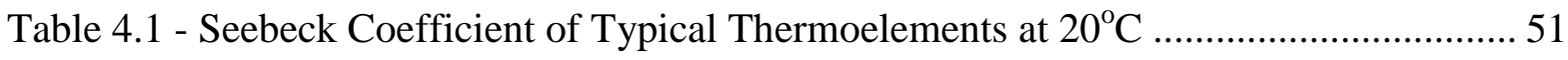

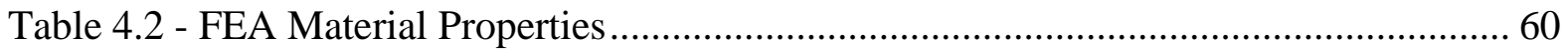

Table 4.3 - FEA Sensitivity Analysis Material Properties.................................................. 69

Table 5.1 - Wire/Hole Diameter Combinations Used in Plug Tests .................................... 75

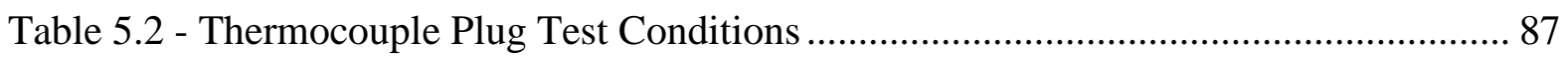

Table 6.1 - Piston Thermocouple Calibration Coefficients ............................................. 101

Table C.1 Samples Engine Test Noise Data (in Volts) ................................................. 172

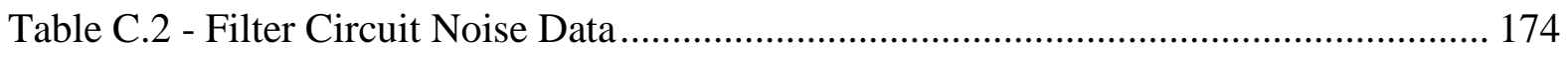

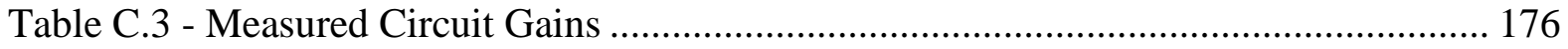

Table C.4 - Circuit Board Bill of Materials ................................................................... 177

Table E.1 - Comparison of Techniques Used to Calculate Thermocouple Response Time. 183 


\section{List of Figures}

Figure 2.1 - Scaled In-Cylinder Velocity Profile .......................................................... 27

Figure 2.2 - Effect of Intake Air Flow Rate on In-Cylinder Velocity in a Motored Engine .. 28

Figure 2.3 - Mean In-Cylinder Velocity in CFR Engine (near Exhaust Valve) ................... 29

Figure 2.4 - Mean In-Cylinder Velocity in CFR Engine (30deg ATDC) ............................ 29

Figure 2.5- Comparison of Motored and Fired Ensemble-Averaged Mean Velocities .......... 31

Figure 2.7 - Breakdown of Engine Heat Transfer............................................................ 36

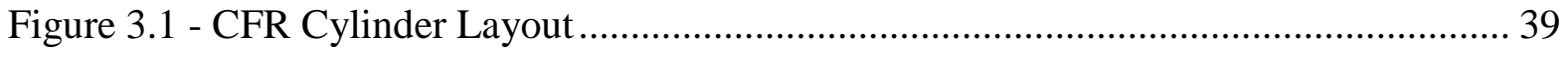

Figure 4.1 - Thermoelectric Effect..................................................................... 51

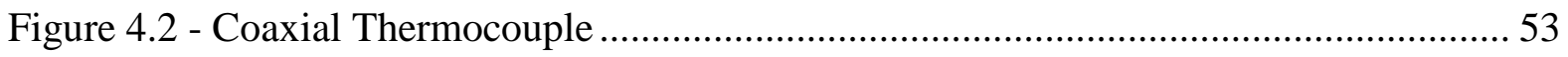

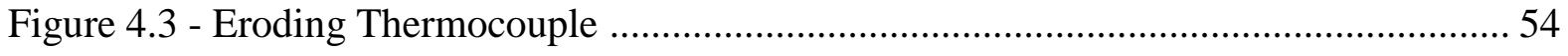

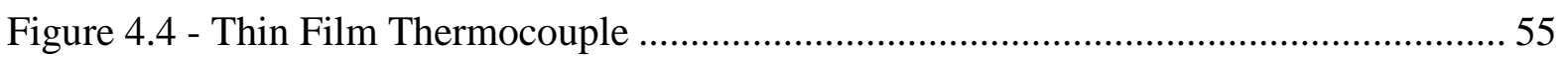

Figure 4.5 - Heichal Surface Thermocouple ............................................................... 56

Figure 4.6 - Surface Thermocouple Schematic............................................................. 58

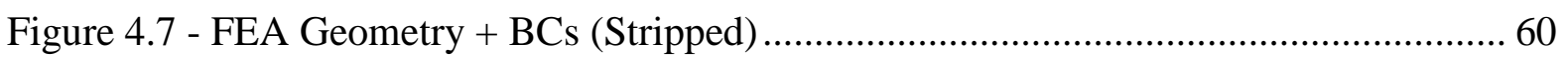

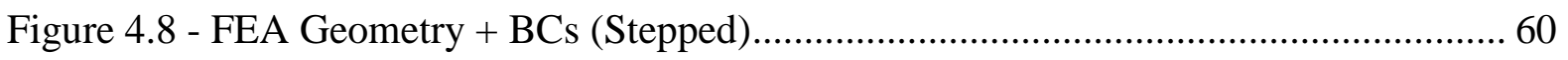

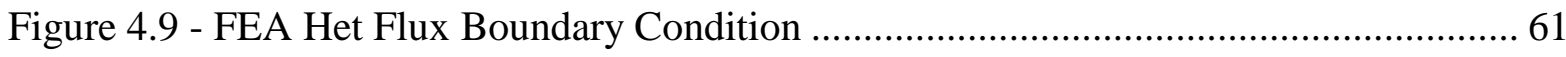

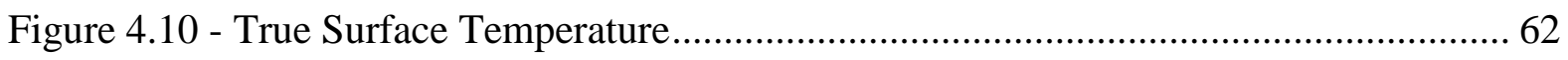

Figure 4.11 - Stripped Geometry FEA Hot Junction Temperature (No Copper Coating) ..... 63

Figure 4.12 - Copper Coating Comparison - Stripped 0.010" Wire Case ............................ 64

Figure 4.13 - FEA Analysis Results - Stepped....................................................... 65

Figure 4.14 - Temperature Response using Different Constantan Wire Diameters $(\mathrm{t}=100 \mathrm{um})$ 66

Figure 4.15 - Comparison of Stepped and Stripped Configurations for 0.015" Wire ........... 67

Figure 4.16 - Comparison of Ideal and Low Conductivity Cases for Different Wire Diameters

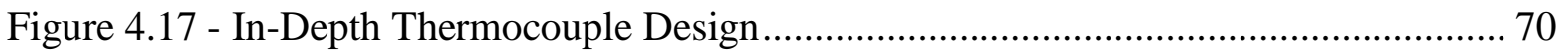

Figure 4.18 - Ratio of In-Depth Thermocouple Temperature Swing (at Different Depths) to

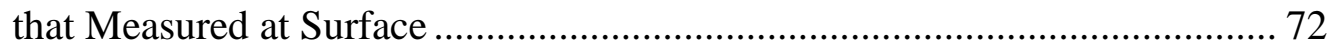


Figure 5.1 - Surface Thermocouple Constantan Wire in Aluminum Substrate Prior to Coating 76

Figure 5.2 - Thermocouple Calibration Apparatus ......................................................... 78

Figure 5.3 - Sample Thermocouple Calibration Curve ..................................................... 80

Figure 5.4 - Thermocouple Time Delay Measurements at Varying Energy Levels .............. 83

Figure 5.5 - Rate of Temperature Change at Varying Energy Levels ................................ 84

Figure 5.6 - Ensemble-Averaged Thermocouple Response Time ...................................... 85

Figure 5.7 - Plug Test Surface Temperature Data vs. BMEP ........................................... 89

Figure 5.8 - Power-Specific Surface Temperatures at Varying Engine Speed and Boost

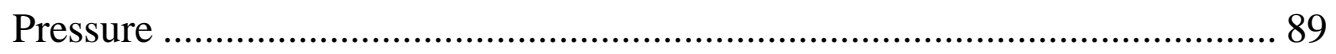

Figure 5.9 - Plug Surface Temperatures as a Function of Wire Diameter ......................... 89

Figure 5.10 - Average Noise in Plug Test Temperature Data for Different Wire Diameters. 90

Figure 6.1 - Tapered Plug Surface Thermocouple and In-Depth Thermocouple Arrangement 93

Figure 6.2 - Piston Thermocouple Layout ...................................................................... 94

Figure 6.3 - Wire Routing Path in CFR Piston ........................................................... 96

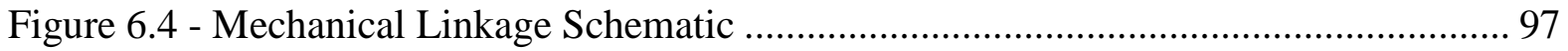

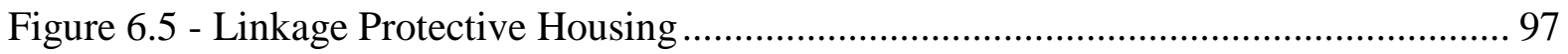

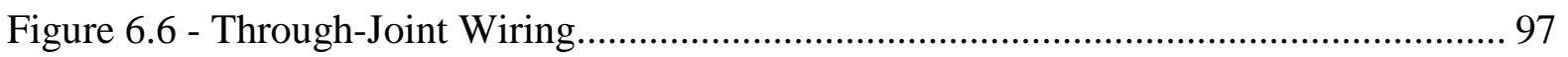

Figure 6.7 - Instrumented Piston - Linkage Assembly ................................................ 98

Figure 6.8 - Preliminary High Temperature Thermocouple Calibration Results Using Test

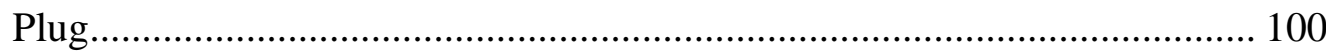

Figure 7.1 - Roughness Reynolds Number at Different Engine Setpoints $(\mathrm{T}=2000 \mathrm{~K})$...... 109

Figure 7.2 - Temperature Dependence of Roughness Reynolds Number .......................... 109

Figure 7.3 - Brake Power vs. Measured Surface Roughness at a) 1350rpm b) 1500rpm and c)

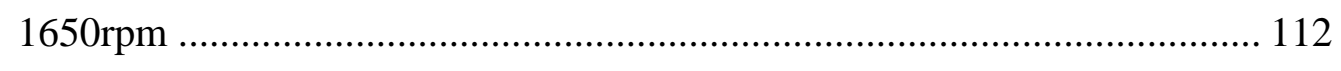

Figure 7.4 - BSFC vs. Measured Surface Roughness at a) 1350rpm b) 1500rpm and c)

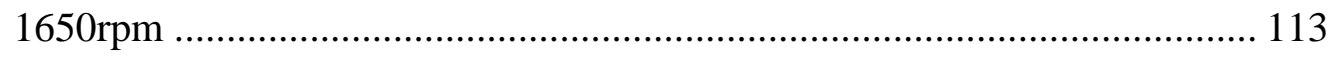

Figure 7.5 - Comparison of a) Copper and b) TBC Mirror Finishes (different scales) ........ 115

Figure 7.6 - Metal TBC Roughness vs. Thickness .......................................................... 116

Figure 7.7 - Emissions in a Gasoline Fueled SI Engine as a Function of $\phi[2]$.................. 120 
Figure 7.8 - Equivalence Ratio at Engine Test Points 120

Figure 7.9 - Carbon Monoxide Emissions vs. Measured Surface Roughness at a) 1350rpm b) 1500rpm and c) $1650 \mathrm{rpm}$

Figure 7.10 - Total Hydrocarbon Emissions vs. Measured Surface Roughness at a) 1350rpm

b) $1500 \mathrm{rpm}$ and c) $1650 \mathrm{rpm}$..... 124

Figure $7.11-\mathrm{NO}_{\mathrm{x}}$ Concentration vs. $\phi$ and Roughness 127

Figure $7.12-\mathrm{NO}_{\mathrm{x}}$ Emissions vs. Surface Roughness at a) 1350rpm b) 1500rpm and c) $1650 \mathrm{rpm}$ 129

Figure 7.13 - IMEP vs. Surface Roughness at a) 1350rpm b) 1500rpm and c) 1650rpm .... 132

Figure 7.14 - IMEP Coefficient of Variability..... 133

Figure 7.15 - Average Peak In-Cylinder Pressure vs. Surface Roughness at a) 1350rpm b) 1500rpm and c) $1650 \mathrm{rpm}$ 135

Figure 7.16 - Average Angle of Peak Pressure $\left(\theta_{\mathrm{Pmax}}\right)$ vs. Surface Roughness at a) 1350rpm b) $1500 \mathrm{rpm}$ and c) $1650 \mathrm{rpm}$. 136

Figure 7.17- Changes in Peak Pressure and Angle of Occurrence. 137

Figure 7.18 - Exhaust Temperature vs. Surface Roughness at a) 1350rpm b) 1500rpm and c) $1650 \mathrm{rpm}$ 140

Figure 7.19 - Exhaust Temperature vs. Combustion Phasing ........................................... 141

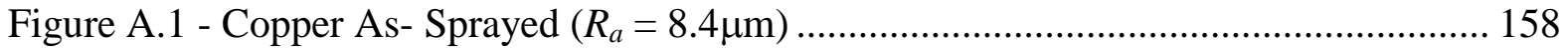

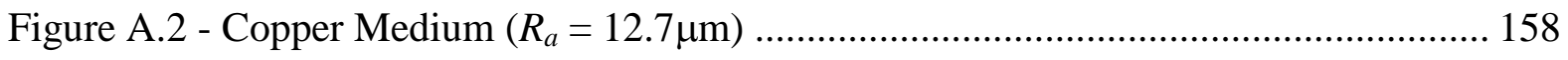

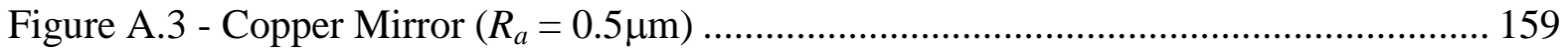

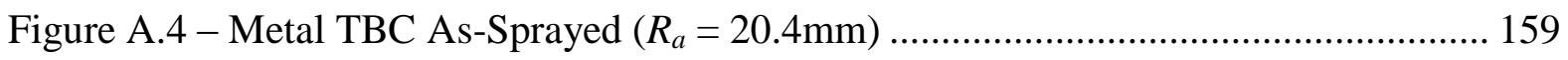

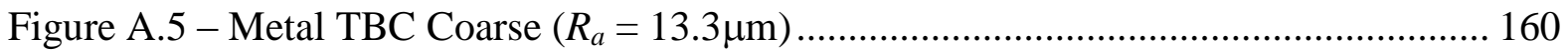

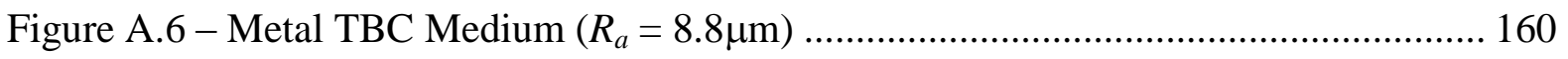

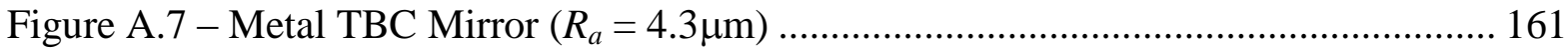

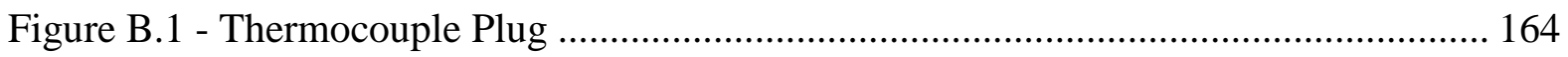

Figure B.2 - Modified Piston ........................................................................................ 165

Figure B.3 - Thermocouple Body - Tapered Pin .......................................................... 166

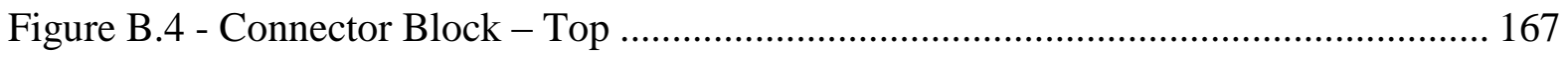

Figure B.5 - Connector Block - Bottom..................................................................... 168 
Figure C.1 - Example of Filtered Temperature Profile 174

Figure C.2 - Filter Circuit Time Delay a) Full cycle and b) Zoom Showing Time Delay ... 175

Figure E.1 - Surface Thermocouple Response to a Single 120mJ Laser Pulse .................. 182

Figure E.2 - Half-Rise Time Method of Determining Thermocouple Response Time ........ 183

Figure E.3 - Thermocouple Time Delay Calculated at Cycle Maximum Temperature........ 184

Figure E.4 - Thermocouple Time Delay Calculated Using Half Rise Time Method .......... 184

Figure G.1 - Instantaneous Surface Temperature Measurement ...................................... 190

Figure G.2 - Instantaneous Heat Flux Measurements................................................... 190

Figure G.3 - Average Piston Surface Temperature Measurements ................................. 191

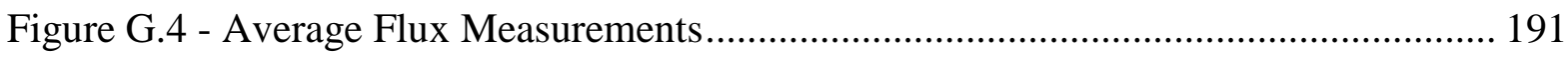

Figure G.5 - Peak Heat Flux Measurements ................................................................ 192 


\section{Nomenclature}

\section{Acronyms}
AFR Air-Fuel Ratio
BMEP Brake Mean Effective Pressure
BSFC Brake Specific Fuel Consumption
CFR Co-operative Fuel Research
COV Coefficient of Variability
CTE Coefficient of Thermal Expansion
$c_{f} \quad$ Friction Coefficient
$e \quad$ Laser Pulse Energy
E Emissive Power
FID Flame Ionization Detector
$f_{c} \quad$ Cut-off Frequency
$h \quad$ Convective Heat Transfer Coefficient
IC Internal Combustion
$k_{s} \quad$ Equivalent Sand Grain Roughness
LDV Laser Doppler Velocimetry
MAP Manifold Air Pressure
MBT Timing for Maximum Brake Torque
MEP Mean Effective Pressure
NDIR Non-Dispersive Infrared Analyzer
NA Naturally Aspirated
NO Nitrogen Monoxide
$\mathrm{NO}_{2} \quad$ Nitrogen Dioxide
$\mathrm{NO}_{\mathrm{x}} \quad$ Oxides of Nitrogen
$\mathrm{Nu} \quad$ Nusselt Number
$\mathrm{P}_{\max } \quad$ Peak Pressure
$\operatorname{Pr} \quad$ Prandtl Number
$R_{a} \quad$ Centreline Average Roughness or Absolute Roughness Height
$R_{r m s} \quad$ Root Mean Square Roughness Height 


$\begin{array}{ll}R e_{k} & \text { Roughness Reynolds Number } \\ R e & \text { Reynolds Number } \\ \bar{s}_{p} & \text { Mean Piston Speed } \\ \mathrm{SI} & \text { Spark Ignition } \\ \mathrm{T} & \text { Temperature } \\ \mathrm{THC} & \text { Total Hydrocarbons } \\ u_{\infty} & \text { Freestream Velocity } \\ \mathrm{UHC} & \text { Unburned Hydrocarbons } \\ v^{*} & \text { Friction Velocity }\end{array}$

\section{Greek Symbols}

$\begin{array}{ll}\alpha & \text { Thermal Diffusivity } \\ \delta & \text { Coating Thickness } \\ \varepsilon & \text { Emissivity } \\ \phi & \text { Equivalence Ratio } \\ \nu & \text { Kinematic Viscosity } \\ \theta_{\text {Pmax }} & \text { Angle of Peak Pressure } \\ \rho & \text { Density } \\ \sigma & \text { Stefan-Boltzman Constant } \\ \tau & \text { Thermocouple Time Delay } \\ \tau_{w} & \text { Wall Shear Stress }\end{array}$




\section{Chapter 1}

\section{Introduction}

The desire to reach higher efficiencies, lower specific fuel consumptions and reduce emissions in modern internal combustion (IC) engines has become the focus of engine researchers and manufacturers for the past three decades. The global concern over the decreasing supply of fossil fuels and the more stringent emissions regulations has placed the onus on the engine industry to produce practical, economical and environmentally conscious solutions to power our vehicles.

Over the years, a variety of different approaches have been taken to attain improvements in efficiency and reduce emissions in existing engine designs. The introduction of new technologies has played a role in making advancements to this centuryold technology. Lighter and stronger materials, advanced manufacturing processes, improved combustion chamber designs, advanced exhaust after-treatment technologies, and new computational means for designing, analyzing and optimizing the internal combustion engine are just a few of the advancements we have made to achieve significant improvements in 
performance, efficiency and emissions. However, over $60 \%$ of the fuel energy we put into our engines is still being wasted due to the inherent inefficiencies in today's internal combustion engines.

\subsection{Importance of Heat Transfer}

Heat loss is one of the primary loss mechanisms in an internal combustion engine and plays a critical role in all aspects of engine operation: performance, efficiency and emissions. The primary means of heat loss from an engine is through the engine cooling system which absorbs combustion- and friction-generated heat energy into a cooling medium (liquid- or air-cooled) and dissipates it to the surroundings to ensure engine temperatures remain below the material and tribological limits of the engine. The heat energy of the exhaust gases accounts for the remainder of the heat losses from the combustion process.

Heat losses from an engine result in decreased engine performance and efficiency. This is due to a portion of the thermal energy from the combustion gases being rejected to the surroundings rather than being converted to increased in-cylinder gas temperatures and pressure, and thus useful engine output. Therefore, thermodynamically, a reduction in engine heat transfer results in increases in overall engine performance.

Heat transfer also plays a critical role in the combustion process in an IC engine, and thus has a direct impact on emissions. Surface temperatures, which directly affect in-cylinder gas temperatures, are critical in the formation/destruction of different products of combustion (i.e. $\mathrm{NO}_{\mathrm{x}}$, unburned hydrocarbons) [1]. Surface temperatures also play an important role in the formation of engine deposits and the tribological behaviour of the lubricant within the engine [2]. Perhaps one of the most important effects heat transfer has on the combustion process in a spark ignition (SI) engine is its effect on knock, or spontaneous pre-ignition of 
the engine fuel. With increasing charge temperatures due to reductions in heat transfer, the likelihood of an SI engine to knock is significantly increased, and thus acts as a limiting factor on the level of combustion chamber heat transfer, which can reduce power output.

Heat transfer also has auxiliary effects on engine operation which do not directly affect performance, but are nonetheless significant. With changes in heat flux reaching $10 \mathrm{MW} / \mathrm{m}^{2}$ during combustion [3], the resulting temperature swings can lead to the thermal fatigue of critical engine components such as the piston, cylinder liner, valves, etc, ultimately leading to the deterioration of the mechanical properties of these components. Decreased exhaust temperatures due to heat losses also results in lower potential for exhaust energy recovery. On the other hand, a reduction in heat rejection allows for reduced cooling requirements, which allows for reductions in engine size, weight and increases vehicle fuel efficiency.

Thus, it is evident that heat management is crucial to the operation and optimization of the internal combustion engine. As a result, the desire to better understand the effects of heat transfer on engine dynamics has led to a great deal of work in the field.

\section{$\underline{1.2}$ Heat Transfer Studies}

Many experimental studies have been conducted in an attempt to gain a better understanding of the mechanisms which affect heat transfer within the combustion chamber. Numerous engine studies have focussed on instrumentation and the effects of engine operating conditions on heat transfer $[\mathbf{4 , 5 , 6 , 7 ]}$, the development of engine heat transfer correlations $[\mathbf{8 , 9 , 1 0}]$, and the relationship between in-cylinder deposit formation and heat transfer $[\mathbf{1 1}, \mathbf{1 2}, \mathbf{1 3}]$. Various computational and analytical models were also developed to aid in predicting heat transfer effects $[\mathbf{1 4 , 1 5 , 1 6 ]}$. Due to the impact of heat transfer on the 
combustion process, work has also been done characterizing the effects of heat transfer on emissions in diesel, gasoline and homogeneous charge compression ignition (HCCI) engines $[\mathbf{1}, \mathbf{1 7}, \mathbf{1 8}, \mathbf{1 9}]$. Borman and Nishiwaki $[3]$ present an overview of the early fundamental studies which had been completed in each of these facets of engine heat transfer.

Each of these fundamental studies has contributed to the understanding of heat transfer in IC engine, with the ultimate goal of improved engine performance and efficiency. They have demonstrated that the most basic factors affecting heat transfer include: engine load, speed, compression ratio, equivalence ratio, ignition timing and in-cylinder flow [2]. Manipulation of these factors can thus be used to control and reduce these losses. This will provide improvements to overall engine performance, reduce thermal loading in components, allow for smaller and lighter cooling systems, and help increase efficiency while decreasing emissions. A means of potentially achieving these goals is through the implementation of thermal barrier coatings (TBC) within the engine.

\subsection{TBCs in Engines}

The purpose of applying thermal barrier coatings to engine components is to impede heat flow by increasing the thermal resistance at the interface between high temperature combustion gases and metallic surfaces. Thermal barrier coatings provide a means of doing this due to their very low thermal conductivities in comparison to the metallic substrates upon which they are applied. This reduction in heat loss to the metallic components translates to higher gas temperatures, which can lead to greater work output and therefore improvements in efficiency. Likewise, the metallic substrates will be exposed to lower peak temperatures as a result of the coatings, and thus reduce the thermal stresses in the engine components. 
Therefore, the following study will investigate the application of thermal barrier coatings in an internal combustion engine with the goal of reducing heat transfer from the combustion chamber and ultimately improving overall engine performance.

\subsection{Motivations/Objectives}

Studies have shown that TBCs have the potential for improving engine performance and emissions in both diesel and SI engines (refer to Chapter 2: Literature Review). Though the ability of thermal barrier coatings to reduce heat transfer in an engine and improve performance seem encouraging, a clear understanding of the true effects these coatings have on engine behaviour has yet to be achieved in the engine research community. After a large influx of work in the 1980's focussing on the development of the "adiabatic" compression ignition engine using thick $(>1 \mathrm{~mm})$ ceramic coatings, interest in $\mathrm{TBCs}$ in $\mathrm{IC}$ engines diminished due to coating durability issues and inconclusive heat transfer/emissions data. The fears of engine knock and irregular combustion resulting from thermal insulation has also deterred any serious attention from using thin TBCs in SI engines, even though studies have shown promising results. In general, a clear understanding of the true reasons for the inconsistency seen in these studies has yet to be agreed upon and has led to an apparent loss of interest in the field.

This has provided an impetus to study and isolate possible explanations for the conflicting heat transfer effects resulting from the introduction of TBCs in the combustion chamber. As will be discussed in detail in Section 2.3, multiple studies have shown that one of the potential causes for the unpredictable results seen from the TBC studies was surface roughness. The use of thermal barrier coatings introduces a rougher surface finish in comparison to the metallic substrate upon which it is applied. This increased roughness can 
therefore have the effect of promoting heat flux through a surface as a result of increased surface area and its effect on the convective heat transfer coefficient, $h$ of the surface [20].

The purpose of this detailed investigation of surface roughness in an IC engine is to provide experimental evidence of whether roughness plays a role in increasing heat transfer in an insulated engine, as well as to quantify any effects it may have on engine emissions and performance. This study will also attempt to contribute to the available information regarding the application of thermal barrier coatings within SI engines. By testing both an uncoated piston and a piston with a metallic thermal barrier coating of different surface finishes at varying engine conditions (i.e. speeds, loads, inlet flow conditions, etc), the experimental data acquired through this testing regime will provide further insight on the feasibility of thin TBCs for the development of cleaner and more efficient SI engines. 


\section{Chapter 2}

\section{Literature Review}

The following chapter will discuss the principles of using thermal barrier coatings within an internal combustion engine and the effects their surface finish may have on heat transfer. The review will begin with a brief overview of TBC characteristics followed by a summary of the previous experimental work which has studied their use in both compression and spark ignition engines. The basic principles governing heat transfer over a rough surface will be discussed, followed by a summary of various heat transfer studies which have examined the effects of surface roughness. Finally, a synopsis of roughness effects on incylinder flow and emissivity will be presented.

\subsection{Thermal Barrier Coatings}

The most common coatings currently used in high temperature engine applications are stabilized zirconias due to their very low thermal conductivity and a coefficient of 
thermal expansion which is higher than the vast majority of insulating ceramics [21]. Coating thicknesses used in engine applications have varied from $0.1 \mathrm{~mm}$ [22] to $4.5 \mathrm{~mm}$ [23], with thicker coatings theoretically providing greater resistance to heat flux. The most common way of applying these coatings has been through plasma spraying which has been used to apply coatings both selectively to specific engine components (i.e. valves, cylinder head, piston crown) and to the entire combustion chamber.

The primary challenges posed by thermal barrier coatings within engine environments stem from their durability. Due to their low coefficients of thermal expansion (CTE) in comparison to the metallic substrates upon which they are applied, ceramic TBCs are prone to cracking, spalling and eventual failure resulting from the cyclic thermal stresses created by the temperature differential between the coating and the substrate. In an attempt to alleviate these problems, new nano-structured ceramic $[\mathbf{2 4}]$ and metal-based TBCs $[\mathbf{2 5 , 2 6}]$ with CTEs more comparable to typical metallic substrates have been studied, with some promising results. Typical material properties of yttria-stabilized zirconium (YSZ), metallic TBCs and a typical aluminum piston material are shown in Table 2.1.

The increased surface temperatures in a TBC-coated combustion chamber may also result in the degradation of engine lubricants, while decreasing the volumetric efficiency of the engine due to heating of the intake charge. As will be discussed, the higher temperatures may also have significant effects on combustion and thus engine emissions.

Though not currently used in production engines, a great deal of research has been conducted studying the use of TBCs in both compression and spark ignition engines as a means of managing heat losses. In the following, a brief overview of the available work in the two research areas is given. 
Table 2.1 - Material Properties

\begin{tabular}{|c|c|c|c|}
\hline & $\begin{array}{c}\text { Yttria-Stabilized } \\
\text { Zirconia (YSZ) } \\
{[26]} \\
\end{array}$ & Metallic TBC [27] & $\begin{array}{c}2618 \text { Aluminum } \\
{[28]}\end{array}$ \\
\hline Application Method & Plasma Spray & $\begin{array}{c}\text { Wire Arc Thermal } \\
\text { Spray }\end{array}$ & - \\
\hline $\begin{array}{c}\text { Thermal Conductivity } \\
(\mathrm{W} / \mathbf{m} \cdot \mathbf{K})\end{array}$ & 1.2 & 1.22 & 146 \\
\hline $\begin{array}{l}\text { Coefficient of Thermal } \\
\text { Expansion }\left(\mathrm{K}^{-1}\right)\end{array}$ & $9.8 \mathrm{E}-6$ [27] & $15 \mathrm{E}-6$ & $2.2 \mathrm{E}-5$ \\
\hline Density $\left(\mathrm{kg} / \mathrm{m}^{3}\right)$ & $5700[27]$ & 7077 & 2760 \\
\hline $\begin{array}{c}\text { Specific Heat Capacity } \\
(\mathrm{J} / \mathrm{kg} \cdot \mathrm{K})\end{array}$ & 490 & 255 & 875 \\
\hline $\begin{array}{c}\text { Thermal Diffusivity } \\
\left(\mathbf{m}^{2} / \mathbf{s}\right)\end{array}$ & $4.9 \times 10^{-7}$ & $6.8 \times 10^{-7}$ & $6.05 \times 10^{-5}$ \\
\hline Porosity (\%) & 10 & 7.5 & - \\
\hline $\begin{array}{l}\text { Average Roughness, } \boldsymbol{R}_{a} \\
(\mu \mathrm{m})\end{array}$ & $7-12$ & $12-20$ & - \\
\hline
\end{tabular}

\subsubsection{TBCs in Diesel Engines}

The vast majority of research studying the use of TBCs in diesel engines was in the development of the adiabatic engine. The premise of this technology was to reduce heat losses from the combustion chamber to a minimum by applying thick plasma-sprayed ceramic coatings throughout the combustion chamber. The goal was to maximize the amount of energy extracted from each cycle by reducing losses, which would ultimately lead to improved fuel efficiency and reductions in cooling requirements for the engine. Though many studies on this topic showed significant reductions in heat loss, increases in efficiency and reduced fuel consumption, some unexpected results were also encountered.

Morel et al. $[\mathbf{2 9 , 3 0 ]}$ conducted multiple studies in a single cylinder turbocharged diesel engine analyzing the feasibility of the low heat rejection engine. In each of these studies, the piston crown, cylinder head and valves were coated with $1.25 \mathrm{~mm}$ of plasma sprayed zirconia. In-cylinder surface temperature measurements demonstrated that the peak and average heat flux decreased by up to $50 \%$ with the introduction of the $\mathrm{TBC}$ in 
comparison to the baseline, uncoated engine. Similar decreases in heat transfer were seen by Cheng et al. [31] in their heat transfer study of an uncoated exhaust valve placed in a diesel engine whose piston and remaining valves were coated in $1.52 \mathrm{~mm}$ of plasma sprayed zirconia. Decreases in heat flux amplitude between 10\% - 30\% and increased surface temperatures of up to $200 \mathrm{~K}$ with respect to an uncoated engine were seen. Assanis saw an $80 \%$ decrease in peak heat flux when comparing ceramic-coated to uncoated plugs and temperature increases on the order of $150 \mathrm{~K}$ for the coated plugs [32]. Thus, the potential for TBCs as a means of reducing engine heat transfer is evident.

However, other researchers had findings contradicting these claims of improved efficiency and decreased heat transfer. Using heavily insulated pistons in diesel engines, both Woschni et al. [33,34] and Furuhama and Enomoto [23] saw increases in peak heat flux of up to $100 \%$, which they attributed to the increase in heat transfer coefficient with increasing surface temperatures. They credited this temperature dependence to a reduction in thermal boundary layer thickness due to increased surface temperatures which allowed for closer interaction of the flame with the piston surface.

In addition, Dickey [35] and Cheng et al. [31] attributed increases in fuel consumption and decreased thermal efficiency seen in their low heat rejection engine experiments to degraded combustion. It was concluded by various authors $[\mathbf{3 1 , 3 6}]$ that in order to extract maximum benefits from the introduction of ceramic coatings, combustion quality must be optimized by making appropriate changes to the injection timing.

Studies have also been conducted using thin ceramic TBCs $(<1 \mathrm{~mm})$ as opposed to the much thicker coatings originally implemented in the adiabatic engine studies. Thin coatings have been shown to reduce the negative effects associated with thicker coatings such as poor 
mechanical reliability, decreased volumetric efficiency due to excessive heating of the intake charge and poor tribological behaviour due the significantly higher surface temperatures. They can also be used to effectively control deposit build-up within the engine due to increased surface temperatures which help oxidize the deposits [37]. Experimental studies have shown that small $(1 \%-9 \%)$ improvements in engine fuel consumption could be achieved when the piston crown and cylinder head of turbocharged diesels were coated with $0.3-0.35 \mathrm{~mm}$ of a ceramic coating $[\mathbf{3 8}, \mathbf{3 9}, \mathbf{4 0}]$.

A thorough overview of the low heat rejection engine studies spanning two decades was conducted by Jaichandar et al. [41]. An important finding from the study was that forced induction provided significant improvements to engine fuel consumption due to improved volumetric efficiency. However, this review showed that though there are underlying trends of reduced heat losses and increases in efficiency when using TBCs in diesel engines, there is still some uncertainty regarding the effects of using thick thermal barrier coatings in a diesel engine on overall engine performance, efficiency and emissions. The authors concluded that the large study-to-study variations in results could be attributed primarily to differences in testing procedures and engine setups, and that further studies should be conducted to gain a better understanding of the effects these coatings have on engine operation.

\subsubsection{TBCs in SI Engines}

Much less attention has been placed on TBCs in SI engines due to the adverse effects elevated in-cylinder temperatures produced by the TBCs are known to have on engine knock. However, by selectively applying thin coatings in the combustion chamber, the increased gas and surface temperatures may provide several benefits. A theoretical study conducted by Kamo et al. [37] showed that it may be possible to achieve increases in volumetric efficiency 
due to the reduced thermal inertia of thin coatings, which allows the coatings to remain hot during the expansion process and cooler during the intake process. Kamo also predicted a reduction in deposit formation due to the higher surface temperatures which hinder accumulation on engine surfaces.

To verify these potential benefits of thin coatings within SI engines, Assanis et al. [22] tested a naturally aspirated four cylinder engine with the head, valves, ports, and piston coated in between $0.13 \mathrm{~mm}$ to $0.27 \mathrm{~mm}$ of plasma sprayed zirconia and the liner coated in chromium oxide for wear resistance. Testing at different loads and speeds demonstrated decreases in fuel consumption of up to $20 \%$ at high load and speed conditions. At mid speed, part load conditions more characteristic of typical driving conditions, an $8 \%-18 \%$ increase in power and torque was seen, with 5\% - 10\% decrease in fuel consumption. These gains were primarily attributed to the increases in volumetric efficiency and better combustion quality due to a lower thermal inertia of the coating. Engine knock was not experienced during the testing regime, and no signs of coating failure were seen after 40 hours of testing. Chan et al. [42] conducted similar tests using a piston with a coated crown $(0.45 \mathrm{~mm}$ of YSZ with $0.15 \mathrm{~mm}$ bond coat) in a small displacement SI engine at varying speeds and loads. Results of this study showed decreases in fuel consumption of up to $6 \%$ at lower engine outputs and decreases in exhaust gas temperatures, which the authors attributed to a more effective expansion stroke. Mendera et al. [43] experienced similar decreases in fuel consumption between $2 \%-6 \%$, as well as decreases in heat transfer.

On the other hand, Furuhama et al. [23] saw increases in instantaneous peak heat flux $(\sim 25 \%)$ during the power stroke when their insulated piston was run in an SI engine. It was seen, however, that the mean heat flux decreased by about $50 \%$, thus allowing the 
researchers to conclude that thermal barrier coatings could provide potential benefits to reducing engine cooling requirements and had the potential for increases in performance.

As predicted by Kamo et al. in their analytical study [37], the use of thermal barrier coatings in SI engines can also play a significant role in reducing deposit build-up. Deposits in an IC engine play a detrimental role for several reasons. These carbonaceous accumulations in an engine act as insulators, leading to increased surface temperatures. Though this may reduce heat transfer, continued deposit growth leads to greater than desired increases in surface temperature which promote knock and surface ignition and ultimately cause an Octane Requirement Increase (ORI) $[\mathbf{4 4 , 1 2}]$. Due to their porous structures, they are also known to absorb vaporized fuel during the intake and compression strokes which are later released during the exhaust stroke as unburned hydrocarbons $[\mathbf{2 2 , 4 4 ]}$. Due to these undesired characteristics, work has been done to study the effects of deposits within SI engines in an attempt to minimize accumulation. It was seen by Nakic et al. [45] that by increasing piston crown temperatures using ceramic insulating layers of varying thickness (1mm-3mm), deposit accumulation was greatly reduced due to the inability of the fuel to condense to a carbonaceous film on the hot piston surface. Similarly, both Cheng and Kim [46] and Lauer and Friel [47] saw that fuel deposit accumulation was retarded once combustion chamber surface temperatures reached approximately $300^{\circ} \mathrm{C}$. Thus, by introducing thermal barrier coatings into an SI engine, the increased surface temperatures provide the benefit of inhibiting the uncontrolled growth of cylinder deposits, which may have both emissions and performance benefits.

Finally, the elevated surface temperatures which result from the use of TBCs in SI engines also present a means of decreasing hydrocarbon emissions from the combustion 
process since increased surface temperatures provide a means of oxidizing any postcombustion UHCs. An increase in combustion chamber surface temperatures provided significant decreases in UHCs [48]. Wang and Stone [18] saw decreases in UHC emissions of up to $40 \%$ with increasing surface temperature at engine start-up which they attributed to a reduction in flame quenching on the hotter surfaces. Likewise, by controlling the combustion chamber surface temperatures through changes in the coolant temperature, Myers and Alkidas [1] saw similar decreases in UHC emissions; at the time, they believed this to be as a result of a decrease in quench layer thickness. This study did however show the large dependence of $\mathrm{NO}_{\mathrm{x}}$ emissions on surface temperature, with nearly $100 \%$ increases in $\mathrm{NO}_{\mathrm{x}}$ concentrations with resulting from a 75 degree increase in surface temperature. Increases in $\mathrm{NO}_{\mathrm{x}}$ concentrations were also seen by Wang and Stone [18] and by Assanis et al. [22] as engine surface temperatures increased.

By coating the piston crown of a two-stroke engine with a ceramic TBC, Moughdal and Samuel [48] also saw decreases in UHC emissions of up to 40\%. Likewise, Poola et al. [49] obtained similar results when testing thin $(0.5 \mathrm{~mm})$ ceramic coatings in a carbureted two stroke engine at varying engine speeds. The increased gas temperatures resulting from the introduction of insulating layers were believed to provide these notable reductions in unburned hydrocarbon and $\mathrm{CO}$ concentrations due to improved evaporation and mixing of the rich air-fuel mixtures used in two-stroke engines. Conversely, Chan et al. [42] saw increases in UHC concentration of up to $30 \%$ in the exhaust gas of a gasoline engine with YSZ sprayed piston crowns. Though the causes were not explicitly quantified, it was believed to be a result of the increased porosity and surface roughness of the coating. Thus, although questions still remain regarding the effectiveness of TBCs in emissions control, it is 
evident that the potential to reduce hydrocarbon emissions thanks to increased surface temperatures exists.

\subsubsection{Summary: TBCs in Engines}

Though results were somewhat conflicting, the potential benefits of using TBCs to limit the heat losses in IC engines are evident. TBCs have shown the potential to improve emissions and performance characteristics in both diesel and spark ignition engines. However, some unexpected results showing increases in heat transfer and inconclusive performance effects have also been seen. These aforementioned studies have demonstrated that some of the possible causes for the varying effects TBCs have on performance, fuel consumption and emissions in both diesel and SI engines include temperature-dependant heat transfer coefficients, degradation of combustion, optical and mechanical properties, porosity and surface roughness.

In order to narrow this list of potential causes, it was felt that a simple and worthwhile factor to study which played an important role in the effectiveness of TBCs in improving engine performance was surface roughness.

In the following, a through overview of the principles of surface roughness and the effects that it has on heat transfer in an engine environment with respect to the use of thermal barrier coatings will be presented.

\subsection{Surface Roughness}

Accepted engineering theory states that increasing the surface roughness of a flat plate or a pipe results in higher levels of heat transfer with respect to a smooth sample in the same flow conditions [50]. This elevated heat transfer is attributed to the predisposition of a 
rough surface to cause transition from laminar to turbulent flow, which results in higher $h$ values. Increased roughness also provides greater surface area for heat transfer to occur. An overview of the basic principles of heat transfer over a rough surface is presented.

\subsubsection{Basic Principles}

Two basic approaches have been used to characterize a rough surface: the equivalent sand grain and the discrete element methods. Both will be briefly described in the following.

\section{Equivalent Sand Grain Size}

By correlating roughness data obtained by Nikuradse [51] for flow in a rough pipe, Schlichting [52] proposed the concept of the equivalent sand grain roughness $\left(k_{s}\right)$. He defined this as the size of the sand grain Nikuradse used that gave the same flow resistance as the tested surface finish. This value allowed for extrapolation of the results seen by Nikuradse for different flow conditions based on the surface characteristics of a sample. Schlichting calculated $k_{s}$ by first assuming the logarithmic wall profile for each rough surface,

$$
\frac{u}{u^{*}}=5.75 \log \frac{y}{k}+A
$$

where $k$ is the measured roughness height and $A$ is the y-intercept of the velocity profile, which was assumed to vary as a function of surface roughness only and can be determined by plotting the values of $u / u^{*}$ against $\log (y / k)$. By equating this expression to that describing a hydraulically smooth surface (defined by Nikuradse to have $k=k_{s}$ and $A=8.48$ ), the ratio of $k / k_{s}$ is:

$$
\frac{k_{s}}{k}=10^{\frac{8.48-A}{5.75}}
$$

Following Schlichting's work, several other methods of calculating $k_{s}$ have been expressed in an attempt to improve the accuracy of this method $[\mathbf{5 3}, \mathbf{5 4}, \mathbf{5 5}, \mathbf{5 6}, \mathbf{5 7}]$ in defining a rough 
surface. These techniques attempt to account for roughness spacing and density, and require the estimation of various roughness element characteristics (i.e. height, spacing, shape, etc), which may be difficult to determine for real surfaces. A conservative technique to calculating $k_{s}$ is suggested by Koch and Smith [58]. This method takes a statistical approach to determining $k_{s}$ by making use of the classic statistical parameters used to characterize a rough surface: 1) centreline average roughness, or absolute roughness height, $\left(R_{a}\right)$ and 2$)$ root mean square roughness height $\left(R_{r m s}\right)$ as defined below:

$$
\begin{aligned}
R_{a} & =\frac{\sum_{i=1}^{n}\left|y_{i}-\bar{y}\right|}{n} \\
R_{r m s} & =\sqrt{\frac{\sum_{i=1}^{n}\left(y_{i}-y\right)^{2}}{n-1}}
\end{aligned}
$$

These roughness values can be obtained using standard mechanical and optical measurement techniques. Using these values, the equivalent sand grain roughness is defined as

$$
k_{s}=6.2 R_{a} \text { or } k_{s}=4.2 R_{r m s}
$$

This length scale then provides a means of correlating the measured $R_{a}$ values to the fluid motion over a rough surface using the roughness Reynolds number $R e_{k}$.

$$
R e_{k}=\frac{k_{s} v^{*}}{v}
$$

where $v^{*}$ is the friction velocity which can be defined as

$$
v^{*}=\sqrt{\frac{\tau_{w}}{\rho}}=u_{\infty} \sqrt{\frac{c_{f}}{2}}
$$

The skin friction coefficient, $c_{f}$ for a turbulent boundary layer over a smooth plate is:

$$
c_{f}=\frac{0.026}{R e_{\chi}^{1 / 7}}
$$


Various skin friction coefficients have also been defined for flow over rough plates in the fully rough regime (described below), as was summarized by Bons et al. [59].

$$
\begin{array}{cr}
c_{f}=\left[1.4+3.7 \log \left(x / k_{s}\right)\right]^{-2} & \text { from White } \\
c_{f}=0.168\left[\ln \left(84 \delta / k_{s}\right)\right]^{2} & \text { from Kays and Crawford } \\
c_{f}=\left[2.87+1.58 \log \left(x / k_{s}\right)\right]^{-2.5} & \text { from Schlichting } \\
c_{f}=\left[3.476+0.707 \log \left(x / k_{s}\right)\right]^{-2.46} & \text { from Mills }
\end{array}
$$

The roughness Reynolds number can then be used to define the roughness regime into which the flow falls. The three flow regimes, as defined by Nikuradse [51], are:

$$
\begin{array}{ll}
R e_{k}<5 & \text { Smooth } \\
5<R e_{k}<70 & \text { Transitional rough } \\
R e_{k}>70 & \text { Fully rough }
\end{array}
$$

With the heat transfer to a flat plate being characterized by the dimensionless Nusselt number $(\mathrm{Nu})$ which can be expressed in the form

$$
N u=a R e^{b} \operatorname{Pr}^{c}
$$

it is clear that increases in $R e_{k}$ due to elevated surface roughness will result in greater heat flux to the specimen. This increase in heat transfer can be attributed to the rough surface finish thinning the viscous sublayer near the surface, with the sublayer disappearing entirely when $R e_{k}>70$. The lack of a viscous sublayer means that the turbulent transport of momentum and energy can occur up to the wall surface, thereby increasing the rate of heat transfer to the surface $[\mathbf{6 0}]$.

The equivalent sand grain roughness technique provides a simple way of characterizing surface roughness, but has some inherent issues. Firstly, a rough surface is dependent on roughness height, shape and density [61]. However, Schlichting's method 
characterizes the roughness with a single length scale, $k_{s}$, which may be insufficient to describe a surface of varying roughness. Also, the principles behind Schlichting's derivation are based solely on momentum transfer, neglecting energy transfer. This therefore makes it difficult to use $k_{s}$ in heat transfer studies on the basis of theory. It does, however, still provide a simple way of correlating empirical roughness data to heat transfer measurements.

\section{Discrete Element Method}

The discrete element method is a second way of characterizing surface roughness, which was also originally presented by Schlichting [52] as an alternative to the equivalent sand grain roughness approach. The discrete element method makes use of the geometric characteristics of a discrete roughness element (i.e. cone, hemisphere, pyramid) to solve the two-dimensional turbulent boundary layer equations over a surface [62]. Schlichting originally defined this method as a means of accounting for the spacing and density of roughness elements on a surface by accounting for the form drag of each element and the skin friction on the flat surfaces between them. This idea is the basis of the discrete element method, and was expanded on by multiple authors to solve the turbulent boundary layer equations over these rough elements. An example of a rigorous derivation of the equations governing this method is given by Taylor [61].

This technique provides a more deterministic approach to defining surface roughness, and thus lends itself for use in computational modeling techniques. As outlined by Taylor [61], this technique also addresses some of the problems associated with the equivalent sand grain roughness approach; namely, the equations are derived based on the roughness geometry, and thus take account for all length scales (height, spacing and shape). Likewise, the equations also inherently account for energy transport, and do not require a reference 
datum plane from which the roughness heights are determined. The primary pitfall of this method is the difficulty to simulate a real surface with discrete elements due to the variability of roughness density and heights along a sample [63]. Attempts have been made to modify the discrete element method to account for random roughness using both two- and threedimensional profilometer scans, with some positive results $[\mathbf{6 1 , 6 2}]$.

\section{$\underline{2.3 \text { Roughness Studies }}$}

In the following, a brief overview of various studies that have been conducted in the field of heat transfer on rough surface is provided. As a result of the extensive use of TBCs in gas turbines and the rough surface characteristics of TBCs, the majority of the studies reviewed focus on the effects of roughness on heat transfer in gas turbines using both flat plate and airfoil experiments. The review will then focus on IC engine roughness studies.

\subsubsection{Gas Turbines}

Though thermal barrier coatings have not been introduced into production IC engines, they have been used extensively in the gas turbine industry. To maximize the efficiency of modern gas turbine engines, high temperature components are typically coated with roughly $0.25 \mathrm{~mm}$ of low conductivity ceramic thermal barrier coatings such as YSZ to reduce heat losses from the engine and allow for higher working temperatures. These coatings allow for higher combustion temperatures, thus increasing efficiency, while shielding the metallic components from above-melting-point temperatures [64].

However, as shown in Table 2.1 - Material Properties (p.9), these TBCs increase turbine blade roughness, which has undesired effects on overall engine performance. The desire to quantify and minimize the aerodynamic and heat transfer losses due to surface 
roughness in gas turbines has led to a great deal of research investigating the effects of both TBC- and deposit-induced roughness on heat transfer. Thus, this field provides a useful source of information on the effects of roughness on heat transfer within an engine environment. However, to transfer the conclusions of these studies to an IC engine, a comparison of the typical flow conditions in an engine with a TBC-coated piston and the test conditions used in the rough plate studies is necessary. This comparison, as described in Section 0 , can be conducted by determining the roughness Reynolds number for each case, which is then used to conclude whether the roughness conditions are analogous.

Heat transfer studies of turbine vane components have generally demonstrated that increased surface roughness translates to larger heat losses. Turner et al. [65] used a threevane linear cascade coated in abrasive powders of four different grit sizes $(54,76,105$ and $250 \mu \mathrm{m})$ placed in a wind tunnel fed by $90^{\circ} \mathrm{C}$ air with $\operatorname{Re}=1.2 \mathrm{e} 6$. Heat flux measurements showed increases of up to $100 \%$ at the roughest surface conditions. Blair et al. [66] saw similar results using a 1.5 stage turbine assembly coated with different surface finishes, with maximum increases in heat transfer greater than $100 \%$ for a grit-coated vane. Studies which analyzed TBC coated samples also clearly demonstrated the effects of roughness on heat transfer. Using flat plates coated in a ceramic TBC that were polished to three surface finishes $\left(R_{a}=1.09,7.19\right.$ and $\left.9.7 \mu \mathrm{m}\right)$ and tested with a turbulence intensity of between $4.5 \%$ and $6 \%$, Bunker [67] saw increases in heat transfer of between $10 \%$ and $45 \%$ in comparison to the smooth metallic surface $\left(R_{a}=1.19 \mu \mathrm{m}\right)$. Boyle and Senyitko [68] tested a TBC coated turbine vane $\left(R_{a}=10-14 \mu \mathrm{m}\right)$ in a linear cascade at low turbulence intensities and saw similar increases in heat transfer along the turbine vane with increasing surface roughness. 
Another important finding from these studies was that heat transfer was seen to increase significantly with increasing flow Reynolds number. However, once the roughness Reynolds number entered the fully rough regime (i.e. $R e_{k}>70$ due to large $k_{s}$ ), heat transfer into the samples became independent of Re since the turbulence intensity of the flow over the airfoil became governed by the roughness height rather than flow velocity, thus showing minimal heat flux augmentation with increased flow velocity [69]. Similar results were seen by artificially inducing a turbulent inlet flow over a test sample using different turbulenceinducing devices (i.e. steps [67], trip wire [69]). In these studies, it was seen that while the turbulent inlet flow greatly increased heat transfer to relatively smooth samples, increasing roughness height had little effect on overall heat loss since the flow characteristics were the predominant factor in heat loss as opposed to the surface roughness (i.e. roughness height had no effect on increasing turbulence intensity of flow over the plate and thus did not contribute significantly to heat transfer). This demonstrates the importance of turbulence intensity on heat transfer over a rough surface.

Due to the random nature of a real rough surface, many researchers have used discrete elements to model a rough surface in an attempt to obtain a clearer attribution of roughness effects on heat transfer. Barlow et al. [70] used discrete elements $\left(R_{a}=0.1 \mathrm{~mm}\right.$ and $\left.0.18 \mathrm{~mm}\right)$ on a flat plate subject to $30 \mathrm{~m} / \mathrm{s}$ flow $\left(R e_{k}>70\right)$ and saw increases in heat transfer of $70 \%$ and $120 \%$ with respect to smooth plates. These effects were seen to be even greater when subjected to $50 \mathrm{~m} / \mathrm{s}$ free-stream velocities. An interesting finding from this study was the author's comparison of the wetted and planar areas for the rough samples. This clearly demonstrated that increased surface area due to roughness did not account for all of the increase in heat flux through the surface, and thus roughness effects resulted in increased $h$ 
values, as expected. Various studies $[\mathbf{6 9 , 7 1 , 7 2 , 7 3 , 7 4 ]}$ using different discrete element geometries (truncated cones, hemispheres, etc.) each clearly showed significant increases in heat transfer with increasing surface roughness. In addition, Hosni et al. [75] used flat plates with simulated rough surfaces (truncated cones and hemispheres) to demonstrate the effects of roughness density on heat transfer through the plate. It was again seen that heat transfer increased by up to $40 \%$ by introducing roughness elements, with the denser roughness $(\mathrm{L} / \mathrm{d}=$ 2) having up to $10 \%$ more heat losses than the less dense $(\mathrm{L} / \mathrm{d}=4)$ surface finish.

It is therefore clear from these results that surface finish plays a significant role in heat transfer through a specimen. This provides a strong basis for the argument that the introduction of rough surfaces (i.e. application of rough TBCs) within an internal combustion engine may have significant effects on engine heat transfer characteristics. In the following, an overview of studies analyzing heat transfer effects in the IC engine field will be discussed.

\subsubsection{IC Engine}

To date, studies examining the effects of surface roughness on heat transfer in IC engines have been very limited, with a review of the current literature revealing two primary studies. After having concluded that thick ceramic TBCs proved to be ineffective in reducing heat transfer based on the findings of previous research studies, Tsutsumi et al. [76] attempted to reduce the available surface area for heat transfer in a spark ignition (SI) engine by polishing the engine components to a mirror finish. Comparing standard to polished components (30 times smoother), it was seen that under full load at 3600rpm, decreases in piston surface temperature of up to $16^{\circ} \mathrm{C}$ were achieved, with an average overall decrease of $8^{\circ} \mathrm{C}$. Increases in exhaust temperature of up to $10^{\circ} \mathrm{C}$ were also seen, as well as small improvements (1\%-3\%) in torque and fuel consumption. After allowing for the accumulation 
of carbon deposits on the piston crown, it was seen that though the effectiveness was reduced, the polished piston maintained some improvements in fuel consumption.

Similar results were seen by Marr et al. [77], which compared heat transfer measurements for plugs in an SI engine with four different surface finishes. Measurements were taken for smooth/grit blasted plugs, as well as polished and unpolished samples coated in a rough metallic TBC $\left(R_{a}=12-20 \mu \mathrm{m}\right)$. In each case, the smoother of the two samples (smooth uncoated and polished TBC) showed surface temperatures approximately $5^{\circ} \mathrm{C}$ lower than the rough samples, and thus a reduction in heat transfer.

\subsubsection{Summary: Roughness Studies}

The results of the roughness studies discussed in Sections 2.3.1 and 2.3.2 provided a foundation for the argument that decreasing surface roughness plays a role in reducing SI engine heat transfer, which would provide benefits in terms of both performance and component life. Thus, it is clear that the effects of TBC roughness may prove to be a significant factor in determining the effectiveness of these coatings on reducing heat transfer and ultimately improving overall engine performance.

\section{$\underline{\text { 2.4 Emissivity }}$}

Radiation heat transfer is another mechanism through which thermal energy can be transmitted to a body, and is governed by the Stefan-Boltzman law. This states that the emissive power, $E$, from a grey body with area, $A$, is governed by the equation:

$$
E=\sigma \varepsilon A T^{4}
$$

where $\sigma$ is the Stefan-Boltzman constant, and $\varepsilon$ is the emissivity of the surface. A change in emissivity is another means through which surface roughness has the potential of affecting 
heat transfer. The emissivity of a surface, which is defined as the ratio of radiation emitted by a real surface to that emitted by a black body, is highly dependent on the ratio of surface roughness height to radiation wavelength, and is known to increase with increasing roughness. This is a result of a greater percentage of incident radiation being trapped within the crevices of a rough surface due to multiple reflections within these cavities (emissivity, $\varepsilon$ $=$ absorptivity, $\alpha$ ), ultimately resulting in increased heat flux to the surface [78].

\subsubsection{Emissivity Studies}

Emissivity studies on metallic specimens have demonstrated that though a great deal of variance is seen for randomly rough surfaces, a general decrease in $\varepsilon$ is evident when a rough surface is polished $[\mathbf{7 9 , 8 0 , 8 1 ]}$. Thus, the introduction of a rough TBC into an environment exposed to radiation can expect to have increased heat transfer. In addition to increased surface roughness, ceramic TBCs such as YSZ are also optically translucent to radiation at short wavelengths or in thin coatings. This therefore may result in a decrease in effectiveness when used in environments subject to high radiation [82]. However, Ganz et al. demonstrated that increasing coating thickness to greater than $0.5 \mathrm{~mm}$ was sufficient to classify the coating as opaque to radiation [83]. Likewise, Wahiduzzaman and Morel also concluded that, for the range of radiation seen in a diesel engine $(0.5$ to $5 \mu \mathrm{m}), \mathrm{YSZ}$ thicknesses greater than $1.5 \mathrm{~mm}$ were considered optically thick [84].

\subsubsection{Radiation in Engines}

Radiation heat transfer in an IC engine stems from three primary sources: the luminous flame, hot combustion gases, and glowing soot particles [2]. Engine studies have shown that radiation heat transfer in diesel engines is a significant portion of its heat loss, 
accounting for up to $35 \%$ of the total heat flux. This can be attributed to the luminous diffusion flame which characterizes combustion within the engine and the large concentration of high heat capacity soot particles which form during combustion [2]. Spark ignition engines, on the other hand, experience much less radiation heat flux (only $5 \%$ of convective heat transfer) as a result of the premixed combustion process which produces a mostly non-luminous flame and very little soot. The hot combustion gases in the engines are virtually transparent and thus have a very little effect on radiative heat flux [2].

Therefore, since this heat transfer mechanism is significantly less of a factor than the convective and conductive losses in an SI engine, it is considered to be negligible.

\subsection{IC Engine Flow Characteristics}

Convection is the primary mode of heat transfer in an internal combustion engine. It primarily occurs through transmission of energy from the hot combustion gases to the combustion chamber walls, a process governed by Newton's law of cooling that states,

$$
q=h A\left(T_{g}-T_{w}\right)
$$

where $h$ is the heat transfer coefficient and $T_{g}$ and $T_{w}$ are the gas and wall temperatures, respectively. The flow conditions within the cylinder of an IC engine have a large effect on $h$, since this value is dependent on flow behaviour (i.e. Reynolds number). Likewise, as seen in Section 2.3, it is clear that surface roughness plays a role in heat transfer due to its effects on flow. Therefore, to obtain a clear understanding of convective heat losses in the cylinder and how surface finish may affect these losses, an understanding of in-cylinder flows is critical. 
Due to the importance of in-cylinder flow on the combustion process and its effects on overall engine performance, a great deal of research has been conducted on engine flow characteristics in both motored and fired engines, as discussed in the following.

\subsubsection{Motored Engine}

The vast majority of work in the field of in-cylinder flow has studied the flow characteristics in motored engines. This is due to the difficulty of obtaining accurate data during combustion and the importance of understanding the effects of in-cylinder flows on the combustion process. The pre-combustion portion of the cycle begins with a peak in velocity during the intake stroke. Piston speed has been shown to be the variable which has the greatest effect on in-cylinder velocity. The magnitude of the in-cylinder velocities and the resulting turbulence has been shown to be proportional to the mean piston speed $[\mathbf{2}, \mathbf{8 5}, \mathbf{8 6}, \mathbf{8 7}, \mathbf{8 8}, \mathbf{8 9}]$. This is seen in Figure 2.1 taken from Heywood [2] which shows the ensemble-averaged mean velocity profile within a motored engine normalized by mean piston speed. Since the profiles collapse to roughly the same results, it can be concluded that the relationship between piston speed and in-cylinder velocity exists.

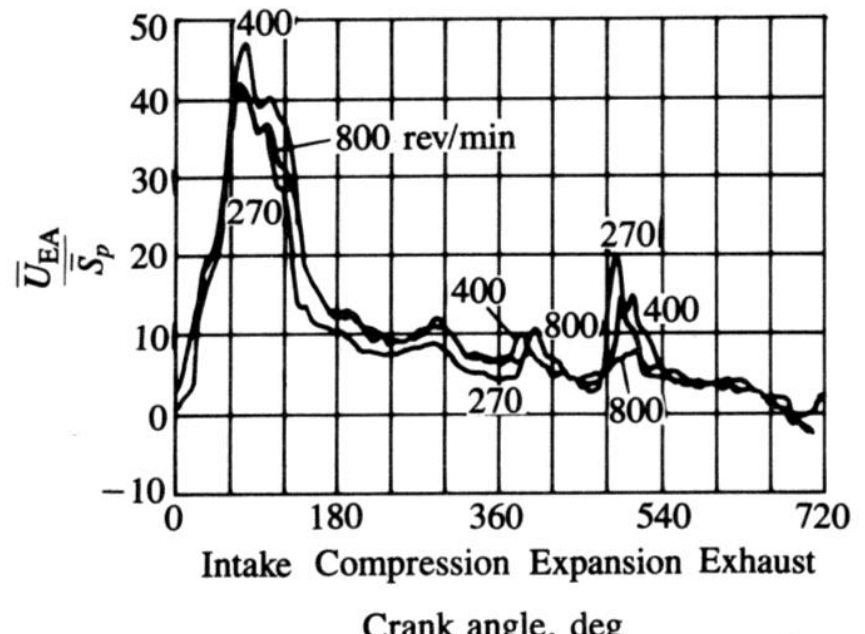

Figure 2.1 - Scaled In-Cylinder Velocity Profile [2] 
After the peak in velocity which occurs during the intake valve opening, the flow velocity is seen to decrease until the moment the exhaust valve opens as a result of viscous dissipation of flow energy on the cylinder walls $[\mathbf{2 , 8 8 , 8 9}]$. Without any imposed flow structures (swirl, tumble, squish), the flow at TDC is seen to be relatively quiescent.

Another important factor seen to affect in-cylinder flows was the flow rate of the intake air. As discussed by Hall and Bracco [86], increasing the flow rate of the intake air at a given engine speed is seen to increase in-cylinder velocities near TDC in a motored engine. As seen in Figure 2.2, in-cylinder velocity increased almost proportionally with intake flow rate. The same study found that increasing the flow rate had little effect on turbulence intensity within the cylinder.

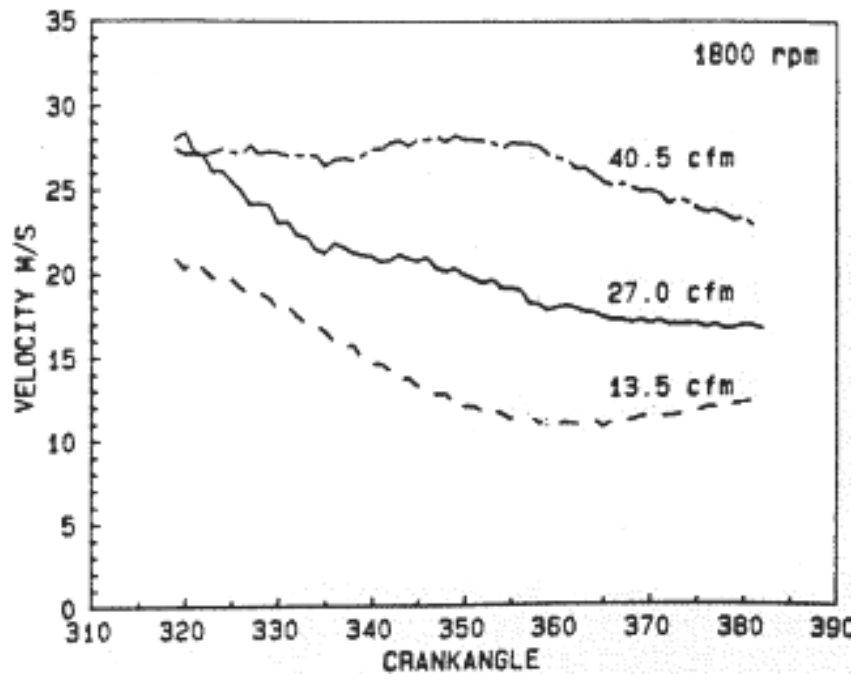

Figure 2.2 - Effect of Intake Air Flow Rate on In-Cylinder Velocity in a Motored Engine

\section{Effect of Structured Flows}

The introduction of imposed flow structures has been seen to have significant effects on in-cylinder flows in a motored engine. This flow is dependent on intake conditions, with factors such as intake geometry and pressure playing a very large role in the in-cylinder conditions [2]. Namely, the intake and combustion chamber geometry impart flow 
characteristics such as tumble and swirl on the intake charge, which increase the turbulence intensity ( $R e$ values) within the cylinder and directly impact heat transfer. Boggs and Borman [90] demonstrated that increasing in-cylinder turbulence by introducing tumble or swirl resulted in increases in peak heat flux in a motoring engine by $70 \%$, with Overbye et al. [11] showing a similar relationship between turbulence and heat transfer in a motored CFR engine. Mean gas velocities within the cylinder have also been seen to double as a result of using a shrouded intake valve versus an unshrouded valve [85].

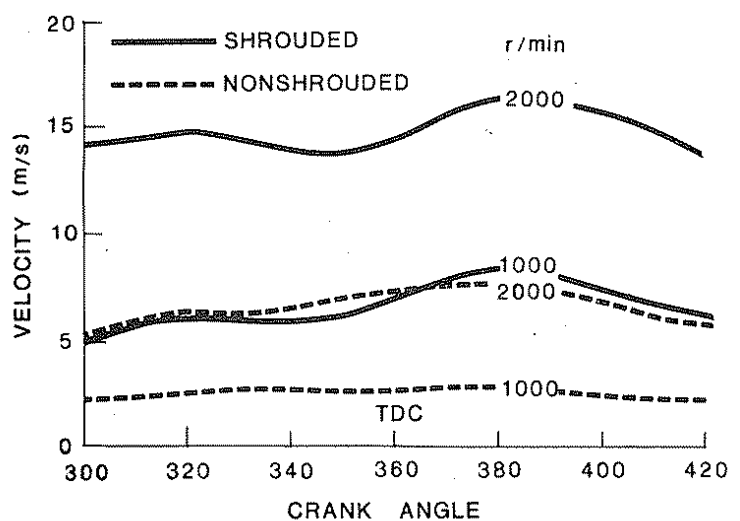

Figure 2.3 - Mean In-Cylinder Velocity in CFR Engine (near Exhaust Valve) [85]

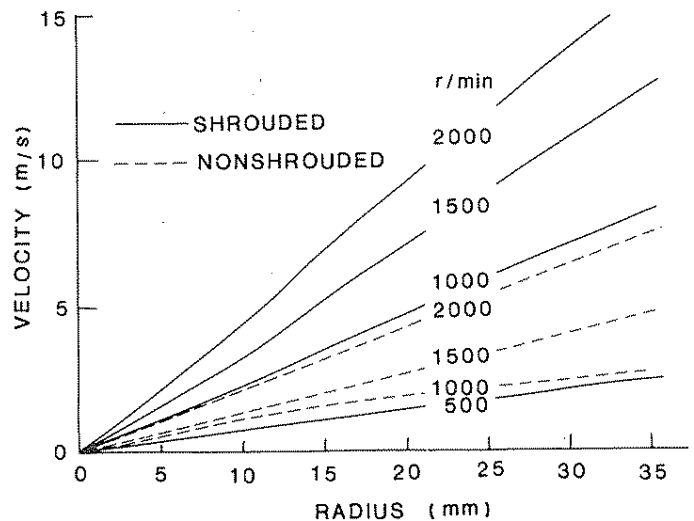

Figure 2.4 - Mean In-Cylinder Velocity in CFR Engine (30deg ATDC) [85]

This can be seen clearly in Figure 2.3 and Figure 2.4 above which show the effects increasing swirl in a CFR engine has on in-cylinder velocity, as well as the correlation between piston speed and flow velocity. The introduction of swirl as a result of using a shrouded intake valve has also been seen to produce near solid-body rotation $[\mathbf{2 , 8 5}]$. In addition, both Liou et al. [89] and Lancaster et al. [88] demonstrated that imposing swirl reduced the rate of velocity dissipation in their disk shaped cylinders with flat topped pistons. The flow retained its structure until the end of the compression stroke, which should lend itself to higher mixing rates for improved combustion as well as greater heat transfer. 
Turbulence intensity was also greatly affected by the presence of swirl. Hall and Bracco [86] saw that introducing swirl increased the turbulence intensity by $60 \%$ due to shear dissipation of the structured flow near the combustion chamber walls. Similar results were reported by Liou et al. [89] and Groff et al. [85]. Another important finding from these studies was that the turbulence intensity in an engine was seen to be proportional to mean piston speed, $\bar{s}_{p}[\mathbf{8 5 , 8 9 , 8 7}$, with a maximum turbulence intensity equal to approximately $1 / 2 \bar{S}_{p}[\mathbf{2 , 8 9 , 8 7 ]}$. Additionally, it was noted that the turbulence characteristics within the cylinder have a tendency to become both homogeneous and isotropic at the end of the compression stroke when no swirl was present $[\mathbf{2 , 8 6 , 8 9 , 9 1 ]}$.

Therefore, it is clear that with the introduction of a structured flow in an internal combustion engine, there is a significant increase in turbulence intensity; this ultimately promotes better mixing of the fuel-air mixture and thus improved combustion quality. Likewise, this increase in turbulent flow within the engine will also result in greater heat flux in the cylinder. It should also be noted that volumetric efficiency and compression ratio have been shown to have small effects on in-cylinder velocities [87].

\subsubsection{Fired Engine}

Combustion has significant effects on the flow conditions in an IC engine, as ignition of the fuel-air mixture results in higher gas velocities and in-cylinder turbulence compared to a motored engine. This was clearly demonstrated by Hall and Bracco [86] who reported that the turbulence intensity in a fired engine (measured using Laser Doppler Velocimetry $(\mathrm{LDV})$ ) was twice that seen in a motored engine at the same speed. Combustion also resulted in significant increases in mean in-cylinder velocities, as is seen in Figure 2.5 which compares motored and fired ensemble-averaged mean velocities. 


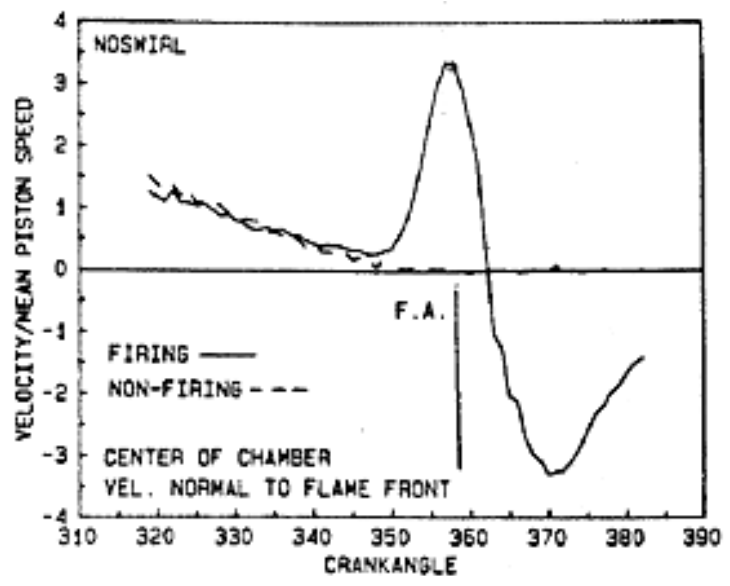

Figure 2.5- Comparison of Motored and Fired Ensemble-Averaged Mean Velocities [86]

It has also been demonstrated that engine speed and the flow structure prior to combustion have an important effect on the resulting flame behaviour. Various studies have shown that an increase in turbulence due to intake-generated swirl and tumble in SI engines increases flame speed $[\mathbf{8 5}, \mathbf{8 6}, \mathbf{8 8 , 8 9 , 9 2 ]}$. These studies also demonstrated a strong relationship between engine speed and flame speed, with Lancaster et al. [88] finding that flame speed nearly doubled when increasing the speed of a CFR engine from 1000rpm to 2000rpm. These increases in flame speed as a function of engine speed/turbulence intensity result from the increase in large scale turbulence characteristic of structured swirling flows that distort the flame and increase flame front area. Increases in small scale turbulence (due to dissipation of structured flow which is greatly enhanced by increased surface roughness) also plays a role in increasing local flame propagation due to increased local reaction rates $[\mathbf{8 8}]$. These higher flame speeds, larger flame fronts, and improved combustion quality ultimately result in higher heat flux to the combustion chamber walls due to increased in-cylinder turbulence, and cause changes in emission characteristics (lower UHCs but greater $\mathrm{NO}_{\mathrm{x}}$ ). 


\subsubsection{Roughness Effects on Convective Heat Transfer in CFR Engine}

As demonstrated by the turbine blade and flat plate studies in Section 2.3.1, surface roughness has an important effect on convective heat transfer. The relative effect of surface roughness is defined by the roughness Reynolds number, which is a function of roughness height and fluid velocity (see Equation 2.6 on p.17). To apply the conclusions from the previous roughness studies and quantify the significance of the roughness introduced into the combustion chamber of an IC engine, the non-dimensional $R e_{k}$ values for the engine and airfoil/flat plate studies should be comparable.

An approximate $R e_{k}$ value for the rough piston crown of an IC engine can be calculated based on in-cylinder flow conditions and knowledge of the surface finish within the cylinder. Assuming that the only rough surface in the cylinder is the piston crown and that it behaves as a flat plate in a free-stream, an estimate of roughness Reynolds number can be calculated using Equations 2.3 to 2.9 on page 18. Using the Laser Doppler velocity measurements taken by Hall and Bracco [86], who found that the maximum in-cylinder velocity in a fired CFR engine was approximately $20 \mathrm{~m} / \mathrm{s}$, and $R_{a}$ measurements for YSZ and metallic TBCs given in Table 2.1 - Material Properties (see p.9), it was seen that the values of $R e_{k}$ for the two surfaces ranges between roughly 5 and 15 (depending on the choice of $c_{f}$ in equation 2.9), thus falling within the transitionally rough regime. However, it should be noted that free-stream turbulence within the cylinder may play an important role in the heat transfer and flow characteristics within the engine.

These estimates of $\operatorname{Re}_{k}$ in the cylinder of a CFR engine can thus be compared to the previous roughness studies. The testing conditions for the roughness studies discussed in Section 2.3.1 varied significantly, which ultimately allowed for a comparison of the heat 
transfer characteristics across the three different roughness regimes. The flat plate studies conducted by Barlow et al. [70] on plates with $R_{a}$ values of $100 \mu \mathrm{m}$ and $180 \mu \mathrm{m}$ at $30 \mathrm{~m} / \mathrm{s}$ and $50 \mathrm{~m} / \mathrm{s}$ and very low turbulence intensity resulted in flows which were in the fully rough regime. These rough conditions were seen to result in increases in heat transfer through the plate by $70 \%$ - 120\%. Likewise, Bogard et al. [71] showed that at $R e_{k}$ values of 60 (transitionally rough) and 120 (fully rough), there were increases in surface heat transfer of $50 \%-60 \%$. On the other hand, Abuaf et al. [93] showed that at very low roughness levels spanning from $R_{a}=0.8 \mu \mathrm{m}$ to $R_{a}=2.3 \mu \mathrm{m}$ and flow conditions which maintained the flow near the hydraulically smooth flow regime (extrapolation of given data), virtually no heat transfer effects were seen at low Re values. At the highest Re values $\left(2.3 \times 10^{6}\right)$ tested, an increase in heat transfer coefficient of about $15 \%$ was seen, thus demonstrating that roughness effects in the hydraulically smooth and low transitionally rough regime are much less significant than those seen at high $R e_{k}$ values.

These studies also showed the significance of free-stream turbulence on the heat transfer characteristics of a flat plate study. Bogard et al. [71] showed that the introduction of free-stream turbulence over the flat plate had an important effect on heat transfer, with increases of $15 \%$ and $30 \%$ with respect to a smooth surface for induced turbulence intensities of $10 \%$ and $17 \%$, respectively. The introduction of free-stream turbulence over a rough surface resulted in even greater increases in heat transfer $(\sim 100 \%)$. Similar results were seen by Wang and Rice [94], Turner et al. [65] and Bons [59] when increasing turbulence intensity over a rough surface. These studies also showed that the effects of surface roughness and turbulence intensity on heat transfer seemed to be roughly cumulative. Bons speculated that there exists a level of synergy between the two factors due to the non-linear 
increase in heat transfer that was seen when increasing the surface roughness and turbulence intensities. Additionally, Bunker [67] saw that by inducing turbulence over smooth and TBC coated plates using small (1-4mm) steps in the flowpath, heat transfer through the plate was increased by up to a factor of 2 . The levels of enhancement were similar for both rough and smooth surfaces, which can be attributed to the fact that the turbulent flow, rather than roughness, became the dominant factor in heat transfer.

Thus, based on these results, it is evident that though the estimated $\operatorname{Re}_{k}$ value for the rough surfaces in a CFR engine are in the smooth/transitional regime, the effects of roughness can still be expected to exist. Flat plate studies in the smooth/transitional region demonstrated increases in heat transfer on the order of $10 \%$. The effects of turbulence within the engine can also be expected to result in significant increases in this estimate. The approximately linear relationship between turbulence intensity and surface roughness that was seen in various flat plate studies also provides support for this hypothesis. Since turbulence levels within an IC engine are quite high, this can have a large effect on increasing heat transfer even though the flow over the rough piston crown is not in the fully rough regime.

\subsection{Summary}

Several important factors have become evident from this literature survey. An examination of the work studying thermal barrier coatings in internal combustion engines has shown the potential improvements that selectively applying thin coatings throughout the combustion chamber of an SI engine can have on engine performance and heat transfer. However, from the results of these studies, it is also clear that more work must be conducted to obtain a better understanding of this technology. 
A potential contributor to the often inconclusive heat transfer results in TBC coated engines was found to be surface roughness. Research from the gas turbine field studying this factor demonstrated that roughness had a very large impact on heat transfer, citing increases of more than $100 \%$ for rough surfaces in high turbulence intensity flows. Though fewer roughness studies were conducted in IC engines, decreases in heat transfer were once again seen with decreasing surface roughness. In general, these studies showed that a rough surface finish resulted in increases in each of the three primary modes of heat transfer:

1. Conduction: increased surface area

2. Convection: dissipation of viscous sublayer, increased turbulence

3. Radiation: increased radiant heat being trapped in surface imperfections

Since surface roughness plays an important role in convection, a survey of incylinder charge motion studies was presented to understand typical flow behaviours and the variables which may affect this flow. It was seen that intake geometry and engine speed had the largest effect on in-cylinder flow and that these factors resulted in considerable increases in flame speeds within the engine. These changes in flow ultimately translated to increases in heat transfer from the combustion chamber due to increased turbulence which leads to dissipation of the boundary layer and allows for a greater rate of energy transfer.

The potential effects of surface roughness within the cylinder of a CFR engine were compared to the results seen in the flat plate roughness studies by calculating an estimate of the non-dimensional roughness Reynolds number. This comparison would allow for a link to be made between the results seen in the roughness studies to the results which could be expected in the CFR engine. It was seen that by applying rough TBCs onto the piston crown, the resulting flow was in the transitionally rough regime, which, based on the results of the flat plate studies, could lead to potential increases in $q$ of $10 \%$ or more. These results could 
be increased by the turbulence levels within the cylinder. Finally, it was also concluded that since radiation is known to be minimal in SI engines, its effects could be ignored. Table 2.2 provides a basic energy balance for a SI engine demonstrating the percentage of fuel energy that is typically transferred to power, absorbed by the coolant and the surrounding environment, and the exhaust enthalpy [2]. Figure 2.6 below shows how the heat losses are divided into the three primary heat transfer mechanisms.

Table 2.2 - Energy Balance for SI Engine (\% of Fuel Energy)

\begin{tabular}{cccc}
\hline Brake Power & $\mathbf{Q}_{\text {coolant }}$ & $\mathbf{Q}_{\text {misc }}$ & $\begin{array}{c}\text { Exhaust Enthalpy+ } \\
\text { Incomplete Combustion }\end{array}$ \\
\hline $25 \%-28 \%$ & $17 \%-26 \%$ & $3 \%-10 \%$ & $36 \%-50 \%$ \\
\hline
\end{tabular}

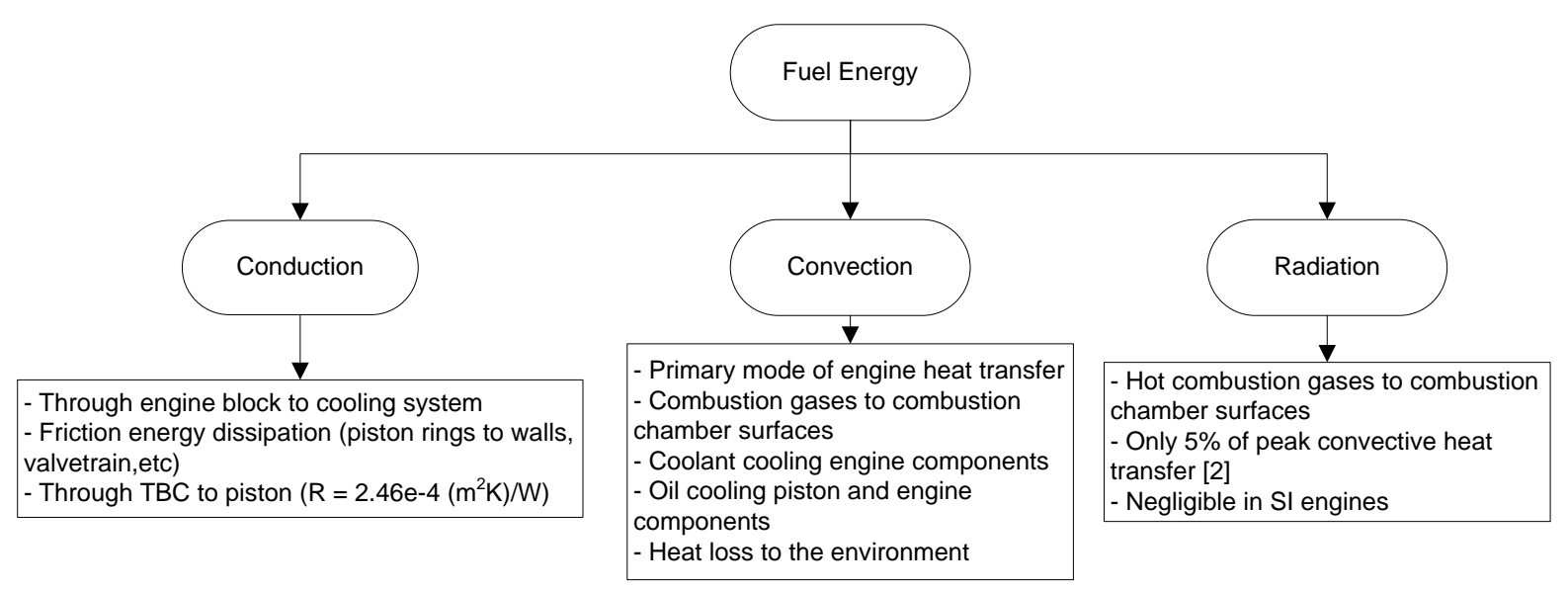

Figure 2.6 - Breakdown of SI Engine Heat Transfer

The literature therefore provided a basis upon which a test matrix can be formed to study the effects of surface roughness on heat transfer in a TBC-coated SI engine. Heat transfer measurements will be correlated to engine performance and emissions measurements to define any potential benefits of thermal barrier coatings on SI engine performance. The design of the apparatus used to quantify the engine heat transfer and the details of the test matrix used to isolate both material and surface finish effects on the aforementioned performance parameters will be discussed in the following sections. 


\section{Chapter 3}

\section{Experimental Setup and Procedures}

The following chapter provides a description of the general apparatus used throughout the testing regime. Any specific changes made to the apparatus for individual tests will be described in the appropriate chapters. A brief overview of the testing procedure used to study the effects of TBC surface roughness on engine performance is also presented.

\subsection{Engine}

The engine used for all tests in this experimental study was a Waukesha Cooperative Fuel Research (CFR) engine. This single cylinder, water-cooled engine allowed for a variable compression ratio through movement of the one-piece cylinder/head assembly relative to the piston. The cylinder assembly contained four $18 \mathrm{~mm}$ threaded access ports which allowed for various spark plug and pressure transducer configurations. This allows for the study of flame propagation and combustion quality from varying points of ignition within the cylinder. A 
diagram of the ports is shown in Figure 3.1. The engine was equipped with a high energy coil ignition system, and was controlled by a General Electric variable speed DC dynamometer (P/N 2454169 TLC-6) which was used to motor and load the engine. A large opening in the engine crankcase provides access to internal engine components.

Table 3.1 provides the primary specifications of the engine. Further details can be found in the ASTM Manual of Engine Test Methods for Rating Fuels [95].

Table 3.1 - CFR Engine Specifications

\begin{tabular}{cc}
\hline Bore & 3.270 in \\
\hline Stroke & 4.5 in \\
Displacement & 37.792 in $^{3}$ \\
Compression Ratio & Variable \\
Spark Timing & Variable \\
Fuel & Compressed Natural Gas \\
Fuel Metering & Carburetor \\
& (Impco CA55) \\
Boost Pressure & 15 psig max \\
Cooling System & Evaporative Cooling \\
Cooling Medium & Water \\
\hline
\end{tabular}

\subsubsection{Engine Modifications}

Major modifications were made to the original CFR engine to improve overall engine operation and address issues such as oil consumption and in-cylinder deposit build-up which had the potential to affect test repeatability and skew heat transfer measurements. Firstly, a complete overhaul and reboring of the cast iron cylinder assembly was completed. The original cast iron pistons were replaced with custom aluminum (AL2618) pistons produced by Arias Pistons (Gardena, California) which are more representative of modern engine technology. The original five-piece cast iron ring pack was also replaced with a more typical 3-ring pack (including a 3-piece oil ring) to provide an improved seal along the cylinder wall. These changes, in addition to the installation of a PID-controlled oil heater, were found to 
significantly reduce the amount of oil which was seen to accumulate on the piston crown prior to being overhauled.

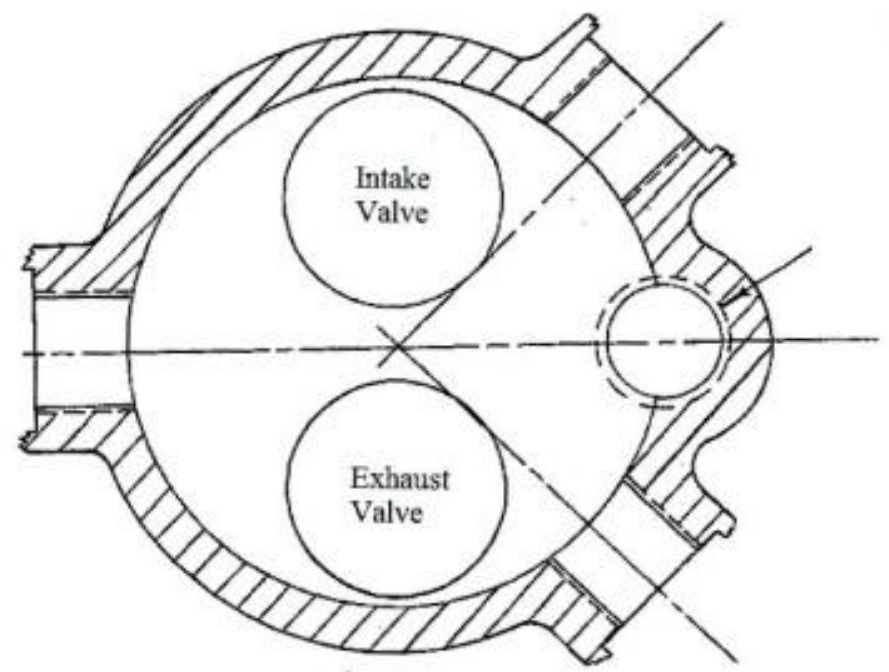

Figure 3.1 - CFR Cylinder Layout [96]

To further address the issue of deposit accumulation within the combustion chamber, the CFR engine was converted to burn natural gas. This gaseous fuel was chosen since it produces less carbonaceous soot during combustion than gasoline. Natural gas was supplied to the engine via compressed tanks which were filled on-site using a FuelMaker natural gas refilling station (FuelMaker P/N C3). The compressed gas was supplied to the engine through a regulator/carburetor assembly (Impco Beam T60 and CA-55). A needle valve was placed upstream of the carburetor to provide final trimming of the fuel supply.

In addition, the engine was supercharged to a maximum boost pressure of $\sim 10 \mathrm{psi}$ (165 kPa) using compressed air from the building supply to allow for engine outputs more representative of a modern spark ignition engine. At maximum boost, an indicated mean effective pressure (IMEP) of approximately $1 \mathrm{MPa}$ was achievable. A 60-gallon receiver tank 
was also placed at the engine intake to minimize the fluctuations in intake air pressure characteristic of single cylinder engines and thus improve engine breathing.

\section{$\underline{3.2 \text { Instrumentation }}$}

The CFR engine was instrumented with various measurement devices to characterize engine behaviour at varying conditions. The following sections provide a brief description of the instrumentation used throughout the testing to monitor basic engine parameters.

\subsubsection{Temperature and Pressure Measurement}

Four basic temperature measurements were used to define an engine operating condition: intake air, oil, coolant and exhaust temperatures. Each of these temperatures was measured using standard Type $K$ thermocouples from Omega Engineering (P/N KQXL116G-12). The intake air, oil and coolant temperatures were used as inputs to PID controller heaters set to $30{ }^{\circ} \mathrm{C}, 80{ }^{\circ} \mathrm{C}$ and $100^{\circ} \mathrm{C}$, respectively throughout testing unless otherwise specified. Each measurement was recorded by the data acquisition system (refer to Section 3.3 - Data Acquisition System) and displayed at the engine control panel.

A piezoelectric pressure gage (Kistler 6125B) was used to measure engine in-cylinder pressures. The voltage output of the transducer was passed through a dual mode charge amplifier (Kistler 5010) equipped with a $33 \mathrm{kHz}$ low pass filter (Kistler 5311A) to minimize unwanted signal noise. Intake air pressure was measured using an OEM manifold air pressure (MAP) sensor (P/N GM 866 7212) salvaged from an old automobile.

\subsubsection{Speed and Torque}

Engine rotational speed was measured using a 60 tooth wheel and a magnetic pickup whose signal was displayed using a frequency indicator (Daytronic 3140) on the engine 
control panel. The engine was also equipped with a rotational encoder (BEI P/N H25D-SS1800-ABZ-7407-LED-EM16) used to determine engine position with respect to TDC for each of the cycle-resolved measurements recorded using the data acquisition system (refer to Section 3.3 for further detail).

Torque measurements were taken using an Interface strain-gage style load cell (P/N SM100) mounted onto the engine dynamometer. Using the force measurement from the load cell and the known length of the dynamometer armature, the torque was calculated and displayed on a Daytronic 3170 strain gage indicator.

\subsubsection{Flow and Emissions}

The engine was also equipped with two mass flow meters to measure the fuel and air flow rates into the engine. A Hastings HFM 201 flow meter calibrated for use with methane measured engine fuel consumption, while a Hastings STH-400K mass flow meter measured the intake air flowrate.

The engine's air-fuel ratio (AFR) was measured using a standard Nernst cell oxygen sensor whose output signal was displayed using a digital multimeter. The measurements were verified using the air and fuel measurements taken using the mass flow meters.

The CFR engine was also equipped with Horiba EXSA-1500 emissions bench used to measure the products of combustion. The emissions bench is configured with three separate modules which allow for measurement of carbon monoxide $(\mathrm{CO})$, oxides of nitrogen $(\mathrm{NO}+$ $\mathrm{NO}_{2}=\mathrm{NO}_{\mathrm{x}}$ ), total hydrocarbon (THC) and oxygen in the exhaust gas.

The MCA-220UA module was used to measure the $\mathrm{CO}, \mathrm{CO}_{2}$ and $\mathrm{O}_{2}$ concentrations in the exhaust sample. $\mathrm{CO}$ and $\mathrm{CO}_{2}$ measurements were made using a cross modulation, nondispersive infrared (NDIR) technique which measures the difference in infrared radiation 
absorbed between exhaust and zero gas samples. Excess $\mathrm{O}_{2}$ was measured using a magnetic pressure-type oxygen analyzer that magnetically collects oxygen ions and measures its partial pressure in the exhaust flue. This measurement thus allows for a third means of measuring the AFR of the engine. The $\mathrm{NO}_{\mathrm{x}}$ analyzer (Module CLA-220UA) measures NO emissions using a chemiluminescence analyzer which reacts NO and with ozone and measures the amount of light emitted from the ensuing reactions. Nitrogen dioxide is first converted to NO prior to being measured. Finally, THC emissions are measured using a flame ionization detector (Module FIA-225UA) which passes the exhaust sample through a hydrogen flame that produces ions proportional to the number of carbon atoms present in the sample.

\subsection{Data Acquisition System}

Experimental data was gathered using a National Instruments cDAQ-9178 8-slot USB chassis populated with five modules used to acquire the varying signals. A 16-bit NI-9205 module gathered all low speed voltage signals including the emissions analyzer, flow meter and speed/torque readings. An NI-9211 thermocouple module was used to record oil, coolant, intake and exhaust temperature. These low-speed measurements were taken at a sampling rate of $200 \mathrm{~Hz}$, averaged over a 0.5 second period and recorded. Four cDAQ-9215 modules acquired the high-speed pressure and temperature measurements which were sampled as a function of engine speed using the crankshaft encoder. The high-speed measurements were triggered using the one pulse per revolution "Z-pulse" which was manually adjusted to begin signal acquisition at TDC. The encoder "A-pulse" then provided a sampling frequency of 1800 samples per revolution, or a sample every $0.2 \mathrm{CAD}$, for the high speed data. This sampling rate, which was dependant on engine speed, thus translated to a maximum rate $50,000 \mathrm{kS} / \mathrm{second}$ per data channel at an engine speed of $1650 \mathrm{rpm}$. 


\subsection{Proposed Engine Testing Procedure}

The underlying goal of the experimental tests was to analyze the effects of thermal barrier coatings and their surface finish on overall performance and emissions in a spark ignition engine as a result of changes in heat flux attributed to surface roughness. It was concluded that the most effective way of studying this factor was through the coating of the piston crown of the single cylinder CFR engine with different materials and at different finishes and studying the effects changing coating finish/material had on engine performance. By instrumenting the piston with multiple surface and in-depth thermocouple pairs, both instantaneous (cycle-resolved) and average piston heat flux through the coating will be could be measured at various operating conditions. These measurements would therefore provide a quantitative means of explaining the engine responses to the different piston surface finishes and understanding the true effects of surface roughness on TBC effectiveness.

In an attempt to isolate the effects of surface roughness, the main causes of heat transfer over the rough piston crown needed to be accounted for in the test matrix in order to see measurable changes in engine performance. As discussed Chapter 2, the two primary factors expected to affect heat transfer over a rough surface in a spark-ignition engine are:

1) the variation in surface area between different surface finishes

2) the interaction between a rough surface with in-cylinder flows.

The following sections describe how these parameters were incorporated into the test matrix of this study.

\subsubsection{Surface Roughness Measurements}

The in-cylinder temperature tests were to be conducted at varying levels of surface roughness for two coatings. Baseline tests were first conducted with the instrumented piston 
with a bare copper coating $(125 \mu \mathrm{m}$ thick thermocouple junction - refer to Section 4.3 for further detail of the thermocouple design) to eliminate any influence of thermal barrier coatings. The unpolished copper coating was used as the As-Sprayed $\left(R_{a}=12.7 \mu \mathrm{m}\right)$ test condition, which was a roughness level typical of most YSZ thermal barrier coatings used in previous TBC heat transfer studies. To produce the subsequently smoother surface finishes, the piston crown was polished with varying sandpaper grits. Since only one piston was instrumented for heat flux measurements, the roughness tests were conducted sequentially. Tests would then be repeated using a $300 \mu \mathrm{m}$ metal thermal barrier coating on the piston to compare the effects of the coating and its finish on engine performance.

For each of the surface conditions, the piston crown surface roughness was measured using a stylus profilometer (Precision Devices Surfometer). Measurements were taken both before and after the completed set of tests to allow any changes in surface conditions that occurred during the test runs (due to deposit formation, for example) to be accounted for. Table 3.2 below shows the complete list of pre-test surface finishes.

Table 3.2 -Coating Surface Roughness Measurements $\left(R_{a}\right.$ values in $\left.\mu \mathrm{m}\right)$

\begin{tabular}{ccc}
\hline & Copper & Metal TBC \\
\hline As-Sprayed & 12.7 & 20.5 \\
Coarse & - & 13.3 \\
Medium & 8.4 & 8.8 \\
Mirror & 0.5 & 4.3 \\
\hline
\end{tabular}

Note that an attempt was made to create matching $R_{a}$ levels between the two coatings for comparative purposes. Seeing as the metal TBC was significantly rougher than the copper junction, a fourth roughness was tested for this coating. Due to the porosity of the Metal TBC, a mirror finish could not be achieved. 
Appendix A shows images of the piston coatings at the different roughness levels. Also, representative surface profiles taken with an optical profilometer are also included.

\subsubsection{Surface - Flow Interactions}

Due to the strong dependence of heat transfer on roughness Reynolds number and turbulence intensity as demonstrated throughout the literature, the effects of in-cylinder flows and their interaction with rough surfaces were studied by changing intake air flow rate. Hall and Bracco [86] demonstrated that mean in-cylinder velocities scaled proportionally with intake air flow rate, as seen in Figure 2.2 on p.28. Therefore, to produce different in-cylinder flow velocities, the tests were run at four different intake pressures spanning from naturally aspirated (NA) to about 10 psi of boost (165 kPa absolute).

Table 3.3 - Engine Test Conditions for Piston Surface Roughness Tests

\begin{tabular}{cc}
\hline Speed $(\mathbf{R P M})$ & 1350 \\
\hline Boost Pressure (kPa absolute) & NA, 135, 150, 165 \\
Compression Ratio & $9.5: 1$ \\
Spark Timing (CAD BTDC) & MBT $=18$ \\
Air-Fuel Ratio & Stoichiometric \\
Oil Temperature $\left({ }^{\circ} \mathbf{C}\right)$ & 75 \\
Coolant Temperature $\left({ }^{\circ} \mathbf{C}\right)$ & 100 \\
Air Temperature $\left({ }^{\circ} \mathbf{C}\right)$ & 40 \\
\hline
\end{tabular}

Turbulence intensity is another important factor when characterizing heat transfer over a rough surface. Since turbulence scales linearly with mean piston speed $[\mathbf{8 5 , 8 7 , 8 9 ]}$ testing at varying engine speed was desired. However, it was believed the CFR engine's narrow range of operating speeds would make it difficult to produce large enough differences in turbulence intensity to see its effects on heat transfer. Thus, the tests were conducted at a 
constant $1350 \mathrm{rpm}$ to maintain relatively constant in-cylinder turbulence intensity and minimize its effects on the analysis. This relatively low speed was also chosen to help minimize fatigue on the thermocouple wires in the piston surface temperature measurement system that were used to transmit the temperature measurements from the piston to the data acquisition system for analysis (see Section 6.1 - Piston Instrumentation for further detail).

\subsection{Modified Engine Testing Procedure}

Due to difficulties with the custom surface temperature measurement apparatus (described in Chapter 6 for details of the measurement apparatus) used to measure the piston surface temperatures needed for the heat flux analysis, modifications to the proposed test regime were required. The functionality of the measurement system was demonstrated through the successful collection of piston surface temperature measurements over six onehour test runs at the As-Sprayed copper surface condition. However, as a result of the harsh engine conditions and the large number of temperature measurements, the approach to routing the wires from the engine to the data acquisition system resulted in the thermocouple wires breaking in a variety of locations along the wiring route. It was thus deemed an unreliable means of transmitting the thermocouple signals without further modifications. Further details with regards to the wire failures are discussed in Section 6.4.

The inability to obtain consistent temperature measurements thus created an unrealistic time frame to collect the data needed to fully analyze coating effects on heat transfer. The following section describes a modified test matrix designed to facilitate the data collection process. 


\subsubsection{Modified Test Matrix}

While the same approach described in Section 3.4 was used to test coating effects on engine performance, no surface temperature measurements were taken. Power, fuel consumption, emissions, and in-cylinder pressure were used to characterize coating effects.

The tests were conducted at the same engine conditions as outlined in Table 3.3. Two additional engine speeds (1500rpm and 1650rpm) were also included in an attempt to further understand the effect of engine speed, and thus turbulence intensity, when using different surface finishes. Each surface finish was tested at a total of $12 \mathrm{load} / \mathrm{speed}$ conditions and repeated five times over two days to ensure repeatability and minimize the effects of ambient conditions. Spark timing for maximum brake torque (MBT) was found for the baseline AsSprayed copper coating at each test point, as listed in Table 3.4. These values were maintained for all subsequent surface finishes/coatings for comparative purpose.

Table 3.4 - Ignition Timing ( ${ }^{\circ}$ BTDC)

\begin{tabular}{ccccc}
\hline & NA & $135 \mathrm{kPa}$ & $150 \mathrm{kPa}$ & $165 \mathrm{kPa}$ \\
\hline 1350rpm & 16 & 15 & 14 & 14 \\
1500rpm & 18 & 16 & 15 & 15 \\
1650rpm & 20 & 18 & 15 & 15 \\
\hline
\end{tabular}

The results of these tests are presented in Chapter 7 beginning on p.105. Chapters 4 , 5 and 6 describe the development of the thin film surface thermocouples used and the piston surface temperature measurement apparatus. Specifically, Chapters 4 and 5 describes the design of the surface thermocouples using a detailed FEA model and their characterization through various tests. Chapter 6 presents an overview of the apparatus designed for collection of piston surface temperature measurements. This information is provided for documentation purposes, but the reader can proceed to the results in Chapter 7 with no loss of continuity. 


\section{Chapter 4}

\section{Thermocouple Development}

Temperature measurements are the primary pieces of information needed to conduct a heat transfer analysis, as by definition, heat transfer describes energy transport across a temperature gradient. The basics of the heat transfer analysis that will be conducted in this study and the development of the temperature measurement devices using finite element modelling will be discussed in the following chapter.

\section{$\underline{\text { 4.1 Heat Transfer Analysis Basics }}$}

The primary goal of this study was to quantify the effects thermal barrier coatings had on heat transfer in an SI engine, and the role surface finish played in this phenomena. To study this, it was decided that heat transfer through the piston crown would be measured due to it being a large portion of the in-cylinder surface area and the relative ease of applying and studying the coatings on the piston crown in the CFR engine. 
The key to the study was thus instrumenting the piston to gather the necessary temperature boundary conditions for the heat flux analysis. Two temperature measurements are needed: a surface temperature beneath the coating, $T_{s}$, and an "in-depth" measurement, $T_{i}$, at a fixed distance $l$, from the piston surface. The temperatures were then used as the boundary conditions to solve the one-dimensional, transient heat flux equation shown below.

$$
\frac{\partial T}{\partial t}=\alpha \frac{\partial^{2} T}{\partial^{2} x}
$$

where

$$
\begin{gathered}
T(0, t)=T_{s}(t) \\
T(l, t)=T_{i}
\end{gathered}
$$

Using Fourier analysis, as shown in Borman and Nishiwaki [3], the temperature distribution between the two boundaries can be solved for,

$$
T(x, t)=T_{s, m}-\frac{x}{l}\left(T_{s, m}-T_{i}\right)+\sum_{n=1}^{N} e^{\phi_{n} x} F_{n}(x, t)
$$

where

$$
\begin{gathered}
F_{n}(x, t)=A_{n} \cos \left(n \omega t-\phi_{n} x\right)+B_{n} \sin \left(n \omega t-\phi_{n} x\right) \\
\phi_{n}=\sqrt{\frac{n \omega}{2 \alpha}}
\end{gathered}
$$

In the equations above, $T_{s, m}$ is the time-averaged surface temperature while $\omega$ is the engine angular velocity in $\mathrm{rad} / \mathrm{s} . A_{n}$ and $B_{n}$ are the Fourier coefficients determined using a Fourier transform of the surface temperature data while $N$ is the number of harmonics used. Using the temperature distribution $T(x, t)$ and Fourier's Law, the heat flux through the piston crown is given by 


$$
\dot{q}_{s}(t)=-k\left(T_{s, m}-T_{i}\right)+k \sum_{n=1}^{N} \phi_{n}\left[\left(A_{n}+B_{n}\right) \cos (n \omega t)-\left(A_{n}-B_{n}\right) \sin (n \omega t)\right]
$$

The assumption of one-dimensionality was deemed sufficiently accurate since the unsteady fluctuations perpendicular to the piston surface were significantly greater than the fluctuations parallel to the surface [3]. Likewise, the distance between the in-depth and surface temperature measurements was minimized to reduce the two dimensional effects in the temperature measurements.

As seen through the equations above, determining boundary conditions $T_{s}$ and $T_{i}$ are critical to the accuracy of the heat flux calculation. In the following sections, the development of the thermocouples used to take these measurements will be discussed.

\subsection{Thermocouple Basics}

A thermocouple is a basic thermoelectric device that is governed by the Seebeck effect, which states that current will flow through a circuit consisting of two dissimilar metals joined at both ends and heated at one of the junctions [97]. This current flow is as a result of the flow of energized electrons travelling across the temperature gradient in the wire towards the cold junction. Figure 4.1 below depicts the principle of dissimilar metals.

The magnitude of the current produced by a certain temperature difference is material-specific and defined by a metal's Seebeck coefficient. Table 4.1 below provides values of Seebeck coefficients for common thermocouple materials. This behaviour thus allows for the correlation of a temperature to the voltage output of a specific metal pairing. The National Institute of Standards and Technology (NIST) have prepared calibration curves for common metal pairings. 
Table 4.1 - Seebeck Coefficient of Typical Thermoelements at $20^{\circ} \mathrm{C}$

\begin{tabular}{cc}
\hline Conductor & $\begin{array}{c}\text { Seebeck Coefficient, } \boldsymbol{S} \\
(\boldsymbol{\mu} \mathbf{V} / \mathbf{K})\end{array}$ \\
\hline Chromel & 22.2 \\
$\mathbf{F e}$ & 13.3 \\
$\mathbf{C u}$ & 1.9 \\
$\mathbf{A l}$ & -1.3 \\
$\mathbf{P t}$ & -4.7 \\
Alumel & 18.2 \\
Constantan & -38.3 \\
\hline
\end{tabular}

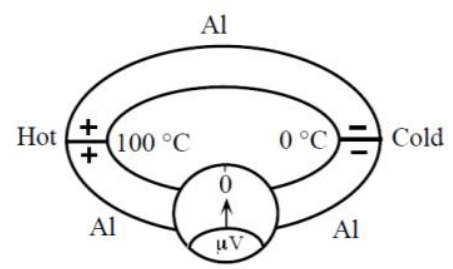

If $\mathrm{Al}$ wires are used to measure the Seebeck voltage across the Al rod, then the net emf is zero.

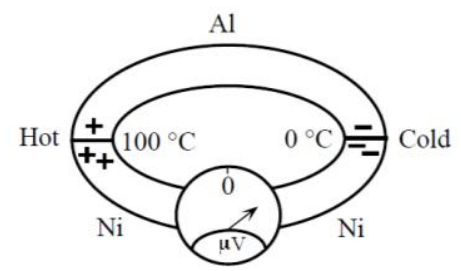

The $\mathrm{Al}$ and $\mathrm{Ni}$ have different Seebeck coefficients. There is therefore a net emf in the Al-Ni circuit between the hot and cold ends that can be measured.

Figure 4.1 - Thermoelectric Effect [98]

The thermocouple was chosen for this study ahead of temperatures other devices such as the resistance temperature detectors (RTD), thermistor, thermocouple, pyrometer and infrared devices for multiple reasons. The primary advantage of a thermocouple is its inherent simplicity. These self-powered devices allow for small packaging and relatively non-invasive measurement. Their small size also allows for fast response times due to their low thermal inertia. They are also inexpensive relative to other solutions, and allow for reasonable accuracy at a wide temperature range. Issues associated with thermocouples are that they produce very low voltages $\left(\sim 40-50 \mu \mathrm{V} /{ }^{\circ} \mathrm{C}\right)$, thus making these signals very 
susceptible to environmental noise. Also, thermocouples are non-linear devices and require a reference temperature for use in the calculation of the hot junction temperature.

\subsubsection{Thermocouple Design Requirements}

The primary goal of the thermocouple is to provide a "true" surface temperature measurement; namely, to measure the temperature of the surface if the thermocouple was not present in the system. To achieve this, the thermocouples needed to be as small as possible to minimize the thermal inertia of the devices, and thus maximize measurement accuracy. Using thermocouple materials with similar thermal properties to the substrate into which they would be installed would also help reduce the invasiveness of the device. The thermocouples also needed to be robust enough to withstand the conditions of the combustion chamber, and provide a fast enough response time to obtain cycle-resolved temperature measurements used to calculate the instantaneous heat flux through the piston crown. Finally, simplicity of construction and cost effectiveness was desired.

\subsubsection{Past Surface Thermocouple Designs}

Various types of surface thermocouple designs have been developed for use in engine heat transfer studies. These thermocouple designs are typically divided into three categories: coaxial, pair-wire and thin film thermocouples. The coaxial thermocouple (Figure 4.2) is a commonly-used device which consists of a thermocouple wire that is coated in an electrical insulator and swaged into a tube of a second thermocouple element. A junction is then formed by applying a thin conductive layer across the coaxial elements. Multiple engine studies $[4,5,11,13,23,34,99]$ have been conducted using these sensors originally presented by Bendersky [100]. 


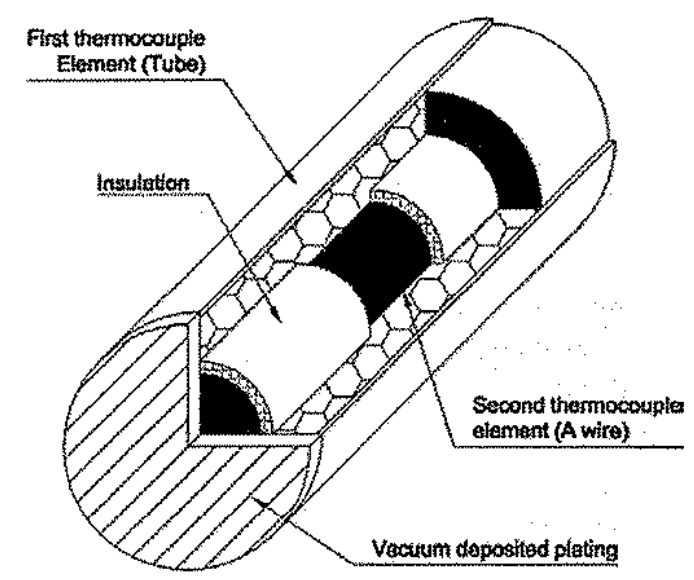

Figure 4.2 - Coaxial Thermocouple [101]

Coaxial thermocouples are commercially available through companies such as Medtherm Corporation [101]. However, finite element analysis studies of these thermocouples (Types J, K, E and S) have shown that they have the tendency to overestimate true temperature swings by up to almost $80 \%$ when installed in cast iron and aluminum pistons [99]. This was attributed to large difference in the thermal diffusivity of the thermoelements and the aluminum piston. Furuhama and Enomoto [23] conducted a similar analysis on a custom coaxial thermocouple which showed they were able closely replicate the true temperature swings in an aluminum piston by using a thin copper coating to form the hot junction. Finite element analysis was used to optimize the coating thickness to provide a response closest to the "true" surface temperature.

The pair-wire thermocouple consists of two thermocouple wires that are electrically insulated from one another and placed in a sheath. A junction is then formed by applying a thin conductive coating on the thermoelements. A variant of the pair-wire surface thermocouple is the eroding thermocouple (Figure 4.3) which has been used in various engine heat transfer studies to-date $[\mathbf{1 8}, \mathbf{1 0 2}, \mathbf{1 0 3}]$. 
These thermocouples consist of two ribbons of thermoelectric materials separated by an insulating film and placed in a metallic sheath. The self-renewing hot junction is formed by abrading its surface to form micro junctions between the two elements. This allows for extremely fast response times due to the microscopic electrical connections. However, Buttsworth et al. [105] demonstrated through finite element modelling that the construction of these thermocouples and the use of the different materials result in two-dimensional heat transfer which introduce errors into the typical one-dimensional transient heat flux analysis (refer to Section 4.1- Heat Transfer Analysis Basics).
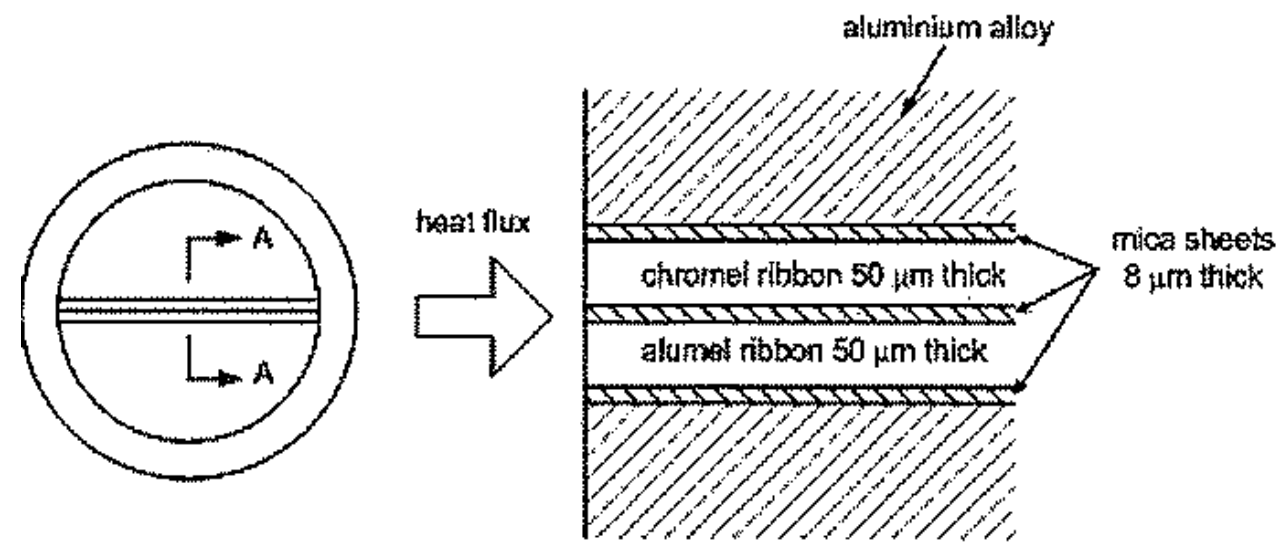

Figure 4.3 - Eroding Thermocouple [104]

The thin film family of surface thermocouples attempts to address the issue of hot spots at the hot junction due to dissimilarities in thermocouple materials and the base substrate by isolating the hot junction from the thermocouple wires. Assanis et al. [32] developed a thermocouple which used overlapping vapour-deposited thin films to create a junction between two thermocouple wires, as shown in Figure 4.4 below. This isolated junction was used to minimize the thermal interference of the low thermal conductivity thermocouple elements. Annand [9], Wimmer [106], Dent and Suliaman [107] each used thermocouples based on similar thin film concepts in engine heat transfer studies. 


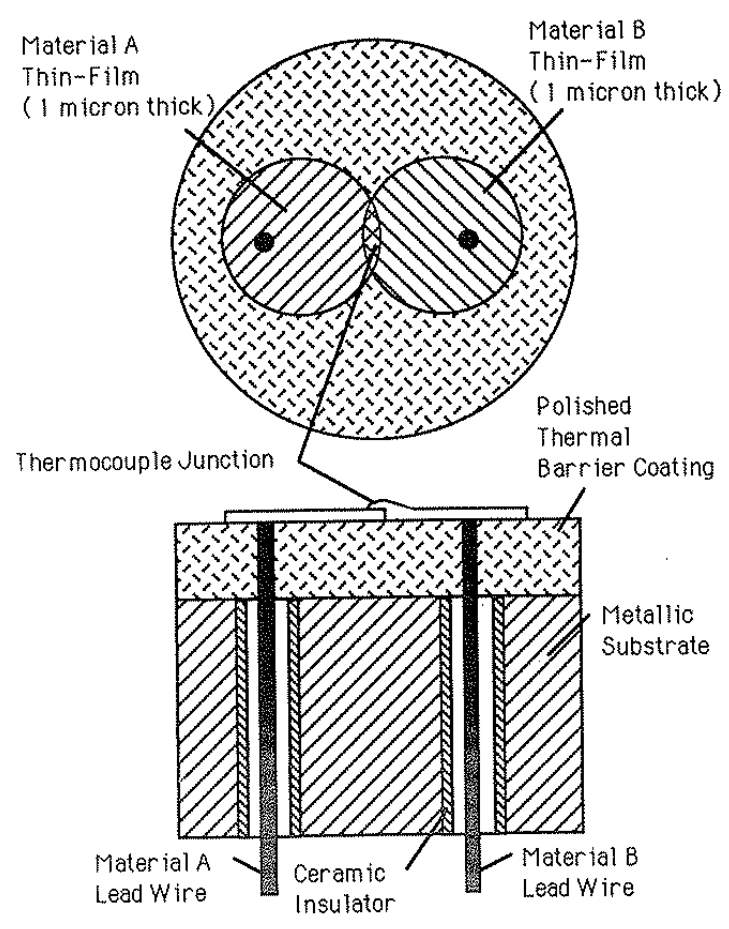

Figure 4.4 - Thin Film Thermocouple [32]

Each of the abovementioned designs attempt to maximize measurement accuracy and minimize response time by reducing junction size to diminish interruptions in heat flow through the substrate. However, they each use at least two thermocouple materials which have significantly lower thermal diffusivity than the metallic substrates into which they were installed. This results in inaccuracy in measuring absolute temperatures and temperature swings due to the formation of hotspots. A thermocouple design that attempts to address this issue was presented by Heichal et al [99]. This design, as shown in Figure 4.5 below, inserts a single thermoelement into the substrate whose surface temperature is being measured, and uses the substrate as the second thermoelement. The junction is formed by using an electrically conductive thin film. Since only one foreign thermocouple element must be inserted into the system, this design allows for small thermocouple junctions that provide extremely fast response times (on the order of nanoseconds) and reduce the chances of 
measurement error due to hotspots. Also, this design had the advantage of being simple to manufacture relative to the abovementioned designs.

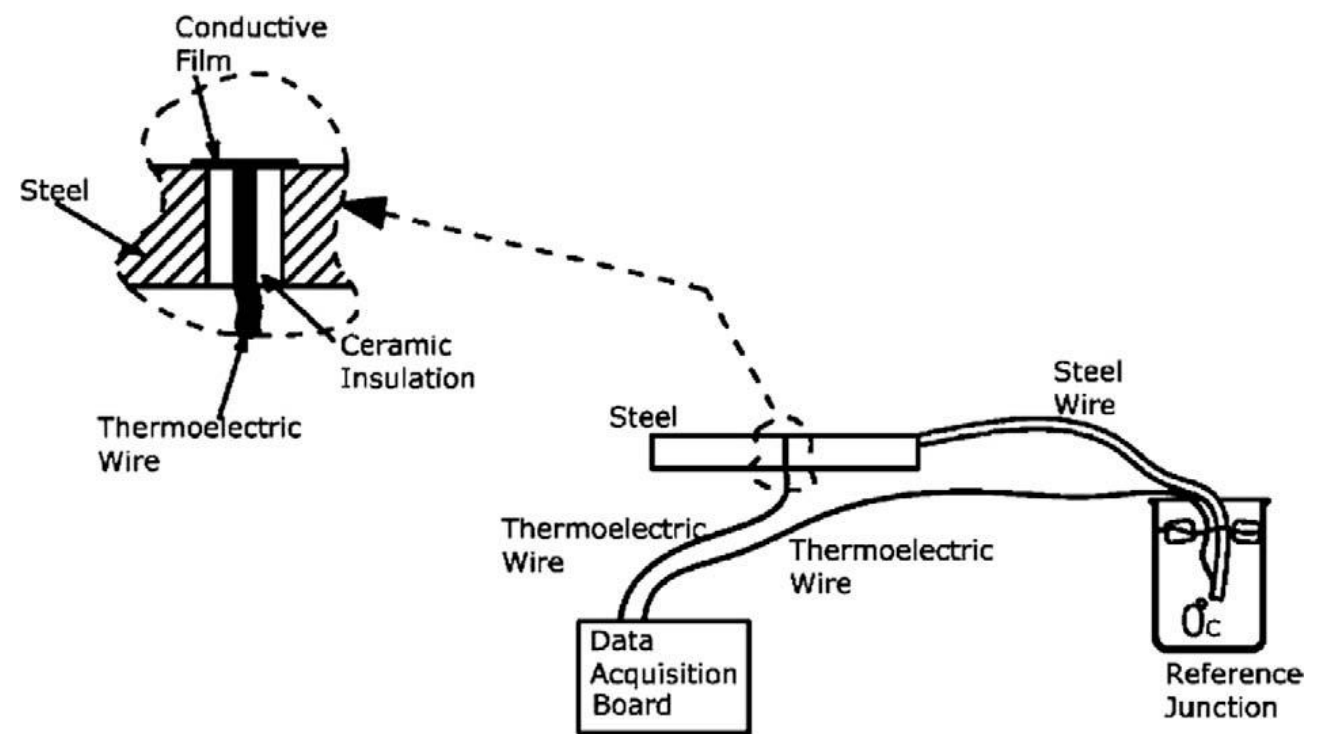

Figure 4.5 - Heichal Surface Thermocouple [108]

Marr et al. [109] made this design more suitable for use in engine testing by using a wire-arc sprayed copper coating to form the thermocouple's hot junction and by replacing the ice-bath cold junction used in Heichal's original design with a cold junction located in the piston. Finite element analysis of the thermocouple design demonstrated the thermocouple's ability to produce very accurate thermocouple measurements, while being rugged and reliable enough to withstand in-cylinder engine testing.

Due to this design's ability to produce accurate measurements at a low cost, it was chosen to conduct this heat transfer study. However, a few potential areas of improvement for the design remained. Namely, the relatively thick ( 100 mm) copper coating used to form the thermocouple's hot junction introduced a time delay in the temperature measurements. Finite element modelling by Marr et al. predicted that a time delay of less than five crank angle degrees could be expected, though the value was not quantified experimentally. Also, 
the thermocouple signals gathered during engine testing were seen to be very susceptible to electrical noise in the test environment, thus producing a low signal-to-noise ratio and requiring substantial filtering which introduced signal offsets and potential data loss. In addition, the use of the Teflon wire coating and ceramic cement to provide electrical isolation introduced two low thermal diffusivity materials into the design which interrupted heat flow and thus required the use of a thick copper layer.

Changes in material selection and manufacturing could thus provide improvements to overall thermocouple accuracy and signal quality. In the following section, these issues are addressed in an attempt to improve to the thermocouple design.

\subsection{Surface Thermocouple Design and Construction}

Figure 4.6 shows the basic design of the surface thermocouple used in this study. The thermocouple consisted of a single constantan wire (Omega Engineering TFCI series) fed through an aluminum (AL 2618) substrate. Constantan was selected due to its high Seebeck coefficient $(S=-38.3 \mathrm{mV} / \mathrm{K}$, see Table 4.1 on p.51) relative to other typical thermocouple materials [110]. The thermocouple's hot junction was formed using a thin plasma-sprayed copper coating which damped the hotspot created at the junction due to differences in material properties, and thus increasing the one dimensionality and accuracy of the device. The optimization of the copper layer is presented in Section 4.4.

While based on Marr's design, several changes were made to improve the accuracy of the temperature measurements. Firstly, an attempt was made to reduce the thermal mass of the thermocouple by eliminating the low conductivity Teflon $(k=0.23 \mathrm{~W} / \mathrm{m} \mathrm{K})$ coating and ceramic cement $(k=1.2 \mathrm{~W} / \mathrm{m} \mathrm{K})$ used in the original design [109]. To minimize the effects of the Teflon insulation at the hot junction, a small portion $(\sim 5 \mathrm{~mm})$ of the tip of the wire was 
stripped. Likewise, a thin coating of high thermal conductivity thermocouple potting material (Aremco Ceramacast 675-N) was used to secure the constantan wire in the aluminum substrate. This ceramic cement, according to Aremco, consists of approximately $80 \%$ aluminum nitride, thus giving it a high thermal conductivity $(\sim 10 \mathrm{~W} / \mathrm{mK})$ in comparison to the original ceramic cement used by Marr et al. In addition, the Ceramacast 675-N's long setting time allows for much simpler construction of the thermocouples.

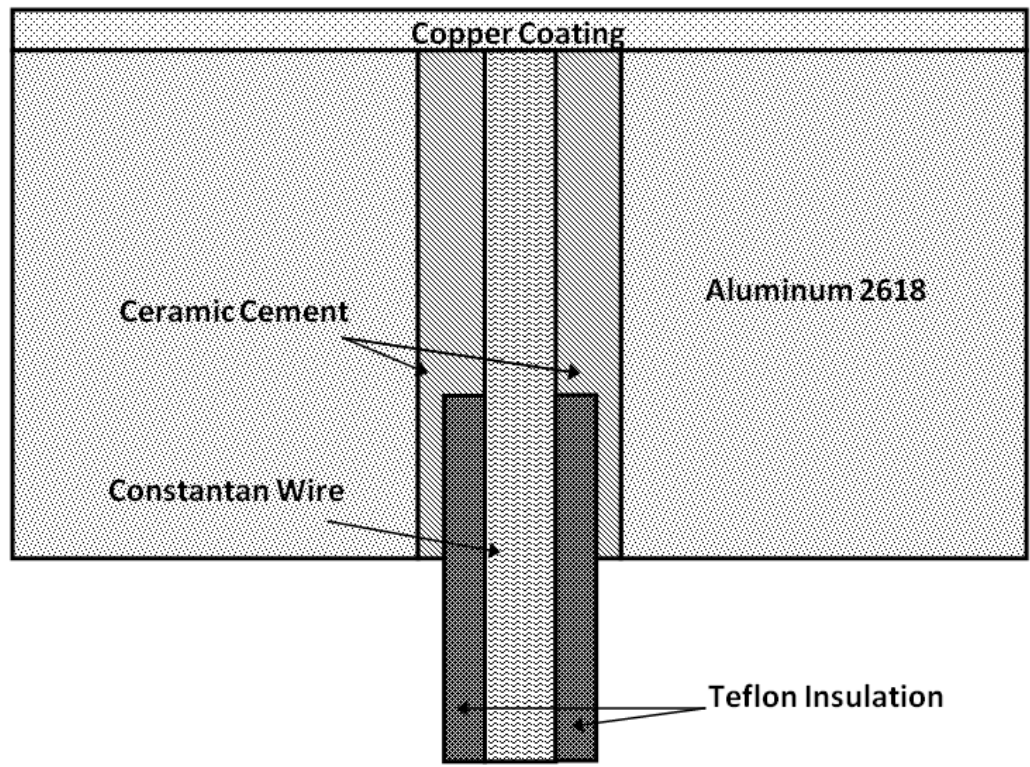

Figure 4.6 - Surface Thermocouple Schematic

An attempt was also made to increase the signal-to-noise ratio of the surface thermocouples by using larger diameter wires. This was done to reduce the resistance of the thermocouple wires (which is inversely proportional to cross sectional area), and thus reduce noise in the thermocouple signals. The effects this increase in thermal mass at the thermocouple junction had on accuracy will be addressed through a finite element analysis study (Section 4.4) and experimental testing (Section 5.4).

In the following section, a finite element analysis used to optimize the thermocouple design geometry using different wire diameters is presented. 


\subsection{Surface Thermocouple Finite Element Analysis}

The COMSOL Multiphysics 4.1 finite element code was used to analyze different configurations of the surface thermocouple and optimize it to provide the most accurate temperature measurements. The goal was to determine the optimal combination of wire/hole diameters and the film thickness needed to ensure the thermocouples measured the "True" surface temperature; namely, the surface temperature if the thermocouple was not present.

The parameters used to determine the quality of the thermocouple design were: 1) the thermocouple's ability to accurately measure absolute temperatures and temperature swings, and 2) the time delay resulting from the introduction of the copper coating. An analysis studying the sensitivity of the temperature measurements to different design parameters is discussed in Section 4.5 - FEA Sensitivity Analysis.

\subsubsection{Basic Model Parameters}

Figure 4.7 and Figure 4.8 below show the two surface thermocouple geometries and their corresponding boundary conditions as modelled in COMSOL. The Stepped configuration replaces the through-hole seen in the basic Stripped configuration with a twostage hole in an attempt to minimize the overall size (and thus thermal mass) of the junction. In both cases, an area surrounding the thermocouple hot junction was modelled in a twodimensional axisymettric space to reduce computational requirements. Table 4.2 lists the pertinent material properties used in the model. Three different wire diameters $(0.010$ ", 0.015 " and 0.020 ") were tested in the Stripped and Stepped configurations (Figure 4.7 and Figure 4.8) to determine the impact using larger diameter wires had on the accuracy of the thermocouple in measuring the True surface temperature. It should be noted that the hole diameters for the three wires were $0.020 ", 0.035$ " and $0.040 "$, respectively, in the "Stripped" 
configuration. Throughout this analysis, the centre of constantan wire was taken as the thermocouple hot junction, which was a fair assumption due to the small temperature differences seen at points on the junction (less than $0.2^{\circ} \mathrm{C}$ at steady state in FEA results).

Table 4.2 - FEA Material Properties

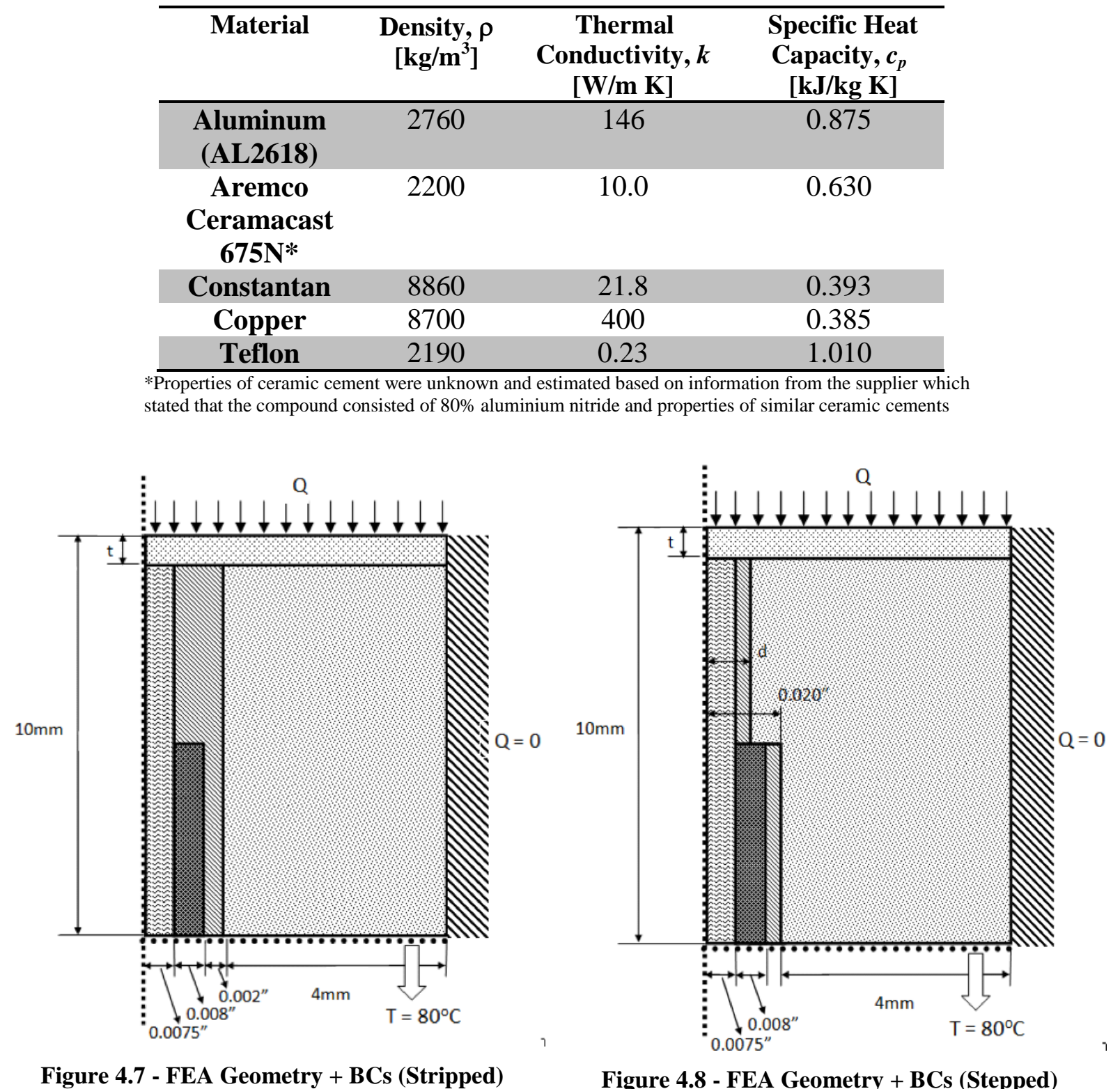

The periodic heat flux boundary condition applied to the thermocouple hot junction, shown in Figure 4.9 below, was calculated from piston surface temperature measurements 
taken during a previous heat transfer study conducted by Marr et al [111] using the same CFR engine described in Section 3.1. The heat flux measurements were taken as the engine ran at WOT at $1200 \mathrm{rpm}$ when fuelled with gasoline. The lower boundary condition on the thermocouple sample was set to a constant temperature of $80^{\circ} \mathrm{C}$ to represent the temperature of the cooling oil on the underside of the piston. Varying this boundary condition was shown to not affect the overall trend of the analysis, but rather the final steady state temperature reached, which was not of concern in this qualitative analysis studying the response of different thermocouple configurations. The outer boundary condition was set to a zero heat flux boundary condition as was done in similar thermocouple modelling studies by Buttsworth et al [105] and Enomoto and Furuhama [5]. This is a fair assumption since the aluminum substrate is more than 10 wire diameters from the hot junction, thus allowing ample space for any two-dimensional effects at the hot junction to present themselves in the substrate (i.e. has little bearing on the directionality of the heat transfer).

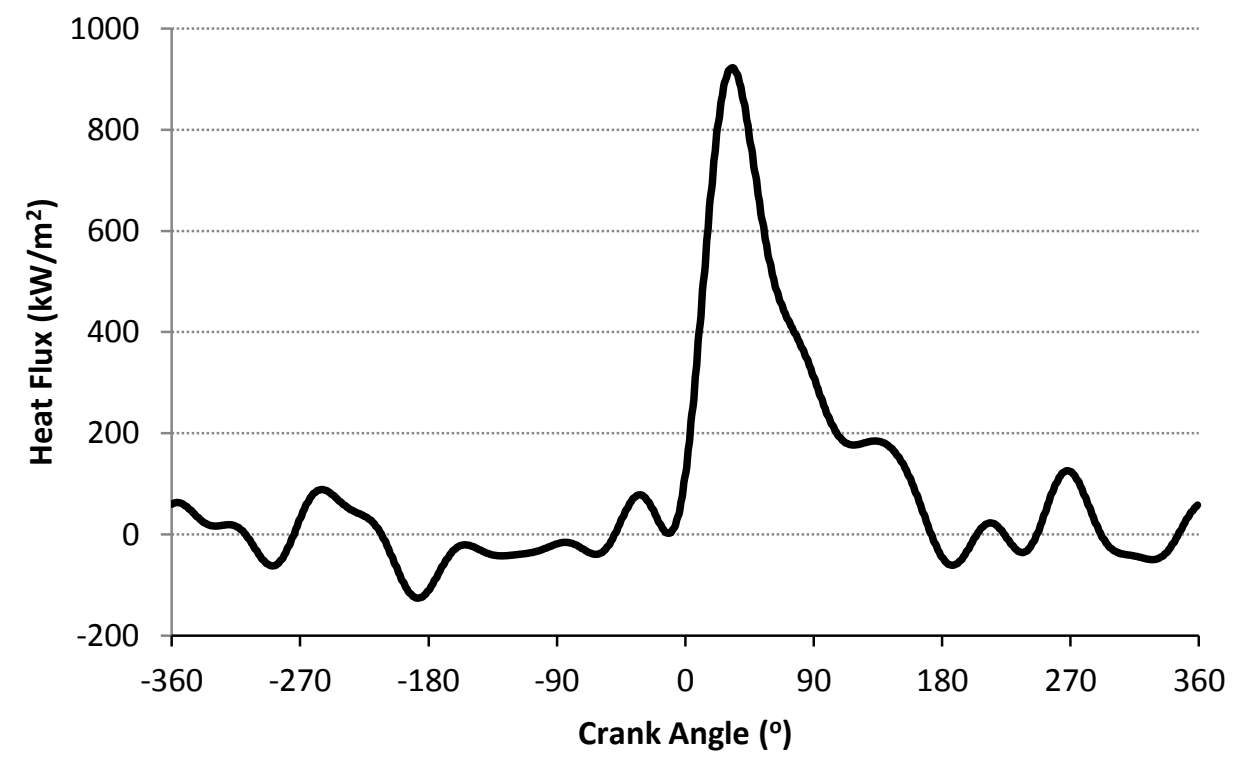

Figure 4.9 - FEA Het Flux Boundary Condition 
The geometry was meshed in COMSOL into approximately 3300 triangular elements with a variable mesh density focussed around the hot junction. A $1.3888 \mathrm{e}-4 \mathrm{~s}$ time step was used, which corresponds to the sampling period used by Marr et al. in the collection of the boundary condition data ( 1 sample/CAD at 1200rpm). Further refinements to the mesh density and time step were seen not to have any effect on the solution.

\subsubsection{Wire and Coating Optimization}

Figure 4.10 depicts the "True" substrate temperature response at steady state when the thermocouple is not present in the aluminum substrate, and thus represents the ideal response a thermocouple placed within the substrate should be able to accurately recreate. Using the boundary conditions described in Section 4.4.1, this temperature profile is achieved by changing all material properties in the FEA model to those of aluminium.

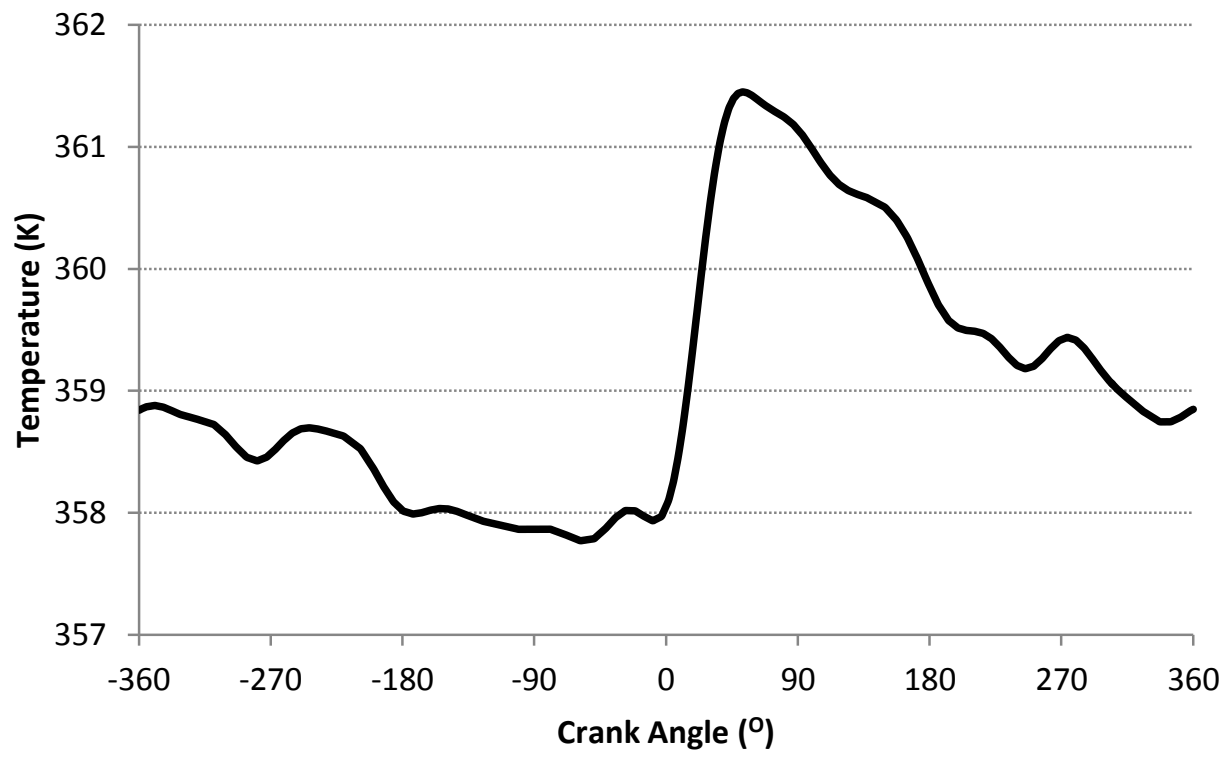

Figure 4.10 - True Surface Temperature

Figure 4.11 below shows the temperature profiles obtained when the material properties of the constantan wire, Aremco potting cement and Teflon coating were applied to 
the Stripped geometry. It is clear from Figure 4.11 below that the introduction of the thermocouple into the aluminum substrate disrupts heat flow and produces a hotspot at the thermocouple junction, thus resulting in inaccurate temperature readings. The low thermal diffusivity of the thermocouple materials with respect to that of aluminum results in an overestimation of the maximum peak temperature of the cycle by $5.2 \mathrm{~K}, 6.5 \mathrm{~K}$, and $6.0 \mathrm{~K}$ for the $0.010 ", 0.015 "$ and 0.020 " wires, respectively. The larger deviation of the 0.015 " wire relative to the 0.020 " wire was attributed to its higher percentage of low diffusivity ceramic cement at the hot junction. Likewise, temperature swings were overestimated by as much as $180 \%$ with respect to the True values.

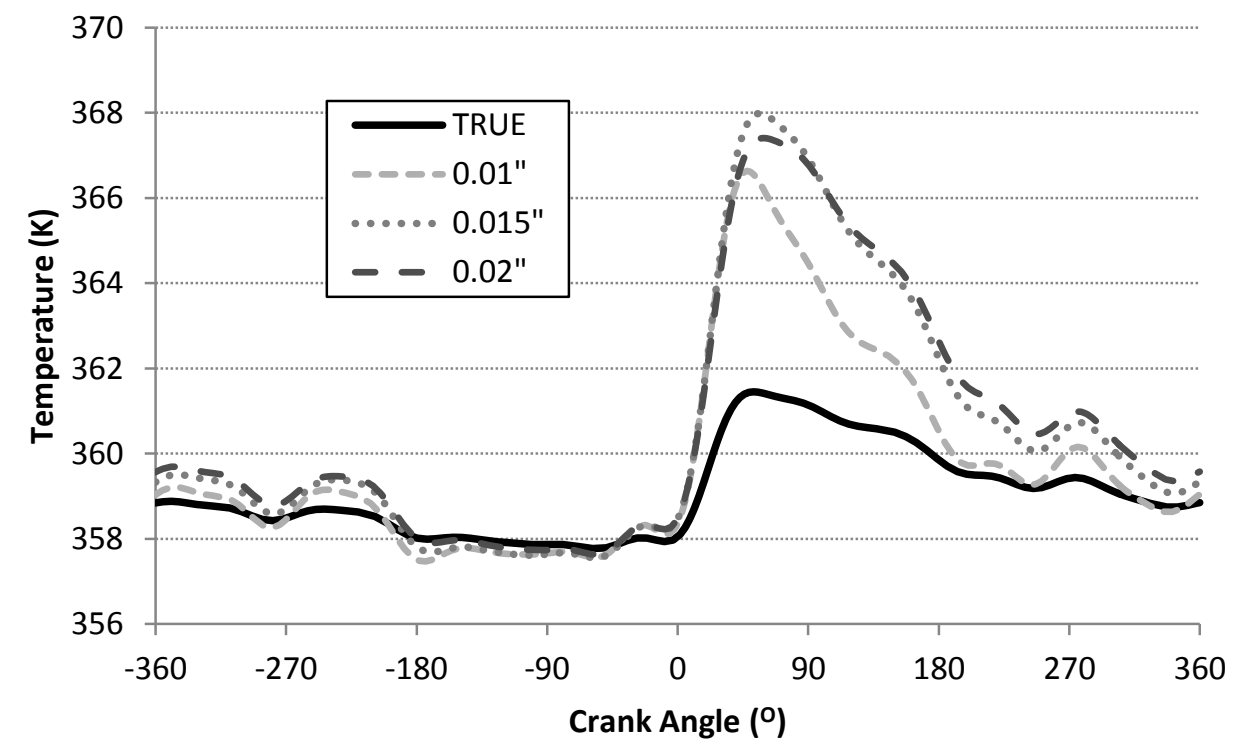

Figure 4.11 - Stripped Geometry FEA Hot Junction Temperature (No Copper Coating)

These errors in measurement were alleviated by applying a thin copper coating to the hot junction to help equalize the temperature between the thermocouple and the substrate. As seen in Figure 4.12 for the case of a 0.010 " wire in the Stripped configuration, the introduction of a thin copper layer of approximately $100 \mu \mathrm{m}$ eliminates the large temperature swing seen in the uncoated case and brings the measured temperature to within 0.2 degrees of 
the True temperature. The copper layer resulted in a time delay of about 5 CAD in reaching the peak temperature and a $2 \%$ damping of the temperature swing was observed, which was an acceptable trade-off for improved measurement accuracy.

The Stepped thermocouple configuration was tested to further reduce thermal mass of the hot junction by reducing the diameter of the hole through which the constantan wire was fed. The primary goal of these studies was to determine the effect different hole/wire diameter combinations had on thermocouple accuracy while maximizing the ease of manufacturability. Coating thickness was again optimized for each design variation.

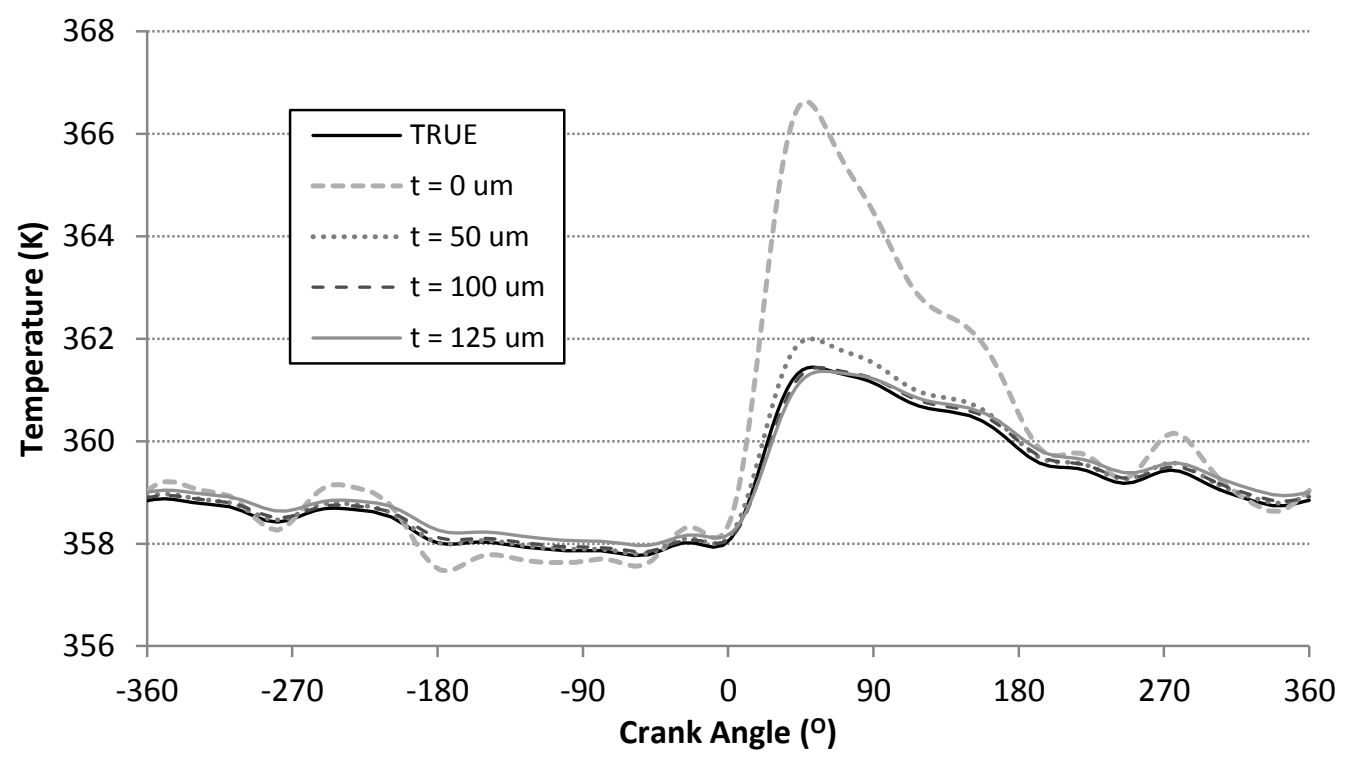

Figure 4.12 - Copper Coating Comparison - Stripped 0.010" Wire Case

Figure 4.13 shows the results of each of the cases in a plot of accuracy (presented as root mean square deviation temperature, $\left.\mathrm{T}_{\mathrm{RMSD}}\right)$ and time delay $(\phi)$ for three different coating thicknesses $(\delta=50 \mu \mathrm{m}, 100 \mu \mathrm{m}$, and $125 \mu \mathrm{m})$. This graph clearly shows that for each of the six wire/hole combinations tested, the maximum accuracy was achieved when a copper coating of approximately $100 \mu \mathrm{m}$ was applied to the hot junction. Root mean square errors of between 0.08 and 0.17 degrees were predicted under these conditions with a corresponding 
maximum time delay of approximately $5 \mathrm{CAD}$, which were deemed acceptable. Coatings much thinner than $100 \mu \mathrm{m}$ coatings were shown not to provide sufficient thermal mass to buffer the negative effects of the low diffusivity thermoelements, while increasing the thickness of the copper coating above the $100 \mu \mathrm{m}$ point resulted in increased time delays. Thus, a $100 \mu \mathrm{m}$ copper film was determined to be the appropriate thickness to be implemented in the final thermocouple design.

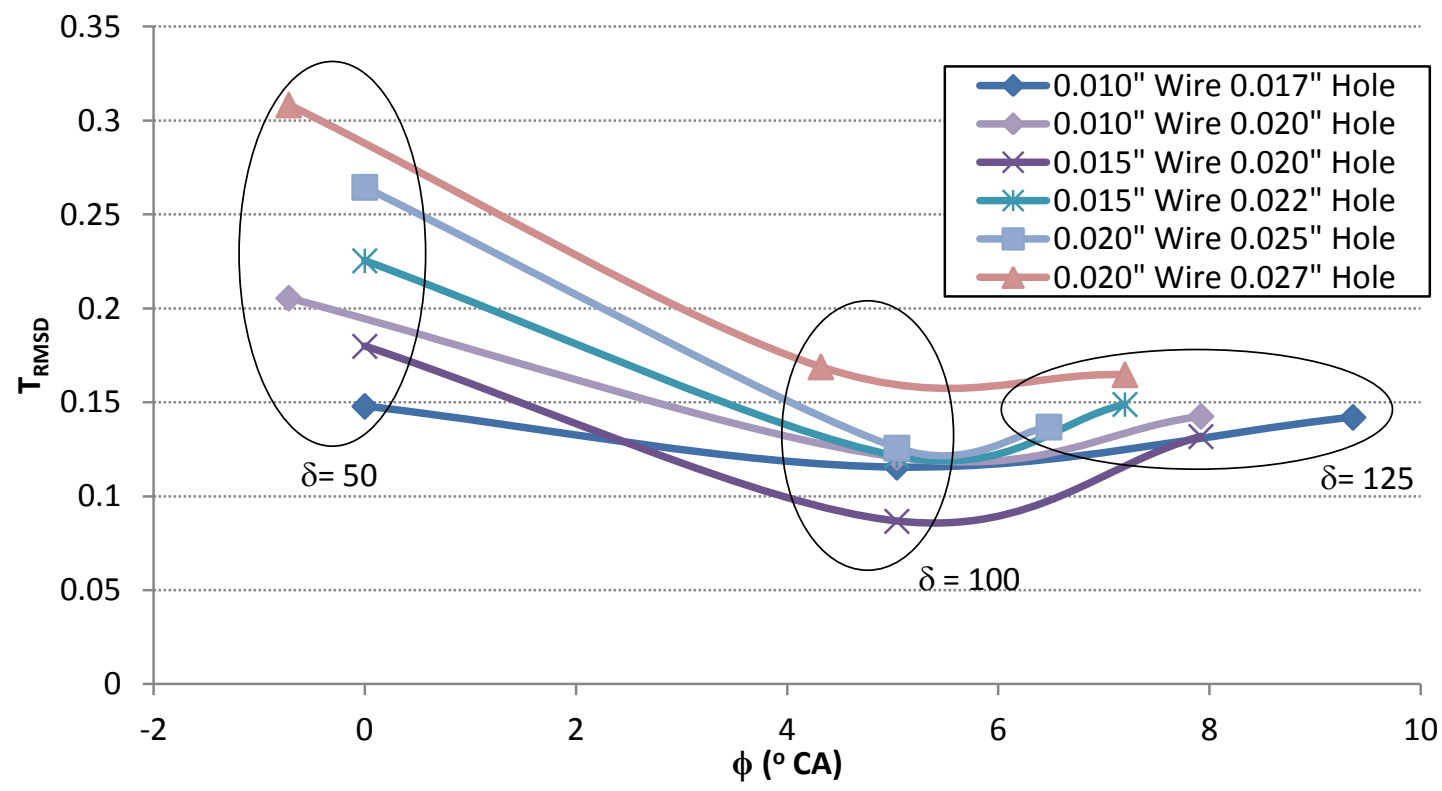

Figure 4.13 - FEA Analysis Results - Stepped

Figure 4.13 also shows that the accuracy of the thermocouple is not strongly dependant on the wire and hole diameters chosen. For each of the three wire diameters, two hole sizes were modelled. The hole sizes were chosen to provide between 0.005 " and 0.007 " of clearance for the constantan wire, which was similar to those used in the original designs by Heichal and Marr. For each wire diameter/coating thickness combination, varying hole diameter had little effect on overall accuracy, as they were each still theoretically capable of measuring the true temperature within 0.2 degrees when using a $100 \mu \mathrm{m}$ copper coating. 
Figure 4.14 shows the predicted temperature profiles for the three wire diameters and the corresponding large diameter holes when a $100 \mu \mathrm{m}$ copper coating is applied. It can be seen from this graph that there is negligible variation between the three cases and that they are each capable of accurately predicting the True surface temperature within 0.25 degrees. The $100 \mu \mathrm{m}$ coating slightly damped the temperature swings of the 0.010 " and 0.015 " cases by $2.3 \%$ and $1.6 \%$, respectively, while slightly overpredicting the temperature swing of the 0.020 " wire by $2.3 \%$. The phase shifts were approximately 5 CAD for all three cases.

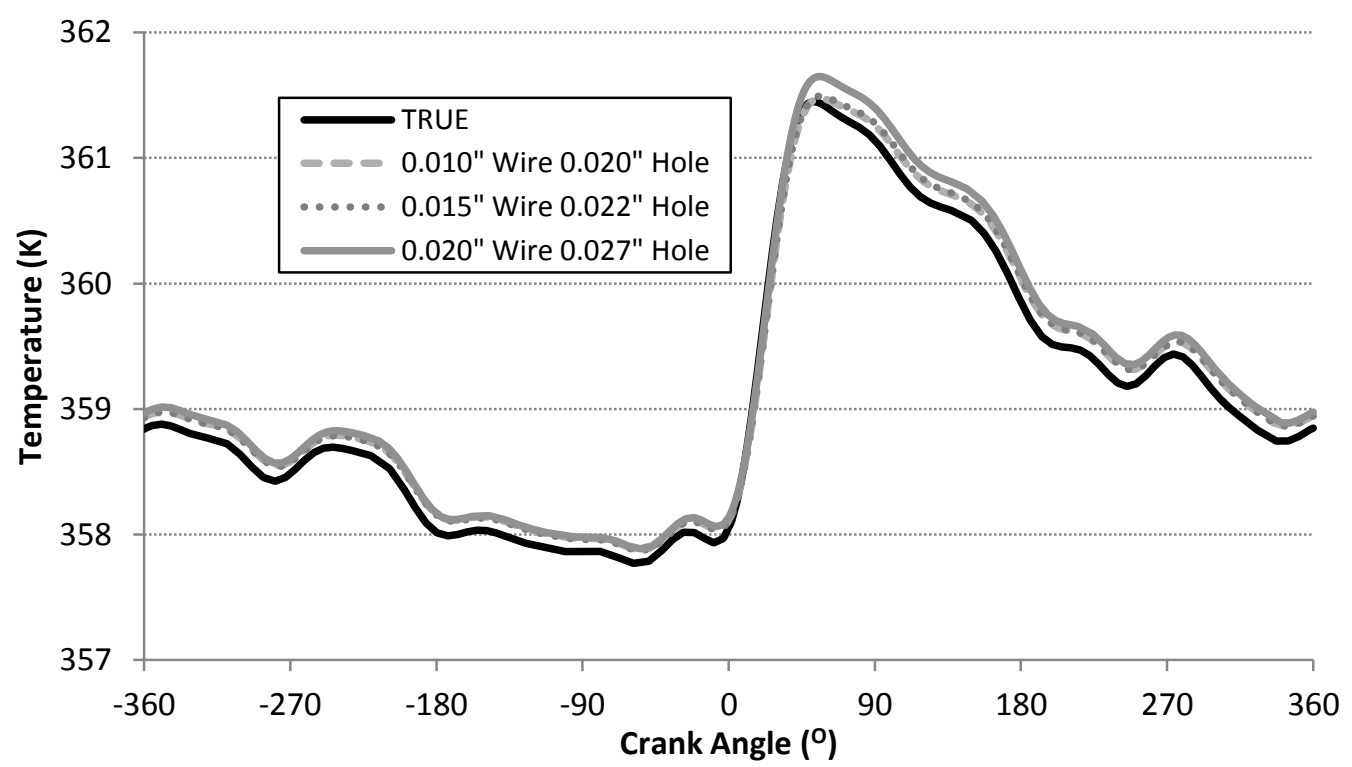

Figure 4.14 - Temperature Response using Different Constantan Wire Diameters $(\delta=100 \mathrm{um})$

A comparison of the Stripped and Stepped (Figure 4.15 below) results for the same copper layer thicknesses clearly demonstrates the advantages of using the Stepped configuration to maximize thermocouple accuracy. As a result of the large hole diameters needed to accommodate the thick Teflon coatings in the Stripped configuration, a much larger temperature gradient is seen at the hot junction, thus the need for a much thicker copper coating and longer time delays. Taking the Stripped and Stepped configurations using 0.015 " wire as an example, it can be seen in Figure 4.15 that to obtain a similar accuracy as 
the Stepped configuration $\left(\mathrm{T}_{\mathrm{RMSD}}=0.086 \mathrm{~K}, \phi=5.04^{\circ}\right)$, a copper coating between $150 \mu \mathrm{m}$ and $175 \mu \mathrm{m}$ was needed. This ultimately introduced a time delay of approximately $10 \mathrm{CAD}$ and a damping of the temperature swings of 5\%. This trade-off thus made the Stepped configuration the chosen geometry to be implemented in the final thermocouple design.

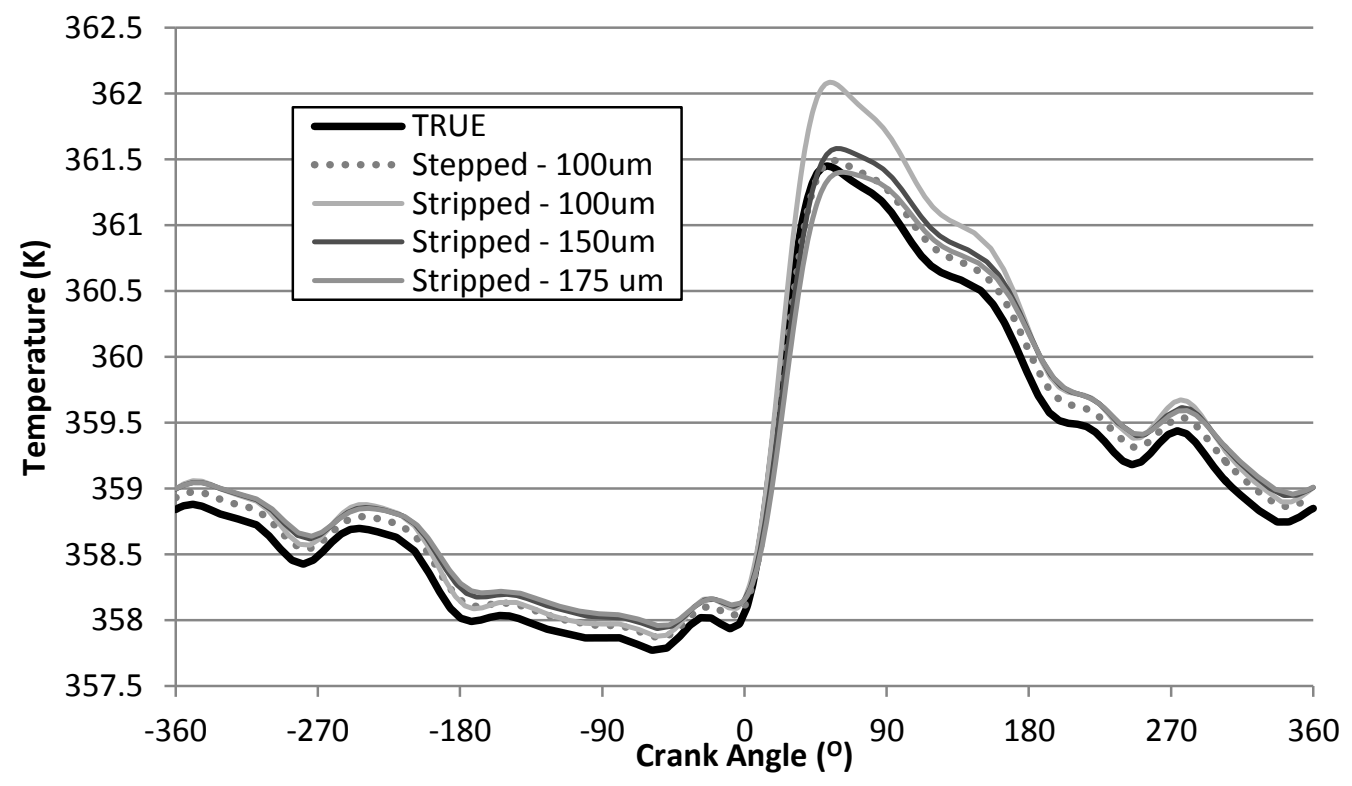

Figure 4.15 - Comparison of Stepped and Stripped Configurations for 0.015" Wire

Based on these results, the design variable seen to have the greatest impact on thermocouple accuracy were the characteristics of the copper coating rather than hole and wire diameters. Therefore, to increase the manufacturability of the thermocouples, the larger of the two hole diameters tested in each case was chosen for the final thermocouple design. In addition, due to the seemingly small effects wire diameter was seen to have on predicted overall accuracy, the final dimensions used for the thermocouple were based on the susceptibility of the different constantan wire diameters to noise. This issue will be addressed through the experimental testing of the thermocouples in Section 5.4. 
Due to the clear dependence of thermocouple accuracy on the copper coating demonstrated in this analysis, the following section will attempt to determine the effects varying the properties of the copper coating may have on overall accuracy.

\subsection{FEA Sensitivity Analysis}

There was some uncertainty pertaining to the properties of the sprayed copper coating which may impact the accuracy of the surface thermocouple. Properties such as thermal contact resistance between substrate and coating, porosity and oxidation of the coating each created a deviation from the ideal physical properties of the copper film implemented in the FEA model.

An attempt was made to address these issues by using the finite element model to determine a lower bound for thermocouple accuracy assuming less-than-ideal properties for the thin copper film. Through thickness and weight measurements, the porosity of a thin copper coating was estimated to be approximately $30 \%$. This large concentration of air in the copper coating would result in a proportional reduction in density of the coating and was accounted for in the specific heat capacity of the coating. The thermal conductivity of the coating to be implemented in this worst-case model was estimated to be $25 \%$ of the bulk $k$ value of copper, or $100 \mathrm{~W} / \mathrm{mK}$. To account for the uncertainty in the $k$ value for the Aremco potting compound, the value $k=10 \mathrm{~W} / \mathrm{mK}$ was reduced to $5 \mathrm{~W} / \mathrm{mK}$ as a worst case scenario.

Thermal contact resistance, $R_{c}$ is another potential contributor to deviations from the expected thermal properties of the thermocouple. Heichal et al. [112] measured contact resistance between molten bismuth and aluminium droplets on solid steel and brass substrates to fall within a range of $10^{-7}$ to $3 \times 10^{-6} \mathrm{~m}^{2} \mathrm{~K} / \mathrm{W}$. Using this as an estimate of the contact resistance which could be expected for the sprayed copper coatings, a thin $0.05 \mu \mathrm{m}$ air layer 
(which corresponds to $R_{c}=1.3 \times 10^{-6} \mathrm{~m}^{2} \mathrm{~K} / \mathrm{W}$ ) was included into the FEA model between the copper film and substrate. Table 4.3 summarizes the changes that were made to the material properties used in the FEA model for the sensitivity analysis.

Table 4.3 - FEA Sensitivity Analysis Material Properties

\begin{tabular}{cccc}
\hline Material & $\begin{array}{c}\text { Density, } \rho \\
{\left[\mathrm{kg} / \mathbf{m}^{\left.{ }^{3}\right]}\right.}\end{array}$ & $\begin{array}{c}\text { Thermal } \\
\text { Conductivity, } \boldsymbol{k} \\
{[\mathbf{W} / \mathbf{m ~ K}]}\end{array}$ & $\begin{array}{c}\text { Specific Heat } \\
\text { Capacity, } \boldsymbol{c}_{\boldsymbol{p}} \\
{[\mathbf{k J} / \mathbf{k g ~ K}]}\end{array}$ \\
\hline $\begin{array}{c}\text { Air (@ 200C) } \\
\text { Aremco Ceramacast } \\
\text { 675N }\end{array}$ & 0.746 & 0.0386 & 1.026 \\
Copper & 2200 & 5 & 0.630 \\
\hline
\end{tabular}

Figure 4.16 below shows the $\mathrm{T}_{\mathrm{RMSD}}$ vs. $\phi$ graph for the large hole diameter cases for each of the three wire sizes at varying coating thicknesses. It can be seen that accounting for the deviation from an ideal copper coating introduces significant time delays and a decrease in thermocouple accuracy. As expected, the deviation from the True response increased with larger wire diameters due to the need for thicker coating.

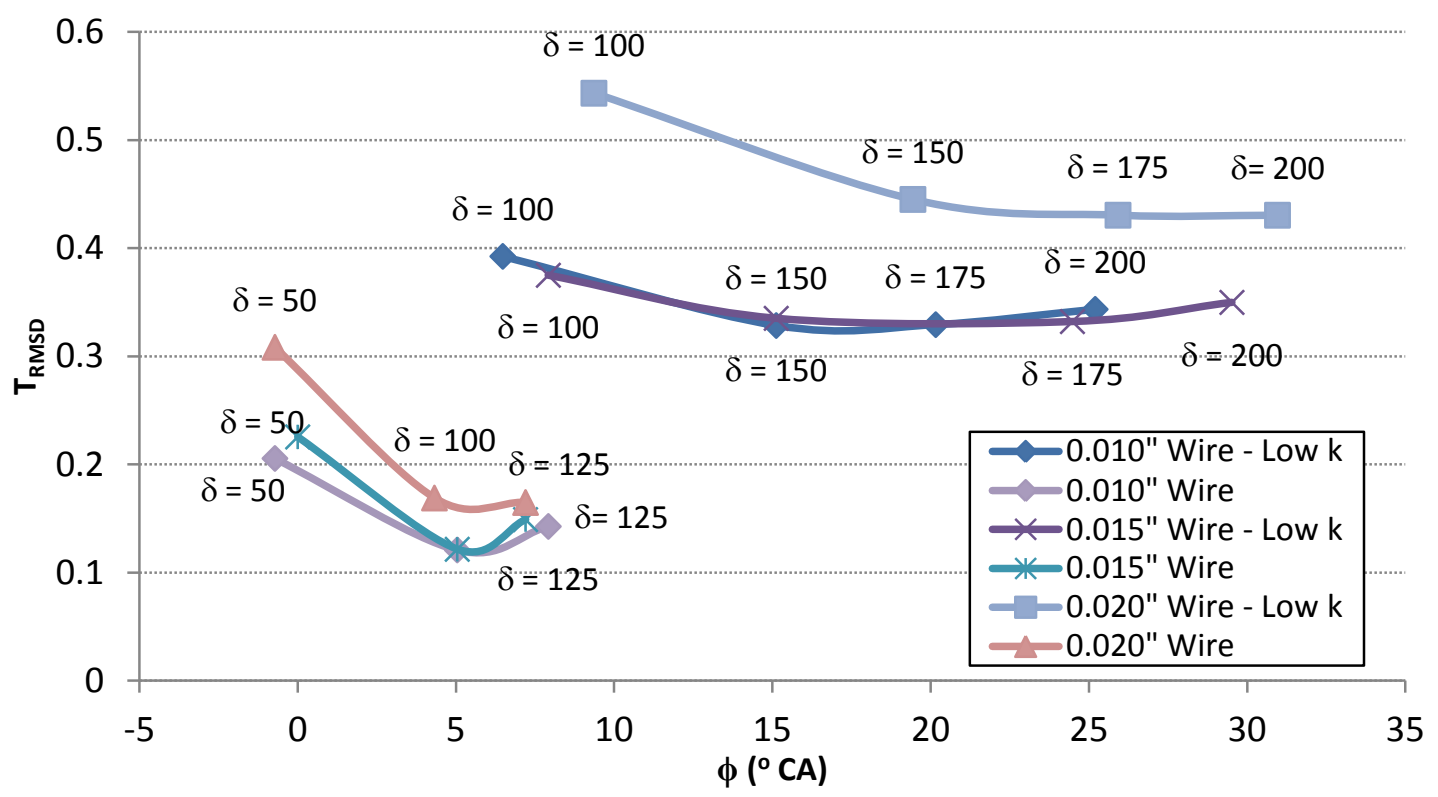

Figure 4.16 - Comparison of Ideal and Low Conductivity Cases for Different Wire Diameters 
The maximum deviation from the True temperature in the worst case scenario $(0.020$ " wire $100 \mu \mathrm{m}$ ) is 1.3 degrees, with temperature swings being overestimated by up to $30 \%$ in these conditions. Using a copper coating between 150 and $175 \mathrm{~mm}$ thick reduces the maximum deviation to approximately 0.7 degrees and brings temperature swings within $2 \%$ for the 0.010 " and 0.015 " cases, though delay times of between 15-20 CAD are expected.

\subsection{In-Depth Thermocouple Development}

In addition to the surface temperature boundary condition, a second temperature measurement a fixed distance from the surface was required to conduct a heat transfer analysis of the piston. The second boundary condition should have minimal temperature fluctuations, and thus thermocouple response time is not crucial in this application. Using a similar approach to that taken by Marr [113], a second constantan-aluminum thermocouple hot junction was created by affixing a single constantan wire to the underside of the piston crown. Figure 4.17 depicts a schematic of the in-depth thermocouple layout.

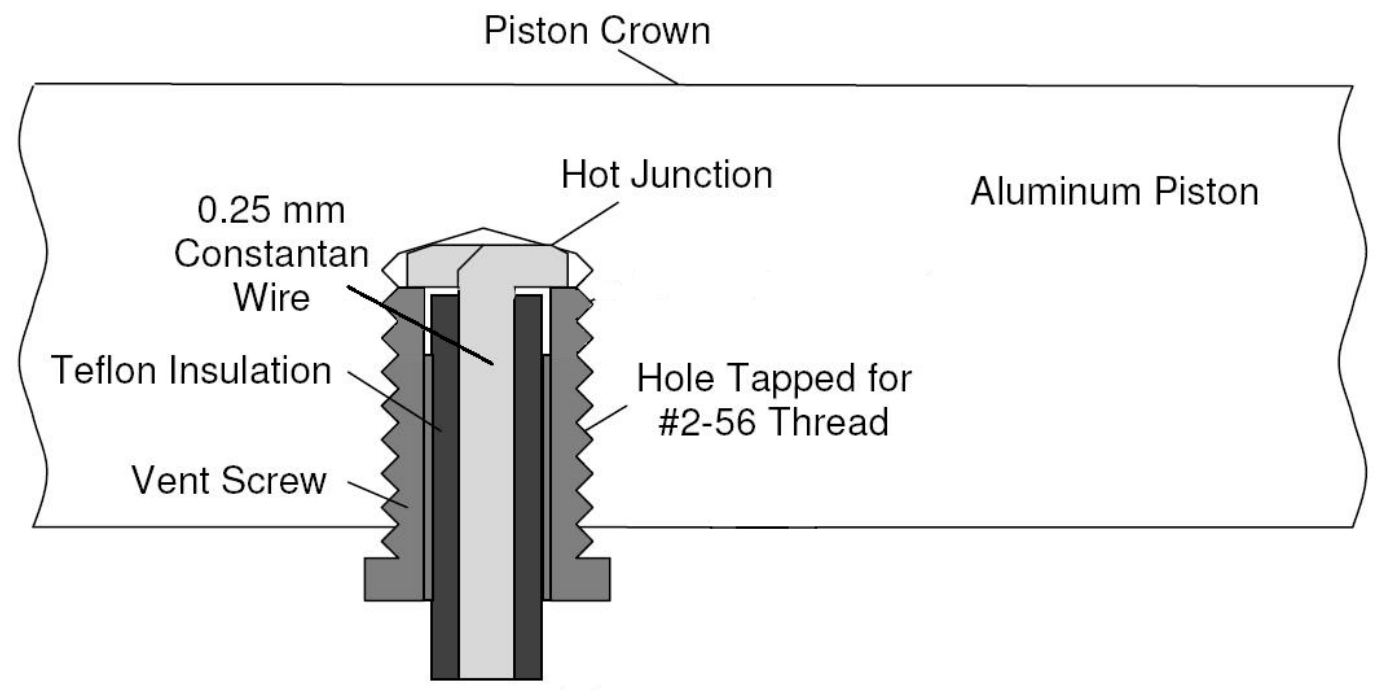

Figure 4.17 - In-Depth Thermocouple Design [113] 
The depth at which the wires were installed in the piston crown was determined using a finite element model based on the model described in Section 4.4. The heat flux boundary condition used in this analysis was modified to account for the increased heat transfer that would result from the increased load due to supercharging. Using equation 2.39 from Heywood [2] for mean effective pressure,

$$
M E P=\eta_{f} \eta_{v} Q_{H V} \rho_{a}(F / A)
$$

where $\eta_{\mathrm{f}}, \eta_{\mathrm{v}}, \mathrm{Q}_{\mathrm{HV}}, \rho_{\mathrm{a}}$ and (F/A) represent fuel conversion efficiency, volumetric efficiency, fuel heating value, air density and fuel/air ratio, respectively, a comparison of the engine test conditions to those used during the testing conducted by Marr show that loads were expected to double. Thus, for the purpose of the FEA model, the heat flux boundary condition shown in Figure 4.9 (p.61) was estimated to be twice that measured during the previous testing regime. All remaining boundary conditions were maintained the same as those used in the previous model.

The position of the in-depth thermocouple was tested at $1 \mathrm{~mm}$ intervals from the piston crown. The temperature swing measured by the wire was compared to that seen at the surface. The in-depth thermocouple was deemed to be sufficiently deep to approximate steady-state conditions when the measured temperature swings were $1 \%$ of those seen at the surface. Figure 4.18 below, which shows the ratio of in-depth to surface temperature swings at varying depths, shows that steady-state conditions were achieved with the constantan wire located at approximately $5.5 \mathrm{~mm}$ from the surface. 


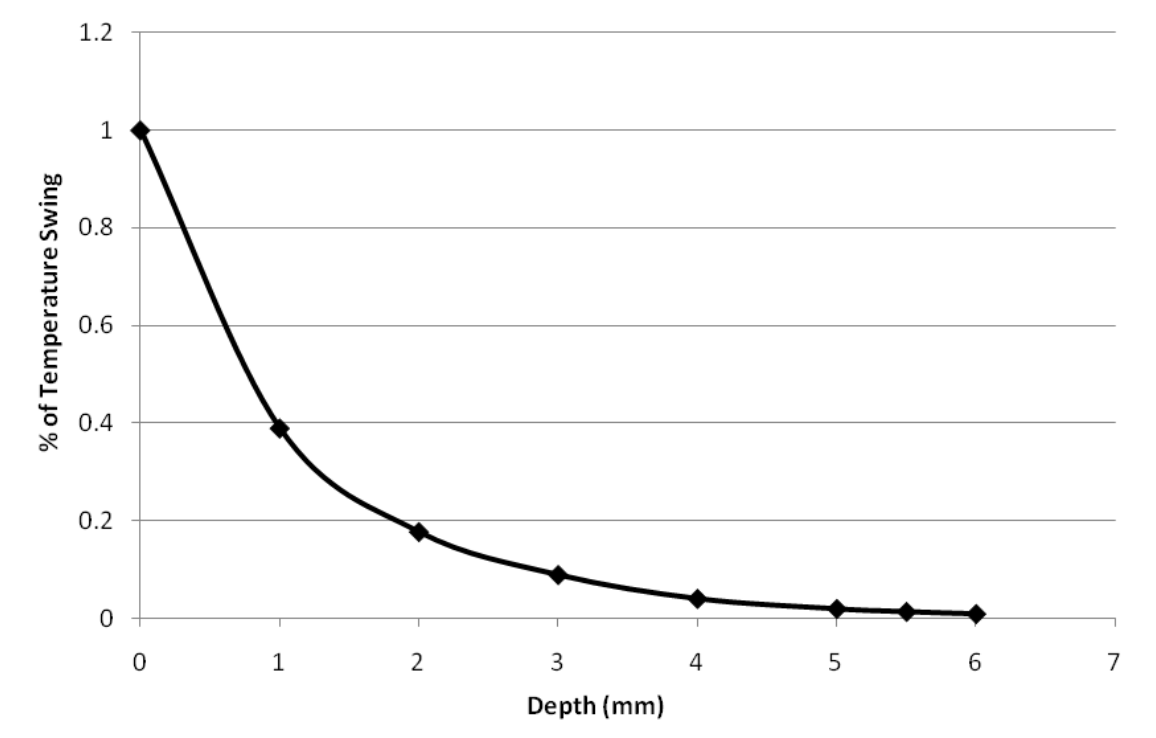

Figure 4.18 - Ratio of In-Depth Thermocouple Temperature Swing (at Different Depths) to that Measured at Surface

To verify the accuracy of the in-depth thermocouples, these results were compared to the True substrate temperature calculated by setting the materials in the model to aluminum. At a $5.5 \mathrm{~mm}$ depth, the True and measured temperatures were seen to vary by less than $0.2^{\circ} \mathrm{C}$ under steady-state conditions, which was deemed sufficiently accurate.

\subsection{Surface Thermocouple FEA Summary}

The finite element analysis of the surface thermocouple has demonstrated that the modifications made to the original design used by Marr et al. allow for more accurate measurement of True surface temperatures. It was seen that variations in wire/hole diameter had minimal effect on thermocouple accuracy. Optimal results were seen to be achievable using $100 \mu \mathrm{m}$ copper coatings to form the hot junction, which measured absolute temperature within 0.2 degrees and temperature swings within $\pm 2 \%$ of the True value. Time delays of about $5 \mathrm{CAD}$ could be expected as a result of introducing the copper coating. Due to the accuracy of this thermocouple across a wide range of designs, a final determination of 
thermocouple geometry was based on ease of manufacturability and susceptibility of the thermocouple to noise as determined through experimental testing.

A sensitivity analysis was conducted to determine the effect copper coating properties had on thermocouple performance by estimating porosity, contact resistance, and changes in the thermal properties of the sprayed coatings. It was shown that significantly thicker copper coatings $(150-175 \mu \mathrm{m})$ were needed to achieve similar accuracies to those predicted using ideal copper properties, though they would introduce time delays between 15-20 CAD.

Finally, the design of the in-depth thermocouple needed to calculate heat flux during the piston tests was also presented. Using FEA, it was seen that the ideal thermocouple depth was approximately $5 \mathrm{~mm}$.

The following section will attempt to verify the results seen in the FEA analysis through experimental testing of the surface thermocouples. 


\section{Chapter 5}

\section{Experimental Thermocouple Testing}

Experimental tests using instrumented plugs installed in the cylinder wall of the CFR engine were used to validate the surface thermocouple design. These tests helped determine the effects different thermocouple configurations had on temperature measurements while also helping develop the experimental apparatus for the final piston tests. In the following, the manufacturing, calibration and testing of the instrumented test plugs will be presented. A method for testing thermocouple response time is also verified discussed.

\subsection{Thermocouple Test Plug Design and Construction}

The surface thermocouple designs discussed in Section 4.4 were tested in-cylinder using aluminum plugs that were threaded into the empty spark plug ports in the CFR engine's cylinder (see Figure 3.1 on p.39). Figure B.1 in Appendix B shows a schematic of 
the plugs. The aluminum alloy used to machine the plugs was the same as the custom pistons (AL2618) and was provided by GE Aircraft Engines (Rutland, Vermont).

The thermocouple design implemented in the test plugs varies slightly from the Stepped design model previously presented (see Figure 4.8 on p.60) to facilitate plug fabrication. Due to the length of the plug, the 0.040 " clearance hole could not be drilled using standard drill bits and was replaced by a 0.100 " hole. To compensate, the depth of the clearance hole was reduced to increase the amount of aluminum near the thermocouple junction and reduce the effects of the larger clearance hole. The primary thermocouple holes were then drilled concentric to the clearance holes using a micro drill press. Diameters varied between 0.025 " and $0.040 "$ to allow for comparison of different wire/hole combinations.

Table 5.1 - Wire/Hole Diameter Combinations Used in Plug Tests

\begin{tabular}{ccccccc}
\hline & \multicolumn{2}{c}{ Plug 1 } & \multicolumn{2}{c}{ Plug 2 } & \multicolumn{2}{c}{ Plug 3 } \\
\hline $\begin{array}{c}\text { Wire } \\
\text { Label }\end{array}$ & Wire (in) & Hole (in) & Wire (in) & Hole (in) & Wire (in) & Hole (in) \\
$\mathbf{1}$ & 0.020 & 0.028 & 0.02 & 0.028 & 0.015 & 0.028 \\
$\mathbf{2}$ & 0.015 & 0.022 & 0.015 & 0.025 & 0.01 & 0.022 \\
$\mathbf{3}$ & 0.020 & 0.025 & 0.01 & 0.017 & 0.01 & 0.017 \\
$\mathbf{4}$ & - & - & 0.015 & 0.028 & 0.02 & 0.028 \\
\hline
\end{tabular}

Each plug was instrumented with thermocouple wires of varying size to determine what, if any, differences were discernible between the temperature profiles registered by the plugs. Constantan wires of three different diameters (0.010", $0.015 "$ and $0.020 ")$ were fed through the plugs and secured using Aremco Ceramacast $675 \mathrm{~N}$ potting material. After allowing the potting material to cure, the measuring faces of the thermocouples were airplasma sprayed with a $200 \mu \mathrm{m}$ film of pure copper (Sulzer Metco P/N Metco 55) and polished to approximately $100 \mu \mathrm{m}$. Coating thicknesses were measured using a micrometer and were 
estimated to be accurate within $25 \mu \mathrm{m}$. In total, three test plugs, labelled Plug 1 to Plug 3, were assembled. The wire-hole diameter combination for each plug is shown in Table 5.1.

Prior to coating, photographs of the wire-hole combination were taken to obtain visual feedback of the manufacturing process. In Figure 5.1a, the constantan wire is concentric with the drilled hole and insulated from the aluminum plug by the ceramic potting material. Figure $5.1 \mathrm{~b}$ shows a case in which the constantan wire was not entirely concentric with the drilled hole, making contact with the plug. This created an unwanted thermocouple junction that would result in inaccurate temperature measurements. Particular care must be taken in manufacturing the sensors to ensure concentricity of the two thermocouple elements.

A digital multimeter was used to ensure the isolation between the two thermoelements.

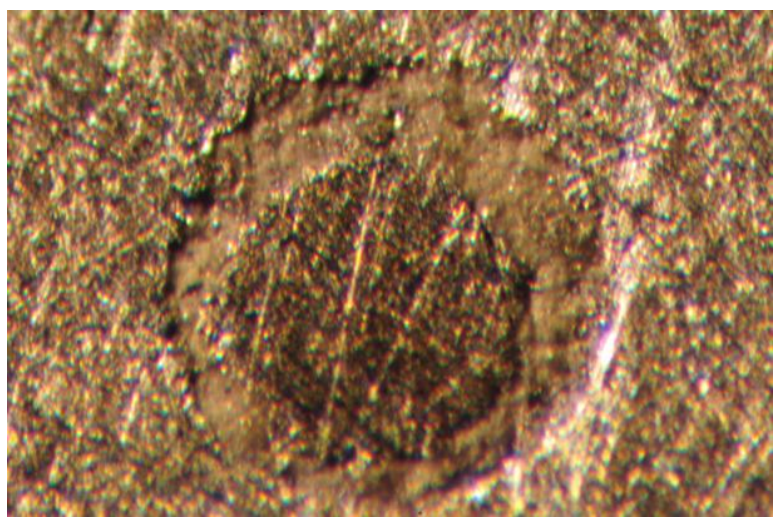

a)

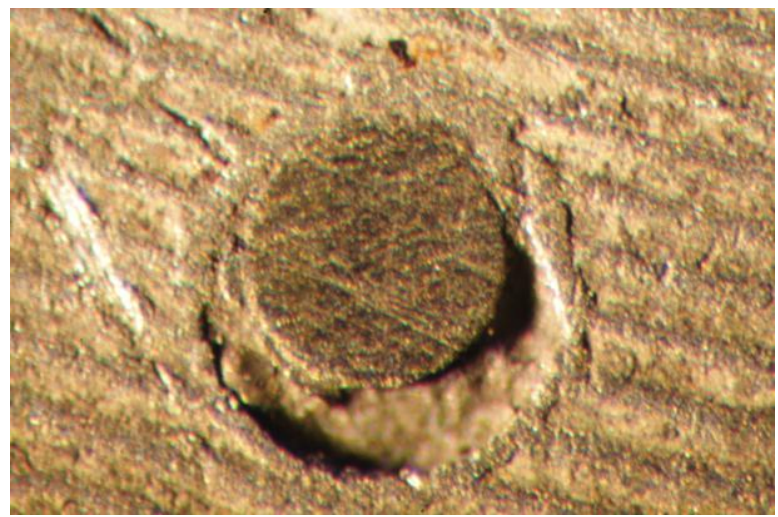

b)

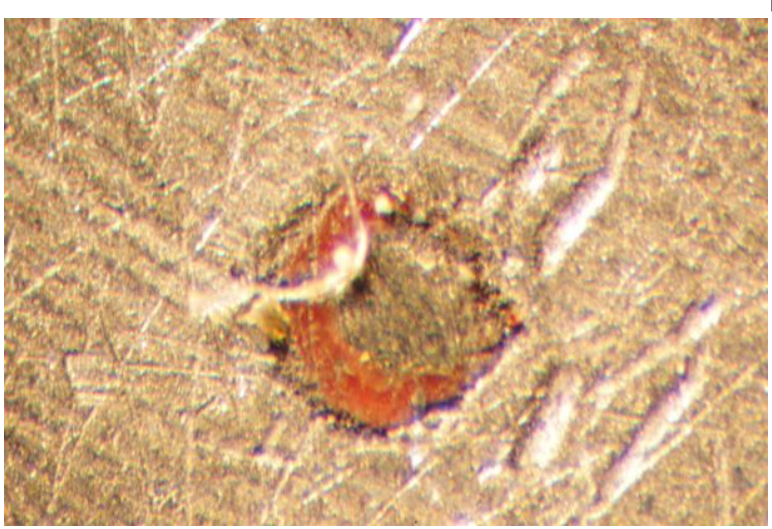

c)

Figure 5.1 - Surface Thermocouple Constantan Wire in Aluminum Substrate Prior to Coating a) Concentric b) Off Centre c) Teflon Insulation 
It was also noted that when using fully insulated wires (i.e. not stripped), the insulation was seen to be present at the thermocouple junction. Figure 5.1c shows the Teflon insulation of a 0.010 " wire filling the majority of the hole. This not only causes a potential loss of signal once the insulation begins to soften at high temperature, but also results in an undesired temperature distribution at the location due to Teflon's low thermal conductivity.

\subsection{Plug Thermocouple Calibration}

Since the custom thermocouples being used in these heat transfer experiments are not a standard metal pairing, a custom calibration was required to relate the measured thermocouple voltage outputs to its associated temperature. In the following, the calibration procedure used to generate the thermocouple calibration curve for the aluminium-constantan metal pairing will be presented. A discussion of the thermocouple analog filtering circuit used for processing of the high speed thermocouple signals is also discussed.

\subsubsection{Calibration Apparatus}

A heated circulating bath was used to calibrate the custom constantan-aluminum thermocouple pairings. The measuring side of the instrumented plugs was coated in a thermal paste (Omega Engineering P/N OMEGATHERM 201) and threaded into an aluminum block to minimize the thermal gradients during the calibration process. A PT100 RTD (Omega Engineering P/N PR-11-2-100) and a type K thermocouple were inserted into the aluminum block and used as the reference temperatures for the thermocouple calibrations. The block was then suspended in the circulating bath (Haake N3) filled with synthetic thermal bath oil (Thermo Fisher Scientific P/N SYNTH 260) at constant immersion depth to ensure consistency in the EMF developed in the thermocouple leads. This apparatus allowed for 
calibrations of up to $250^{\circ} \mathrm{C}$ and could be controlled to greater than one degree precision. This system also eliminated the radiation errors and thermal gradients which are typical drawbacks of performing thermocouple calibrations in ovens.

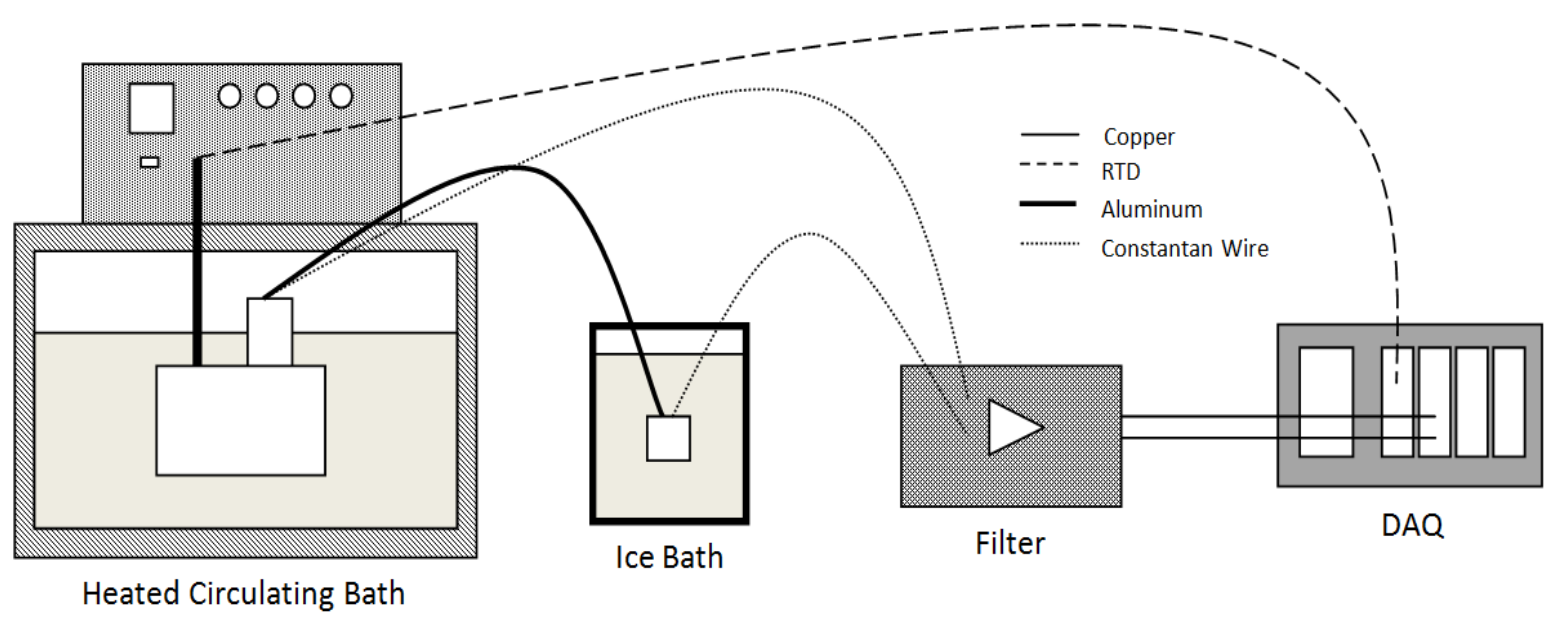

Figure 5.2 - Thermocouple Calibration Apparatus

Figure 5.2 shows a schematic of the thermocouple calibration apparatus. An ice bath was used as a cold junction for each of the thermocouples during the calibration process. Since aluminum wire of the same alloy as that used to make the plugs (AL2618) was not readily available, a wire of the alloy was turned on a lathe. The wire was sealed in heat shrink to avoid short circuiting and fastened to the test plugs using a screw made of AL2618. The opposing end of the wire was then fastened to a small aluminum block which contained the second leg of constantan wires and placed in the ice point, thus completing the thermocouple circuit. The thermocouples were plugged into the input of the custom filtering circuit (see Section 5.2.2 below), and the test plug was grounded to the circuit power supply common. The filtered signals were simultaneously collected using the National Instruments CDAQ NI 9215 module at a rate of $1000 \mathrm{~S} / \mathrm{s}$. The reference thermocouple temperature was logged using a National Instruments M Series PCIe-6251 card with built-in cold junction compensation, 
while RTD measurements were displayed using a temperature readout and recorded manually at one minute intervals.

\subsubsection{Signal Conditioning Circuit}

Due to the inherently low voltage output from thermocouples, they are extremely susceptible to noise in the test environment. A variable gain, analog signal conditioning circuit was designed to amplify and filter the thermocouple outputs to increase signal strength and resolution. This conditioning circuit consisted of three stages: primary amplification, filtering and final amplification. The raw thermocouple signals were fed through an instrumentation amplifier (Analog Devices P/N AD8221BRZ) which provided an initial amplification of up to 500x (DIP switch selectable) and helped eliminate common mode noise due to a high common mode rejection ratio $(\mathrm{CMRR}=80 \mathrm{db}$ at $10 \mathrm{kHz})$. The signal was then passed through an $8^{\text {th }}$ order, continuous-time active low-pass Bessel filter (Maxim Integration Products P/N MAX275BCNG) to further attenuate high frequency noise.

Experimentation with different cut-off frequencies $\left(f_{c}\right)$ showed that $f_{c}=1000 \mathrm{~Hz}$ provided the best noise reduction without any resulting signal attenuation. A final amplification stage (Analog Devices P/N AD797) allowed for up to 80X amplification to bring the thermocouple signal into the $\pm 10 \mathrm{~V}$ range of the DAQ for maximum signal resolution. Further details on the filtering circuit can be found in Appendix C.

\subsubsection{Calibration Procedure}

The thermocouples were calibrated in accordance with ASTM standards E207 and E220 [114,115]. The reference thermometer temperatures and the surface thermocouple voltages were measured simultaneously at ten points throughout the calibration temperature 
range. At each temperature, the reference thermocouple readings were allowed to stabilize prior to taking measurements over three minute intervals. The reference temperatures and thermocouple voltages were averaged over these intervals to provide voltage-temperature data pairs for each thermocouple.

In the temperature range of interest $\left(100^{\circ} \mathrm{C}\right.$ to $\left.300^{\circ} \mathrm{C}\right)$, the thermocouple output was distinctly linear. Thus, a linear regression $\left(\mathrm{R}^{2}>0.99\right)$ of the voltage-temperature data was used to produce a calibration curve for each thermocouple. Figure 5.3 below shows a sample 10-point calibration for a test plug in the $120^{\circ} \mathrm{C}$ to $210^{\circ} \mathrm{C}$ range. The thermocouple Seebeck coefficient was found to be approximately $44 \mu \mathrm{V} / \mathrm{oC}$ in this range. Refer to Appendix D for further details regarding the calibration process.

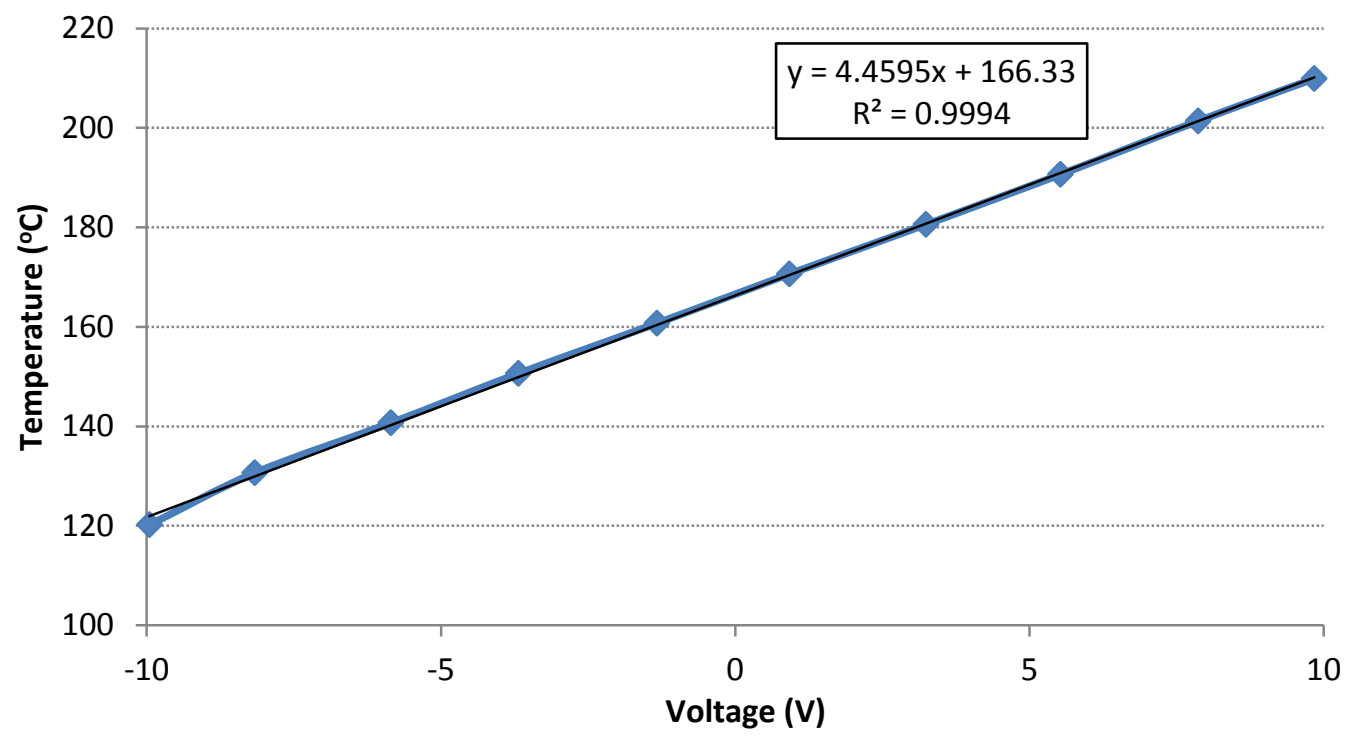

Figure 5.3 - Sample Thermocouple Calibration Curve

\subsection{Thermocouple Response Test}

Having determined the geometric characteristics of the thermocouple, the sensor response time was characterized. The response time of a surface thermocouple is a key characteristic when measuring in-cylinder surface temperatures, as the sensor must be 
capable of resolving the cycle-to-cycle temperature variations of the combustion process. Determining the response of the thermal sensor allows for the temporal adjustment of the measured temperatures and helps extract the "true" surface temperature profile from the collected temperature traces.

\subsubsection{Response Time: Background}

The response of a surface thermocouple is a function of the physical and material properties of the sensor. The primary factor affecting the response time is the thermal mass of the sensor junction. The $100 \mu \mathrm{m}$ copper film which forms the junction in the custom thermocouple is the primary source of the thermocouple delay, as any temperature disturbance must first diffuse through the copper film prior to being sensed. An estimate of the effects of this coating on thermocouple response time can be determined based on the principles of one-dimensional transient heat conduction, which states that the time $\tau$ required for energy to diffuse through a substrate of thickness $\delta$ can be expressed as

$$
\tau \sim \frac{\delta^{2}}{\alpha}
$$

where $\alpha$ is the thermal diffusivity of the substrate. Assuming the copper layer $(\delta=100 \mu \mathrm{m}$, $\alpha=1.1234 \times 10^{-4} \mathrm{~m}^{2} / \mathrm{s}$ ) to be the substrate of interest, it should take on the order of $90 \mu$ s for a thermal disturbance to be registered by the thermocouple. This is somewhat slower than sensors typically used for in-cylinder surface temperature measurements, but is a compromise made for improved thermocouple accuracy (see Section 4.4).

A method used to quantify the dynamic response of a surface thermocouple is by subjecting it to an impulse energy of known shape and duration and comparing it to the 
sensor response. Various studies $[\mathbf{1 0 8 , 1 1 6 , 1 0 3 , 1 0 2}]$ have used a pulsed laser to approximate an impulse function in determining the response times of fast response thermocouples.

\subsubsection{Response Time Test Apparatus}

An Nd:YAG laser (New Wave Research P/N Solo PIV 120) with maximum beam energy $(e)$ of $120 \mathrm{~mJ}$ and $5 \mathrm{~ns}$ pulse duration was shone at the test plugs described in Table 5.1 above. The thermocouple tested consisted of a 0.015 " wire with a $100 \mu \mathrm{m}$ copper junction which was exposed to a single laser pulse with beam diameter of approximately 0.0125 ".

The measurements were recorded using a National Instruments M-Series PCI-6251 card via an SCB-68 terminal block at a sampling rate of $1 \mathrm{MHz}$. After testing at varying sampling rates, $1 \mathrm{MHz}$ was seen to be sufficient in resolving the thermocouple response to the laser pulse. The Q-switch trigger signal from the laser power supply indicating the time of light emission was used to initiate the collection of the thermocouple measurements. The relatively low energy output of the laser and the large thermal mass of the test specimen meant large temperature swings were not achieved, resulting in poor signal-to-noise ratios. This required the thermocouple response to be filtered using analog circuitry, meaning the measured response time represented the sum of the thermocouple and circuit delays. This sum was used as the correcting factor during in-cylinder testing. The true thermocouple-only response time was determined by eliminating the constant phase delay of $1.562 \mathrm{~ms}$ introduced by the circuitry (see Appendix C.3).

\subsubsection{Response Time Results}

The thermocouple response time, $\tau$ was defined as the time from light emissions to the time of peak temperature registered by the thermocouple. Measurements were taken at 
three different pulse energies to determine any relationship of response time and pulse energy. In analyzing 30 individual cycles at each condition, it was seen that the slope of the temperature profile prior to reaching the peak temperature was relatively constant at each individual energy level. However, the occurrence of the peak temperature was variable between cycles, particularly at low pulse energies as a result of the low signal-to-noise ratio at the lower energy levels. To minimize the noise effects, $\tau$ was defined as twice the time needed to reach half of the peak temperature. This technique reduced the variability in the response time data and provided a closer approximation to the location of the maximum temperature in each cycle. Further details of this technique can be seen in Appendix E.

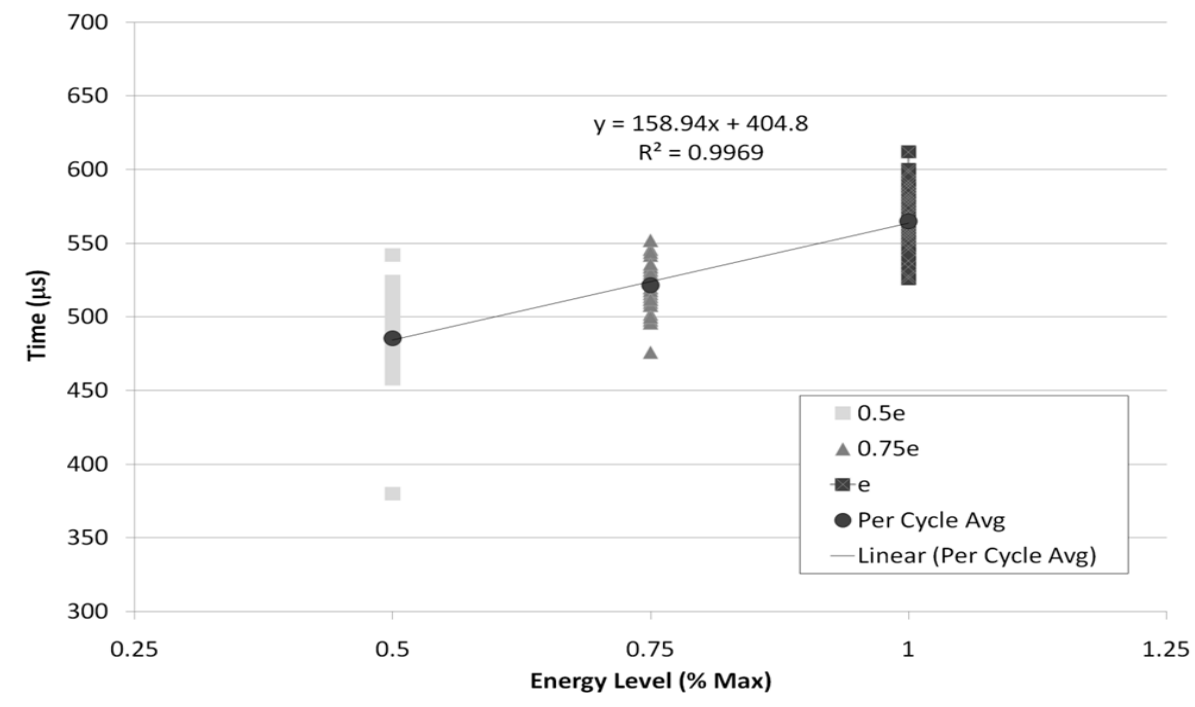

Figure 5.4 - Thermocouple Time Delay Measurements at Varying Energy Levels

Figure 5.4 shows the measured response times at three energy levels and the average response time at each condition. The thermocouple response time was seen to vary between $475 \mu$ s to $575 \mu \mathrm{s}$, which translates to approximately 5-6 CAD at an engine speed of $1650 \mathrm{rpm}$. This was on the same order of magnitude as the one dimensional heat transfer approximation previously discussed, and was in the same range as the FEA results discussed in Section 4.4. 
The results in Figure 5.4 show a linear relationship between pulse energy and thermocouple response time. Though the response time would be expected to be independent of the pulse energy based on the principles of one-dimensional heat transfer, it was seen that the time for the thermocouple to register the maximum temperature increased with increasing energy. Similar results were seen by Heichal et al. [108] and Burgess et al [116]. This was believed to be as a result of a deviation from one-dimensional heat transfer with increasing input energy. The input energy was believed to dissipate laterally through the copper junction, thus increasing the time for the thermocouple to reach a maximum temperature.

This behaviour could also be attributed to unexpected laser behaviour. In studying the surface of the tested thermocouples, the laser was seen to produce an irregularly shaped marking at the location of laser contact. It is hypothesised that potential movement of the laser beam trajectory at varying energy levels may have resulted in the thermocouple not being directly exposed to the maximum beam energy, leading to increasing response time. These hypotheses are further supported by the fact that the rate of temperature increase was also seen to rise in a non-linear fashion, as shown in Figure 5.5.

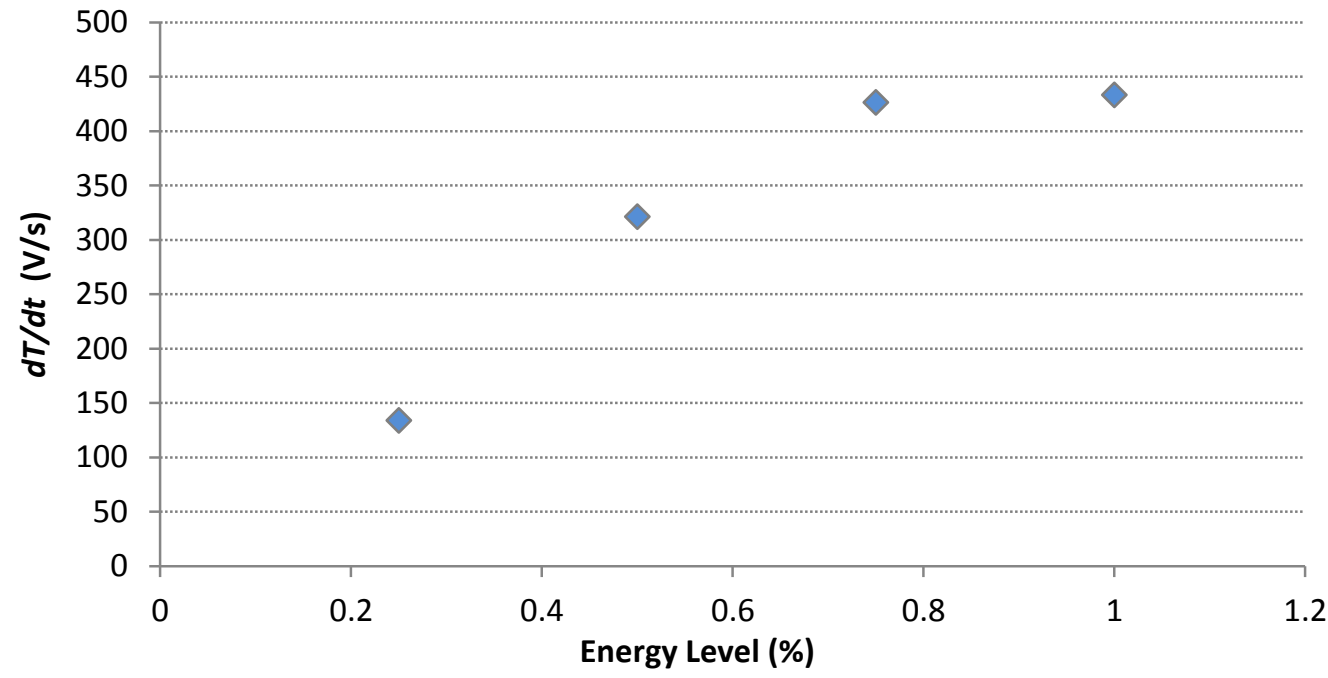

Figure 5.5 - Rate of Temperature Change at Varying Energy Levels 


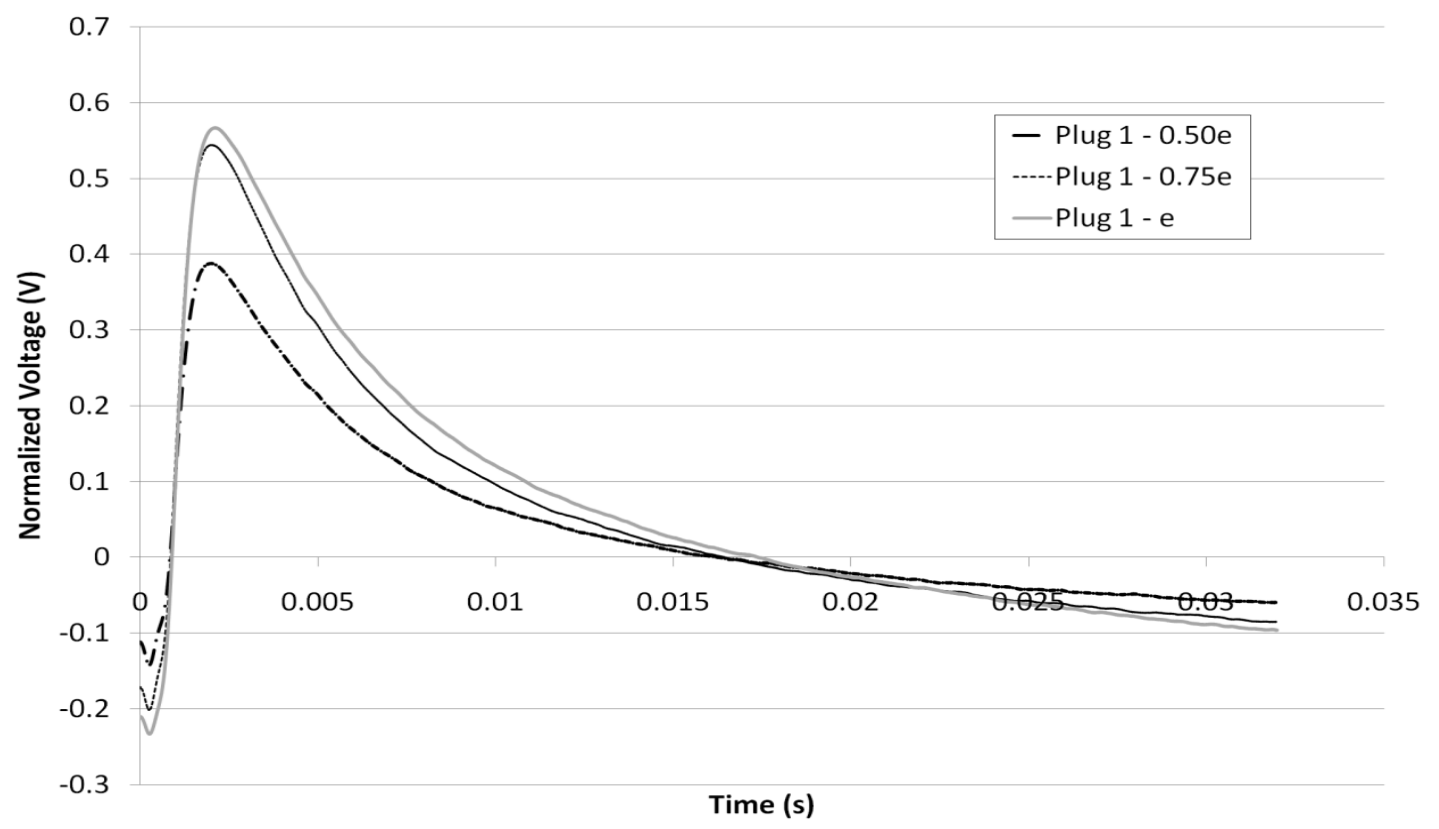

Figure 5.6 - Ensemble-Averaged Thermocouple Response Time

Figure 5.6 shows the ensemble-average temperature profile of the tests shown in Figure 5.4. At least 30 cycles of data were averaged at each energy level. This figure shows the increased surface temperatures and rate of temperature change with increasing pulse energy. Using a calibration slope of $2.156{ }^{\circ} \mathrm{C} / \mathrm{V}$, the maximum power condition produced a temperature rise of $1.725^{\circ} \mathrm{C}$. Based on previous engine tests conducted by Marr et al., this temperature swing is on the order of magnitude which could be expected during TBC-coated piston tests. It should be noted that both Figure 5.5 and Figure 5.6 show that the maximum energy condition produced slightly lower maximum temperatures than would be expected for reasons which were previously discussed. This could have also been as a result of the laser not providing the nominal $120 \mathrm{~mJ}$ expected at the full power condition. 


\subsubsection{Summary: Thermocouple Response Time}

These laser tests thus provide an approximate order of magnitude for the thermocouple response time. Though some variability was seen in the test results, it can be concluded that the thermocouple design to be implemented in the final piston tests $(100 \mathrm{~mm}$ copper junction, 0.015 " constantan wire) has a response time of about $500 \mu$ s. Though slower than surface thermocouples used in previous in-cylinder heat transfer studies due to its relatively thick junction, this time delay was deemed an acceptable compromise for the increase in accuracy of the temperature measurement provided by the copper film. Also, seeing as the in-cylinder measurements are typically in the millisecond timescale, this thermocouple design has been shown to be fast enough to resolve in-cylinder events. This value will be used to shift the measured surface temperature traces in time to provide the correct timing of each of the events relative to crankshaft position.

Further information on processing the laser test data can be found in Appendix E.

\subsection{Thermocouple Test Conditions and Results}

To test the surface thermocouples in in-cylinder temperatures, the instrumented plugs were used to measure cylinder wall temperatures in the CFR engine described in Section 3.1. Table 5.2 below shows the engine conditions at which the thermocouple plug tests were completed. Each plug was run at nine test conditions (three boost pressures (i.e. load) and speeds) to characterize the thermocouple at different in-cylinder conditions. The engine was maintained at stoichiometric equivalence ratio and at a compression ratio of 8:1 throughout the tests. Though somewhat low for $\mathrm{CNG}$ applications, increasing the compression ratio above 8:1 resulted in the piston physically blocking the thermocouple plug at TDC, thus reducing the exposure of the thermocouples to in-cylinder conditions. Though the tests were 
run at slightly lower load conditions during the TBC-coated piston testing, the conditions were deemed sufficient for the evaluation of the thermocouple designs.

Table 5.2 - Thermocouple Plug Test Conditions

\begin{tabular}{cc}
\hline Speed (RPM) & $1275,1450,1650$ \\
\hline Boost Pressure (kPa absolute) & $135,150,165$ \\
Compression Ratio & $8: 1$ \\
Spark Timing (CAD BTDC) & MBT $=23$ \\
Air-Fuel Ratio & Stoichiometric \\
Oil Temperature $\left({ }^{\circ} \mathrm{C}\right)$ & 80 \\
Coolant Temperature $\left({ }^{\circ} \mathbf{C}\right)$ & 100 \\
Air Temperature $\left({ }^{\circ} \mathbf{C}\right)$ & $35-40$ \\
\hline
\end{tabular}

Filtered instantaneous temperature and pressure data was collected throughout the tests. All plugs were tested individually in the CFR engine at the port closest to the intake valve. An ice bath was used as the reference cold junction and the plugs were bonded to the analog circuit power supply ground.

The primary goal of these tests was to compare the effects different wire diameters had on various thermocouple responses. Overall repeatability of the temperature measurements at the test conditions was also studied.

\subsubsection{Repeatability}

The repeatability of the surface thermocouples was verified by studying the measured in-cylinder temperatures with respect to the engine operating characteristics. Figure 5.7 shows the average surface temperature results of five independent test runs with respect to the measured BMEP for each condition. This figure demonstrates that there was a large degree of scatter in the temperature measurements between test runs. Under the same engine conditions, temperature differences of up to 10 degrees were seen. These large differences 
were attributed to test-to-test variations in in-cylinder conditions primarily due to the difficulty in controlling the engine AFR using the existing carburetion system.

However, by normalizing the absolute temperature measurements by load, the surface temperatures were seen to converge at a single point for each of the test conditions. Figure 5.8 shows the BMEP-normalized surface temperatures for the five engine runs at different speed and boost conditions and clearly indicates that the average surface temperatures at each condition was quite repeatable on a power-specific basis. This information also indicates that the cause of the large variance seen in the absolute temperature measurements was primarily as a result of changing engine conditions rather than thermocouple inaccuracy. In order to get a greater understanding of the repeatability of the measurements, correction factors to account for changes in engine conditions (equivalence ratio, load) should be applied. It should be noted that the variance between the test results from the sole Plug 1 test was a result of a correction in the valve clearances prior to this test which improved engine output.

The same test results were also analyzed by studying the temperature profiles for each of the individual thermocouple in an attempt to isolate any wire effects on the temperature measurements. As seen in Figure 5.9, which shows average surface temperature measurements with respect to the constantan wire diameters used, surface temperatures increased with constantan wire diameter. Temperature differences of up to 2.7 degrees were measured. These results were in accordance with the trend seen in the FEA analysis described in Section 4.4. This was attributed to the increasing thermal mass of the thermocouple junctions. As the magnitude of the variations was not entirely consistent between three different plugs, differences in thermocouple construction were also believed to have contributed. The use of smaller wires was therefore recommended. 


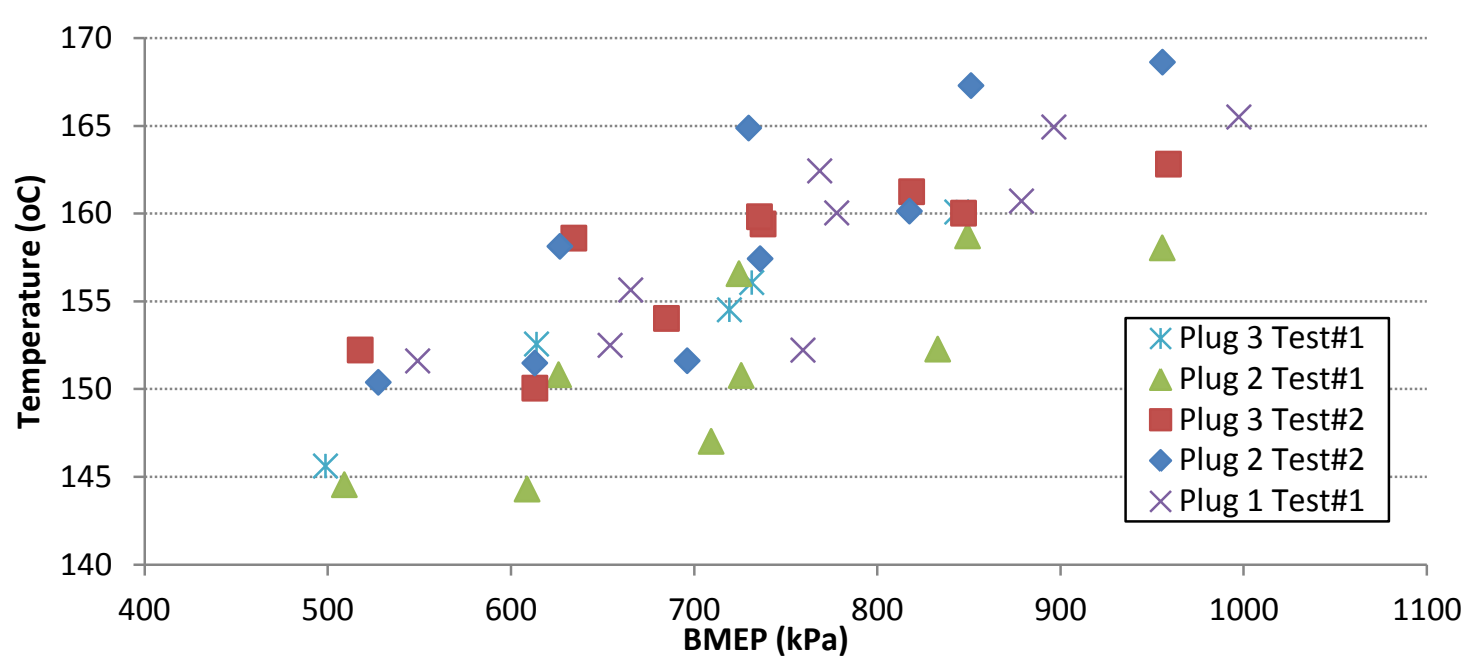

Figure 5.7 - Plug Test Surface Temperature Data vs. BMEP

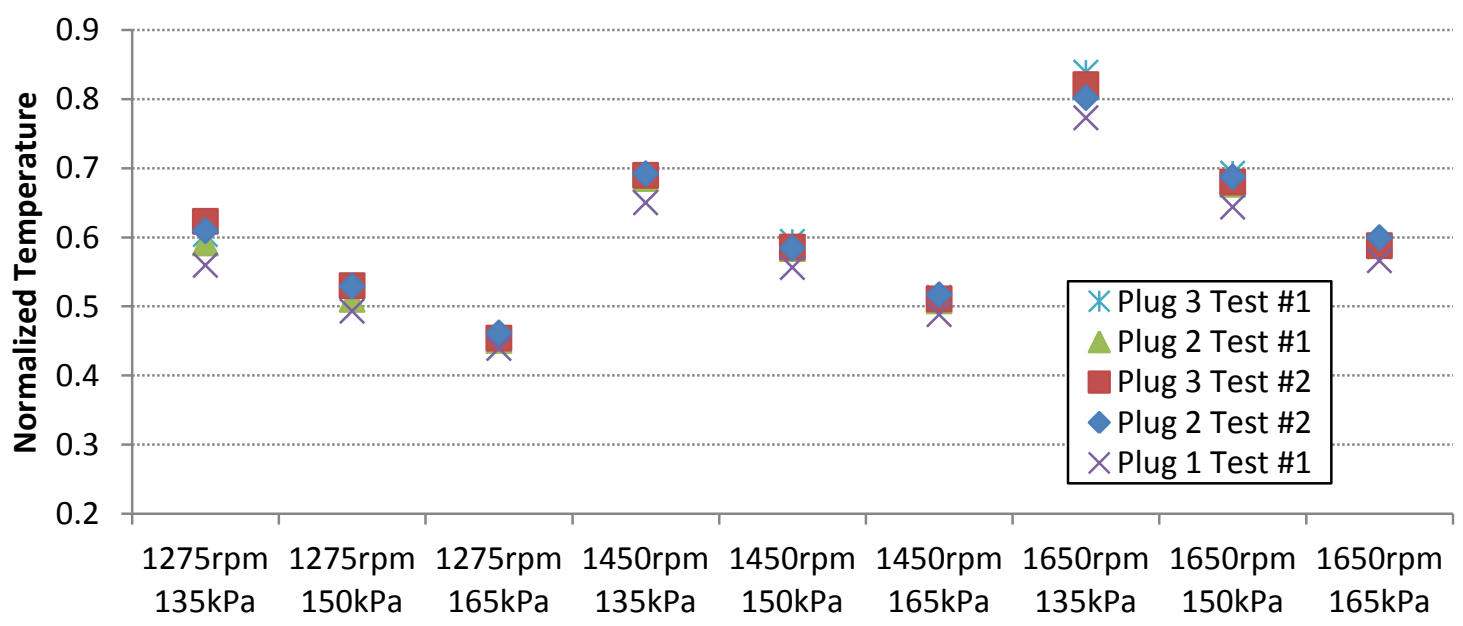

Figure 5.8 - Power-Specific Surface Temperatures at Varying Engine Speed and Boost Pressure

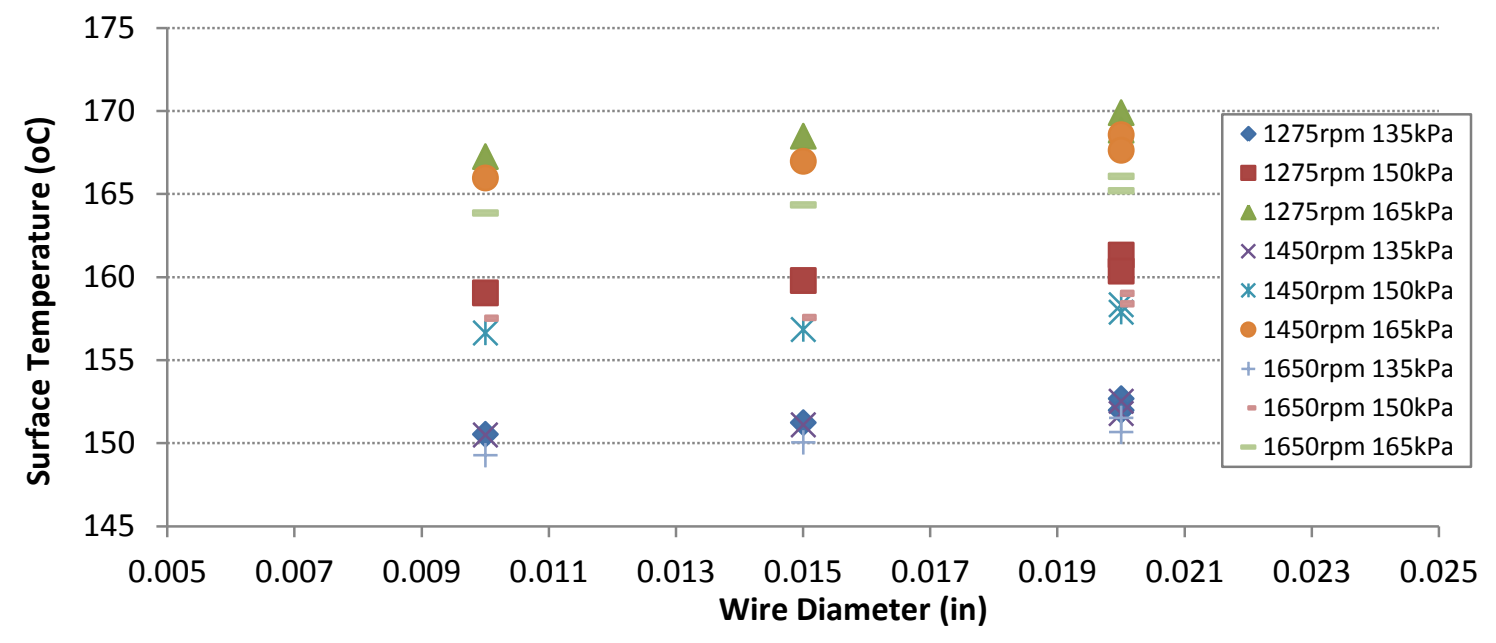

Figure 5.9 - Plug Surface Temperatures as a Function of Wire Diameter (Plug 2) 


\subsubsection{Noise}

Average noise in the collected temperature signals was quantified by determining peak-to-peak variation in the signal over one crank-angle degree intervals (i.e. five points) and averaging this over the duration test. In general, the results of the plug tests showed average noise levels equivalent to between $0.01^{\circ} \mathrm{C}$ and $0.03^{\circ} \mathrm{C}$ in the temperature signals, which was extremely low. This was a testament to the performance of the analog circuitry used throughout the tests. A clear dependence of signal noise on engine load was seen. This was attributed to increased electrical power needed by the ignition system to produce a spark under high in-cylinder pressures. However, a general lack of a relationship between signal noise and thermocouple wire diameter was noted, as shown in Figure 5.10, which depicts the average noise levels for the different wire diameters during the plug tests. Normalizing the results by BMEP to eliminate load dependence also failed to indicate any relationship. Thus, it was concluded that any of the three wire diameters tested could be used to provide clean temperature measurements.

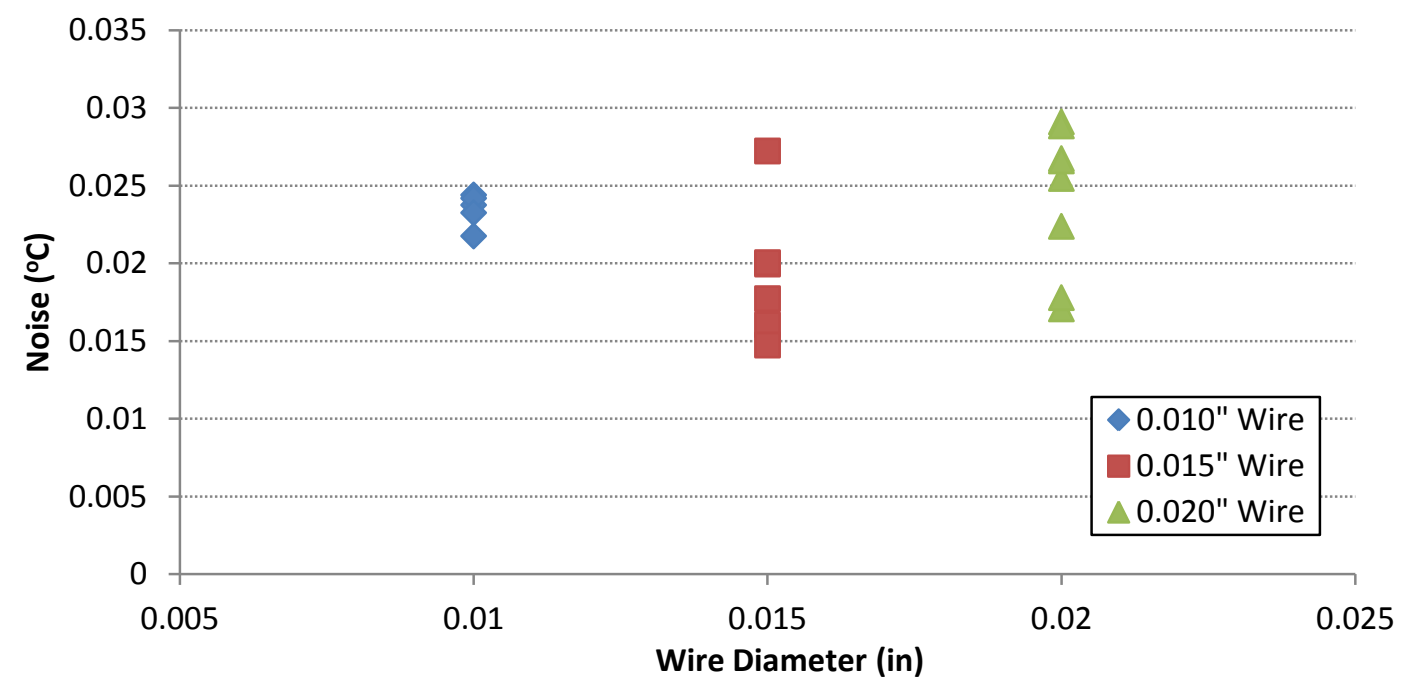

Figure 5.10 - Average Noise in Plug Test Temperature Data for Different Wire Diameters 


\subsection{Thermocouple Development Summary}

The fast response surface thermocouple modelled in Chapter 4 was manufactured in an aluminum plug that was installed into the CFR engine cylinder wall. Three plugs were tested to determine the effects of hole-wire size configurations. It was determined that while smaller wire sizes were preferred as a result of smaller thermal mass and more accurate measurements, there were negligible differences between the various combinations. It was thus recommended to use the most readily reproducible configuration.

A calibration procedure for the custom thermocouples was presented. The thermocouple response in the region of interest was found to be extremely linear, and was found to have a Seebeck coefficient of $44 \mu \mathrm{V} /{ }^{\circ} \mathrm{C}$. Laser impulse tests were conducted on the thermocouples in order to determine the response time. This was found to be approximately $500 \mu$ s, which was marginally slower than typical thin film thermocouples. However, this was deemed an acceptable compromise for the increased accuracy of the design.

In the following chapter, the design of the piston surface temperature measurement apparatus is presented. 


\section{Chapter 6}

\section{Piston Testing Setup and Methodology}

The following chapter outlines the development of the experimental apparatus used to conduct the in-cylinder heat transfer analysis of the thermal barrier coatings. A detailed description of the piston instrumentation process will also be provided. Finally, a summary of the test procedure to be implemented during the engine testing will be discussed.

\subsection{Piston Instrumentation}

The piston used throughout the testing regime was instrumented with five pairs of surface and in-depth thermocouples. Their locations were selected in an attempt to identify any spatial variations in piston surface temperature which may result from the flow structures within the cylinder. Various modifications were made to the piston in an attempt to facilitate the installation of the surface and in-depth thermocouples. Figure B.2 in Appendix B is an engineering drawing of the piston after these modifications. 
The implementation of the Stepped thermocouple geometry described in Section 4.3 was made challenging due to space limitations in the CFR. These geometric constraints made it difficult to machine the countersunk holes required for the design and install the thermocouple wires, thus hindering the quality and repeatability of each Stepped thermocouple. To facilitate their installation into the piston, the surface thermocouples were manufactured in tapered pins which were pressed into the piston. This allowed for greater control during construction of the plugs and allowed for inspection prior to installation. This also facilitated the replacement of the thermocouples in case of failure during testing.

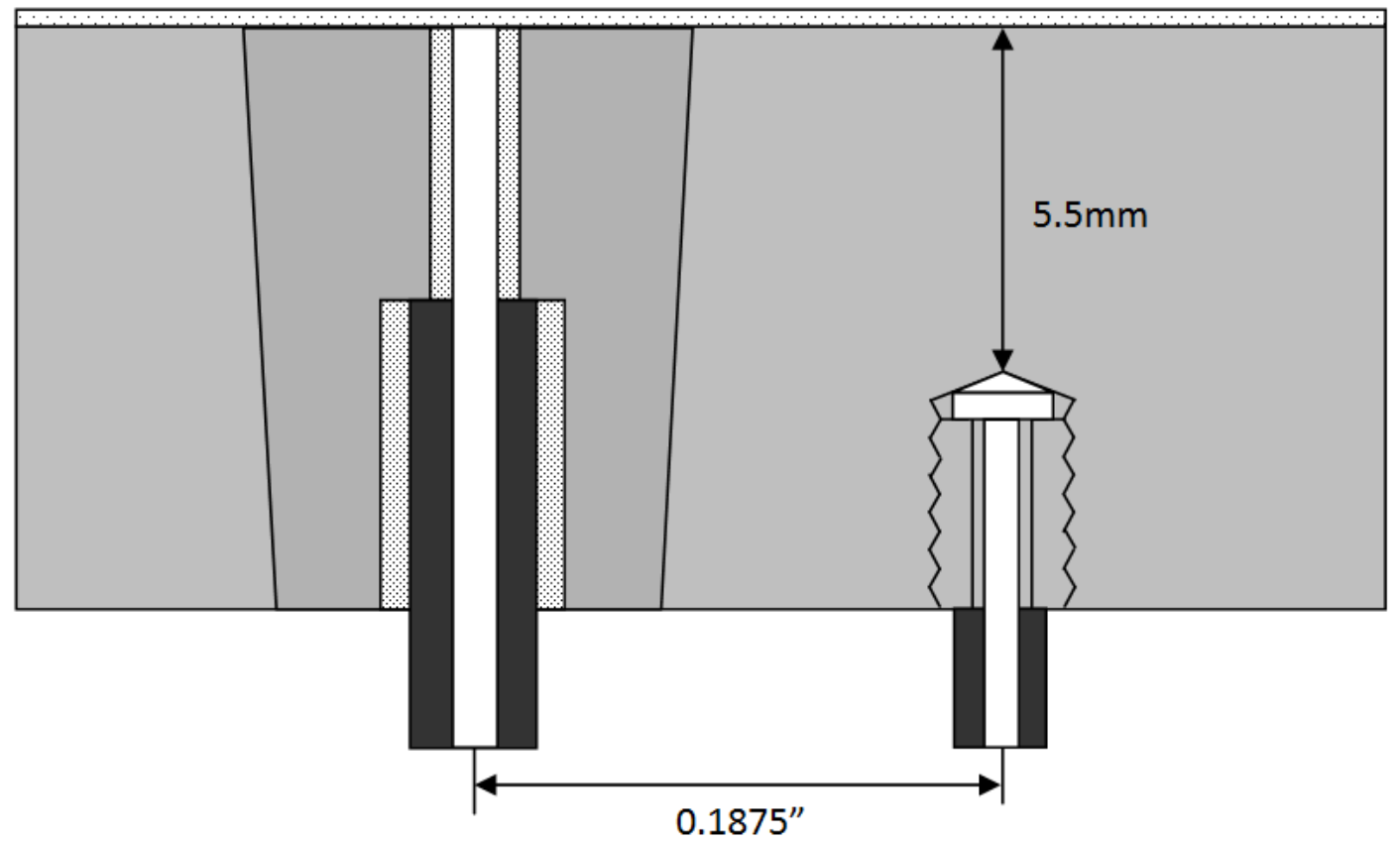

Figure 6.1 - Tapered Plug Surface Thermocouple and In-Depth Thermocouple Arrangement (not to scale)

Figure 6.1 shows a schematic of a surface and in-depth thermocouple pairing. The \#3 tapered pins were machined from the same AL2608 alloy as the piston. A 0.040" clearance hole $5 \mathrm{~mm}$ from the plug's measuring surface was drilled followed by a 0.022 " through hole (see Figure B.3 in Appendix B for drawing). A 0.015” constantan wire was then fed into each plug and secured using the same Aremco Ceramacast $675 \mathrm{~N}$ potting material used for the 
construction of the threaded plugs described in Section 5.1. The plugs were tested with a multimeter to ensure that the wires were electrically insulated from the aluminum plug prior to forming the measuring junction. Each plug was inspected under a microscope to evaluate the position of the wires within the holes to further validate the repeatability of the thermocouple. After being pressed into the piston, the thermocouples were completed by plasma spraying a $125 \mu \mathrm{m}$ copper film on the piston to create the junction between the constantan wire and aluminum. Figure 6.2 shows the thermocouple plugs before and after being installed into the piston.

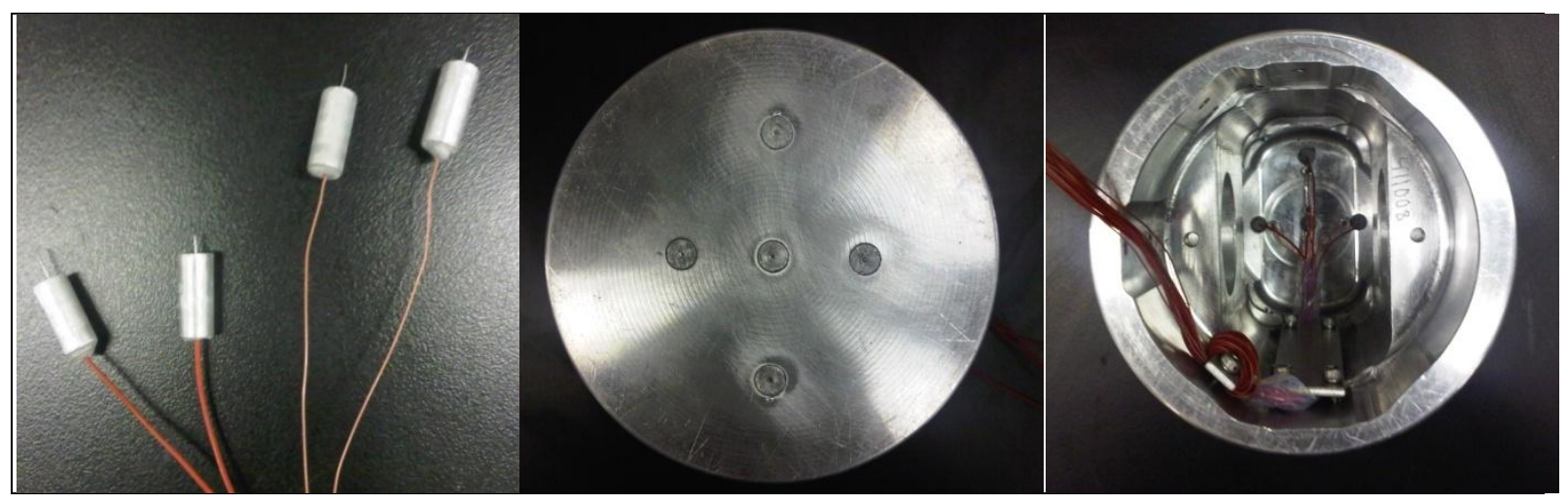

Figure 6.2 - Piston Thermocouple Layout

To form the in-depth thermocouples, a constantan wire was fed through a \#2-56 vented aluminum screw, formed into a ball, and threaded into the piston crown $5.5 \mathrm{~mm}$ from the piston surface in accordance with the FEA results discussed in Section 4.6. Once installed, the thermocouples were sealed with a thin layer of silicone sealant to isolate them from the lubricating oil.

\subsubsection{Wire Routing}

Transferring the thermocouple wires from the piston to the data acquisition unit located outside of the engine was made challenging due to the extreme conditions within the 
engine. The primary challenge was avoiding wire fatigue failure as a result of the cyclic motion of the engine. To minimize the motion of the wires within the piston, they were routed and secured using the same technique described by Marr [113]. As illustrated in Figure 6.3 , the wires were routed from piston crown and secured to the piston side wall (thrust face) using an aluminum plate for strain relief. After being transferred along the piston skirt and fastened for strain relief, the wires were inserted into a connector block (Figures B.4 and B.5 in Appendix B) where they were spliced to a $24 \mathrm{AWG}$ stranded constantan wire (Omega P/N TFCI-24S). These Teflon-coated wires were used as their increased flexibility made them less susceptible to fatigue failure. At the connector, each pair of spliced wires was covered in heat shrink and sealed with high temperature silicone sealant (Dow Corning P/N 736) to provide further electrical insulation and prevent short circuiting.

From the connector block, the stranded wires were then transferred over the wrist pin along a spring steel strap fixed to the piston thrust face. The strap provided a path along which the wires could travel over the engine wrist pin and along the connecting rod without wire bending. The wires were affixed to the strap with silicone sealant and heat shrink tubing and secured to the connecting rod using clamps to prevent any excessive movement.

Various techniques including wireless telemetry $[\mathbf{1 1 7 , 1 1 8 , 1 1 9 ]}$, electromagnetic induction $[\mathbf{1 2 0}]$, contact point transmission $[\mathbf{1 2 1}]$ and mechanical linkages $[\mathbf{7 6 , 1 2 2 , 1 2 3}]$ have been used to transmit these types of signals. A mechanical linkage was implemented due to its simplicity and reliability. Figure 6.4 shows a schematic of the linkage used, with a detailed description of the linkage design being provided by Memme [123]. The linkage was mounted to the engine via the connecting rod bolt at one end and fixed to a protective enclosure mounted on the engine crankcase at the other, as shown in Figure 6.5 below. 
The wires were fed from the piston along the length of the connecting rod and linkage, and affixed in place with clamps to minimize unwanted motion. To further reduce any direct bending, the wires were fed through each of the linkage joints, as shown in Figure 6.6 below. The wires were transferred from the linkage to the data acquisition system through a hole in the linkage housing. Figure 6.7 shows the fully instrumented piston/linkage arrangement.

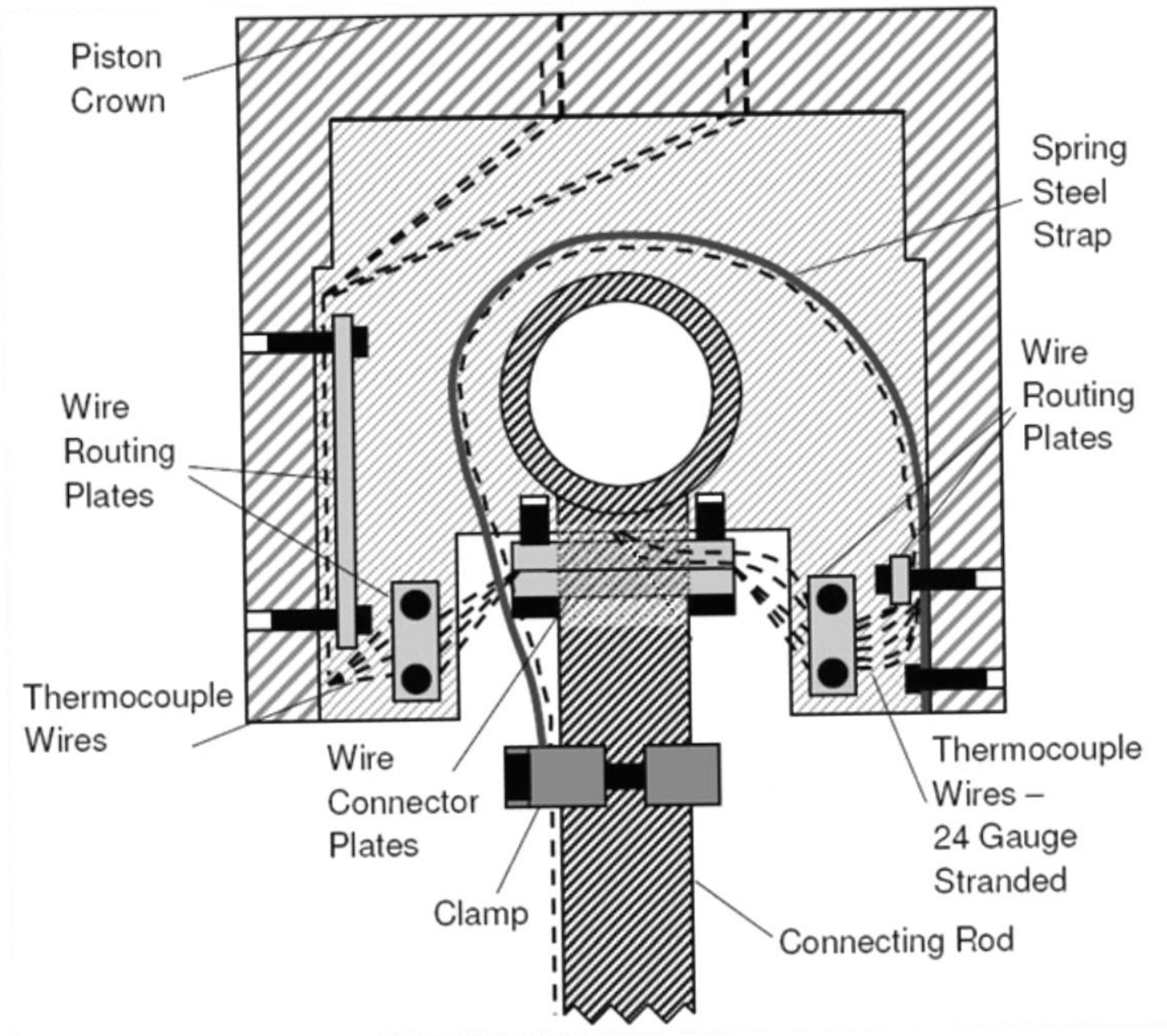

Figure 6.3 - Wire Routing Path in CFR Piston [113] 


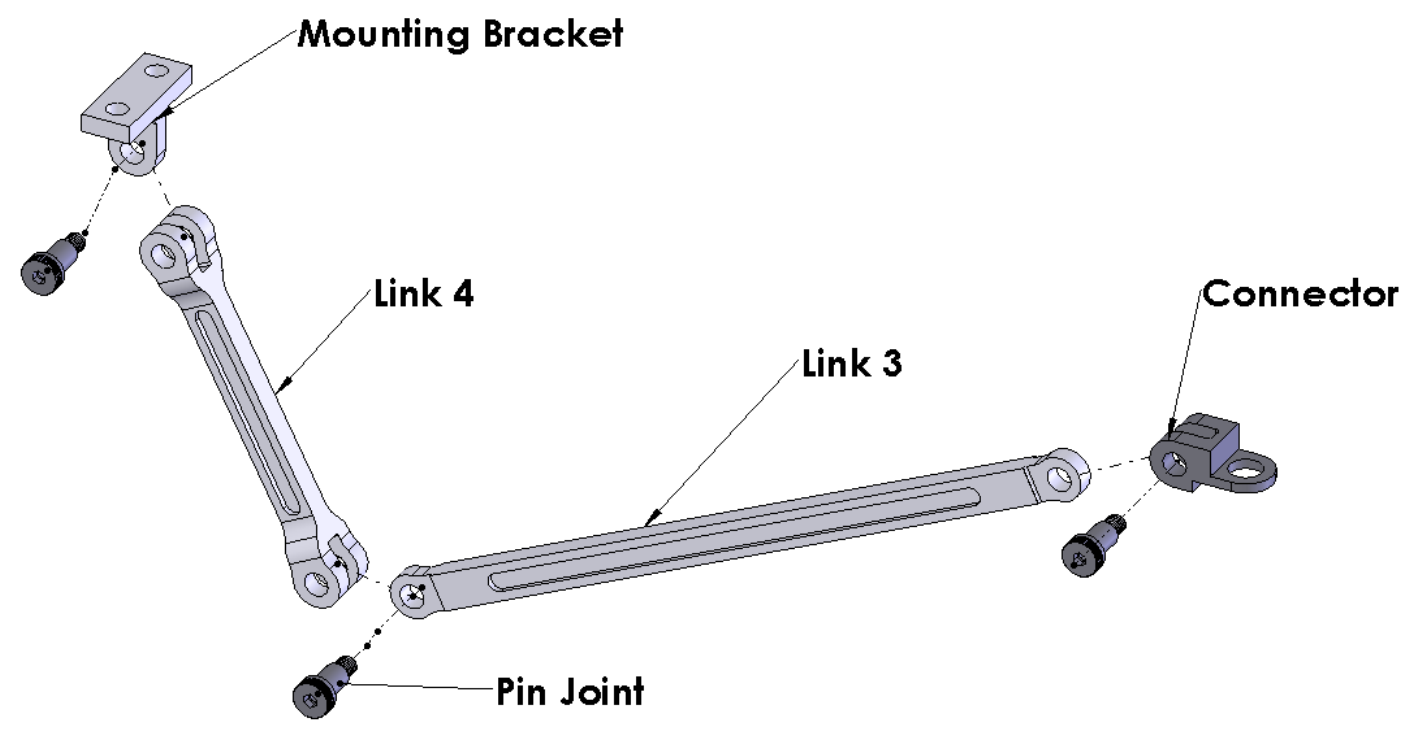

Figure 6.4 - Mechanical Linkage Schematic [123]

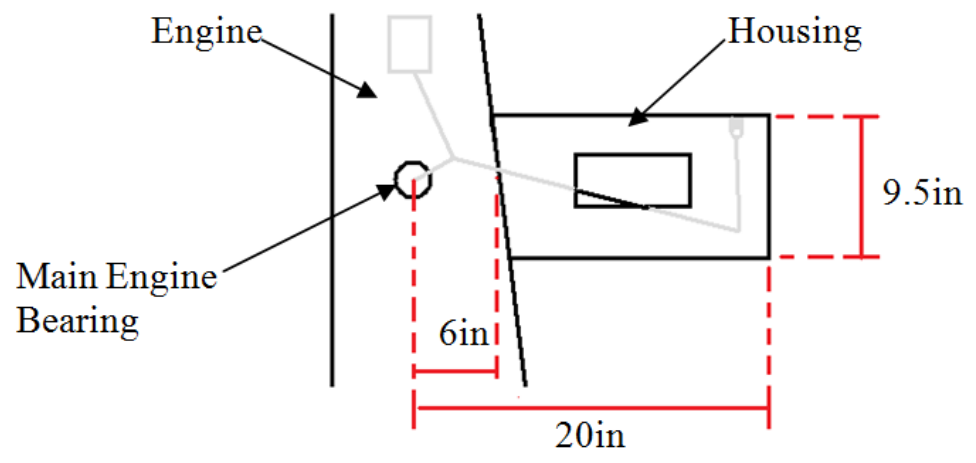

Figure 6.5 - Linkage Protective Housing [123]

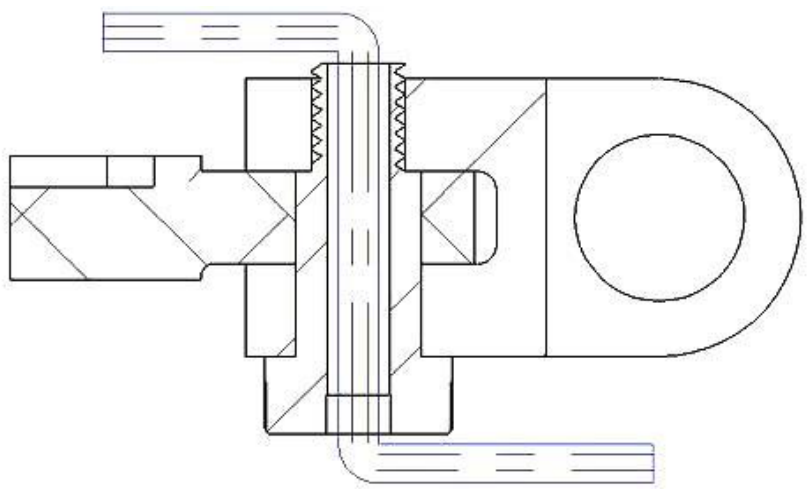

Figure 6.6 - Through-Joint Wiring [123] 


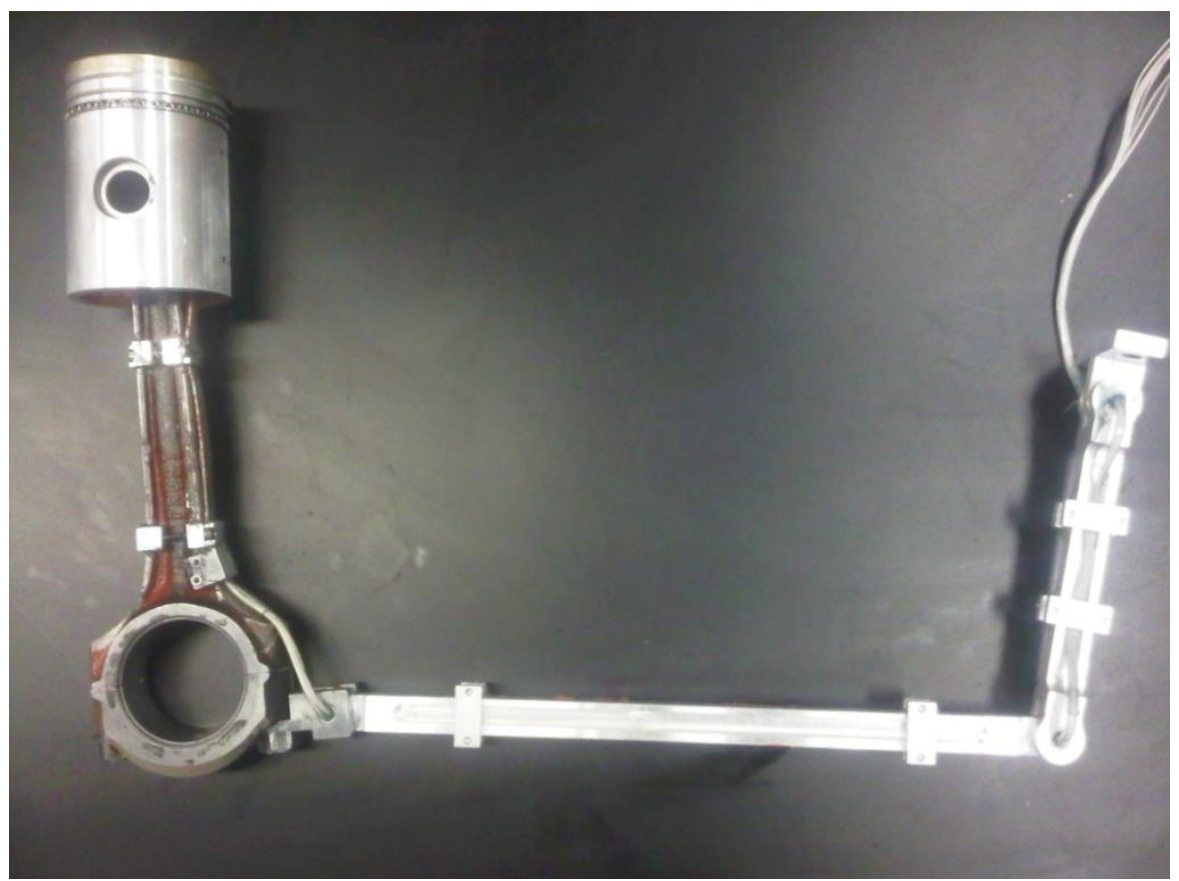

Figure 6.7 - Instrumented Piston - Linkage Assembly

\subsubsection{Thermocouple Signal Splitting}

Each surface and in-depth thermocouple required a measuring (hot) and reference (cold) junction to obtain a temperature measurement. The constantan-aluminum pairs illustrated in Figure 6.1 were the hot junctions for both thermocouples. A cold junction was produced by affixing a stranded aluminum wire (Jersey Strand P/N 10263) to the piston and routing it along the linkage. This wire served as the positive leg for each of the thermocouples, with each constantan wire acting as the negative leg. The aluminum wire allowed for the use of an ice bath outside the engine as the cold junction for all thermocouples. This greatly simplified the thermocouple circuit eliminating the need to place a cold junction on the piston as had been designed by Marr [113].

Upon being transported via the linkage, the double-ended thermocouple signals were conditioned using the same conditioning circuit discussed in Section 5.2.2 and Appendix C. 
The signals were filtered using an 8-pole Bessel low-pass filter with a cut-off frequency of $1000 \mathrm{~Hz}$ and amplified in two stages up to 80,000X depending on thermocouple calibration.

Using four National Instruments NI-9215 CDAQ modules mounted in a CDAQ-9178 chassis, the filtered temperature signals were recorded at both high and low sampling speeds. To obtain cycle-resolved, instantaneous temperature measurements, the thermocouple signals were sampled every 0.2 CAD using a crankshaft-mounted optical encoder. These high-speed measurements were used to conduct heat transfer analysis of different surface conditions used throughout the study. Average in-depth and surface temperature measurements were also collected to study the steady state effects. These measurements, in addition to all primary engine measurements (speed, load, emissions, etc), were sampled at $1 \mathrm{kS} / \mathrm{S}$, averaged over 250 samples and recorded via a 16-bit NI-9205 CDAQ module.

\subsection{Piston Thermocouple Calibration}

Since piston surface temperatures in the CFR engine were expected to be significantly greater than cylinder wall temperatures based on the results seen by Marr [113], the piston was calibrated for a larger temperature range than that used during the plug tests. However, due to the temperature limitations of the Teflon insulation used on the constantan wires, a preliminary calibration of the aluminum-constantan thermocouple pairing was conducted in one of the test plugs ensure the instrumented piston was not damaged. This test thus provided a baseline calibration curve for the thermocouples used throughout the piston testing.

For both tests described below, the same calibration apparatus used in the thermocouple plug tests discussed in Section 5.2 was used. An ice bath was once again used as the cold junction for the aluminum-constantan thermocouples being calibrated. The reference temperatures and measured thermocouple voltages were allowed to stabilize prior 
to each individual thermocouple response being recorded and averaged over a three to five minute period. The voltage measurements were then directly correlated to the corresponding oil temperature measurements taken with the reference thermometers to produce a calibration curve for each thermocouple.

\subsubsection{Preliminary Plug Calibration}

The calibration was performed up to a maximum temperature $260^{\circ} \mathrm{C}$ as limited by the properties of the synthetic oil (Thermo Fisher Scientific P/N SYNTH 260) used in the circulating bath. The test plug instrumented with a surface thermocouple was placed within the heated oil bath at a depth that ensured the wires were not submersed.

It was clear from this calibration results shown in Figure 6.8 that the thermocouple response remained extremely linear at the elevated temperatures. This conclusion thus allowed the thermocouples within the piston to be calibrated at a range below the melting temperature of the Teflon wire insulation $\left(\sim 210^{\circ} \mathrm{C}\right)$ and linearly extrapolate to higher temperatures with some level of confidence.

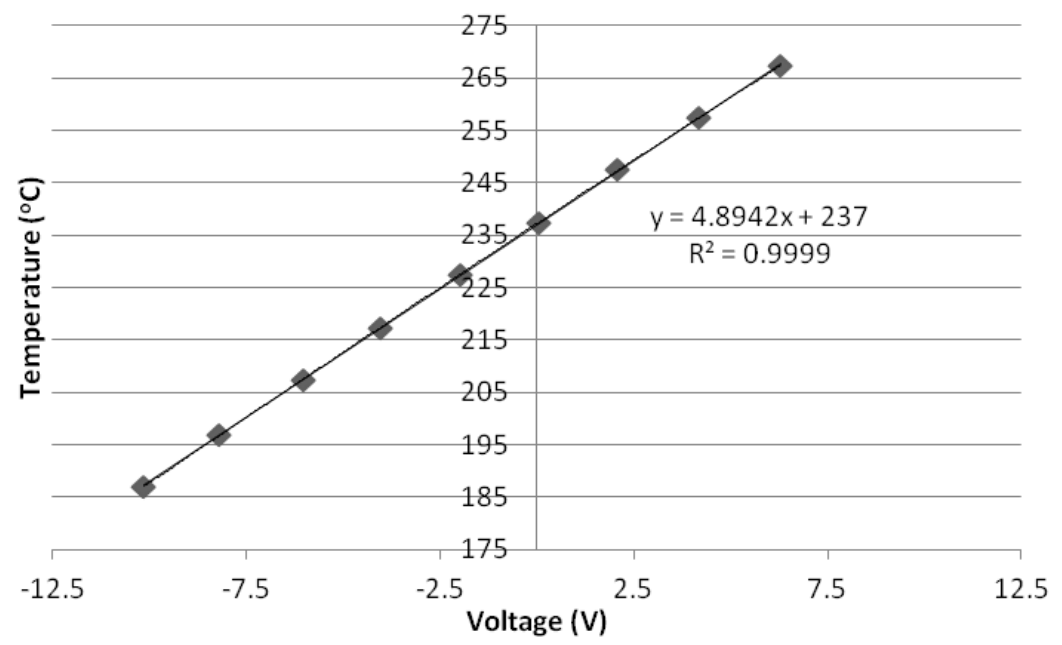

Figure 6.8 - Preliminary High Temperature Thermocouple Calibration Results Using Test Plug 


\subsubsection{Piston Calibration Results}

For calibration of the surface and in-depth thermocouples used throughout the piston tests, the instrumented piston was placed on a thick aluminum plate that left the piston crown exposed, and was submersed into the oil bath. The reference thermometers were embedded within the plate to serve as reference temperatures for the calibration. The piston was submersed in the oil until the underside of the piston crown was at least one inch below the oil level to ensure the in-depth thermocouples measured the same temperature as the oil bath.

An analog filtering circuit gain of 2000x was used and provided a 150 degree temperature range for piston calibration. However, the calibration was completed over only 60 degrees $\left(150^{\circ} \mathrm{C}\right.$ to $\left.210^{\circ} \mathrm{C}\right)$ to ensure that the thermocouple wires were not damaged. This provided a baseline calibration for which any in-cylinder temperature measurements which corresponded to temperatures greater than $210^{\circ} \mathrm{C}$ could be extrapolated from. Table 6.1 shows the calibration coefficients for each of the ten thermocouples installed in the piston.

Table 6.1 - Piston Thermocouple Calibration Coefficients $(\mathrm{T}[\mathrm{oC}]=\mathbf{m x}+\mathbf{b})$

\begin{tabular}{ccc}
\hline Thermocouple & $\begin{array}{c}\text { Slope } \\
\left({ }^{\circ} \mathbf{C} / \mathbf{V}\right)\end{array}$ & $\begin{array}{c}\text { Intercept } \\
\left({ }^{\circ} \mathbf{C}\right)\end{array}$ \\
\hline STC1 & 10.752 & 264.508 \\
ID1 & 10.8298 & 264.972 \\
STC2 & 10.7896 & 264.782 \\
ID2 & 10.8484 & 265.822 \\
STC3 & 10.6702 & 263.552 \\
ID3 & 10.461 & 261.32 \\
STC4 & 12.919 & 279.842 \\
ID4 & 10.7118 & 264.714 \\
STC5 & 10.7596 & 264.388 \\
ID5 & 13.74336 & 287.862 \\
\hline
\end{tabular}

These individual in-situ calibrations thus accounted for any variation in thermocouple construction and analog circuitry. Each thermocouple/circuit channel pairing was maintained 
throughout testing, thus maintaining the calibration for each measurement device. Note that the large deviation in calibration curve for STC4 and ID5 were as a result of these thermocouples being damaged during installation, and thus not used during testing.

\subsection{Data Processing}

Four primary MATLAB codes were written to process the collected control panel, high speed piston surface temperature data and in-cylinder pressure data. TempProcessPiston.m converted the collected voltage signals to temperature measurements by applying the thermocouple calibration curves to each of the individual thermocouple signals. The processed temperature measurements were used as boundary conditions to calculate the heat flux to the piston crown using HeatFlux2.m which solved the onedimensional, unsteady heat transfer equation (Section 4.1) through a semi-infinite wall.

PressureProcess.m was used to convert signals from the Kistler 6125 piezoelectric transducer to pressures using techniques described by Randolph [124]. Since the piezoelectric transducer can only measure differential signals, BDC after the intake stroke was used as the reference pressure for each cycle. Calibration of the transducer showed a measured response of $1022.0 \mathrm{kPa} / \mathrm{V}$. Pressure measurements were used to calculate the indicated mean effective pressure (IMEP) of each test condition and the associated coefficient of variability (COV) which was used as an indicator of the quality of combustion throughout testing. Finally, CPProcess.m processed all primary engine parameters (speed, torque, emissions, etc) measured at 0.5 second intervals throughout testing and was used to calculated performance parameters such as BMEP, power and brake specific fuel consumption (BSFC).

A detailed description of the MATLAB functions used can be found in Appendix F. 


\subsection{Testing Procedure Summary}

The piston surface temperature apparatus was used to quantify the effect of roughness on overall engine performance by varying the degree of surface roughness of the piston crown and the nature of the flow within the cylinder. Two piston coatings were tested at four engine loads (i.e. intake air flow rates) and varying surfaces finishes. At each condition, surface temperatures were allowed to stabilize prior to collecting measurements for three to five minute intervals. Details of the engine settings used for the tests are described in Sections 3.4 and 3.5 (p. 43).

A minimum of 400 cycles of high speed surface temperature and pressure data were collected at each test point in addition to all pertinent engine performance and emissions information taken at 0.5 second intervals. Basic engine data was used to quantify the effects of varying surface roughness at different operating conditions, while the high speed temperature and pressure data was used to help identify the in-cylinder phenomena causing the measured engine responses. Each test run was repeated five times over two days to ensure repeatability and minimize the effects of ambient conditions.

Over a three month period and 12 attempts at rewiring the linkage, an approach which provided robust measurements could not be achieved due to the repeated failure of the thermocouple wires at different points along the wiring path. While temperature measurements were successfully taken in multiple one hour test runs, frequent wire failures made the collection of a sufficient amount of data for analysis unrealistic. One of the primary causes of these failures was deemed to be the lack of space within the piston for the number of wires being routed. This resulted in a bulky wire bundle which was prone to excessive 
movement and rubbing on the piston walls. The number of wires also made it difficult to route them through the linkage joints and created excessive wire chafing.

The use of the metal strap to route the wires around the engine connecting rod was also problematic, as the strap had a tendency to cut the wires if they became loose within the piston. This problem was addressed by eliminating the strap and feeding the thermocouple wires in a flattened $1 / 4$ in Teflon tube which proved to be much more reliable as it underwent more than 30 hours of testing without failure.

Appendix $G$ shows a small sample of the temperature measurements data that was successfully collected with the instrumented piston and a collection of images documenting the various failures which were experienced throughout testing. 


\section{Chapter 7}

\section{Piston Surface Roughness Test Results}

The following chapter outlines the results of the piston surface roughness tests conducted for two coatings (copper and metal based TBC). Each coating surface finish was run at a total of 12 different load/speed conditions in an attempt to isolate changes in heat transfer, and thus engine performance, resulting from the interaction between in-cylinder flows and the varying surface finishes. The general effectiveness of the thermal barrier coating due to its insulating properties, and the effect of surface roughness on its performance, will also be discussed.

Throughout the discussion of the results, an emphasis will be placed on trying to explain engine measurements in terms of changes in heat transfer as a result of 1) surface finish and 2) coating material. The measurements will also be compared to estimates of 
roughness Reynolds number over the piston crown in an attempt to correlate the engine performance to convective heat transfer levels within the cylinder.

Due to the unreliability of the piston surface temperature measurement hardware, the changes in heat transfer at the varying surface conditions could not be quantified directly, but rather were studied through the interpretation of overall engine performance and emissions figures. To aid in the understanding of the effects of the coating materials and surface finish on engine behaviour, the presentation of the test results will be divided into three segments. Firstly, a brief discussion of the expected impact of surface roughness and piston coating material on various engine parameters will be presented. A discussion of the first order effects of the coatings on power output, fuel consumption and emissions will then be compared to the expected behaviours. Finally, in-cylinder pressure traces which contain important information on the combustion process will be used as a means of explaining the first order effects and further understand the impact of the coatings on the fundamentals of engine behaviour. The effects of surface roughness and TBC effectiveness on each of these engine parameters will be analyzed individually.

Note that unless otherwise specified, the values displayed in the figures in this chapter represent the average of five individual test runs at each condition. The error bars on each of these graphs represent the $95 \%$ confidence intervals calculated using the Student $\mathrm{T}$ distribution for the mean of these five tests. Single factor Analysis of Variance (ANOVA) tests were also used to help determine statistical significance of certain datasets.

\subsection{Expected Results}

As discussed in Section 2.1.2 - TBCs in SI Engines, the primary effect of polishing rough surfaces within the combustion chamber or introducing a $\mathrm{TBC}$ in an SI engine is to 
reduce the amount of energy lost during the combustion process to heat transfer. This results in increased combustion temperatures, which has a fundamental impact on the combustion process. As a result of the higher temperatures, faster burn rates are expected which would result in a more efficient energy release, higher peak pressures, and increases in engine output. The higher temperatures may also increase the tendency of engine knock in SI engines, though the high octane number of natural gas was expected to mitigate this.

Decreases in energy loss through heat transfer means that a greater portion of fuel energy is transferred to useful work, and thus engine efficiency increases. This should be evidenced by decreases in brake specific fuel consumption, which is a direct indicator of engine efficiency. Increases in engine output should also be expected as a result of increased in-cylinder pressures caused higher combustion temperatures. These effects were made evident in SI engine tests conducted by Tsutsumi and Nakamura [76] which achieved moderate increases in power and efficiency by polishing combustion chamber surfaces.

Increased in-cylinder temperatures resulting from the polished surfaces and the TBC were also expected to have an effect on exhaust emissions. Nitric oxide (NO) and nitrogen dioxide $\left(\mathrm{NO}_{2}\right)$ are products of the high temperature combustion process in SI engines. Based on the chemical kinetics of the oxidation of atmospheric nitrogen, the $\mathrm{NO}_{\mathrm{x}}$ concentration levels are highly dependent on the in-cylinder temperatures. Due to this strong temperature dependence, it was expected that the reduction of heat transfer from the combustion gases to the combustion chamber surfaces would result in increases in $\mathrm{NO}_{\mathrm{x}}$ concentrations. These effects were clearly demonstrated by Assanis and Mathur [22]. Likewise, increased combustion temperatures provide conditions for exhaust emissions whose formation is ratelimited such as unburned hydrocarbons to more readily oxidize post-formation. 
Varying speed and load conditions were expected to result in variations in overall heat transfer characteristics across different surfaces finishes. At increasing engine speeds, higher in-cylinder bulk flow velocity and turbulence levels, as described in Section 2.5 - IC Engine Flow Characteristics, were expected to result in greater heat flux due to greater flow interaction with the rough surfaces. Likewise, the effects of coating material and roughness were expected to be accentuated by different energy release characteristics at different loads. Energy release in an engine is proportional to fuel rate, which increases with load. However, increased load does not result in proportional increases in combustion temperatures. Thus, at lower load conditions, the percentage of total energy release lost to heat flux is greater. The effects of surface roughness and the TBC on heat flux and the resulting engine responses are thus expected to be more evident at the lower load, naturally aspirated conditions.

To help qualitatively assess the relationship between heat transfer and surface roughness, an analysis of the in-cylinder flow conditions and their interactions with the rough surface is necessary. As described in Section 2.2, a comparison of roughness Reynolds number $\left(R e_{k}\right)$ provides an estimate of the impact a rough surface will have on heat transfer depending on the flow properties over the rough specimen. By extrapolating in-cylinder velocities taken in a CFR engine from previous studies $[\mathbf{8 5 , 8 8 , 8 9}]$, estimates of $R \boldsymbol{e}_{k}$ at each of the surface finishes tested were calculated at the 12 engine setpoints described in the engine test matrix (Table 3.3 on p.45).

Figure 7.1 demonstrates that $R e_{k}$ increases linearly with increasing surface roughness, and that the larger air-flow rate at the higher intake pressures (i.e. load) are expected to have a greater interaction with the rough surfaces than those resulting from increases in engine speed. Figure 7.2 shows an extremely strong dependence of $R e_{k}$ on the gas temperatures over 
the rough surface. This leads to the conclusion that the effects of surface roughness on heat transfer will be different at varying points in the engine cycle.

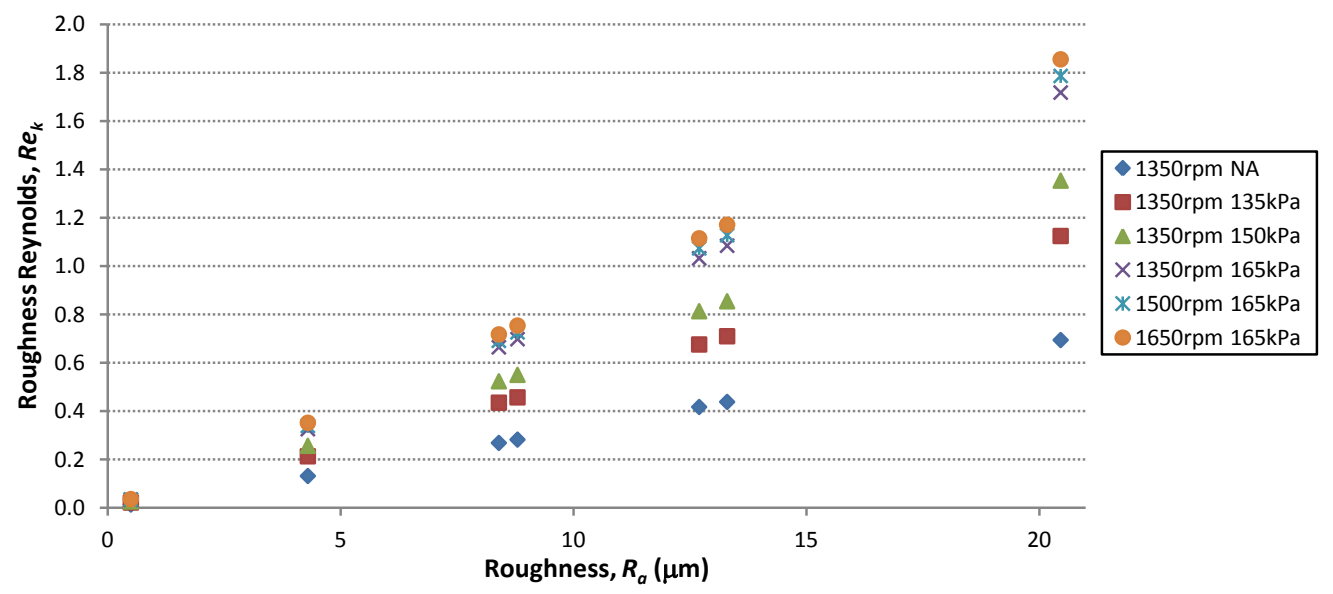

Figure 7.1 - Roughness Reynolds Number at Different Engine Setpoints $(T=2000 K)$

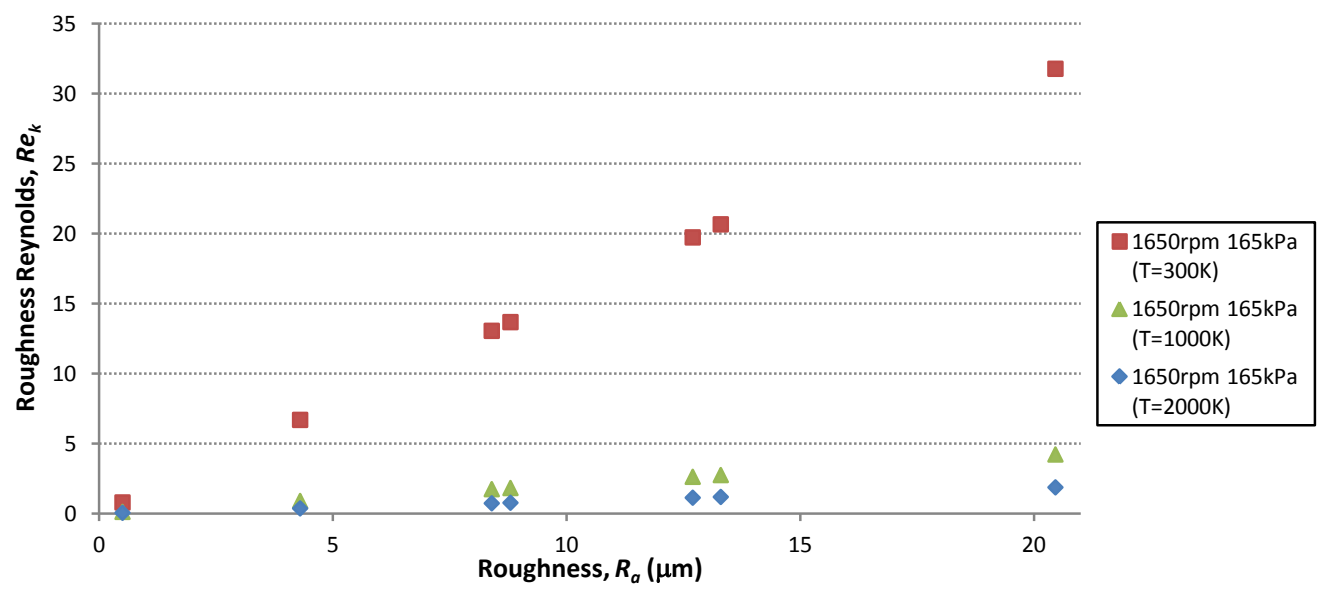

Figure 7.2 - Temperature Dependence of Roughness Reynolds Number

The magnitude of the changes on individual engine parameters is ultimately a function of the impact the coatings and surface roughness have on reducing heat transfer. Any measurable effects on the steady state measurements between varying surface finishes are the net result of varying levels of interaction between convective flows in the cylinder and the piston crown. The remainder of this chapter will assess these effects through the analysis of engine response to seven different material/coating conditions. 


\subsection{Engine Performance Metrics}

The most basic measures of engine performance are power and fuel consumption. The effects of different coatings and surface finishes on these two metrics, as well as their effect on the primary emissions of concern in a spark ignition engine, are presented below.

\subsubsection{Power and BSFC}

\section{$\underline{\text { Surface Roughness Effects }}$}

Figure 7.3 and Figure 7.4 below compare the corrected brake power output and BSFC at each test condition to the measured surface roughness. They demonstrate that coating surface finish clearly has an effect on engine performance. For the copper coating, power was seen to increase by $3.7 \%$ on average between the As-Sprayed and Mirror finishes, with a corresponding decrease in fuel consumption of $2.6 \%$. The largest performance improvements between finishes occurred at the naturally aspirated conditions, with maximums seen at the 1650rpm, naturally aspirated test point (increased output of $6.5 \%$ and $4.8 \%$ decrease in BSFC). The largest incremental improvements were seen between the As-Sprayed and Medium conditions. This was attributed to a reduced heat transfer because of the removal of large surface asperities that were most likely to interact with in-cylinder gases.

However, the degree of improvement between the As-Sprayed and Mirror finish at the three boost conditions was seen to be relatively constant, indicating that the interaction between in-cylinder flow and surface roughness had minimal impact on the heat transfer at the high load conditions. Therefore, changes in in-cylinder flow conditions between boost levels (i.e. $R e_{k}$ ) were not large enough to produce significant changes in heat transfer rates.

Similar trends were seen in comparing different roughness conditions for the metal TBC, as average improvements of $3 \%$ and $2.6 \%$ in power and fuel consumption, 
respectively, were seen between the As-Sprayed and polished finishes across all test points. Maximum improvements in both metrics were measured at naturally aspirated conditions and at the maximum tested engine speeds (power: 6.2\% and BSFC: 4.7\%). However, the optimal performance of the TBC coating was actually achieved at the $R_{a}=8 \mu \mathrm{m}$ finish rather than the Mirror finish. The differences in power and BSFC at the three smoothest finishes were not significant to the $95 \%$ confidence level, but this trend of reduction in TBC performance at the smoother surface conditions will be further addressed in the upcoming paragraphs.

\section{$\underline{\text { TBC Effectiveness on Engine Performance }}$}

The performance figures for the copper and metal TBC coatings were compared at similar surface finishes to evaluate the impact of the TBC on overall engine performance and the role of surface roughness on its heat transfer properties. An ANOVA comparison of the two As-Sprayed conditions $\left(R_{a}=20.5 \mu \mathrm{m}\right.$ vs. $12.7 \mu \mathrm{m}$ of the copper coating) showed that there was no statistically significant difference in either BSFC or engine output between the two rough coatings. It was expected that the insulating properties of the thin TBC coating would be beneficial in reducing the heat losses from the cylinder and thus provide improvements to engine performance. However, the fact that it did not was attributed to the inherently rougher surface of the TBC. Based on a substantial difference in $\operatorname{Re}_{k}$ at these conditions (Section 7.1), this large difference in roughness was believed to negate the benefits of the low conductivity coating in reducing heat transfer, thus resulting in equivalent engine outputs at the As-Sprayed conditions. 

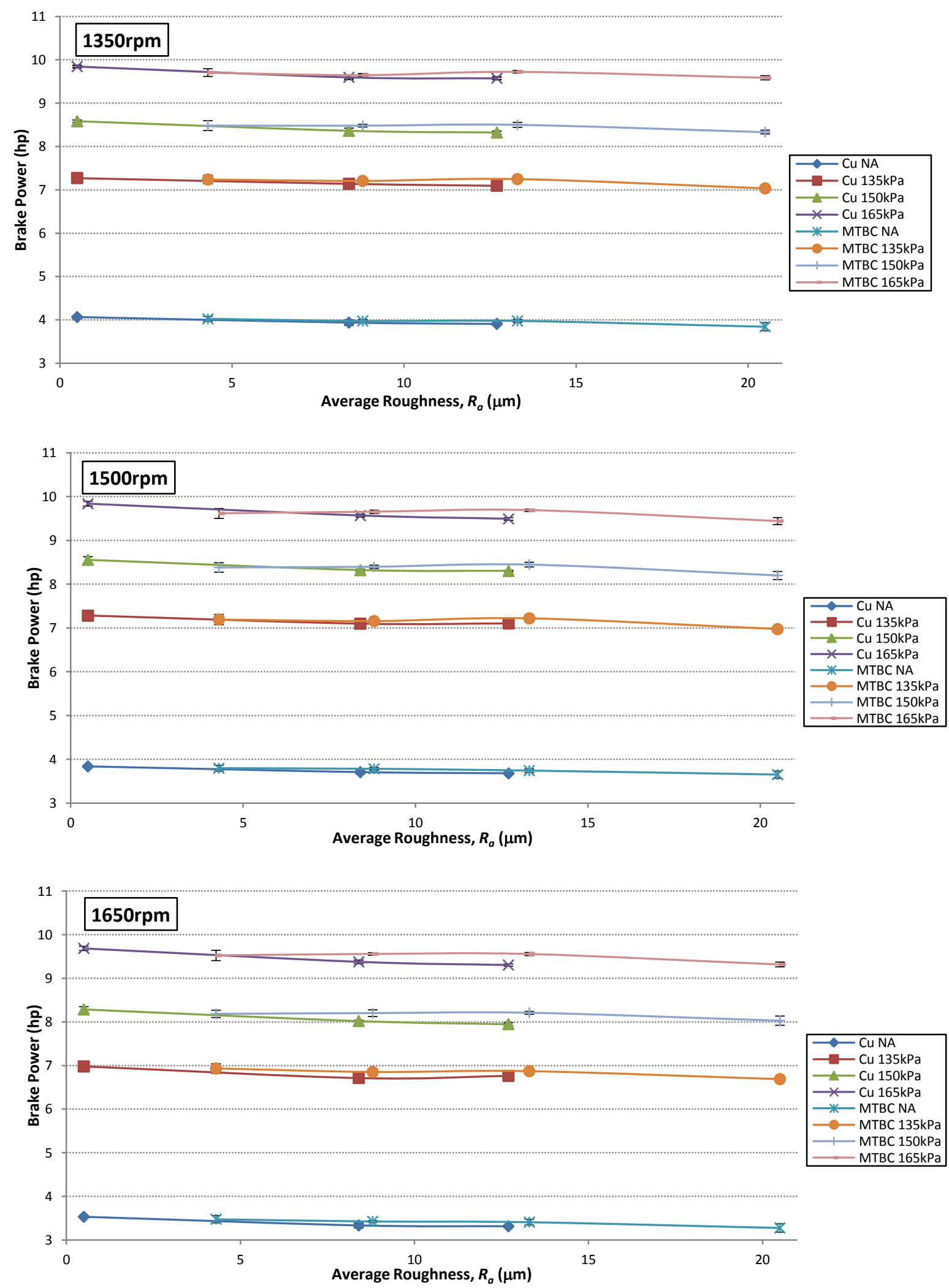

Figure 7.3 - Brake Power vs. Measured Surface Roughness at a) 1350rpm b) 1500rpm and c) 1650rpm 

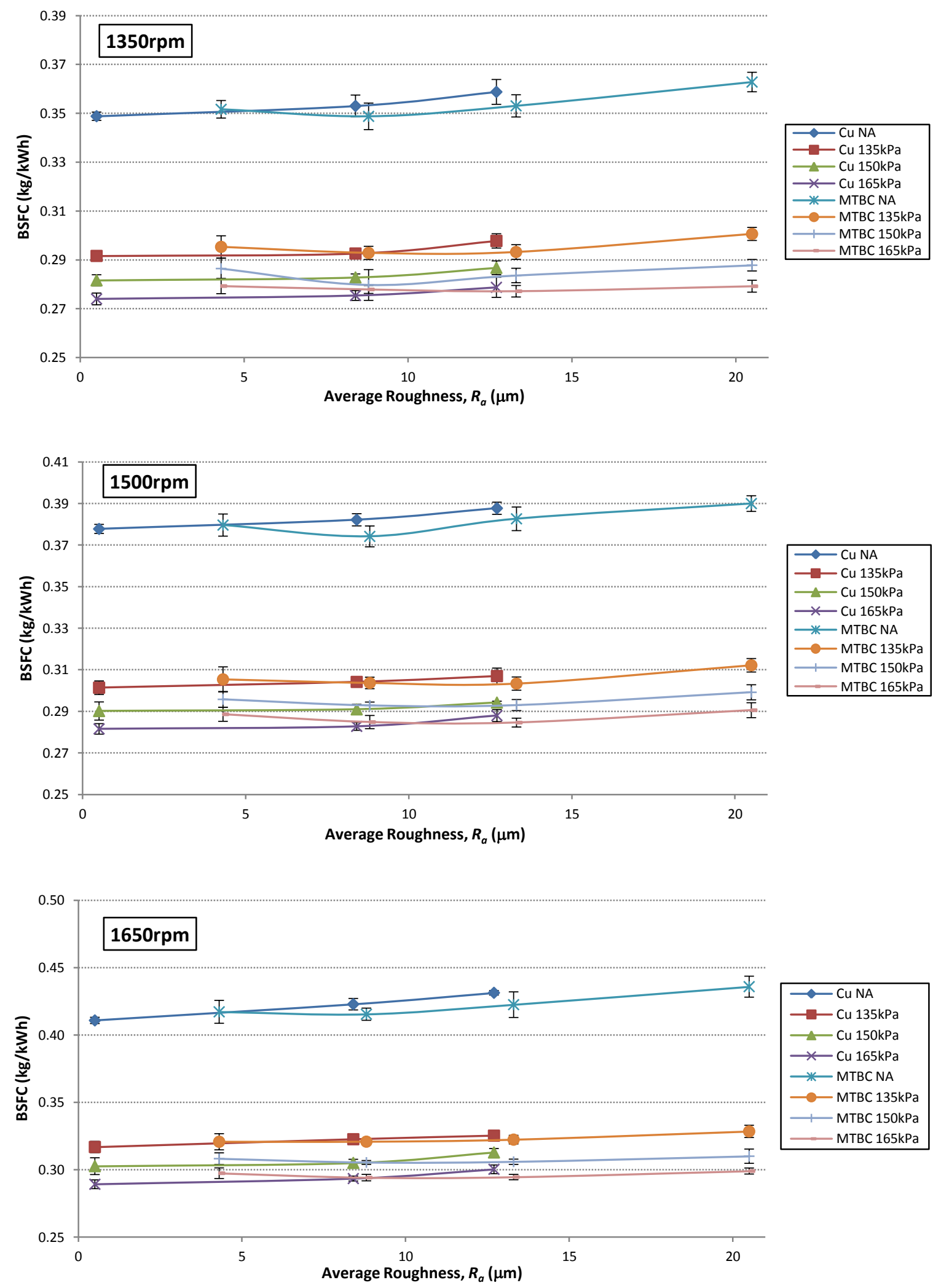

Figure 7.4 - BSFC vs. Measured Surface Roughness at a) 1350rpm b) 1500rpm and c) 1650rpm 
Comparing the TBC and copper coatings of equivalent roughness, it was seen that the TBC was beneficial at some conditions, which further strengthens the conclusion that surface roughness plays an important role in TBC effectiveness. At $R_{a}=13 \mu \mathrm{m}$, the metal TBC provided an average improvement in output of $2.1 \%$ in comparison to the copper coated piston of the same $R_{a}$ value. At the same roughness condition, a $2 \%$ improvement in fuel consumption was seen to be statically significant at the high load, high speed conditions. Similar benefits were seen at a subsequently smoother roughness level $\left(R_{a}=8.8 \mu \mathrm{m}\right)$, though the benefits of the coating at this roughness were not as pronounced. These results demonstrate that the thermal properties of the TBC did have a beneficial effect on reducing the amount of energy lost to heat transfer through the piston crown. However, it is clear that the level of effectiveness is strongly dependant on the surface finish of the coating.

The metal TBC was seen not to improve engine performance with respect to the mirror copper finish, which, from a material standpoint, was deemed to be representative of a production piston without any coating. A direct comparison of the Mirror conditions for the two coatings showed that the TBC performed equivalent to or slightly worse than the copper coating at each of the 12 test set points. The only points at which the differences were found to be statistically significant were at the $165 \mathrm{kPa}$ intake pressure for the three speeds tested, which represent the conditions with the highest overall engine output. The TBC coated piston was seen to produce $1.8 \%$ less power and had $2.5 \%$ greater fuel consumption than the smooth piston on average. It was believed that these slight decreases in engine performance could be attributed to the increased surface roughness of the metal coating compared to the smooth copper coating. Due to the inherent porosity of the coating, the metal TBC could only be polished to $R_{a}=4.3 \mu \mathrm{m}$ in comparison to an average roughness $R_{a}=0.5 \mu \mathrm{m}$ for the Mirror 
finished copper coating. A visual comparison of the coatings at the Mirror conditions can be seen in Figure 7.5 below.

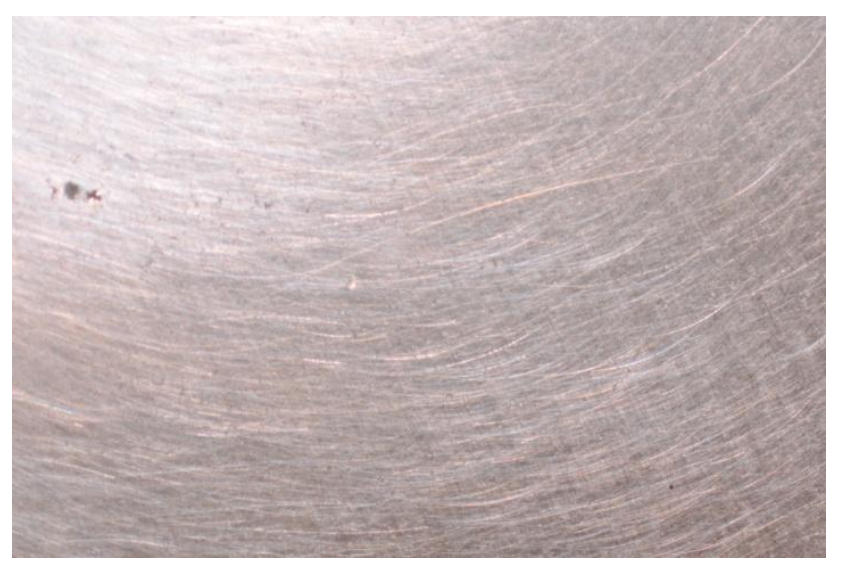

a)

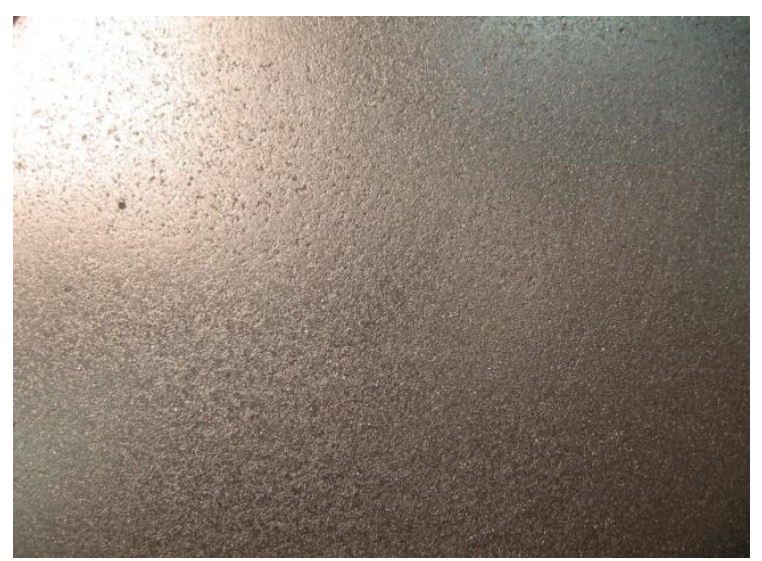

b)

Figure 7.5 - Comparison of a) Copper and b) TBC Mirror Finishes (different scales)

In addition to porosity, changes in TBC coating thickness at different surface finishes as a result of polishing was also believed to impact the effectiveness of the TBC at the smoother surface finishes. The effects of coating thickness are discussed in the following.

\section{$\underline{\text { Thickness Effects }}$}

Since each coating was only applied once, creating all surface finishes subsequent to the As-Sprayed conditions resulted in reductions in coating thickness. For the baseline copper tests, these changes were deemed insignificant since the copper coating was only used to simulate a rough surface. The copper was not expected to have any impact on heat transfer through the piston crown due to it having a greater thermal conductivity than the aluminum base material $\left(k_{C u}=400 \mathrm{~W} / \mathrm{mK}\right.$ vs. $\left.k_{A l}=147 \mathrm{~W} / \mathrm{mK}\right)$. However, for the insulating metal TBC, reductions in coating thickness resulted in a decreased thermal resistance and thus a reduction in its ability to impede heat transfer. Depending on the degree to which the coating thickness was decreased, their effects could be made evident in overall engine performance. 


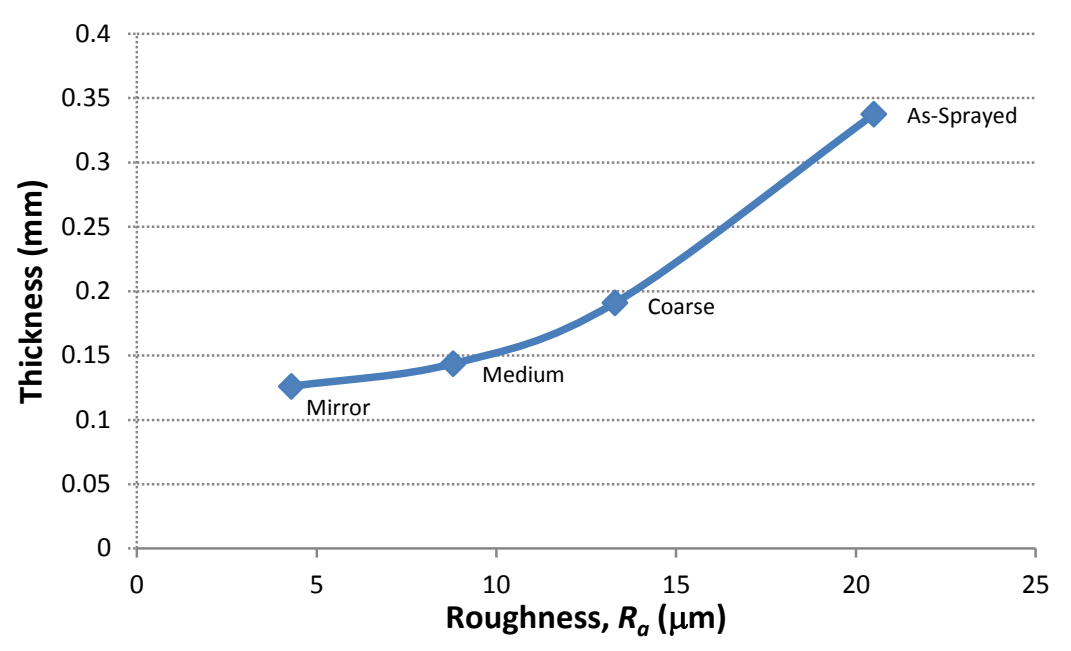

Figure 7.6 - Metal TBC Roughness vs. Thickness

Figure 7.6 shows the TBC coating thickness as a function of surface roughness. It can be seen that in polishing the coating between the As-Sprayed and Mirror roughness conditions, $210 \mu \mathrm{m}$ of the initial $340 \mu \mathrm{m}$ coating was removed. Due to the inversely proportional relationship between coating thickness and heat flux according to Fourier's Law, the reduction in TBC thickness would theoretically result in a $67 \%$ increase in heat flux between the coating conditions. However, initial polishing was seen to primarily eliminate coating peaks rather than the bulk coating material. Evidence of this can be seen in the images in Appendix A which show the coatings at the various finishes. These figures show that the bulk coating material began to be removed at the Medium condition. Thus, reapplying Fourier's law, the increase in heat flux due to polishing from Medium to Mirror was predicted to be about $32 \%$, a much less significant increase.

Thus, while nominally $210 \mu \mathrm{m}$ of material was removed during testing, it was hypothesized that changes in engine performance as a result of loss of thermal insulation of the coating would be minimal for the roughest two finishes tested. Any changes in engine performance between these finishes were attributed to reduction in heat transfer resulting 
from roughness effects rather than changes in coating thickness, as evidenced by the results seen using the rough copper coating. However, at the Medium and Mirror finishes, changes in the insulation properties of the coating could be expected.

In studying Figure 7.3 and Figure 7.4 , it is believed that the reduction in engine performance at the final two roughness conditions tested for the metal TBC were in part due to the reduction in thermal resistance given by the thinner thermal barrier coating. This hypothesis is further supported by the fact that the performance drops were most evident at the highest load conditions, which is where energy transfer across the thin coating would be the highest. Therefore, it is believed that having maintained a consistently thick TBC, larger improvements to engine performance relative to an uncoated piston would have been achieved. Further analysis of the coating thickness effects are required to quantify their contribution to overall engine performance.

\subsubsection{Engine Performance Summary}

A clear improvement in both power and BSFC was achieved through polishing of the coatings. The improvement between surface finishes for both the copper and TBC coatings was attributed to the large reduction in surface area available for heat transfer created by removing the peaks of the rough surfaces. Lower $R e_{k}$ values as a result of polishing were also believed to reduce the convective heat flux to the piston surface by reducing the level of interaction between the hot combustion chamber gases and the piston surface. As discussed in Section 2.3, large surface asperities in a flow path are seen to reduce the thickness of the thermal boundary layer on a flat plate, thus allowing for greater fluid-surface interaction and increased heat transfer. By removing the rough peaks of the As-Sprayed surfaces, it was 
believed that the dissipation of the boundary layer was reduced, with a corresponding decrease in heat flux.

The largest improvements between different surface finishes were seen to occur at the naturally aspirated engine conditions, while the percent improvements remained relatively constant at each of the three boost conditions. Engine speed was seen to have a minimal effect of both power and BSFC when comparing between surface finishes. The fact that varying speed and boost levels did not produce significant changes in percent improvement between surface finishes leads one to conclude that the increases in-cylinder velocities over the rough surfaces were not large enough to change the flow regime within the cylinder. Thus, this did not lead to any significant changes in the rate of heat transfer.

Finally, the TBC coating was seen to have minimal effects on engine performance. While comparison of the TBC and copper coated test results at equal $R_{a}$ values demonstrated small improvements provided by the TBC, the surface roughness and thickness effects were seen to have a large impact on coating performance.

\subsection{Emission Analysis}

Exhaust emission measurements from the CFR engine were used to gather further insight on the effects the TBC coating and roughness effects had on overall engine performance. Changes in carbon monoxide $(\mathrm{CO})$, oxides of nitrogen $\left(\mathrm{NO}_{\mathrm{x}}\right)$ and total unburned hydrocarbons (THC), the three primary regulated emissions of concern in spark ignition engines, are presented in terms of both power specific emissions and absolute concentrations. The discussion of emissions measurements will be preceded by a brief review of engine operating parameters that affect exhaust emissions. 


\subsubsection{Review of Engine Exhaust Emissions}

The production of exhaust emissions is governed by chemical reactions between the species in the fuel-air mixture entering the combustion chamber. The rate of formation of these emissions is therefore strongly dependant on reactant concentrations and temperature. An engine characteristic which has a large impact on both these factors is engine air-fuel ratio (AFR), which is a measure of the mass of fuel per unit mass of air entering the engine. A ratio of the measured and stoichiometric air-fuel ratios, referred to as the equivalence ratio $(\phi)$, is typically used to facilitate comparisons between different fuels. Figure 7.7a shows the effect of equivalence ratio on the primary products of combustion of a hydrocarbon fuel in a spark ignition engine. Figure 7.5b illustrates the strong dependence of $\mathrm{CO}, \mathrm{THC}$ and $\mathrm{NO}_{\mathrm{x}}$ on equivalence ratio. Virtually all current passenger cars equipped with spark ignition engines are operated with a stoichiometric $(\phi=1)$ air-fuel mixture to facilitate use of a three-way catalytic converter that simultaneously reduces $\mathrm{CO}, \mathrm{THC}$ and $\mathrm{NO}_{\mathrm{x}}$ emissions. For this reason, all of the current tests were carried out with a nominally stoichiometric mixture. Figure $7.7 \mathrm{~b}$ shows that the three emissions are quite sensitive to equivalence ratio at the stoichiometric point $(\phi=1)$. This highlights the importance of maintaining a constant equivalence ratio during the tests.

The CFR engine was fitted with a carburetion system to facilitate better fuel-air mixing than can be achieved with a port fuel injector. Due to the lack of a closed loop control system, the engine required manual feedback from the operator using a multi-turn trimming valve in the fuel supply line to ensure a stoichiometric air-fuel mixture. Figure 7.8 shows the average equivalence ratio at each of the 12 load conditions the engine was tested at over a 
total of 35 test runs. The $\phi$ values were calculated using the measured emissions data and equations 4.68 in Heywood [2].

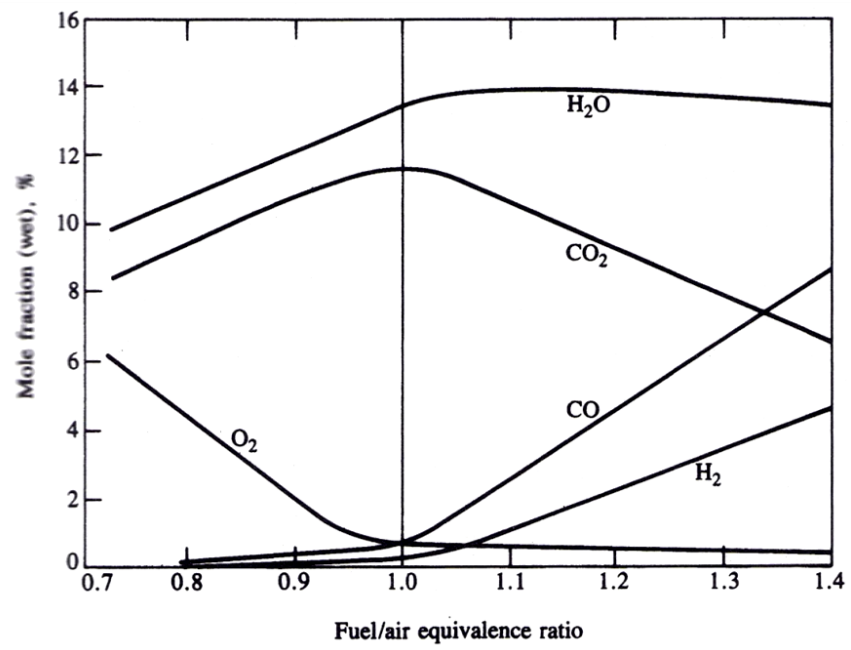

a) Primary Combustion Products

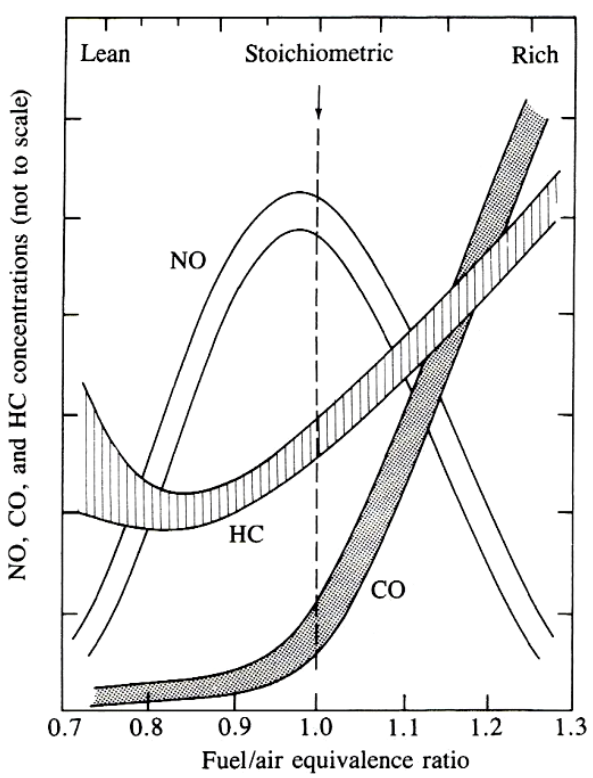

b) Regulated Emissions

Figure 7.7 - Emissions in a Gasoline Fueled SI Engine as a Function of $\phi[2]$

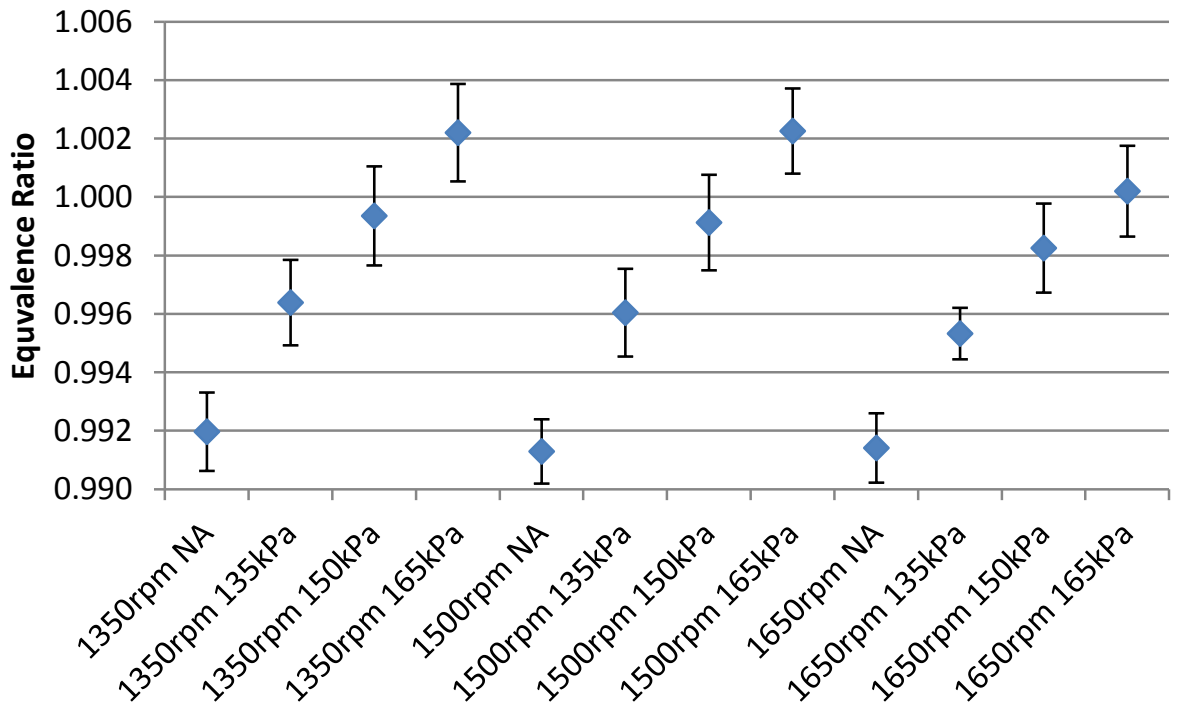

Figure 7.8 - Equivalence Ratio at Engine Test Points

Figure 7.8 clearly shows that the engine ran in very close proximity to stoichiometric

$(\phi=1)$ across all load points. Note that the y-axis has a much expanded scale; the 
equivalence ratio was maintained within a very tight tolerance of $+/-0.6 \%$. Though conditions were very repeatable at each individual load and speed setpoint, Figure 7.8 shows the engine tended to settle at a slightly richer air-fuel ratio at increased load. Due to the aforementioned sensitivity of emissions to equivalence ratio near stoichiometric conditions, these trends in $\phi$ were seen to have an effect on some of the emissions data and will be identified in the discussion of the surface finish on overall emissions.

\subsubsection{Carbon Monoxide (CO)}

Carbon monoxide in spark ignition engines is primarily created as a by-product of incomplete combustion at rich engine conditions. Figure 7.9a-c below, which plots $\mathrm{CO}$ concentration versus surface roughness, demonstrates very little effect of coating material or surface roughness on $\mathrm{CO}$ emissions, as expected. Changes in $\mathrm{CO}$ at a given load condition as a result of surface condition and material were not found to be statistically significant. The dominant effect seen in these figures is the relationship between load and CO. It can be seen that at increasing load, small increases in $\mathrm{CO}$ concentrations were evident as a result of the engine running slightly richer at the higher load conditions, as discussed in Section 7.3.1. Engine speed was seen to have no effect on $\mathrm{CO}$ emissions. 

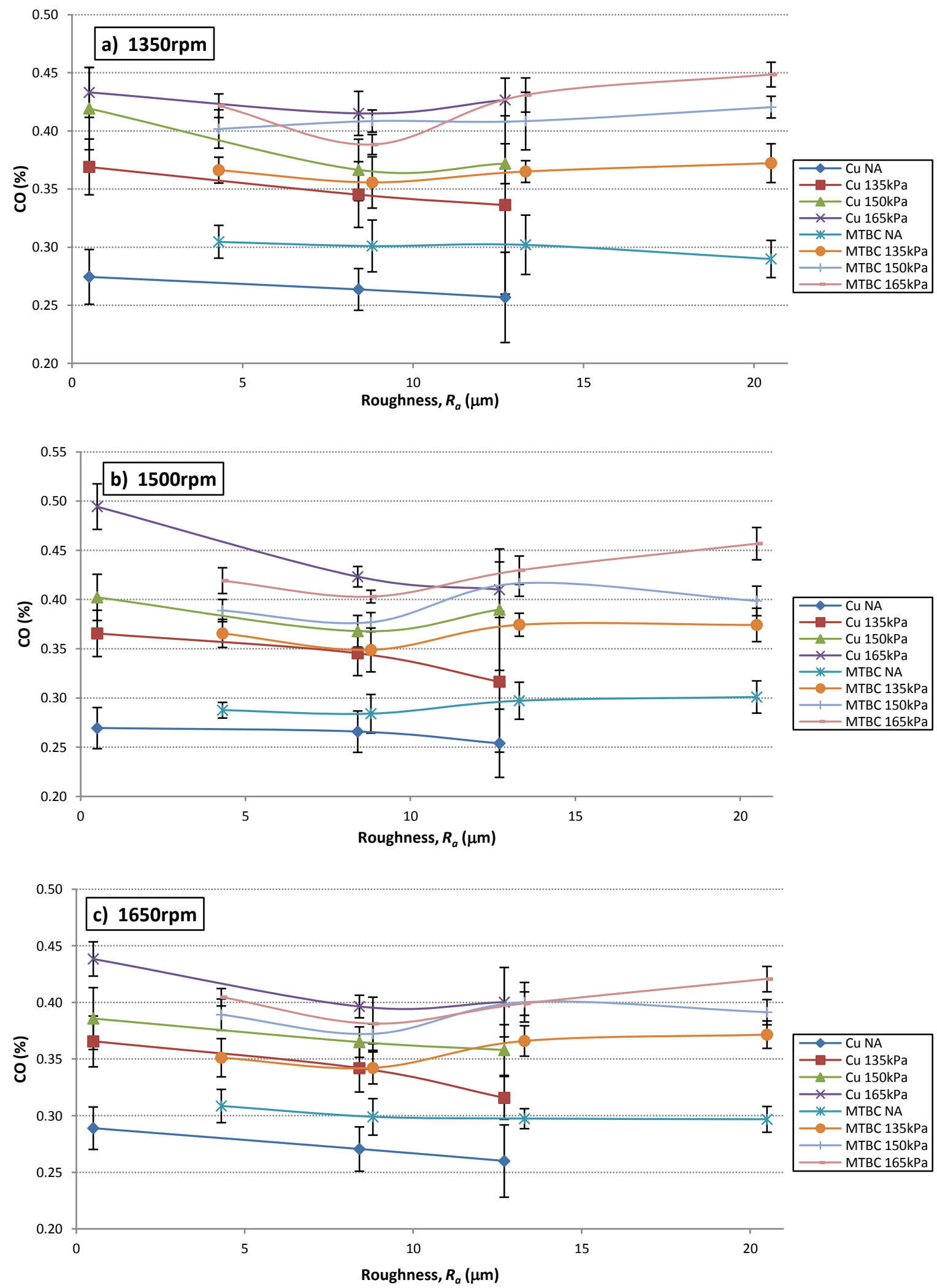

Figure 7.9 - Carbon Monoxide Emissions vs. Measured Surface Roughness at a) 1350rpm b) 1500rpm and c) 1650rpm 


\subsubsection{Total Hydrocarbons (THC)}

The primary cause of hydrocarbon emissions in a natural gas fueled SI engine form is a portion of the fuel-air mixture "escaping" the main combustion process. During the compression stroke, the high pressure premixed gases are pushed into crevices in the combustion chamber such as the piston ring end gaps, the ring lands, spark plug threads, etc. However, this mixture is not oxidized due to quenching of the flame front at the entrance of the crevices. The fuel-air mixture is released back into the combustion chamber during the exhaust stroke as the cylinder pressure falls. The level of oxidation of the returning crevice flow as it is released back into the exhaust gases plays an important role in the level of engine-out emissions. Irregular combustion can also play a role in THC emissions.

Figure 7.10a-c below shows the effects of THC emissions as a function of surface finish for the TBC and copper coated pistons. The graphs are plotted as brake specific hydrocarbon emissions, which is the mass of emissions per unit of brake power output $(\mathrm{g} / \mathrm{kWh})$. At each of the three speeds tested, it is seen that the general tendency of the THC emissions was to decrease with increasing load. Though the engine ran very slightly richer at the higher boost settings, the reduction in THC concentration was believed to be due to the temperature effects on in-cylinder oxidation. With elevated in-cylinder temperatures at higher load settings, the crevice flows primarily responsible for THC emissions were more readily oxidized. The higher THC levels at naturally aspirated conditions were also attributed to slightly higher levels of combustion instability at the lower load conditions. Details of this will be addressed further in Section 7.4.1. 

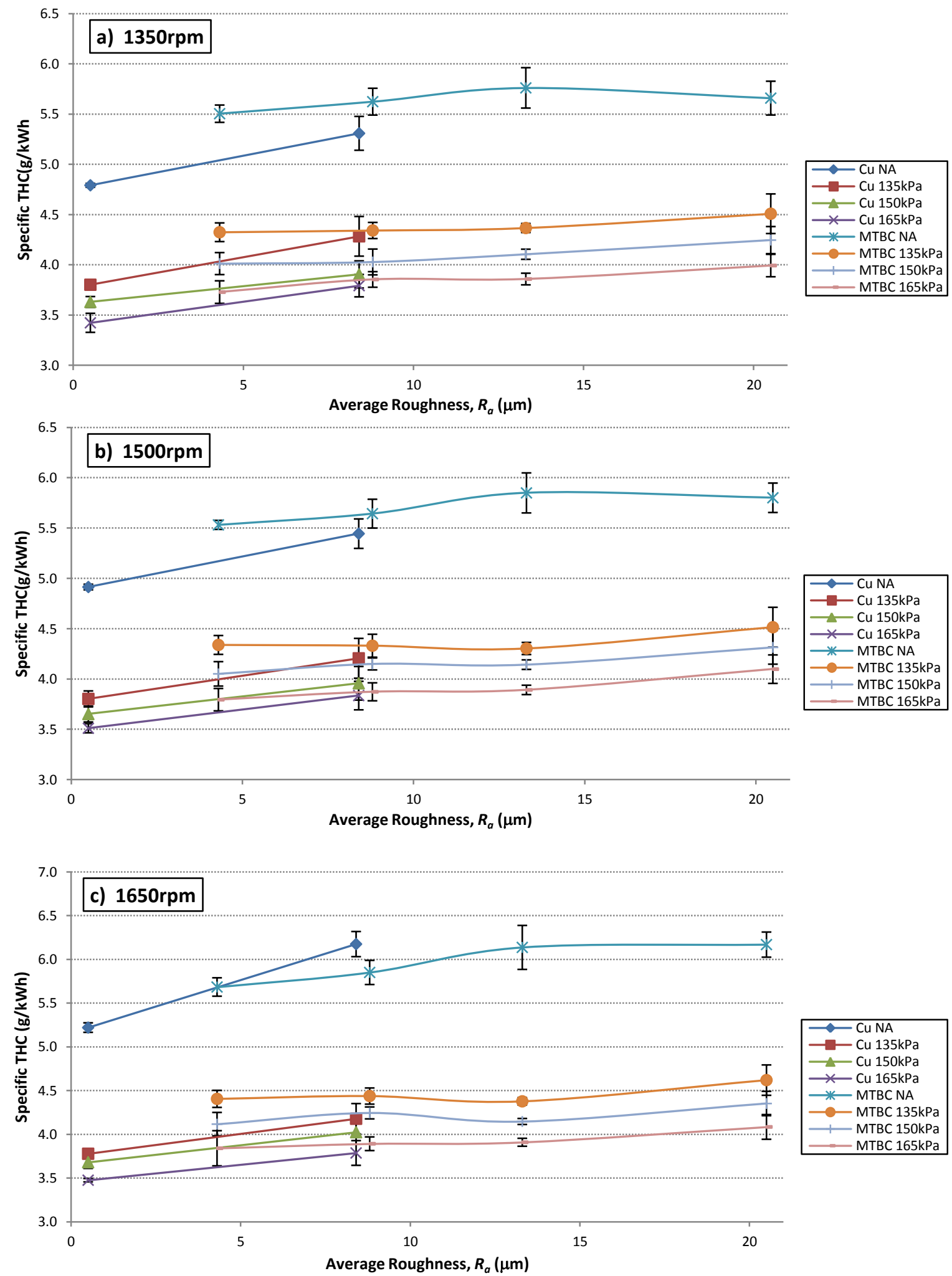

Figure 7.10 - Total Hydrocarbon Emissions vs. Measured Surface Roughness at a) 1350rpm b) 1500rpm and c) 1650rpm 


\section{$\underline{\text { Surface Roughness Effects }}$}

In studying the baseline copper coatings, it is clear that there was an effect of surface finish on THC emissions. By polishing between the Medium and Mirror finishes, an average decrease in THC emissions of almost 10\% (110ppm) across all load and speed conditions was measured. The level of improvement between finishes did not vary significantly with either speed or load. Note that the THC measurements were not available at the copper AsSprayed conditions due to malfunctions of the hydrocarbon analyzer during this test run.

The effects of polishing the metal TBC were less evident on hydrocarbon emissions levels. Changes in THC output were seen to be statistically significant at 8 of the 12 tested conditions, with average decreases of approximately $6 \%$ at these conditions. The most evident changes occurred after the initial polishing step from $R_{a}=20.5 \mu \mathrm{m}$ to $R_{a}=13.3 \mu \mathrm{m}$. Less noticeable reductions in THC emissions for the polished TBC was attributed to coating porosity, as the pores within the coating were believed to behave as crevices. Due to the inherent porosity of the coating even at the polished conditions, the benefits of the reduced surface roughness were not visible. Reductions in coating thickness was also believed to play a role in the relative ineffectiveness of the coating at reducing THC emissions, as a larger degree of insulation would have resulted in higher in-cylinder temperatures and increased oxidation rates. However, this was believed to be secondary to porosity effects.

\section{$\underline{\text { TBC Effectiveness on Hydrocarbon Emissions }}$}

In comparing the relative THC levels between the baseline copper and TBC coatings, it can be seen that the TBC coating tended to produce higher THC levels. Relative to the Mirror copper coating, THC emissions for the As-Sprayed TBC condition were $18 \%$ higher, on average. This was again attributed to the significant porosity of the coating which was 
believed to adsorb and release the unburned fuel-air mixture much more readily than the dense copper film. Surface roughness and the associated heat transfer effects were believed to be secondary due to the large difference in coating densities. Polishing the TBC to the Mirror condition was seen to reduce this difference; however the THC emissions for the TBC remained on average $11.8 \%$ higher than those seen in the polished copper coating.

\subsubsection{Oxides of Nitrogen $\left(\mathrm{NO}_{x}\right)$}

Nitric oxide (NO) and nitrogen dioxide $\left(\mathrm{NO}_{2}\right)$ are products of the high temperature combustion process in SI engines, as discussed in Section 7.3.1. In SI engines, maximum concentrations are reached slightly lean of stoichiometric conditions (see Figure 7.7b) due to the availability of excess oxygen and the high combustion temperatures achieved at stoichiometric conditions. In the following, the effects surface roughness, TBC material properties and equivalence ratio had on $\mathrm{NO}_{\mathrm{x}}$ concentrations will be discussed.

\section{$\underline{\text { Surface Roughness Effects }}$}

Due to the noted sensitivity of $\mathrm{NO}_{\mathrm{x}}$ formation on equivalence ratio near stoichiometric conditions (see Figure 7.7), $\mathrm{NO}_{\mathrm{x}}$ concentrations were plotted versus surface roughness and $\phi$ for the three tested speeds, as seen in Figure 7.11. It should be noted that the load conditions are represented by the lines showing a progressive increase in $\phi$, as shown in the first plot in Figure 7.11.

The dependence of $\mathrm{NO}_{\mathrm{x}}$ formation on both equivalence ratio and surface roughness are clear in these surface plots. As expected, $\mathrm{NO}_{\mathrm{x}}$ emissions were seen to increase by approximately $15 \%$ between the naturally aspirated and boosted conditions due to the large increase in load. However, these figures indicate that the maximum $\mathrm{NO}_{\mathrm{x}}$ concentrations occurred at the $135 \mathrm{kPa}$ load condition rather than at peak load. Due to the shift in $\phi$ to a 
richer air-fuel mixture and the resulting decrease in available $\mathrm{O}_{2}, \mathrm{NO}_{\mathrm{x}}$ concentrations decreased despite the increased in-cylinder temperatures.
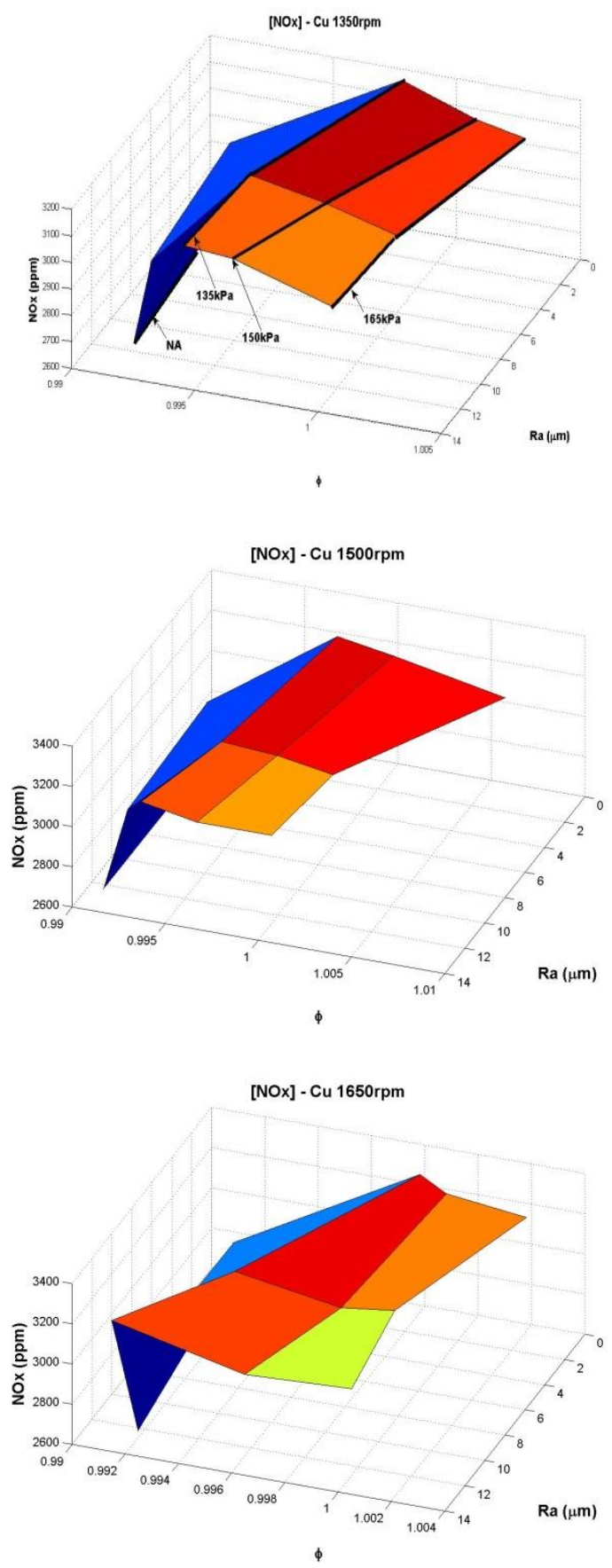
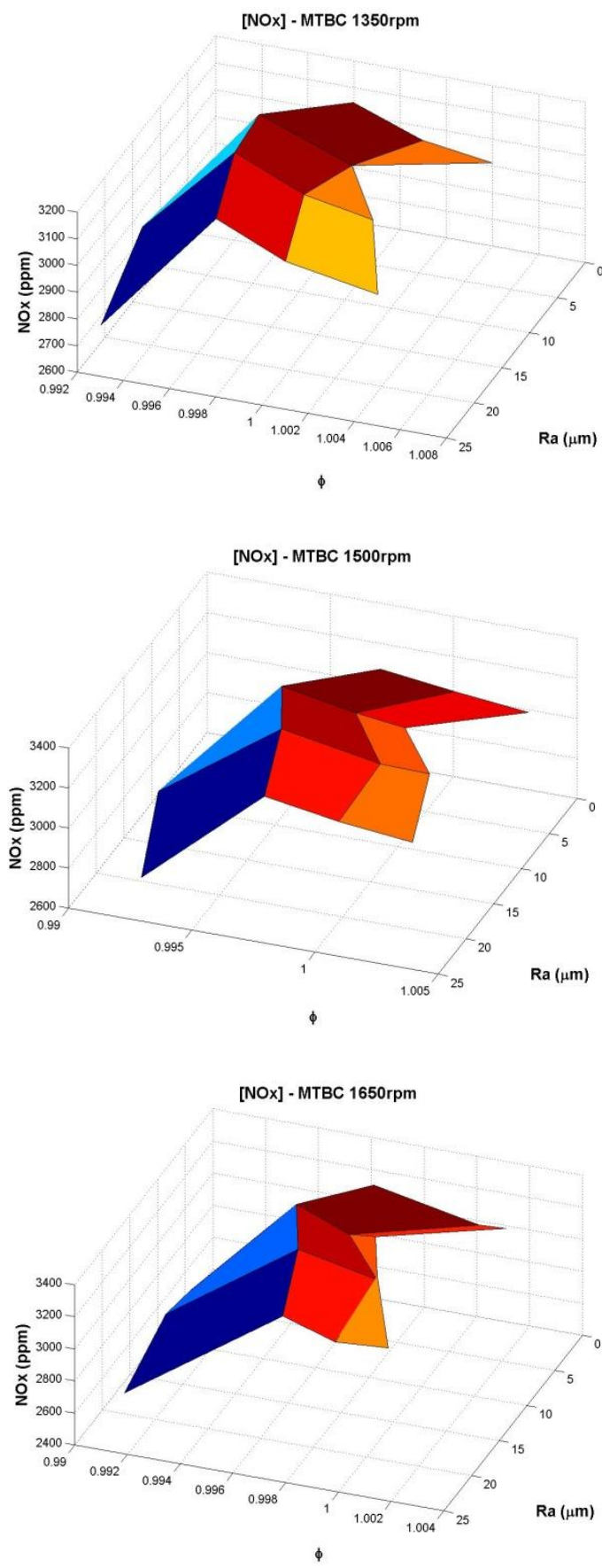

Figure 7.11 - $\mathrm{NO}_{\mathrm{x}}$ Concentration vs. $\phi$ and Roughness 
Figure 7.11 also shows that smoother surface finishes resulted in slight increases in $\mathrm{NO}_{\mathrm{x}}$ for both the baseline copper and metal TBC conditions. At equivalent $\phi$ values, increases in $\mathrm{NO}_{\mathrm{x}}$ concentration at the smoother finishes were indicated by the lightening of the color scale on the graphs. This trend was seen more clearly by plotting $\mathrm{NO}_{\mathrm{x}}$ concentrations (rather than brake specific $\mathrm{NO}_{\mathrm{x}}$ emissions) versus roughness, as shown in Figure 7.12. Note that at a given load, the equivalence ratio is relatively constant (Figure 7.8). Any changes in $\mathrm{NO}_{\mathrm{x}}$ concentrations were therefore attributed to surface roughness at a given load setting. For the copper-coated piston, increases in $\mathrm{NO}_{\mathrm{x}}$ emissions between the AsSprayed and Mirror conditions were on the order of $150 \mathrm{ppm}$ or approximately $5 \%$. These effects were seen to be most prominent at the higher engine speeds. However, the differences were not statistically significant at the majority of the test points. Due to the large sensitivity of $\mathrm{NO}_{\mathrm{x}}$ concentration on $\phi$ and the relative inability to maintain a perfectly constant equivalence ratio, the small variations in $\mathrm{NO}_{\mathrm{x}}$ concentration as a result of polishing were not statistically significant. However, the trend of increased $\mathrm{NO}_{\mathrm{x}}$ at the smoother finishes is in agreement with the conclusion that polishing reduced heat transfer from the in-cylinder gases, and it is believed that with greater control of $\phi$, this would have been more evident.

A similar increasing trend in $\mathrm{NO}_{\mathrm{x}}$ concentration was seen when polishing the metal TBC. Between the As-Sprayed and Mirror finishes, $\mathrm{NO}_{\mathrm{x}}$ concentrations were seen to increase by an average of $3 \%$, a difference that was found to be significant to a $95 \%$ confidence level for 10 of the 12 engine setpoints tested. The largest differences were once again seen at the naturally aspirated conditions. These increases were attributed to the reduction in heat transfer to the piston crown as a result of the smoother coating. 

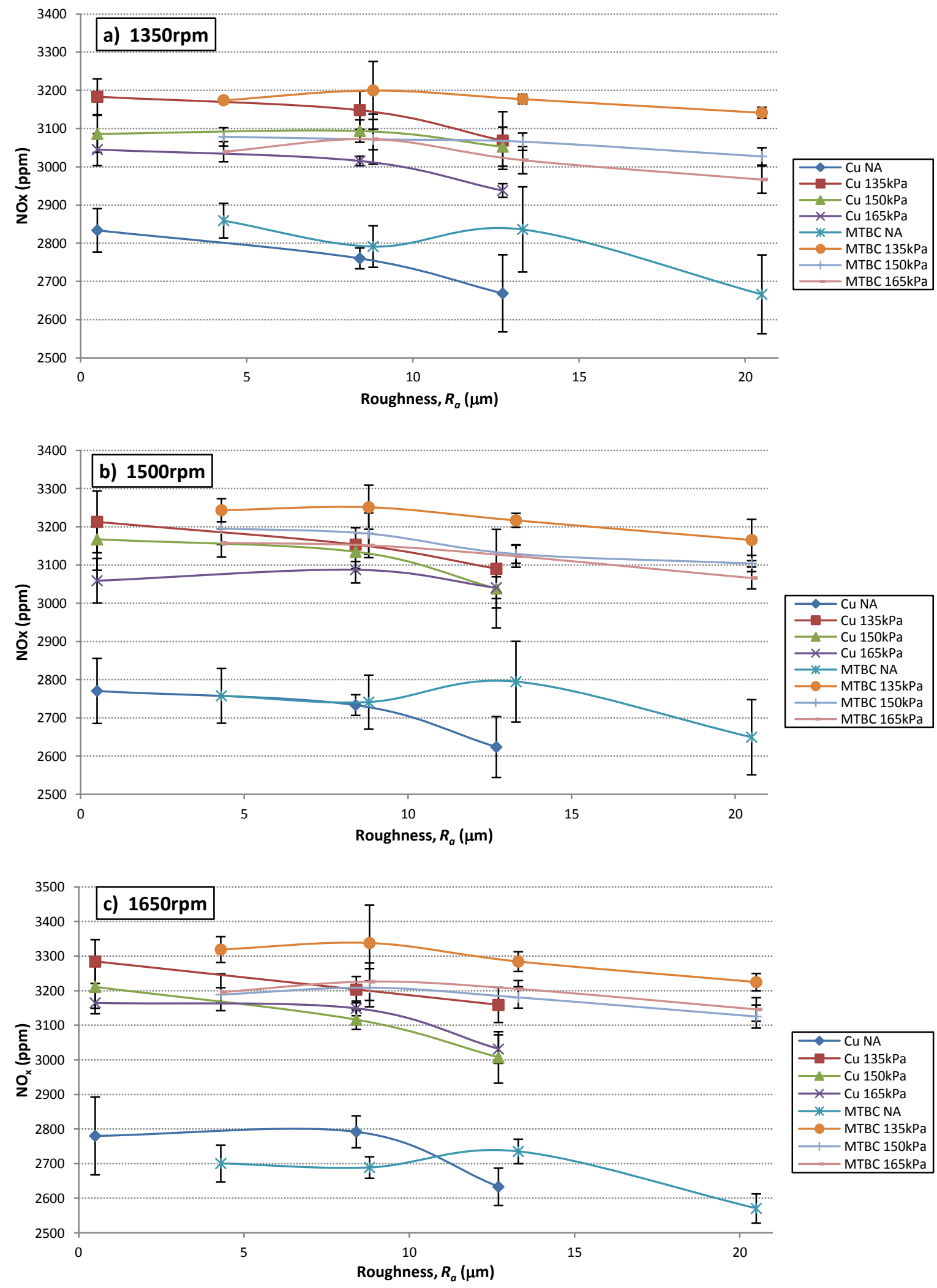

Figure 7.12 - $\mathrm{NO}_{\mathrm{x}}$ Emissions vs. Surface Roughness at a) 1350rpm b) 1500rpm and c) 1650rpm 


\section{$\underline{\text { TBC Effectiveness on } \mathrm{NO}_{\underline{x}} \text { Emissions }}$}

The metal TBC was not seen to have a significant effect on overall $\mathrm{NO}_{\mathrm{x}}$ concentrations with respect to the polished copper coating. While the insulating properties of the TBC were expected to result in significantly higher in-cylinder temperatures which would adversely affect $\mathrm{NO}_{\mathrm{x}}$ emissions, this was not seen throughout the test matrix. At equivalent surface finishes, the metal TBC were seen to have minimal impact on $\mathrm{NO}_{\mathrm{x}}$ emissions relative to the baseline copper coating, but conclusions were not consistently significant to a $95 \%$ confidence level across all test conditions.

The true effects of the TBC coating with respect to the baseline copper coating were determined to be inconclusive as a result of the sensitivity of $\mathrm{NO}_{\mathrm{x}}$ emissions to variations equivalence ratio. Variations in $\phi$ between load conditions and the relatively small magnitude of changes between the coated and uncoated piston made it difficult to make definitive conclusions regarding the effects of $\mathrm{TBC}$ on $\mathrm{NO}_{\mathrm{x}}$ emissions. As discussed in Section 7.2.1, reductions in $\mathrm{TBC}$ thickness as a result of polishing may have also played a role in the relative $\mathrm{NO}_{\mathrm{x}}$ concentrations between the TBC insulated and copper coated piston.

\subsubsection{Emissions Summary}

The effects of surface roughness and the introduction of a thermal barrier coating on engine emissions were discussed. The baseline copper tests demonstrated that polishing had measurable effects on both $\mathrm{NO}_{\mathrm{x}}$ and THC concentrations. As a result of the associated increases in in-cylinder temperatures, polishing the piston crown caused increases in $\mathrm{NO}_{\mathrm{x}}$ concentration, while the in-cylinder conditions also became more conducive to the oxidation of crevice flows which had escaped the primary combustion process. 
The effects of the metal TBC on emission formation was somewhat inconclusive due to variations in equivalence ratio at different test conditions. However, it was seen that TBC porosity played an important role in increasing THC emissions, and the increases in incylinder temperature attributed to the TBC did not produce significant changes in $\mathrm{NO}_{\mathrm{x}}$ concentrations. CO emissions were seen to be solely dependent on $\phi$.

\section{$\underline{7.4 \text { In-Cylinder Conditions }}$}

In-cylinder measurements were used to obtain further insight on the effect of surface finish and coating material on the combustion process and overall engine performance. As described in detail in Section 3.2.1, a Kistler 6125b piezoelectric pressure transducer flushmounted in the engine combustion chamber was used to collect 2500 cycles of cylinder pressure data at each test point. A comparison of the indicated mean effective pressure (IMEP), peak pressure $\left(\mathrm{P}_{\max }\right)$, and angle of peak pressure $\left(\theta_{\mathrm{Pmax}}\right)$ at each coating condition was used as a means of explaining the performance and emissions measurements discussed in the previous sections. Coefficient of variability will also be discussed to help quantify any detrimental effects the TBC may have had on combustion stability.

\subsubsection{IMEP and COV}

The indicated mean effective pressure is used as a size-independent measure of engine performance, and thus provides a means of comparing the effects of the different piston surface treatments. Figure 7.13 below shows the average IMEP at each of the engine test points as a function of surface roughness. As expected, similar trends to the power figures shown in Figure 7.3 were seen, and thus will not be repeated. 

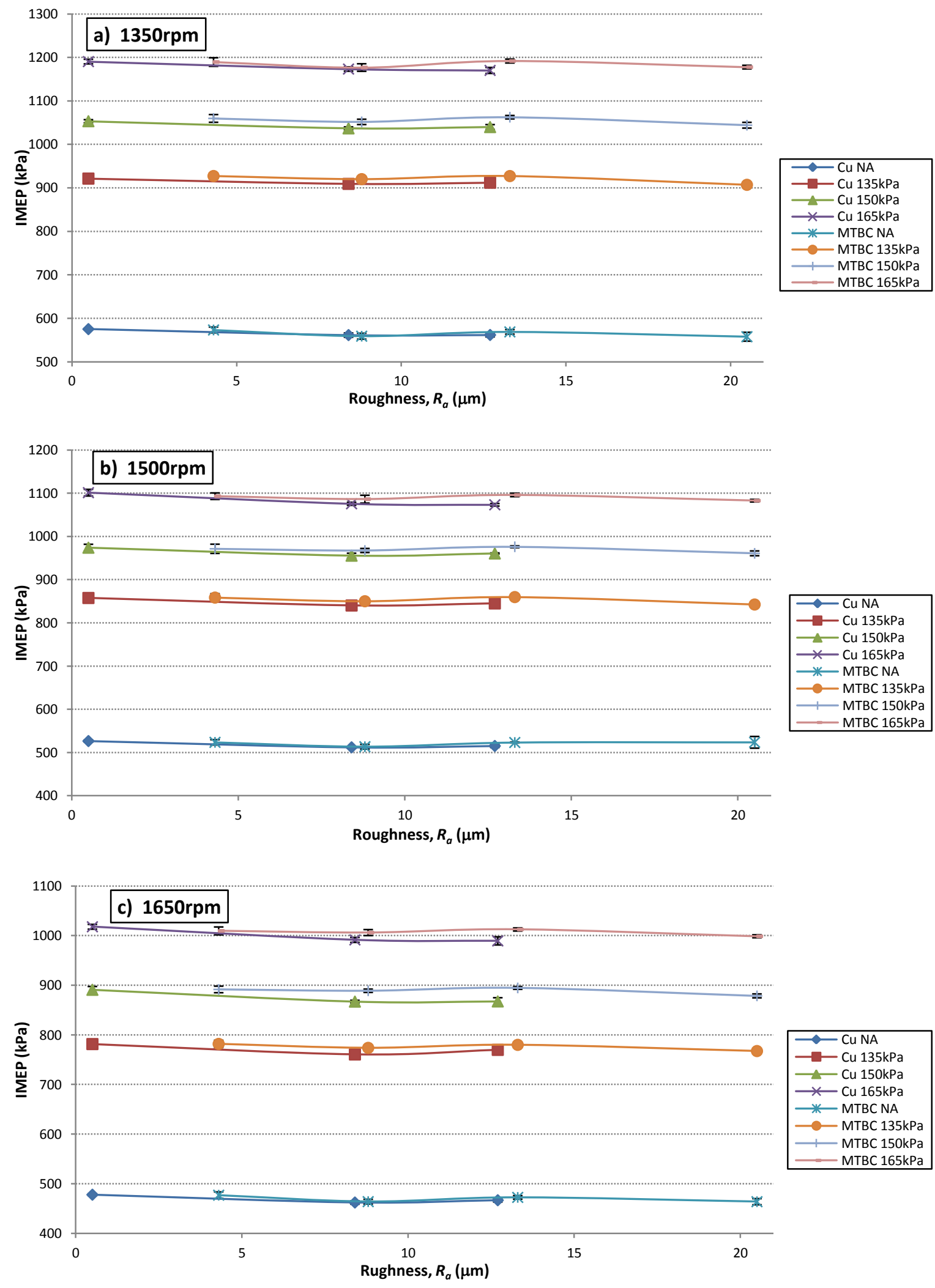

Figure 7.13 - IMEP vs. Surface Roughness at a) 1350rpm b) 1500rpm and c) 1650rpm 
The coefficient of variability (COV) in IMEP, which is defined as the quotient of standard deviation of IMEP and the mean IMEP, is used as a measure of engine stability and combustion quality. It is therefore a good indicator of the effects the different surface conditions had on the combustion process.

As seen in Figure 7.14, the average COV for the CFR engine was typically found to be below $1 \%$ at all of the engine setpoints in the test matrix. A typical limit for COV in SI engines is approximately 5\%, thus signifying excellent engine stability at all conditions.

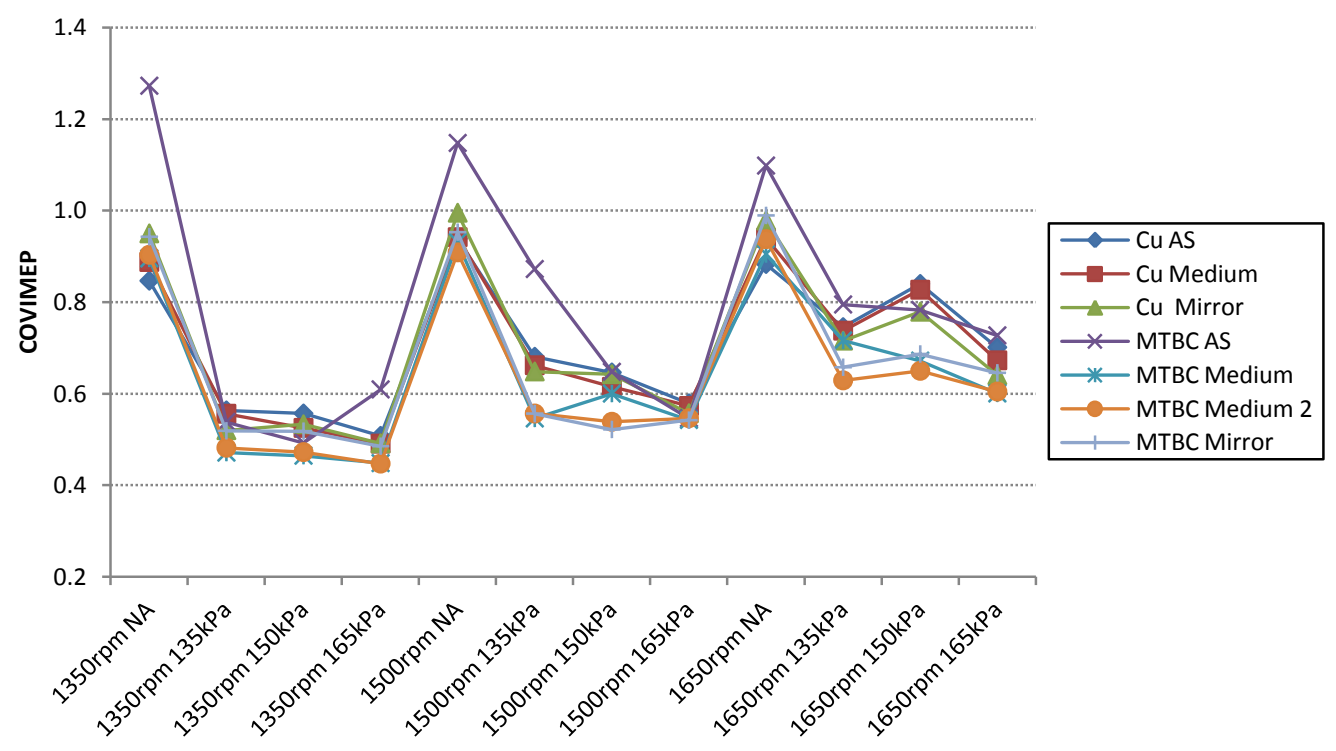

Figure 7.14 - IMEP Coefficient of Variability

The highest COV consistently occurred at the naturally aspirated conditions. As discussed in Section 7.3.3, this corresponds with increases in hydrocarbon emissions at these conditions. This decrease in engine stability was attributed to slower burn rates at the low incylinder temperatures and in-cylinder velocities. It is noted that neither surface finish nor the introduction of the metal TBC were seen to have statistically significant effects on combustion stability. Likewise, engine knock was not experienced at any of the conditions throughout the test matrix. 


\subsubsection{Peak Pressure and Angle of Occurrence}

Peak pressure and angle of occurrence within the cycle are critical to overall engine performance and to the formation of exhaust emissions. They are also important indicators used in the characterization of the combustion process, and thus were useful in helping to identify the effects of the coating material and surface finish within the combustion chamber.

\section{$\underline{\text { Surface Roughness Effects }}$}

As with engine performance and emissions, surface roughness was also seen to have an effect on the peak in-cylinder pressures at each of the test points. As seen in Figure 7.15, polishing both the copper coating and the metal TBC was seen to increase the average peak pressures experienced in the cylinder and also advanced the angle, $\theta_{\mathrm{Pmax}}$ at which it occurred. For the copper coating, peak pressure was seen to increase between 5\% and $8 \%$ at the boosted conditions between the As-Sprayed and Mirror finishes, which corresponded to between $200 \mathrm{kPa}$ and $400 \mathrm{kPa}$. Correspondingly, an advance in $\theta_{\mathrm{Pmax}}$ of up to 1.75 degrees at the low speed, high load conditions was also seen.

Figure 7.17 below shows the relationship between the percent increase in peak pressure and the change in $\theta_{\mathrm{P} \max }$ between the As-Sprayed and Mirror copper finishes at each test point. Note that the differences that were not found to be statistically significant to a $95 \%$ confidence level are filled white. Note that combustion phasing and peak pressure were seen to advance and increase respectively with increasing IMEP (in-cylinder temperatures), as expected. 

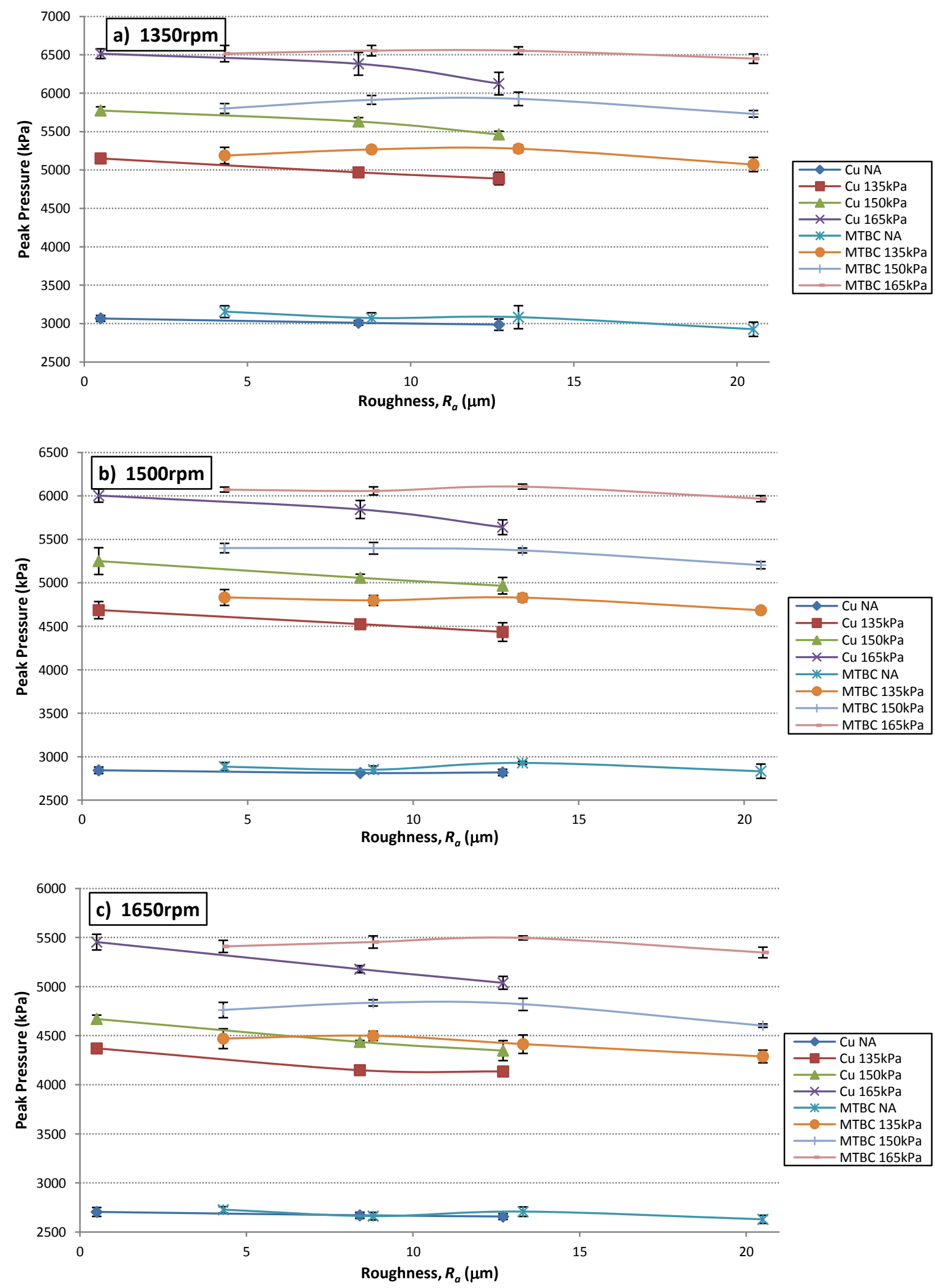

Figure 7.15 - Average Peak In-Cylinder Pressure vs. Surface Roughness at a) 1350rpm b) 1500rpm and c) $1650 \mathrm{rpm}$ 

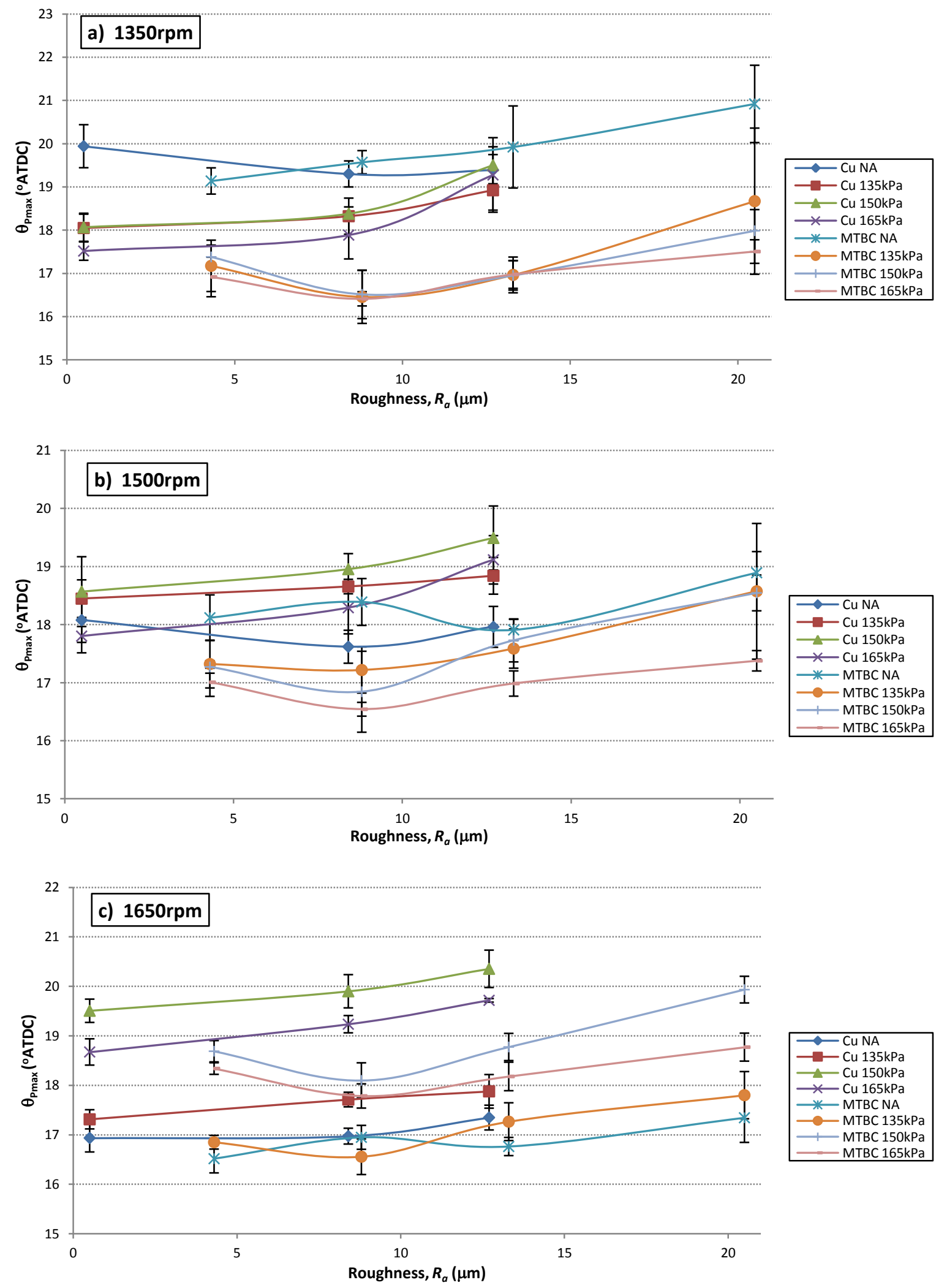

Figure 7.16 - Average Angle of Peak Pressure $\left(\theta_{\mathrm{Pmax}}\right)$ vs. Surface Roughness at a) 1350rpm b) 1500rpm and c) 1650rpm 


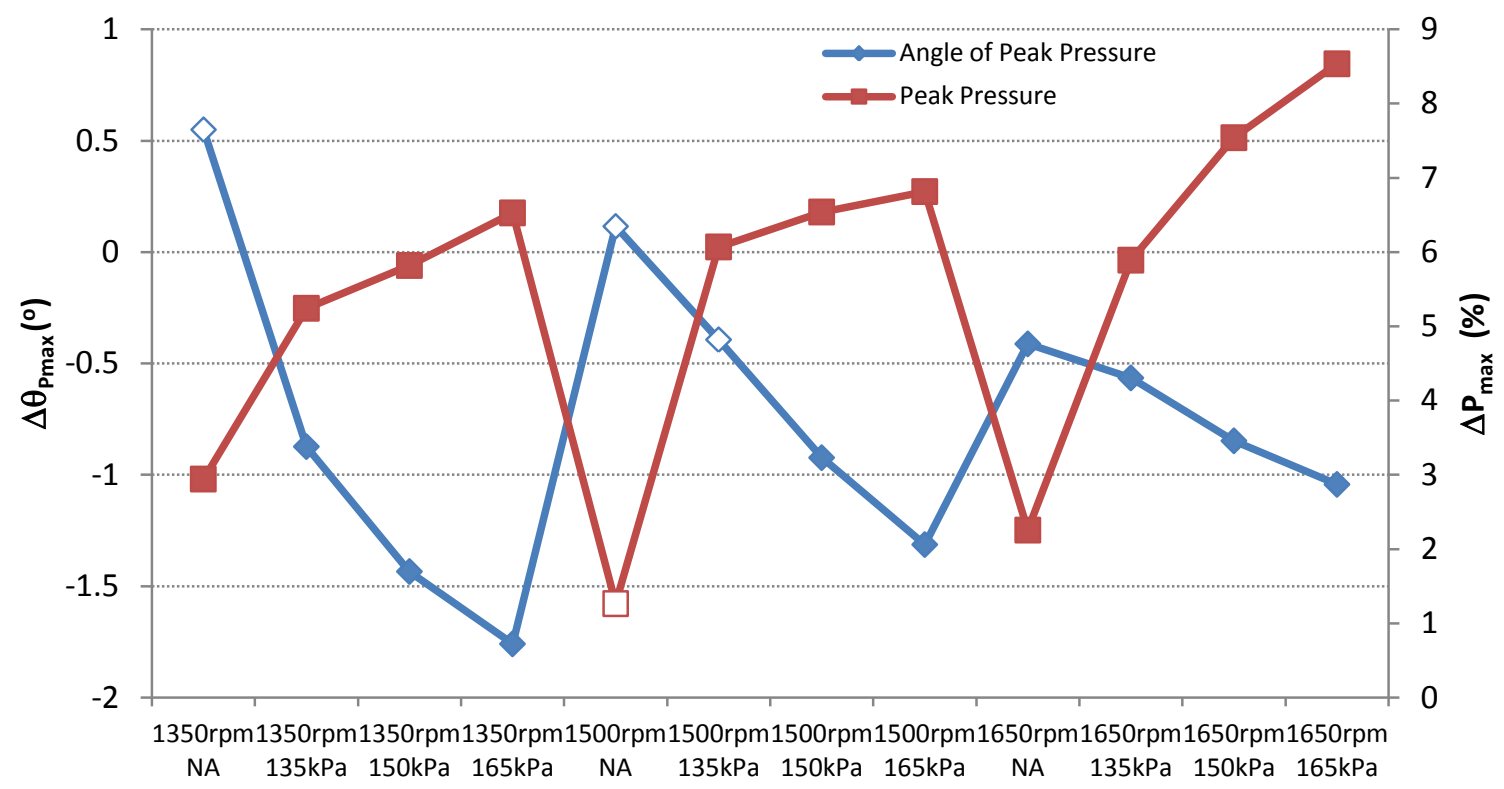

Figure 7.17- Changes in Peak Pressure and Angle of Occurrence

Tests conducted using the TBC coated piston led to similar conclusions regarding the effects of polishing on peak pressure and $\theta_{\mathrm{Pmax}}$. While not as pronounced as with the copper coating, polishing led to average increases in peak pressure of approximately $3 \%$ and advances in $\theta_{\mathrm{Pmax}}$ of approximately 1 degree on average. It was noted that the different levels of polishing were not seen to have a significant effect on the maximum peak pressures achieved. Unlike for the copper coated piston, load effects were minimal. Coating thickness effects were also made evident by the fact that the angle of peak pressure was seen to significantly retard between the Medium and Mirror polishing conditions. Paired with decreases in peak pressure, this is attributed to increases in heat flux through the coating and thus reductions in in-cylinder temperatures.

\section{Effectiveness of TBC Coating}

In comparing the $\mathrm{TBC}$ and copper coatings at equivalent roughness conditions (Figure 7.15 and Figure 7.16), the effects of the TBC on the combustion process become 
extremely evident. At $R_{a}=13 \mu \mathrm{m}$, the TBC coated piston resulted in increases in peak pressure of $8 \%$ on average, which translated to up to $400 \mathrm{kPa}$. Note that the effect of the coating at the naturally aspirated conditions was minimal. Similar results were seen at the $R_{a}$ $=8 \mu \mathrm{m}$ condition, though the benefits were slightly less pronounced with an average increase of peak pressure of $6 \%$, or $290 \mathrm{kPa}$. This reduction in effectiveness was once again attributed to the decrease in TBC thickness.

In comparing the performance of the $\mathrm{TBC}$ relative to the polished copper coating, it was noted that the As-Sprayed TBC coated piston had equivalent peak pressures to the Mirror finish at the 1350rpm and 1500rpm setpoints, while it had slightly lower $(\sim 100 \mathrm{kPa})$ peak pressures at the $1650 \mathrm{rpm}$ setpoint. This demonstrated that even with the very large differential in surface roughness, the coating was still capable of reducing the instantaneous heat transfer to the piston, which was consistent with the results seen by Marr et al. [111] using the same metal TBC. This was attributed to the insulating material properties of the coating. At the same roughness and load conditions, the metal TBC was also seen to reach maximum peak pressures on average 1 degree earlier than the copper TBC (Figure 7.16).

These results lead to the conclusion that greater in-cylinder gas temperatures were achieved due to reductions in heat transfer to the smooth piston. These higher temperatures translated to faster burning cycles (advanced $\theta_{\mathrm{Pmax}}$ ) due to increased reaction rates and thus flame speeds, and correspondingly higher in-cylinder pressures. Likewise, an increase in peak pressure under consistent engine conditions indicates a greater percentage of the fuel energy being converted to useful work, which is evidenced in decreases of BSFC at the smoother piston surfaces. 


\subsubsection{Exhaust Temperature}

Engine exhaust gas temperature provides a basic indicator of the levels of in-cylinder heat flux. At a constant engine setpoint, an increase in exhaust temperature as a result of changing in-cylinder surface treatment suggests a reduction of heat loss from the combustion gases to the in-cylinder surfaces. However, exhaust temperature is very sensitive to combustion stoichiometry, engine speed and spark timing, thus making it difficult to obtain a clear understanding of heat flux characteristics solely from this parameter.

Figure 7.18 below shows the engine exhaust temperatures as a function of surface finish at each of the engine setpoints. Exhaust temperatures significantly increased at higher engine speeds as a result of a reduction in time for heat transfer to occur between the gases and exhaust manifold. Higher loads were also seen to result in higher gas temperatures. However, the figures showed that there were no statistically significant differences in exhaust temperatures between different surface finishes at the majority of the tested conditions. These variations were attributed to changes in engine air-fuel ratio and ambient conditions.

Trends also showed that exhaust temperature were significantly lower for the metal TBC than the copper coating. On average, at equivalent surface roughness, the exhaust temperatures were between 5-10 degrees cooler for the TBC coated piston. While the TBC was expected to result in increased temperatures, plotting the exhaust temperatures versus the angle of peak pressure occurrence demonstrates a clear trend between the two quantities. Figure 7.19 below shows a reduction in exhaust temperature as combustion phasing advanced due to higher in-cylinder temperatures created by polishing and the use of the TBC. This figure therefore suggests that changes in exhaust temperature were primarily a result of changes in combustion phasing as opposed to changes in the heat transfer characteristics. 

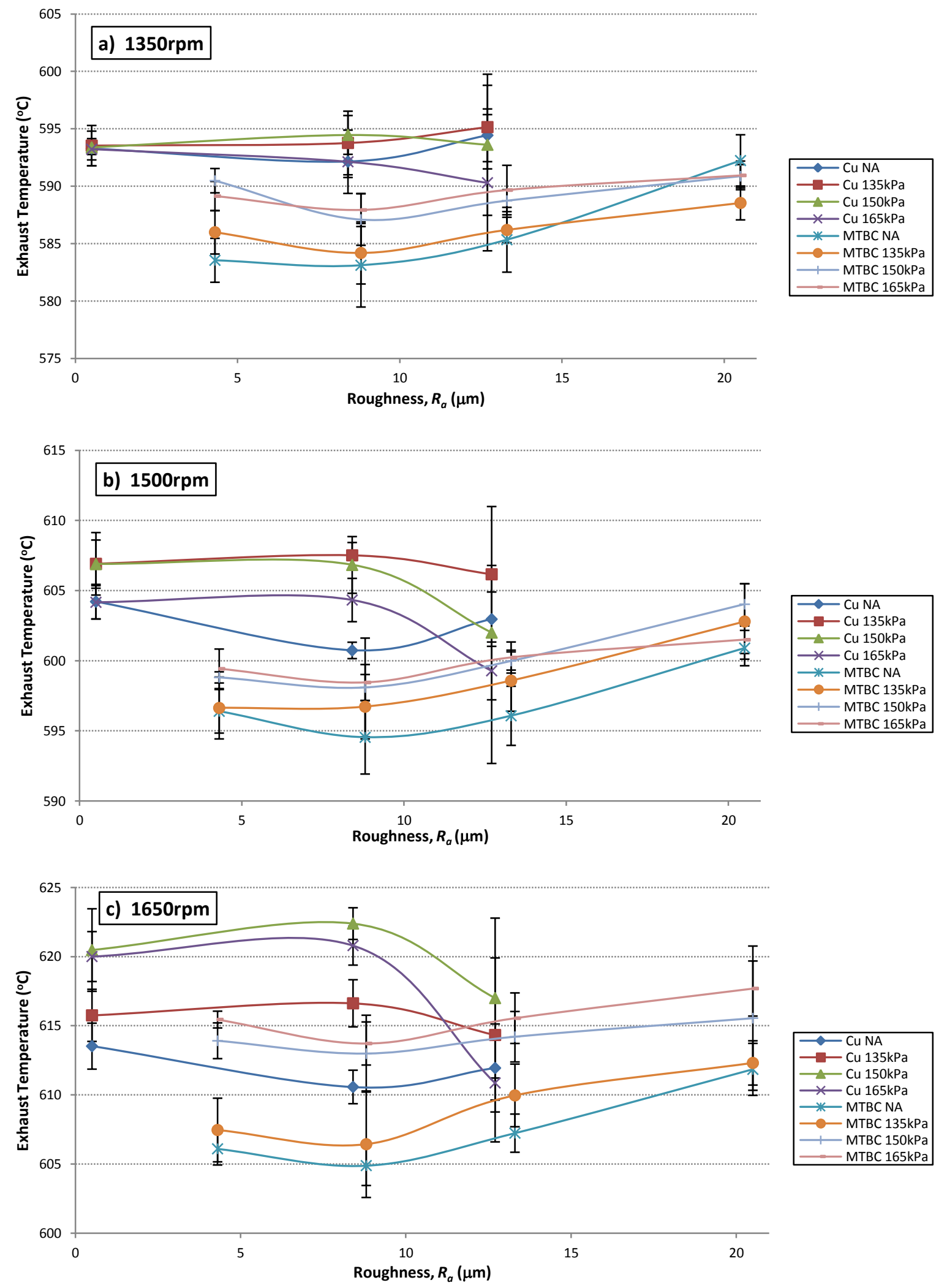

Figure 7.18 - Exhaust Temperature vs. Surface Roughness at a) 1350rpm b) 1500rpm and c) 1650rpm 
It was believed that these trends would have been more visible had the engine conditions been more stable across each of the test runs. Also, seeing as the combustion phasing (i.e. spark timing) was only optimized for the As-Sprayed baseline copper coating, it was believed had the timing for maximum torque been found for the TBC coating, increased exhaust temperatures would have been seen.

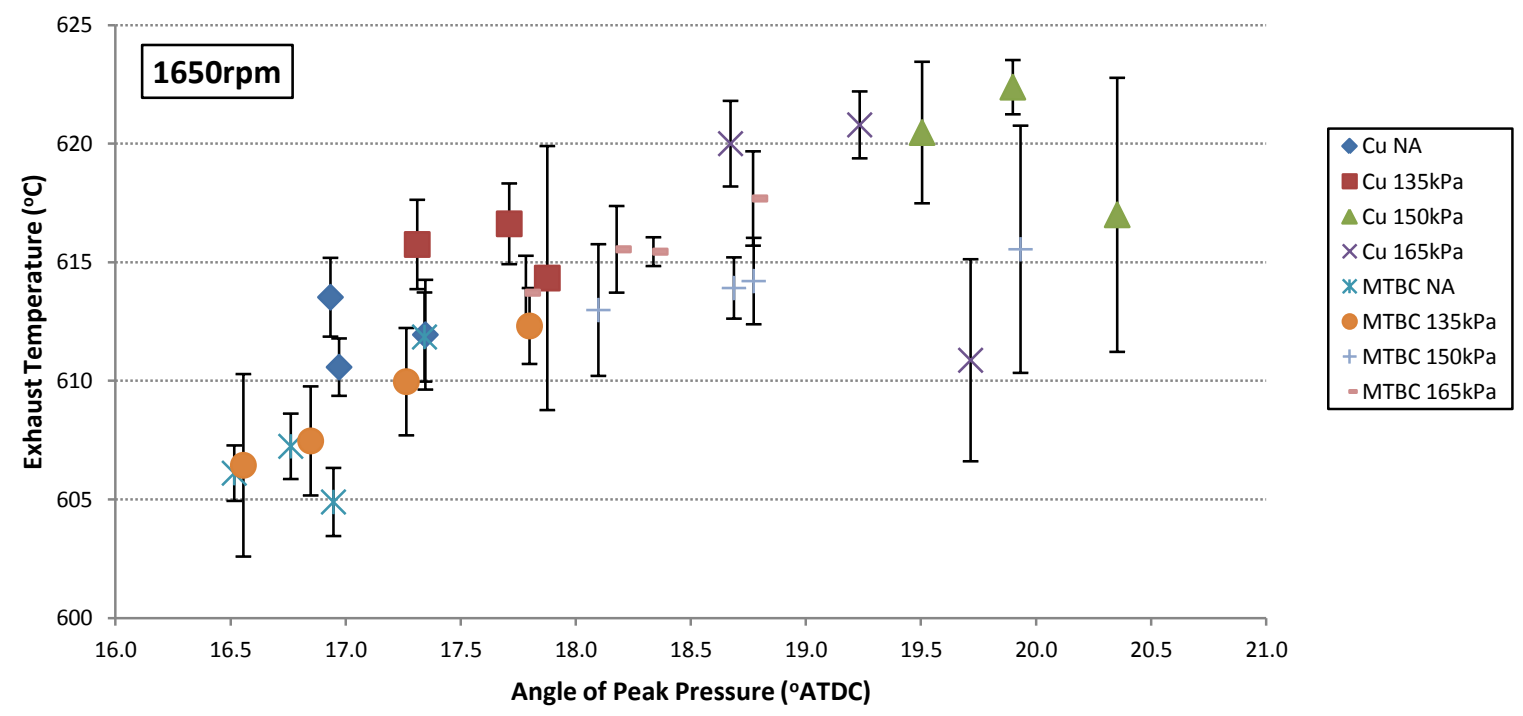

Figure 7.19 - Exhaust Temperature vs. Combustion Phasing

\subsection{Piston Surface Roughness Test Results Summary}

Engine testing of the rough baseline copper coating and the metal TBC demonstrated that piston crown finish played an important role in engine performance. Measurable improvements in engine output and fuel consumption as a result of polishing were attributed to reduced heat transfer from the combustion gases to the piston coating, which was seen to result in higher in-cylinder temperature and pressure. Trends in exhaust emissions (decreasing $\mathrm{THC}$, increased $\mathrm{NO}_{\mathrm{x}}$ ) and in-cylinder pressure data (higher $\mathrm{P}_{\max }$ and advanced $\left.\theta_{\mathrm{Pmax}}\right)$ also supported the conclusion of reduced heat transfer as a result polishing. Exhaust 
temperature did not provide any significant information with regards to heat loss. These effects were generally seen to be most evident at low load conditions.

While the use of the metal TBC was seen to provide some benefits in engine performance as a result of its low thermal conductivity, it was seen that its effectiveness was very dependent on surface finish and coating thickness. 


\section{Chapter 8}

\section{Conclusions and Recommendations}

The primary objective of this research program was to better understand the behaviour of thermal barrier coatings in SI engines and the potential improvements they may provide from the standpoint of heat transfer. A focus was placed on studying how surface roughness affected the TBC's ability to reduce in-cylinder heat losses by measuring the heat flux through a TBC-coated piston.

A fast response thin film thermocouple and a system used to measure piston crown surface temperatures were designed and implemented. Using these temperature measurements, an attempt was made to quantify the change in heat flux resulting from different surface conditions. However, reliability issues with the measurement apparatus did not allow for collection of sufficient data necessary for the analysis. Thus, a modified test matrix was designed to identify the effects of coating material and surface finish through the 
analysis of macroscopic engine responses such as power, fuel consumption and emissions. In-cylinder pressure measurements were used to further understand the coating effects and changes in surface conditions on the combustion process.

Two coatings were used in the analysis: 1) a plasma-sprayed copper coating used to simulate a rough surface for baseline results and 2) a $300 \mu \mathrm{m}$ thick metal TBC coating. Tests were run at varying engine speeds and loads in an attempt to isolate any differences in the relationship between heat transfer and surface finish caused by different in-cylinder conditions.

The main conclusions from the work are summarized in the following two sections: 1) the effects of surface roughness on engine performance and 2) the effectiveness of the metal TBC. Finally, recommendations for further testing will be presented.

\subsection{Effects of Surface Roughness}

For both the baseline copper and TBC coated piston, polishing the rough As-Sprayed coatings was seen to have benefits in improving engine performance. Specifically:

1. Polishing was seen to provide small improvements in brake power and fuel consumption for both the copper and metal TBC coated piston. On average, polishing between the As-Sprayed and Mirror conditions improved brake power and BSFC by $3.7 \%$ and $2.6 \%$, respectively for the copper coating. Equivalent improvements of $3 \%$ and $2.6 \%$ in power and BSFC were seen for the TBC between As-Sprayed and Mirror finishes. Trends in measured IMEP were equivalent to those seen in the power figures.

2. For the copper-coated piston, decreases in THC emissions of almost $10 \%$ across all load and speed conditions were seen when polishing between the Medium and Mirror 
finishes. The effects of polishing the metal TBC were less evident ( $6 \%$ decrease), which was attributed to coating porosity and thickness effects.

3. $\mathrm{NO}_{\mathrm{x}}$ emissions were seen to increase by $5 \%$ between the As-Sprayed and Mirror conditions for the copper coating as a result of the increased in-cylinder temperatures. A similar trend was seen for the metal $\mathrm{TBC}$, as $\mathrm{NO}_{\mathrm{x}}$ concentrations were seen to increase by $3 \%$ on average. However, due to the sensitivity of $\mathrm{NO}_{\mathrm{x}}$ concentration on fuel-air equivalence ratio $\phi$, it was difficult to clearly attribute the degree to which the variations in $\mathrm{NO}_{\mathrm{x}}$ concentration were caused by surface roughness.

4. Increased in-cylinder temperatures resulting from polishing resulted in faster burning rates and more efficient combustion. Polishing both the copper coating and the metal TBC increased the average peak pressures experienced in the cylinder and also advanced the angle $\theta_{\mathrm{Pmax}}$ at which it occurred. Increases in peak pressure were seen to be between $5 \%$ and $8 \%$ for the copper coating (1.75 degree advance) between the AsSprayed and Mirror finishes and about 3\% (1deg) for the TBC. The percentage increases in peak pressure between surfaces finishes was seen to increase with load.

5. The largest impact of polishing both the copper and metal thermal barrier coatings was seen to occur at the naturally aspirated engine conditions for each of the engine performance and emissions parameters. Engine speed was not seen to have significant effects on any of the measured parameters over the range tested.

6. Neither coating material nor surface roughness was seen to have an effect on $\mathrm{CO}$ emissions. The coefficient of variability of IMEP was also seen to be unaffected. 


\subsection{Effectiveness of Metal TBC}

The thermal properties of the metal TBC were seen to have some benefits in reducing heat transfer when compared to the baseline copper coating at equivalent surface roughness. However, it was clear that the effectiveness was strongly dependant on the coating surface finish. The effects of the TBC relative to the baseline copper coating are as follows:

1. The metal $\mathrm{TBC}$ was seen to have an average brake power output $2.1 \%$ higher than the copper coating at an equivalent roughness of $R_{a}=13 \mu \mathrm{m}$. Similar results were seen at $R_{a}=8 \mu \mathrm{m}$. However, these improvements were seen to converge at smoother surface finishes. At Mirror conditions, the TBC was seen to produce 1.8\% less power and had $2.5 \%$ greater fuel consumption than the smooth copper finish. This was attributed to the inherently rougher surface of the metal $\mathrm{TBC}$ due to porosity. Reduction in coating thickness was also believed to have an important impact on this trend.

2. The increases in peak pressure and angle of occurrence relative to the copper coating were clearly evident. At equivalent finishes of $R_{a}=13 \mu \mathrm{m}$ and $R_{a}=8 \mu \mathrm{m}$, the metal TBC was seen to have peak pressures $8 \%$ and $6 \%$ greater than the copper coating, respectively. The angle of peak pressure occurrence was seen to advance by $1 \%$ on average for the metal TBC relative to the copper coating. The fact that the As-Sprayed metal coating produced equivalent peak pressures to the Mirror finished copper coating also lead to the conclusion that the metal $\mathrm{TBC}$ was effective at reducing the instantaneous heat transfer as a result of its insulating material properties. The TBC did not increase engine instability or lead to irregular combustion.

3. TBC thickness was hypothesized to play a role in the results. Polishing between the AsSprayed and Coarse surface finish did not remove the bulk material coating and thus 
was not expected to have a significant impact on the insulating properties of the coating. However, a significant bulk material removal between the Medium and Mirror finishes may have changed insulating properties of the coating and this would have a detrimental effect on all engine parameters. Evidence of a small decrease in all performance parameter for the TBC-coated piston at the Mirror conditions relative to the Medium finishes supported this hypothesis.

4. The inherent porosity of the TBC coating was seen to have a large impact on THC emissions as a result of the coating behaving as multiple crevices. Relative to the Mirror copper coating, THC emissions for the As-Sprayed TBC condition were seen to increase by $18 \%$. This decreased to $11 \%$ for a comparison between the two Mirror finishes, however it remained very large. Thus, heat transfer effects were deemed secondary and the differences were attributed to coating porosity.

5. The effects of the TBC coating with respect to the baseline copper coating were determined to be inconclusive as a result of the sensitivity of $\mathrm{NO}_{\mathrm{x}}$ emissions to variations in equivalence ratio. While increased in-cylinder temperatures as a result of the TBC were expected to result in higher $\mathrm{NO}_{\mathrm{x}}$ concentrations, the effect of fuel-air equivalence ratio $\phi$ was seen to be dominant.

The results of the testing regime thus indicate the importance of surface finish to overall engine performance as a result of reductions in heat transfer from the combustion gases to the piston crown. It was demonstrated that while the metal TBC did not provide large benefits to overall engine performance, it had a clear impact on in-cylinder conditions. Its performance was found to be dependent on surface finish and thickness. Thus, further analysis of the coating is needed to make definitive conclusions regarding their use in SI engines. 


\subsection{Recommendations}

Various steps should be taken to further build on the conclusions reached during this study. To help gain a better understanding of the true impact of the thermal barrier coatings on heat transfer, and how surface roughness affected their effectiveness, heat flux through the thermal barrier coatings should be measured. Cycle-resolved heat flux measurements will provide further evidence to support the macroscopic changes in steady state engine outputs. Also, surface temperature measurements will provide useful insight on the interaction between the coating surface finish and the in-cylinder flow conditions at the different points throughout the engine cycle.

An attempt should be made to better control the engine air-fuel ratio to obtain clearer understanding of the effect of surface roughness and TBCs on exhaust emissions. Likewise, a larger range of engine speeds should be tested to help better isolate the importance of increased in-cylinder turbulence intensities on heat flux.

Further experimentation with different thermal barrier coating thicknesses would be beneficial to quantify the effects thickness had on overall engine performance. If possible, tests should be conducted at different TBC surface finishes at identical thickness. Experimenting with different thermal barrier coating materials (such as Yttria-Stabilized Zirconia) would also be beneficial to better understand the performance of the tested metal TBC and the general applicability of TBCs in spark ignition engine. 


\section{Bibliography}

[1] J.P. Myers and A.C. Alkidas, "Effect of Combustion Chamber Surface Temperature on Exhaust Emissions from an SI Engine," SAE Technical Paper Series, no. 780642, 1978.

[2] J.B Heywood, Internal Combustion Engine Fundamentals. New York, New York: McGraw Hill Inc., 1988.

[3] G. Borman and K. Nishiwaki, "Internal Combustion Engine Heat Transfer," Progress in Energy and Combustion Science, vol. 13, pp. 1-46, 1987.

[4] A.C. Alkidas and J.P. Myers, "Transient Heat Flux Measurements in the Combustion Chamber of an SI Engine," Journal of Heat Transfer, vol. 104, pp. 62-67, February 1982.

[5] Y. Enomoto and S. Furuhama, "Measurement of the Instantaneous Surface Temperature and Heat Loss of Gasoline Engine Combustion Chamber," SAE Technical Paper Series, no. 845007, 1984.

[6] T.K. Hayes, R.A. White, and J.E. Peters, "Combustion Chamber Temperature and Instantaneous Local Heat Flux Measurements in a Spark Ignition Engine," SAE Technical Paper Series, no. 930217, 1993.

[7] B. Tillock and J.K. Martin, "In-Cylinder Heat Flux in a Four Stroke, Air-Cooled, Spark-Ignited Engine with Fixed Timing," SAE Technical Paper Series, no. 972708, 1997.

[8] G. Woschni, "Universally Applicable Equation for the Instantaneous Heat Transfer Coefficient in and SI Engine," SAE Technical Paper Series, no. 67093, 1967.

[9] W.J.D. Annand, "Heat Transfer in the Cylinders of Reciprocating Internal Combustion Engines," Proc. Instn Mech. Engrs, vol. 177, no. 36, pp. 973-990, 1963.

[10] G.F. Hohenberg, "Advanced Approaches for Heat Transfer Calculations," SAE Technical Paper Series, no. 790825, 1979.

[11] V.D. Overbye, J.E. Bennethum, O.A. Uyehara, and P.S. Myers, "Unsteady Heat Transfer in Engines," SAE Technical Paper Series, no. 610041, 1961.

[12] G.T. Kalghatgi, "Experimental Study of Combustion Chamber Deposits and their Effect on SI Engines," SAE Technical Paper Series, no. 950680, 1995.

[13] O.A Güralp, "The Effect of Combustion Chamber Deposits on Heat Transfer and Combustion in a Homogenous Charge Compression Ignition Engine," University of Michigan, Ann Arbor, Ph.D Thesis 2008.

[14] A.R. Noori and M. Rashidi, "Computational Fluid Dynamics Study of Heat Transfer in a Spark-Ignition Engine Combustion Chamber," Journal of Heat Transfer, vol. 129, pp. 609-616, May 2007.

[15] M. Kubicki, H.C. Watson, J. Williams, and P.C. Stryker, "Spatial and Temporal Temperature Distributions in a Spark Ignition Engine Piston at WOT," SAE Technical Paper Series, no. 2007-01-1436, 2007.

[16] P. Popp and M. Baum, "Heat Transfer and Pollutant Formation Mechanisms in Insulated Combustion Chambers," SAE Technical Paper Series, no. 952387, 1995. 
[17] J. Chang et al., "Characterizing the Thermal Sensitivity of a Gasoline Homogeneous Charge Compression Ignition Engine with Measurements of Instantaneous Wall Temperature and Heat Flux," International Journal of Engine Research, vol. 6, pp. 289-309, 2005.

[18] X. Wang and C.R. Stone, "A Study of Combustion, Instantaneous Heat Transfer, and Emissions in a Spark Ignition Engine During Warmup," J. Automobile Engineering, vol. 222, no. D, 2008.

[19] R.M. Frank and J.B. Heywood, "The Effect of Piston Temperature on Hydrocarbon Emissions from a Spark-Ignited Direct-Injection Engine," SAE Technical Paper Series, no. 910558, 1991.

[20] A. Bejan and A. D. Kraus, Heat Transfer Handbook. New Jersey: John Wiley \& Sons, 2003.

[21] W.D. Kingery, H.K. Bowen, and D.R. Uhlmann, Introduction to Ceramics, 2nd ed. New York: John WIley and Sons, 1976.

[22] D.N. Assanis and T. Mathur, "The Effect of Thin Ceramic Coatings on Spark Ignition Engine Performance," SAE Technical Paper Series, no. 900903, 1993.

[23] S. Furuhama and Y. Enomoto, "Heat Transfer into Ceramic Combustion Wall of Internal Combustion Engines," SAE Technical Paper Series, no. 870153, 1987.

[24] R. Soltani, H. Samadi, E. Garcia, and T.W. Coyle, "Development of Alternative Thermal Barrier Coatings for Diesel Engines," SAE Technical Paper Series, no. 200501-0650, 2005.

[25] R.P. Tolokan, J.P. Jarrabet, and J.B. Brady, "Fiber Metal Thermal Barrier Systems for Advanced Engines," SAE Technical Paper Series, 1984.

[26] D.-I. Shin, F. Gitzhofer, and C. Moreau, "Thermal Property Evaluation of Metal Based Thermal Barrier Coatings with Heat Treatments," Journal of Material Science, vol. 42, pp. 5915-5923, 2007.

[27] F. Gitzhofer et al., "Metal-Based Thermal Barrier Coatings for Internal Combustion Engine," Universite de Sherbrooke, University of Toronto and Surface Technologies IMI-NRC, Boucherville, Technical report 2008.

[28] (2010, January) MatWeb, Aluminum 2618-T6. [Online]. http://www.matweb.com/

[29] T. Morel, S. Wahiduzzaman, and E.F. Fort, "Heat Transfer Experiments in an Insulated Diesel," SAE Technical Paper Series, no. 880186, 1988.

[30] T. Morel et al., "Heat Transfer in a Cooled and an Insulated Diesel Engine," SAE Technical Paper Series, no. 890572, 1989.

[31] W. K. Cheng, V. W. Wong, and F. Gao, "Heat Transfer Measurement Comparisons in Insulated and Non-Insulated Diesel Engines," SAE Technical Paper Series, no. 890570, 1989.

[32] D.N. Assanis, F.A. Friedman, K.L. Wiese, M.J. Zaluzec, and and J.M. Rigsbee, "A Prototype Thin-Film Thermocouple for Transient Heat Transfer Measurements in Ceramic-Coated Combustion Chambers," SAE Technical Paper Series, no. 900691, 1990. 
[33] G. Woschni, "Heat Insulation of Combustion Chamber Walls," SAE Technical Paper Series, no. 870339, 1987.

[34] G. Woschni, W. Spindler, and K. Kolesa, "Heat Insulation of Combustion Chamber Walls - A Measure to Decrease the Fuel Consumption of IC Engines?," SAE Technical Paper Series, no. 870339, 1987.

[35] D. W. Dickey, "The Effect of Insulated Combustion Chamber Surfaces on Direct Injection Diesel Engine Performance, Emissions and Combustion," SAE Technical Paper Series, no. 890292, 1995.

[36] D.N. Assanis, K. Wiese, E. Schwardz, and W. Bryzik, "The Effects of Ceramic Coatings on Diesel Engine Performance and Exhaust Emissions," SAE Technical Paper Series, no. 910460, 1991.

[37] R. Kamo, D.N. Assanis, and W. Bryzik, "Thin Thermal Barrier Coatings for Engines," SAE Technical Paper Series, no. 890143, 1989.

[38] M. Ciniviz, C. Hasimoglu, F. Sahin, and M.S. Salman, "Impact of Thermal Barrier Coating Application on the Performance and Emissions on a Turbocharged Diesel Engine," Journal of Automobile Engineering, vol. 222, no. Part D, pp. 2447-2455, 2008.

[39] I. Taymaz, "The Effect of Thermal Barrier Coatings on Diesel Engine Performance," Surface \& Coatings Technology, vol. 201, pp. 5249-5252, 2007.

[40] E. Buyukkaya, T. Engin, and M. Cerit, "Effects of Thermal Barrier Coatings on Gas Emissions and Performance of a LHR Engine with Different Injection Timings and Valve Adjustments," Energy Conversion and Management, vol. 47, pp. 1298-1310, 2006.

[41] S. Jaichandar and P. Tamilporai, "Low Heat Rejection Engines - An Overview," SAE Technical Paper Series, no. 2003-01-0405, 2003.

[42] S.H. Chan and K.A. Khor, "The Effect of Thermal Barrier Coated Piston Crown on Engine Characteristics," Journal of Materials Engineering and Performance, vol. 9, no. 1, pp. 103-109, February 2000.

[43] K.Z. Mendera, "Effectiveness of Plasma Sprayed Coatings for Engine Combustion Chamber," SAE Technical Paper Series, no. 2000-01-2982, 2000.

[44] G.T. Kalghatgi, "Depostis in Gasoline Engines - A Literature Review," SAE Technical Paper Series, no. 902105, 1990.

[45] D.J. Nakic, D.N. Assanis, and R.A. White, "Effect of Elevated Piston Temperature on Combustion Chamber Deposit Growth," SAE Technical Paper Series, no. 900948, 1994.

[46] S.S. Cheng and C. Kim, "Effect of Engine Operating Parameters on Engine Combustion Chamber Deposits," SAE Technical Paper Series, no. 902108, 1990.

[47] J.L. Lauer and P.J., Friel, "Some Properties of Carbanaceous Deposits Accumulated in Internal Combustion Engines," Combustion and Flame, vol. 4, 1960.

[48] K.S. Moughal and S. Samuel, "Exhaust Emissions Level Reduction in a Two-Stroke Engine Using In-Cylinder Combustion Control," SAE Technical Paper Series, no. 2007-01-1085, 2007. 
[49] R.B. Poola, B. Nagalingam, and K.V. Gopalakrishnan, "Peformance of Thin-CeramicCoated Combustion Chamber with Gasoline and Methanol as Fuels in a Two-Stroke Engine," SAE Technical Paper Series, no. 941911, 1994.

[50] Y. A. Cengel, Heat and Mass Transfer: A Practical Approach, 3rd ed. New York, New York: McGraw Hill, 2003.

[51] J. Nikuradse, "Laws for Flows in Rough Pipes," VDI-Forchungsheft 361 Series B, vol. 4, 1933.

[52] H. Schlichting, "Experimental Investigation of the Problem of Surface Roughness," National Advisory Commitee for Aeronautics (NACA Technical Papers), no. 823, 1937.

[53] R.J. Boyle and M. Stripf, "Simplified Approach to Predicting Rough Surface Transition," Journal of Turbomachinery, vol. 131, no. 4, October 2009.

[54] F. A. Dvorak, "Calculation of Turbulent Boundary Layers on Rough Surfaces in Pressure Gradients," AIAA Journal, vol. 7, pp. 1752-1759, 1969.

[55] R. B. Dirling, "A Method for Computing Rough Wall Heat Transfer Rates on Reentry Nose Tips," AIAA Paper, no. 73-763, 1973.

[56] A. Sigal and J. E. Danberg, "New Correlation of Roughness Density Effect on the Turbulent Boundary Layer," AIAA Journal, vol. 28, no. 3, pp. 554-556, 1990.

[57] R.L. Simpson, "A Generalized Correlation of Roughness Density Effects on the Turbulent Boundary Layer," AIAA Journal, vol. 11, pp. 242-244, 1973.

[58] C. C. Koch and L. H. Smith, "Loss Sources and Magnitudes in Axial-Flow Compressors," ASME J. Eng. Power, vol. 98, no. 3, pp. 411-424, 1976.

[59] J.P. Bons, "St and cf Augmentation for Real Turbine Roughness with Elevated Freestream Turbulence," Journal of Turbomachinery, vol. 124, pp. 633-644, October 2002.

[60] W.M. Kays, M.E. Crawford, and B Weigand, Convective Heat and Mass Transfer, 4th ed. New York, New York: McGraw-Hill Higher Education, 2006.

[61] R. P. Taylor, "A Discrete Element Prediction Approach for Turbulent Flow Over a Rough Surface," Mississippi State University, Mississippi, PhD Thesis 1983.

[62] S.T. McClain, B.K. Hodge, and J.P. Bons, "Predicting Skin Friction and Heat Transfer for Turbulent Flow Over Real Gas Turbine Surface Roughness Using the Discrete Element Method," Journal of Turbomachinery, vol. 126, pp. 259-267, April 2004.

[63] J.P. Bons, R.P. Taylor, S.T. McClain, and R.B. Rivir, "The Many Faces of Turbine Surface Roughness," Journal of Turbomachinery, vol. 123, pp. 739-748, October 2001.

[64] S. Bose and J. DeMasi-Marcin, "Thermal Barrier Coating Experience in Gas Turbine Engines at Pratt \& Whitney," Journal of Thermal Spray Technology, vol. 6, no. 1, pp. 99-104, March 1997.

[65] A. B. Turner, F. H.A. Tarada, and F. J. Bailey, "Effects of Surface Roughness on Heat Transfer to Gas Turbine Blades," in AGARD Conference: Heat Transfer and Cooling in Gas Turbines, 1985. 
[66] M. F. Blair, "An Experimental Study of Heat Transfer In a Large-Scale Turbine Rotor Passage," Journal of Turbomachinery, vol. 116, January 1994.

[67] R.S. Bunker, "The Effects of Thermal Barrier Coating Roughness Magnitude on Heat Transfer with and without Flowpath Surface Steps," in Proceedings of IMECE 2003: ASME International Mechanical Engineering Congress, 2003.

[68] R. J. Boyle and R. G. Senyitko, "Effects of Surface Roughness on Turbine Vane Heat Transfer," in Proceedings of GT2005: ASME Turbo Expo 2005, 2005.

[69] M. Stripf, A. Schulz, and S. Wittig, "Surface Roughness Effects on External Heat Transfer of a HP Turbine Vane," Transactions of the ASME, vol. 127, pp. 200-208, January 2005.

[70] D.N. Barlow, Y.W. Kim, and L.W. Florschuetz, "Transient Liquid Crystal Technique for Convective Heat Transfer on Rough Surfaces," Journal of Turbomachinery, vol. 119, pp. 14-22, January 1997.

[71] D. G. Bogard, D. L. Schmidt, and M Tabbita, "Characterization and Laboratory Simulation of Turbine Airfoil Surface Roughness and Heat Transfer," Journal of Turbomachinery, vol. 120, no. 2, pp. 337-342, 1998.

[72] R. P. Taylor, H. W. Coleman, and B. K. Hodge, "Predictions of Turbulent Rough-Wall Skin Friction Using a Discrete Element Approach," Journal of Fluids Engineering , vol. 107, pp. 251-257, 1985.

[73] S.T. McClain, "A Discrete-Element Model for Turbulent Flow Over Randomly-Rough Surfaces," Mississippi State University, Mississippi, PhD Thesis 2002.

[74] M. H. Hosni, H. W. Coleman, and R. P. Taylor, "Measurements and Calculations of Rough Wall Heat Transfer in the Turbulent Boundary Layer," Int. J. Heat Mass Transfer, vol. 34, pp. 1067-1082, 1991.

[75] M. H. Hosni, Hugh W. Coleman, James W. Garner, and Robert P. Taylor, "Roughness Element Shape Effects on Heat Transfer and Skin Friction in Rough-Wall Turbulent Boundary Layers," International Journal of Heat and Mass Transfer, vol. 36, no. 1, pp. 147-153, 1993.

[76] Y. Tsutsumi, K. Nomura, and N. Nakamura, "Effect of a Mirror-Finished Combustion Chamber on Heat Loss," SAE Technical Papers, no. 902141, 1990.

[77] M.A. Marr, J.S. Wallace, L. Pershin, S. Chandra, and J. Mostaghimi, "Preliminary Testing of Metal-Based Thermal Barrier Coating in a Spark-Ignition Engine," Journal of Engineering for Gas Turbines and Power, vol. 132, February 2010.

[78] R. Siegel and J.R. Howell, Thermal Radiation Heat Transfer, 4th ed.: McGraw-Hill Inc, 2002.

[79] A. Seifter, K. Boboridis, and A. W. Obst, "Emissivity Measurements on Metallic Surfaces with Various Degrees of Roughness: A Comparison of Laser Polarimetry and Integrating Sphere Reflectometry," International Journal of Thermophysics, vol. 25, no. 2, March 2004. 
[80] C.D. Wen and I. Mudawar, "Emissivity Characterisitics of Roughened Aluminum Alloy Surfaces and Assessment of Multispectral Radiation Thermometry Emissivity Models," International Journal of Heat and Mass Transfer, vol. 47, pp. 3591-3605, 2004.

[81] C.D. Wen and I. Mudawar, "Modeling the Effects of Surface Roughness on the Emissivity of Aluminum Alloys," International Journal of Heat and Mass Transfer, vol. 49, pp. 4279-4289, 2006.

[82] K.Z. Mendera, "Effectiveness of Plasma Sprayed Coatings for Engine Combustion Chamber," SAE Technical Paper Series, no. 2000-01-2982, 2000.

[83] B. Ganz, W. Krebs, R. Koch, and S.Wittig, "Spectral Emissivity Measurements of Thermal Barrier Coatings," in AIAA/ASME Joint Thermophysics and Heat Transfer Conference, 1998, pp. 291-295.

[84] S. Wahiduzzaman and T. Morel, "Effects of Ceramics Translucence on Heat Barrier Effectiveness in Diesel Engines," SAE Technical Paper Series, no. 890569, 1989.

[85] E.G. Groff and F.A. Matekunas, "The Turbulent Nature of Flame Propogation in a Homogeneous Spark-Ignited Engine," SAE Technical Paper Series, no. 800133, 1980.

[86] M.J. Hall and F.V. Bracco, "A Study of Velocity and Turbulence Intensities Measured in Firing and Motored Engines," SAE Technical Paper Series, no. 870453, 1987.

[87] D.R. Lancaster, "Effects of Engine Variables on Turbulence in a Spark Ignition Engine," SAE Technical Paper Series, no. 760159, 1976.

[88] D.R. Lancaster, R.B. Kreiger, S.C. Sorenson, and W.L. Hull, "Effects of Turbulence on Spark Ignition Engine Combustion," SAE Technical Paper Series, no. 760160, 1976.

[89] T.-M. Liou, M. Hall, D.A. Santavicca, and F.V. Bracco, "Laser Doppler Velocimetry Measurements in Valved and Ported Engines," SAE Technical Paper Series, no. 840375, 1984.

[90] D. Boggs and G. Borman, "Calculation of Heat Flux Integral Length Scale from Spatially-Resolved Surface Temperature Measurements in an Engine," SAE Technical Paper Series, no. 910721, 1991.

[91] J.C. Dent and N.S. Salama, "The Measurement of Turbulence Characterisitcs in an Internal Combustion Engine," SAE Technical Paper Series, no. 750886, 1975.

[92] K. Lee, C. Bae, and K. Kang, "The Effects of Tumble and Swirl Flow on Flame Propogation in a Four Valve SI Engine," Applied Thermal Engineering, vol. 27, pp. 2122-2130, 2007.

[93] N. Abuaf, R.S. Bunker, and C.P. Lee, "Effects of Surface Roughness on Heat Transfer and Aerodynamic Performance of Turbine Airfoils," Journal of Turbomachinery, vol. 120, pp. 522-529, July 1998.

[94] T. Wang and M.C. Rice, "Effect of Elevated Freestream Turbulence on Transitional Flow Heat Transfer over Dual-Scaled Rough Surfaces," Journal of Heat Transfer, vol. 127, pp. 393-403, April 2005.

[95] ASTM Manual of Engine Test Methods for Rating Fuels. Philadelphia: American Society for Testing Materials, 1948. 
[96] H.S. Imming, "The Effect of Piston Head temperature on Knock-Limited Power," National Advisory Committee for Aeronautics, Cleveland, Ohio, 1944.

[97] Omega Engineering, The Temperature Handbook, Canadian ed., vol. 2.

[98] Safa Kasap, "Thermocelectric Effects in Metals: Thermocouples," University of Saskatchewan, Saskatoon, E-Book 2001.

[99] D.N. Assanis and E. Badillo, "Evaluation of Alternative Thermcouple Designs For Transient Heat Transfer Measurements in Metal and Ceramic Engines," SAE Technical Paper Series, no. 890571, pp. 169-184, 1989.

[100] D. Bendersky, "A Special Thermocouple for Measuring Transient Temperatures," Mechanical Engineering, vol. 75, no. 2, pp. 117-121, 1953.

[101] Medtherm Corporation, "Coaxial Thermocouple Probes," Hunstville, Alabama, Bulletin 500, 2000.

[102] D.R. Buttsworth, R. Stevens, and C. R. Stone, "Eroding Ribbon Thermocouples: Impulse Response and Transient Heat Flux Analysis," Measurement Science and Technology, no. 16, pp. 1487-1494, 2005.

[103] J.A. Gatowski, M.K. Smith, and A.C. Alkidas, "An Experimental Investigation of Surface Thermometry and Heat Flux," Experiemental Thermal and Fluid Sciences, no. 2, pp. 280-292, 1989.

[104] D. R. Buttsworth, "Transient Response of an Erodable Heat Flux Gauge Using Finite Element Analysis," Proceedings of the Institution of Mechanical Engineers, vol. 216 (8), no. Part D: Journal of Automobile Engineering, pp. 701-706, 2002.

[105] Xiaowei Wang, Richard Stone, Robert Stevens, Yoshi Arita, and David Buttsworth, "Finite Elelment Analysis of Eroding Type Surface Thermocouple with Application to Engine Heat Flux Measurement," SAE Techinical Paper Series, no. 2006-01-1045, 2006.

[106] A. Wimmer, R. Pivec, and T. Sams, "Heat Transfer to the Combustion Chamber and Port Walls of IC Engines - Measurement and Prediction," SAE Technical Paper Series, no. 2000-01-0568, 2000.

[107] J. C. Dent and S. J. Suliaman, "Convective and Radiative Heat Transfer in a High Swirl Direct Injection Diesel Engine," SAE Technical Paper Series, no. 770407, 1977.

[108] Yoav Heichal, Sanjeev Chandra, and Evgueni Bordatchev, "A Fast Response Thin Film Thermocouple to Measure Rapid Surface Temperature Changes," Experimental Thermal and Fluid Science, vol. 30, pp. 153-159, 2005.

[109] M.A. Marr, J.S. Wallace, S. Chandra, L. Pershin, and J. Mostaghimi, "A Fast Response Surface Thermocouple for Internal Combustion Engine Surface Temperature Measurements," Experimental Thermal and Fluid Science, vol. 34, pp. 183-189, 2009.

[110] R. E. Bentley, Handbook of Temperature Measurement: Theory and Practice of Thermoelectric Thermometry. Singapore: Springer, 1998.

[111] M.A. Marr et al., "An Investigation of Metal and Ceramic Thermal Barrier Coatings in a Spark Ignition Engine," SAE Journal, no. 2010-01-2090, October 2010. 
[112] A. McDonald, C. Moreau, and S. Chandra, "Thermal Contact Resistance Between Plasma-Sprayed Particles and Flat Surfaces," International Hournal of Heat and Mass Transfer, no. 50, pp. 1737-1749, 2007.

[113] M. A. Marr, "An Investigation of Metal and Ceramic Thermal Barrier Coatings in a Spark Ignition Engine," University of Toronto, Toronto, Master's Thesis 2009.

[114] ASTM Standard E220, "Standard Test Method for Calibration of Thermocouples By Comparison Techniques," ASTM International, West Conshohocken, Pennsylvania, DOI:10.1520/E0220-07A, 2007.

[115] ASTM Standard E207, "Standard Test Method for Thermal EMF Test of Single Thermoelement Materials by Comparison with a Reference Thermoelement of Similar EMF-Temperature Properties," ASTM International, West Conshohocken, Pennsylvania, DOI: 10.1520/E0207-08, 2008.

[116] D. Burgess, M. Yust, and K. G. Kreider, "Transient Thermal Response of PlasmaSprayed Zirconia Measured with Thin-Film Thermocouples," Sensors and Actuators, no. 24, pp. 155-161, 1990.

[117] H.W. Lee, C.H. Oh, S.K. Kauh, and K.P. Ha, "Development of a multipiston temperature telemetry system using Bluetooth networks," J. Automobile Engineering, vol. 220, no. D, 2006.

[118] IR Telemetrics Wireless Telemetry Systems, "Model 4000 Microwave Receiver Operators Manua," Houghton, MI, 1999.

[119] A.J. Adler, "Wireless Strain and Temperature with Radio Telemetry Measurement," in SESA Spring Meeting, Huntsville, 1970.

[120] N. Kato, M. Moritsugu, T. Shimura, and J. Matsui, "Piston Temperature Measuring Technology Using Electromagnetic Induction," SAE Technical Paper Series, no. 200101-2027, 2001.

[121] H. Takamatsu and T. Kanazawa, "Piston Temperature Measurement Method for HighSpeed Gasoline Engines," JSAE Review, vol. 20, pp. 259-279, 1999.

[122] D.N. Assanis and F. Friedmann, "Telemetry Linkage System for Piston Temperature Measurements in a Diesel Engine," SAE Technical Paper Series, no. 910299, 1991.

[123] S. Memme, "Design of a Piston Surface Temperature Telemetry System," University of Toronto, Toronto, Undergraduate Thesis 2009.

[124] A.L. Randolph, "Methods of Processing Cylidner-Pressure Transducer Signals to Maximize Data Accuracy," SAE Technical Papers, no. 900170, 1990. 


\section{Appendix A}

\section{Coating Images}

The following section provides images of the copper and metal TBC coatings used during the engine tests taken before each test run. Representative surface scans of the copper coating at the different roughness levels taken with an optical profilometer are also presented. 


\section{$\underline{\text { A.1 Copper Coating }}$}
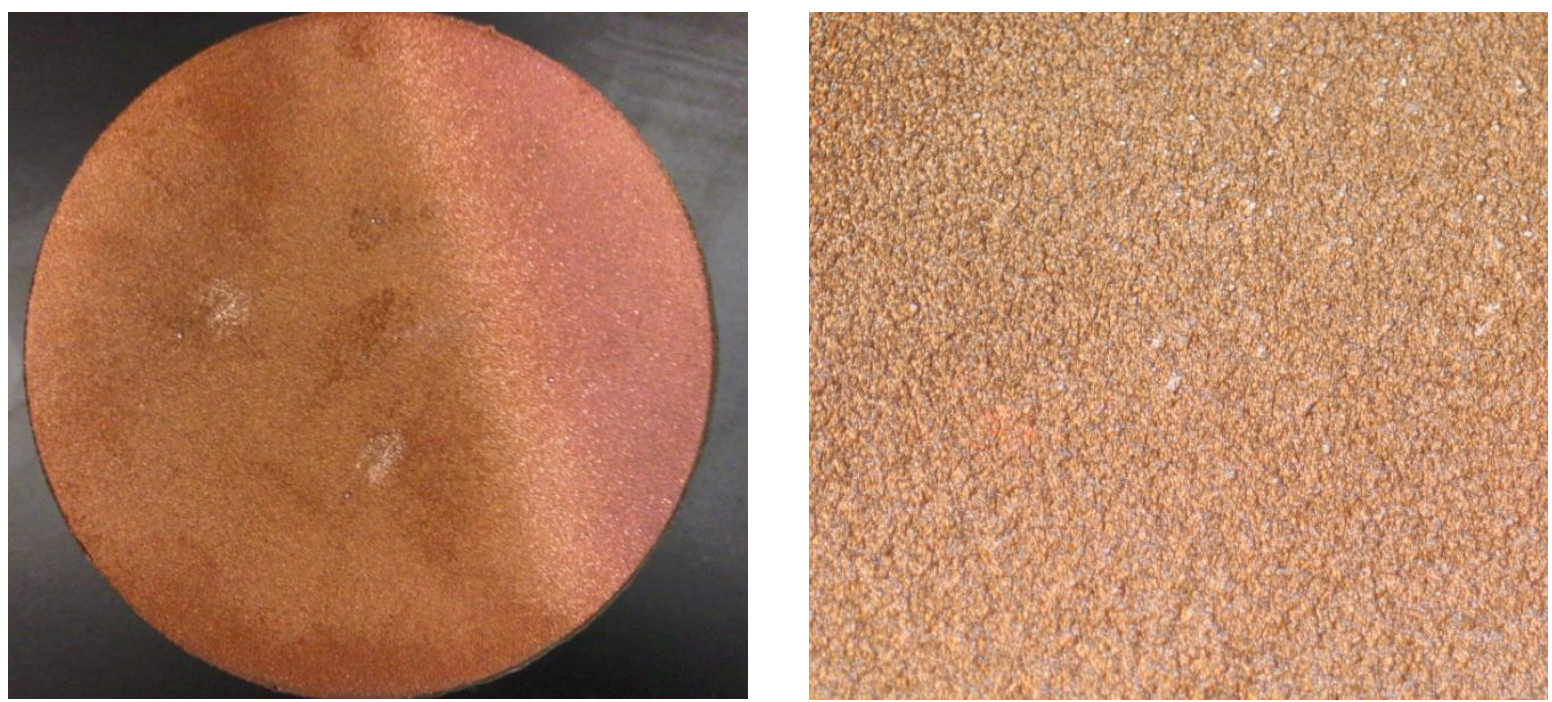

Figure A.1 - Copper As- Sprayed $\left(R_{a}=8.4 \mu \mathrm{m}\right)$
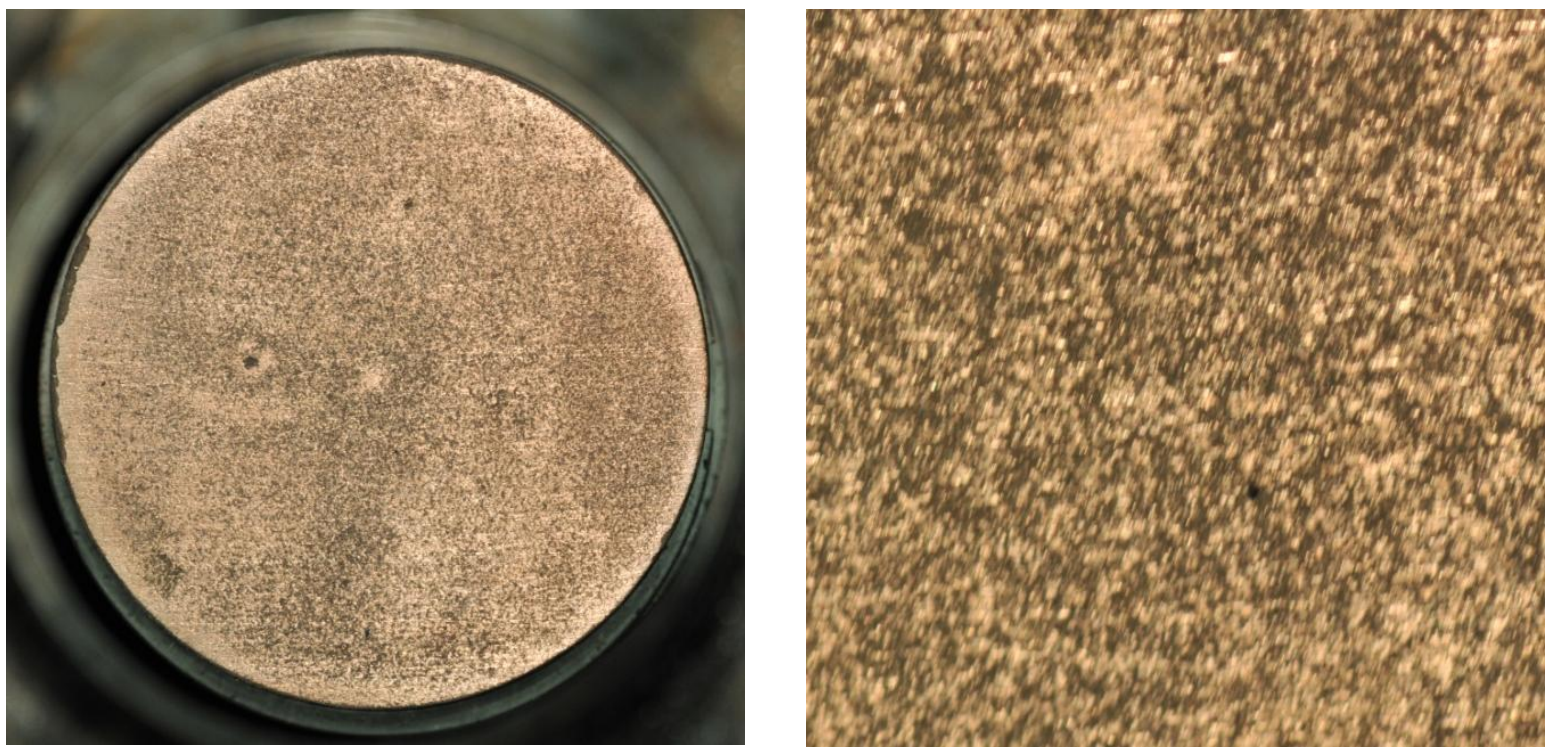

Figure A.2 - Copper Medium $\left(R_{a}=12.7 \mu \mathrm{m}\right)$ 

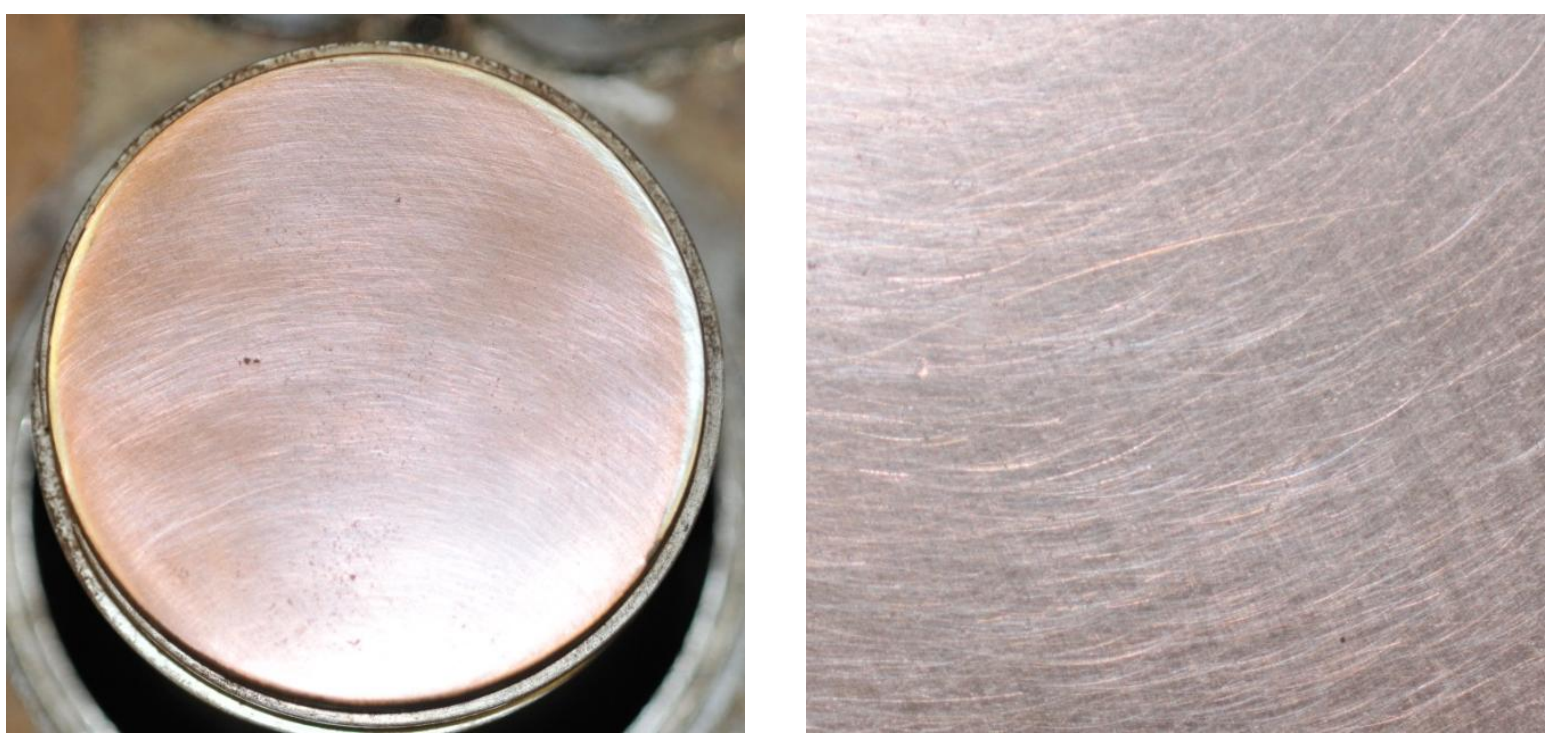

Figure A.3 - Copper Mirror $\left(R_{a}=0.5 \mu \mathrm{m}\right)$

\section{A.2 Metal TBC Coating}
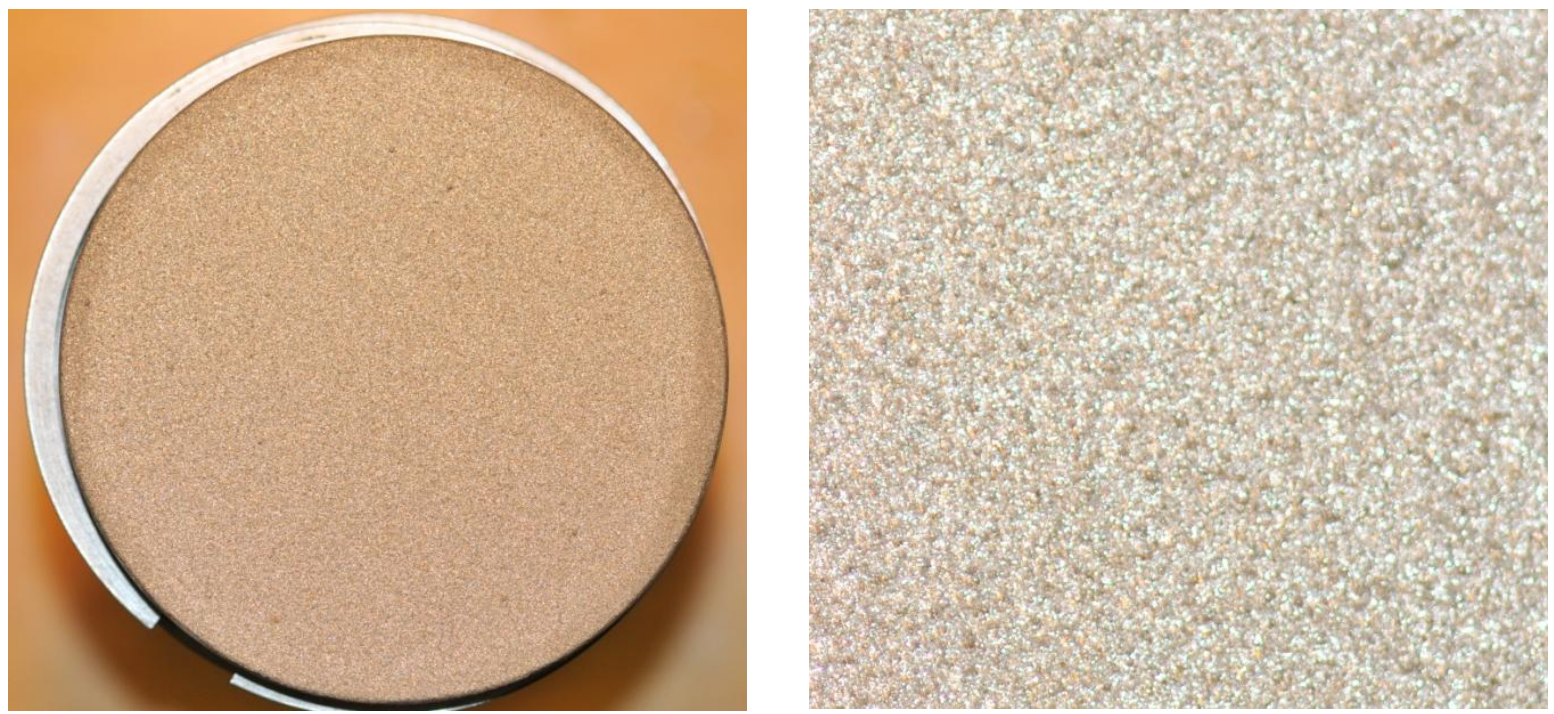

Figure A.4 - Metal TBC As-Sprayed $\left(R_{a}=20.4 \mathrm{~mm}\right)$ 

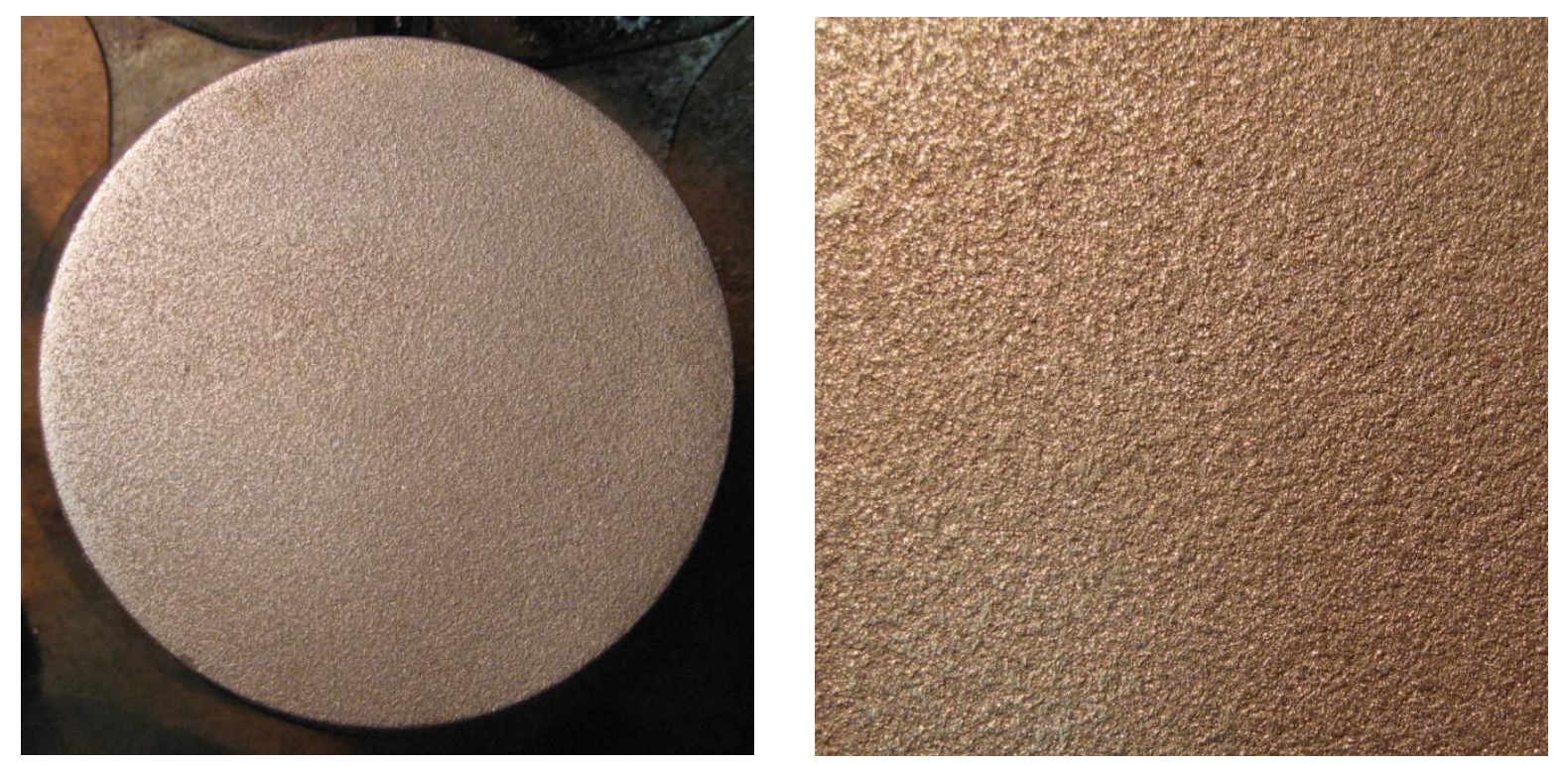

Figure A.5 - Metal TBC Coarse $\left(R_{a}=13.3 \mu \mathrm{m}\right)$
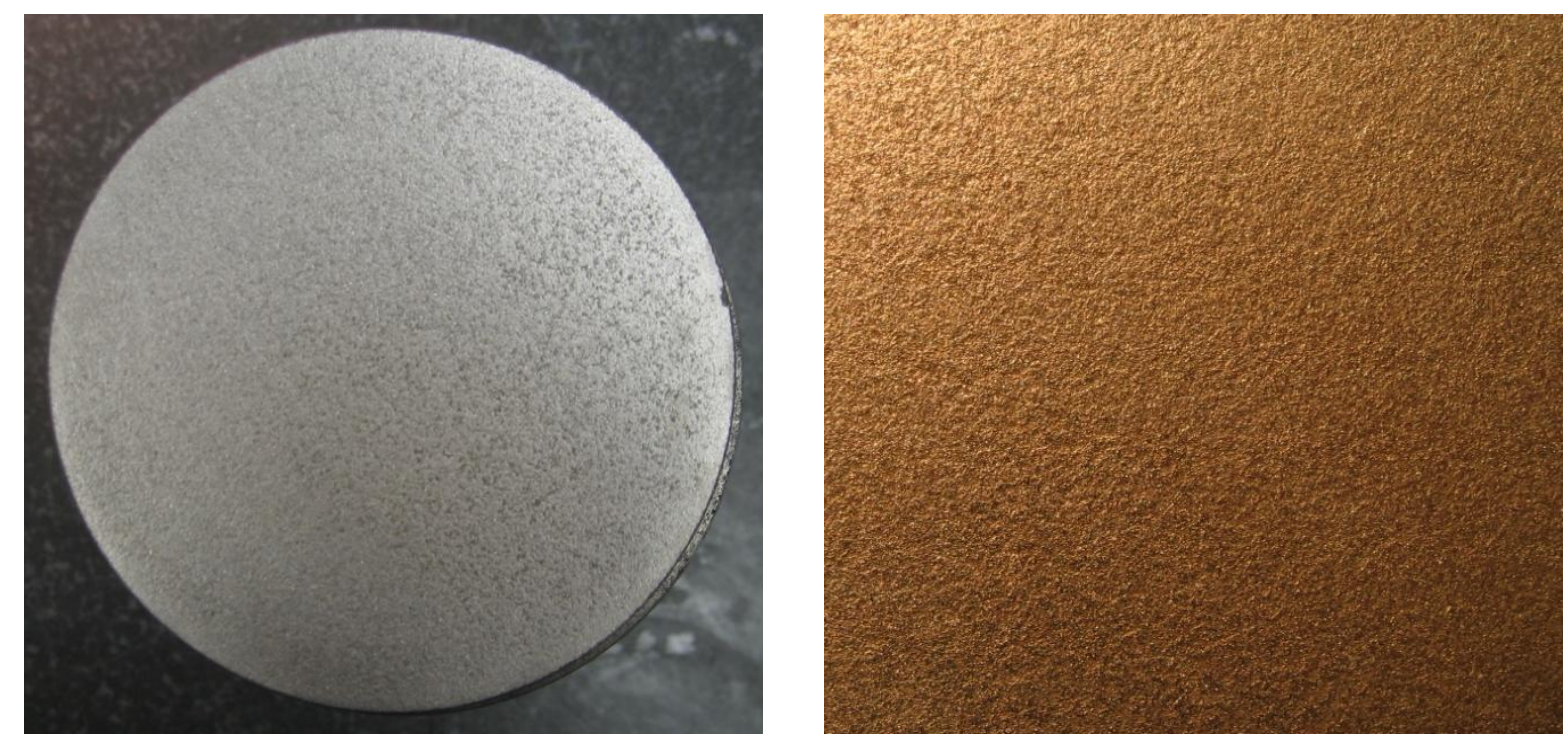

Figure A.6 - Metal TBC Medium $\left(R_{a}=8.8 \mu \mathrm{m}\right)$ 

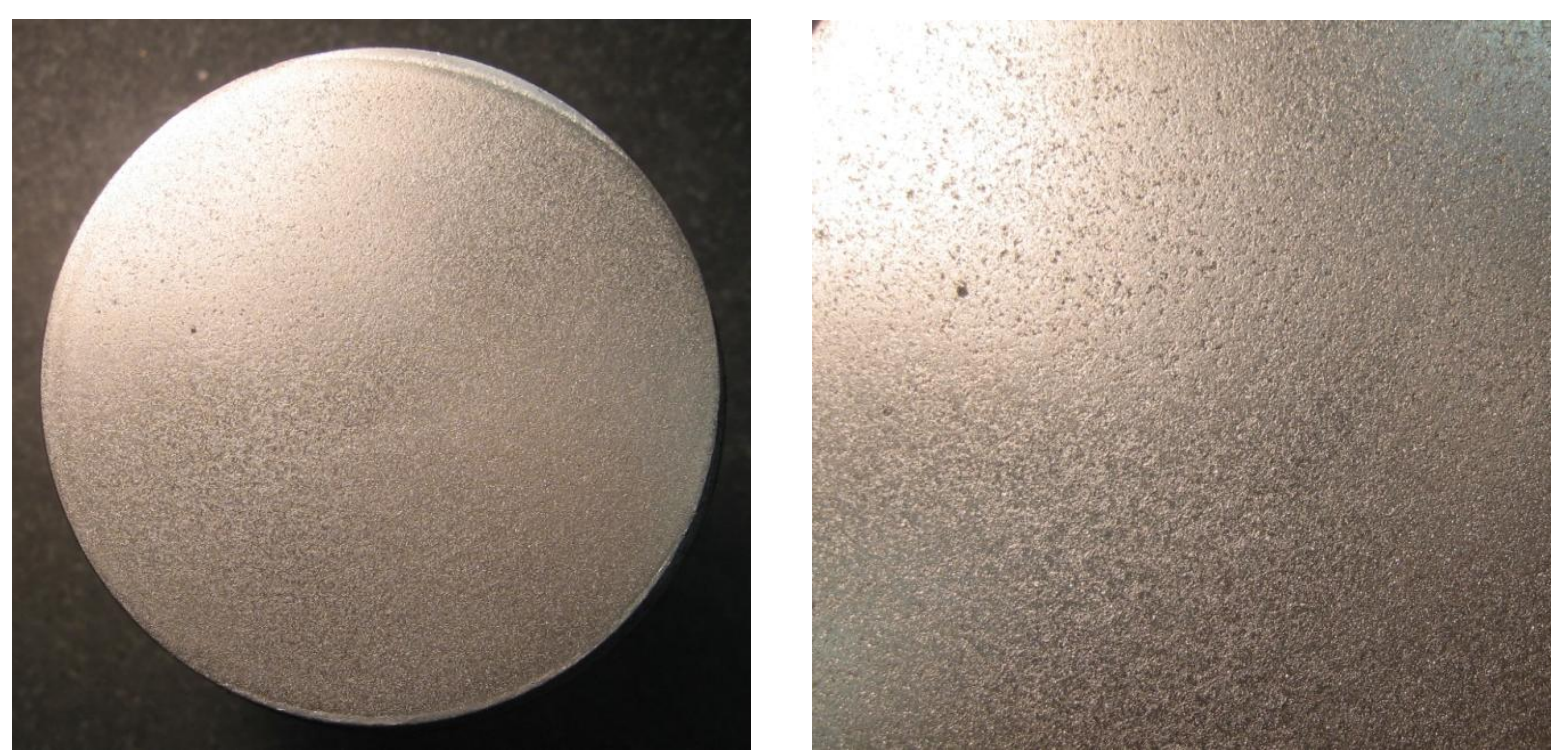

Figure A.7 - Metal TBC Mirror $\left(R_{a}=4.3 \mu \mathrm{m}\right)$

\section{A.3 Optical Profilometer Scans}

The following is a small collection of surface profile scans of the air-plasma sprayed copper coating taken using an optical profilometer (WYKO NT series). The images a provided to obtain a better sense of the true surface profile at a given average roughness, $R_{a}$ value.

Surface Statistics:

Ra: 17.65 um

Rq: $21.63 \mathrm{um}$

Rz: $168.01 \mathrm{um}$

Rt: 190.40 um

Set-up Parameters:

Size: $736 \times 480$

Sampling: $820.31 \mathrm{~nm}$

Processed Options:

Terms Removed:

Tilt

Filtering:

None
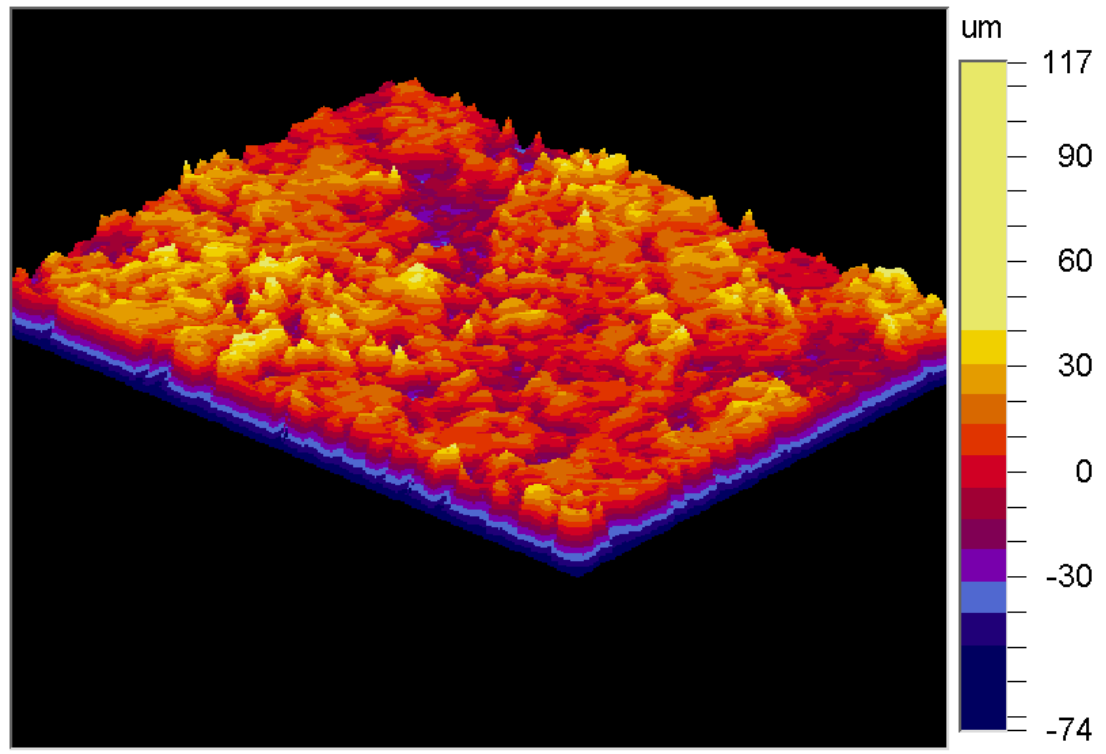
Surface Statistics:

Ra: 5.27 um

Rq: $6.97 \mathrm{um}$

Rz: $68.92 \mathrm{um}$

Rt: 88.01 um

Set-up Parameters:

Size: $736 \times 480$

Sampling: $3.27 \mathrm{um}$

Processed Options:

Terms Removed:

Tilt

Filtering:

None

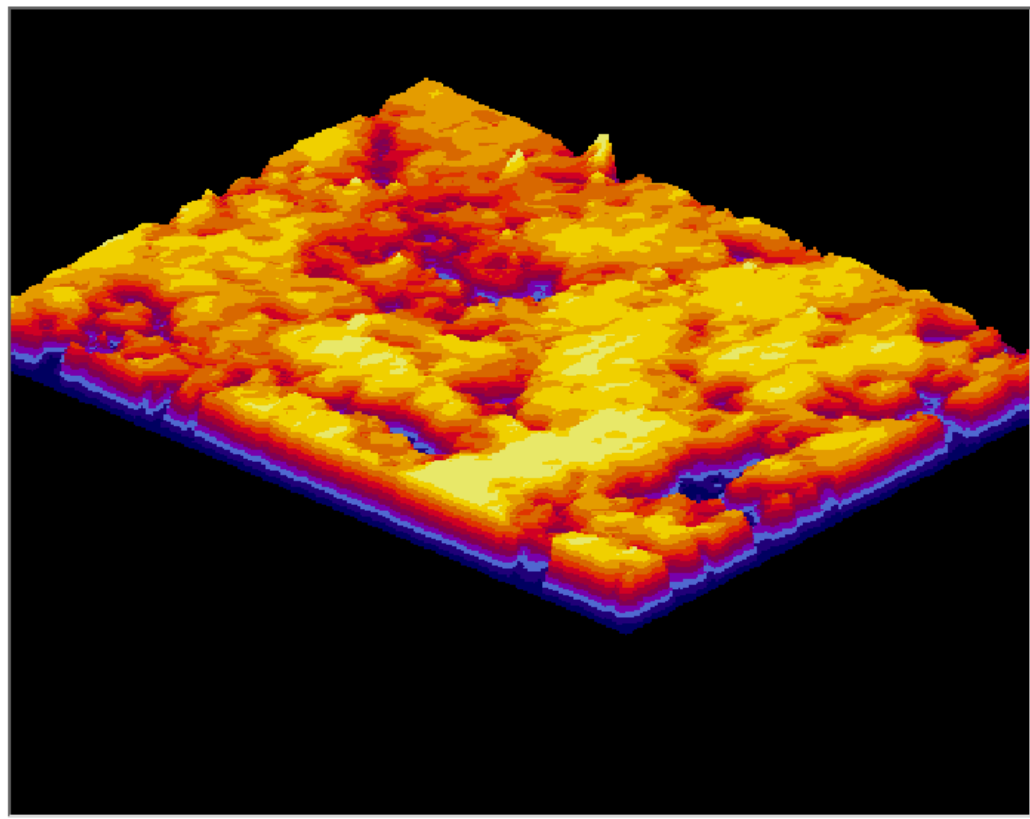

um

Surface Statistics:

$\mathrm{Ra}: 187.65 \mathrm{~nm}$

Rq: $311.82 \mathrm{~nm}$

Rz: 6.24 um

Rt: 6.70 um

Set-up Parameters:

Size: $736 \times 480$

Sampling: $3.27 \mathrm{um}$

Processed Options:

Terms Removed:

Tilt

Filtering:

None

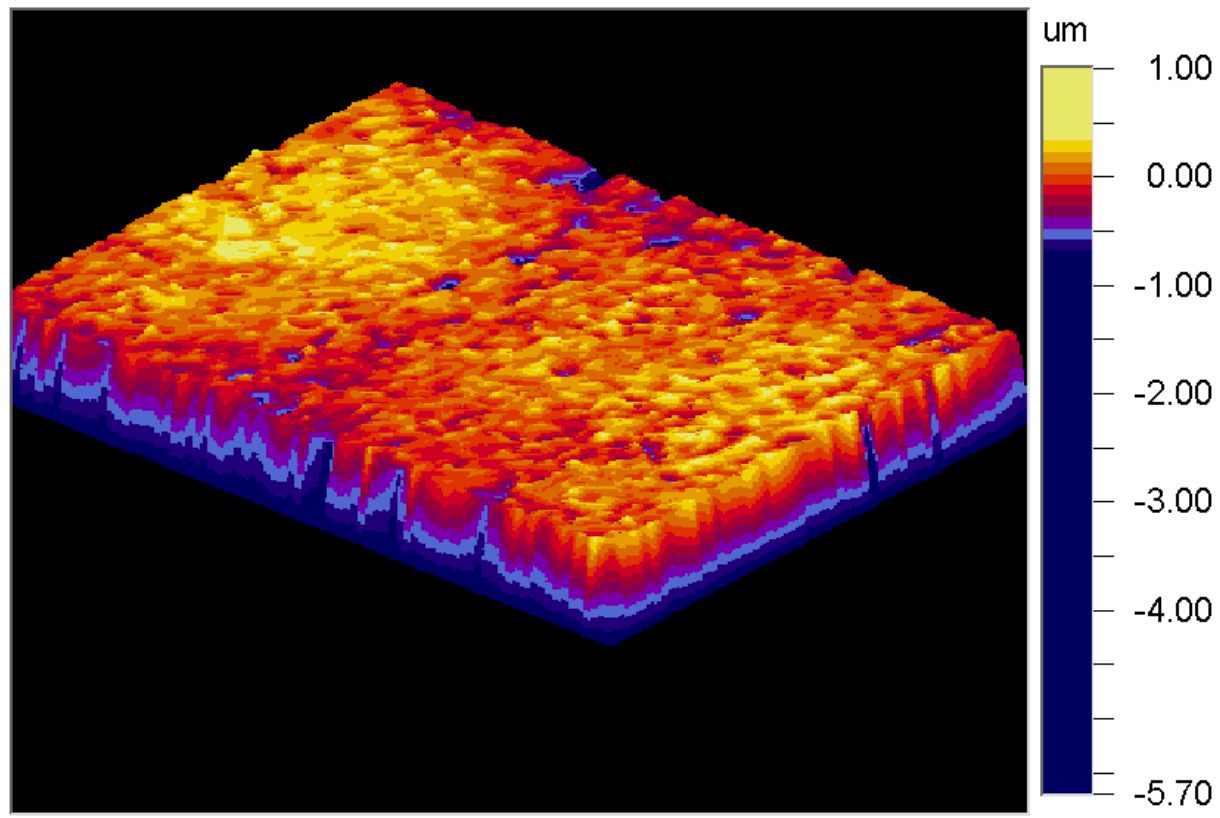




\section{Appendix B}

\section{Engineering Drawings}

The following appendix contains the detailed engineering drawings of the components used throughout the piston instrumentation process. The contents of the appendix are listed below.

Figure B.1: Thermocouple Plug

Figure B.2: Modified Piston

Figure B.3: Thermocouple Body - Tapered Pin

Figure B.4: Connector Block - Top

Figure B.5: Connector Block- Bottom 


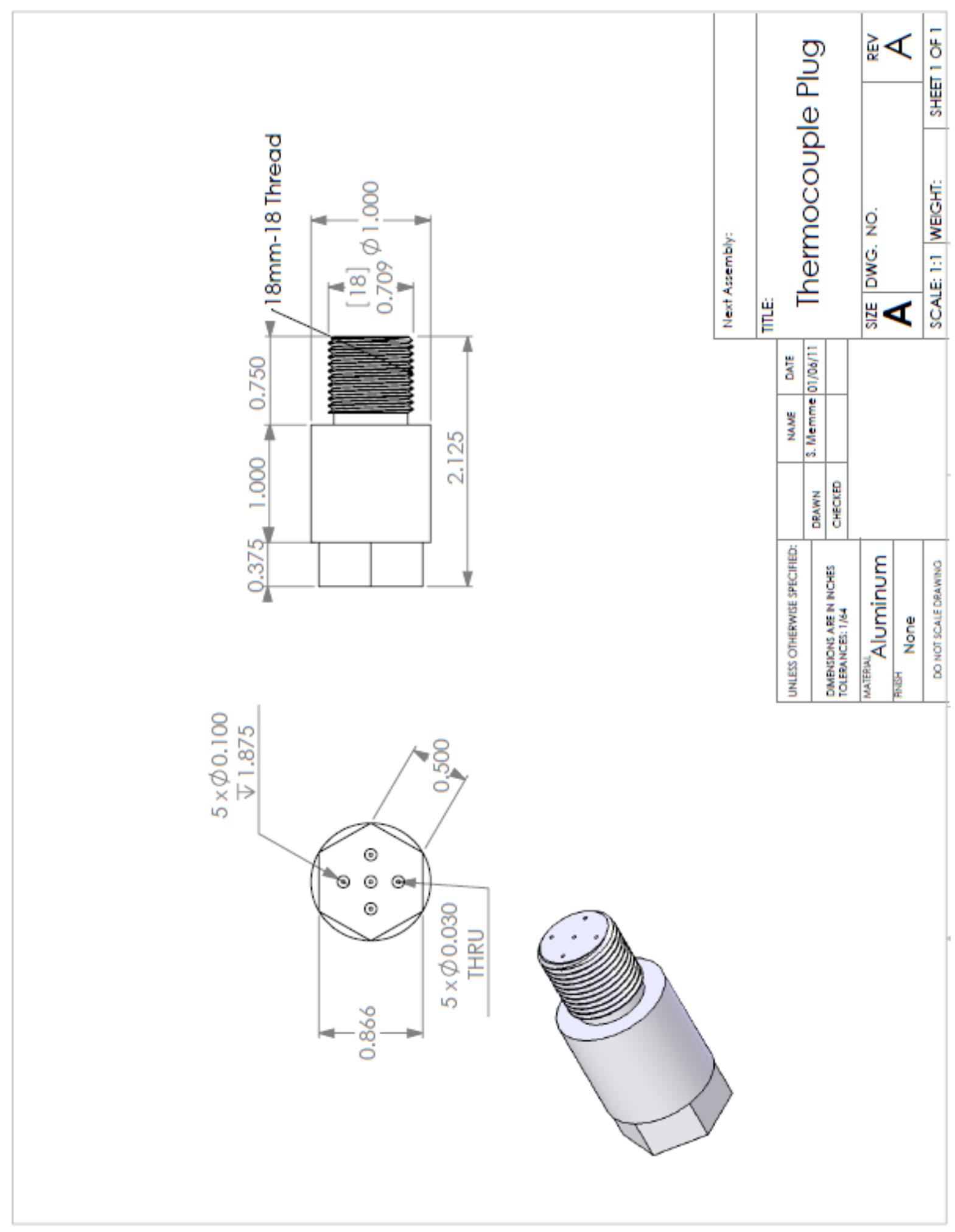

Figure B.1 - Thermocouple Plug 


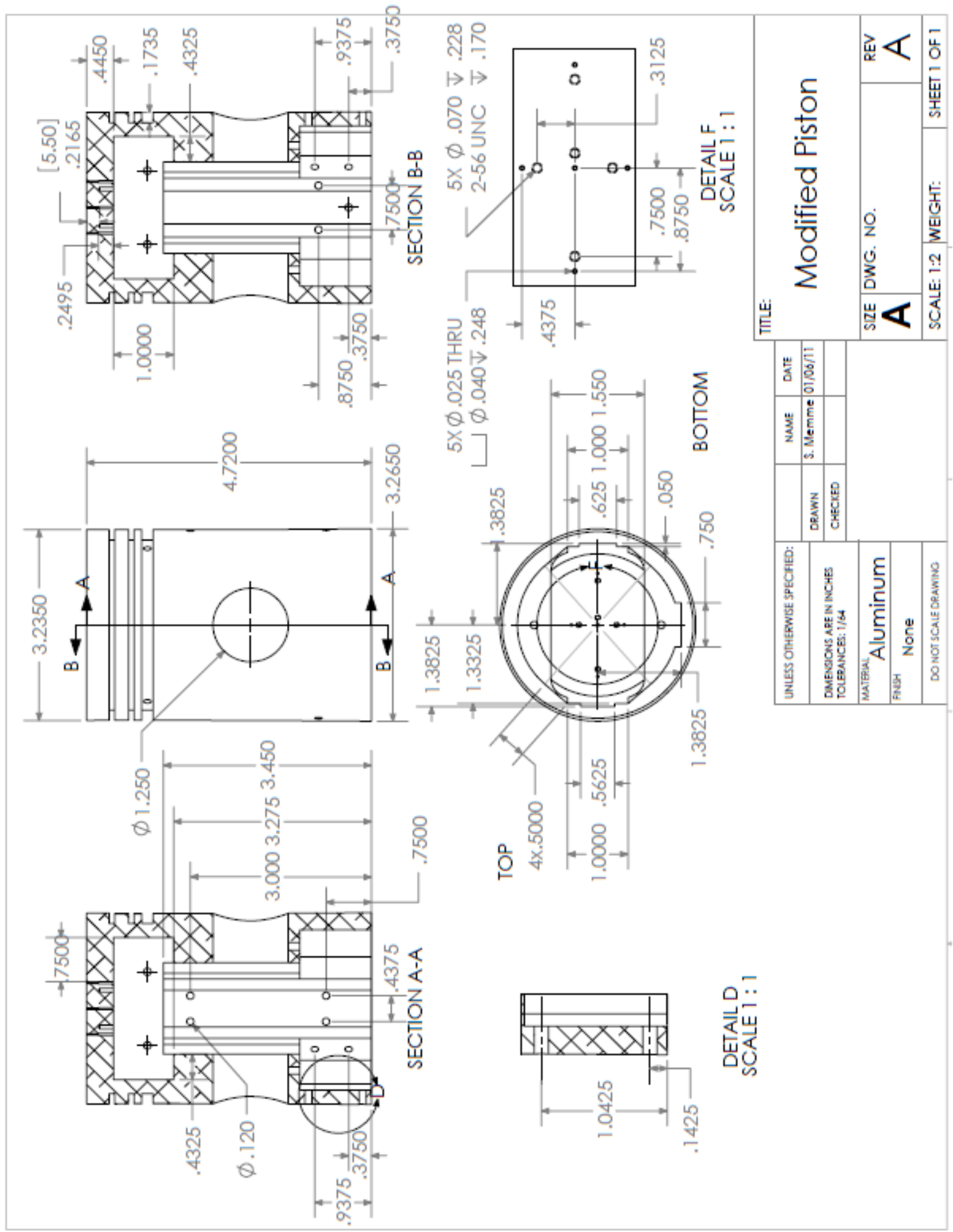

Figure B.2 - Modified Piston 


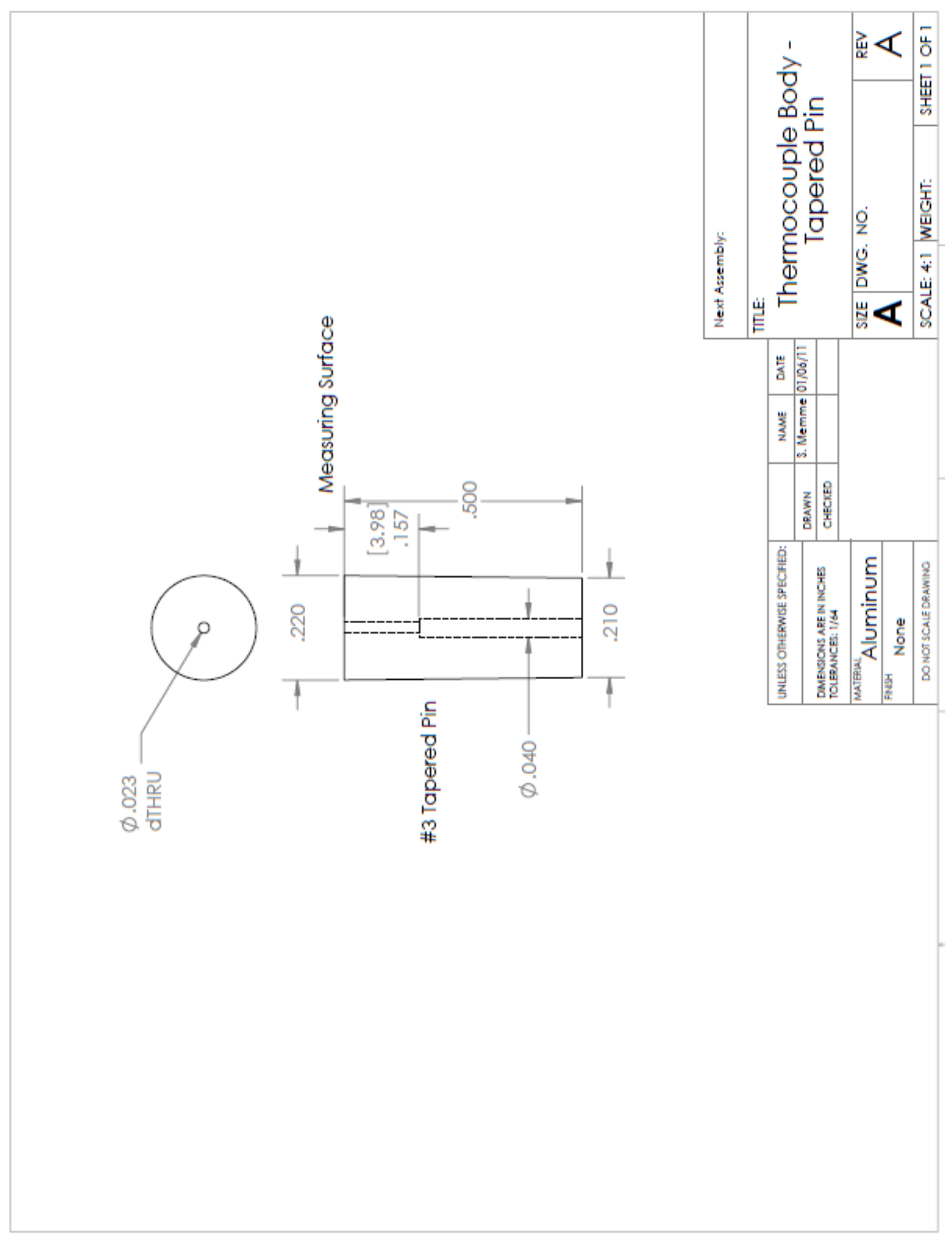

Figure B.3 - Thermocouple Body - Tapered Pin 


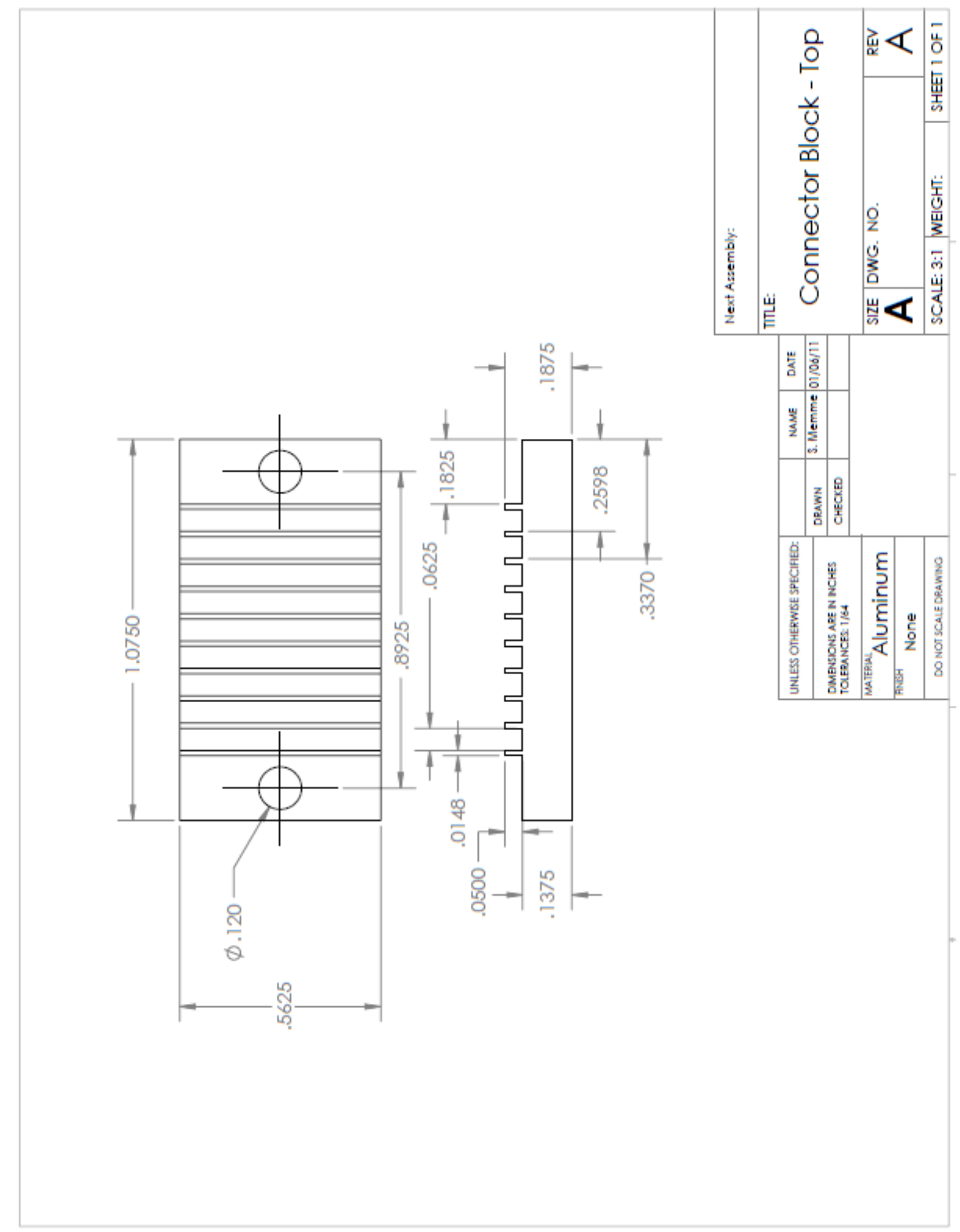

Figure B.4 - Connector Block - Top 


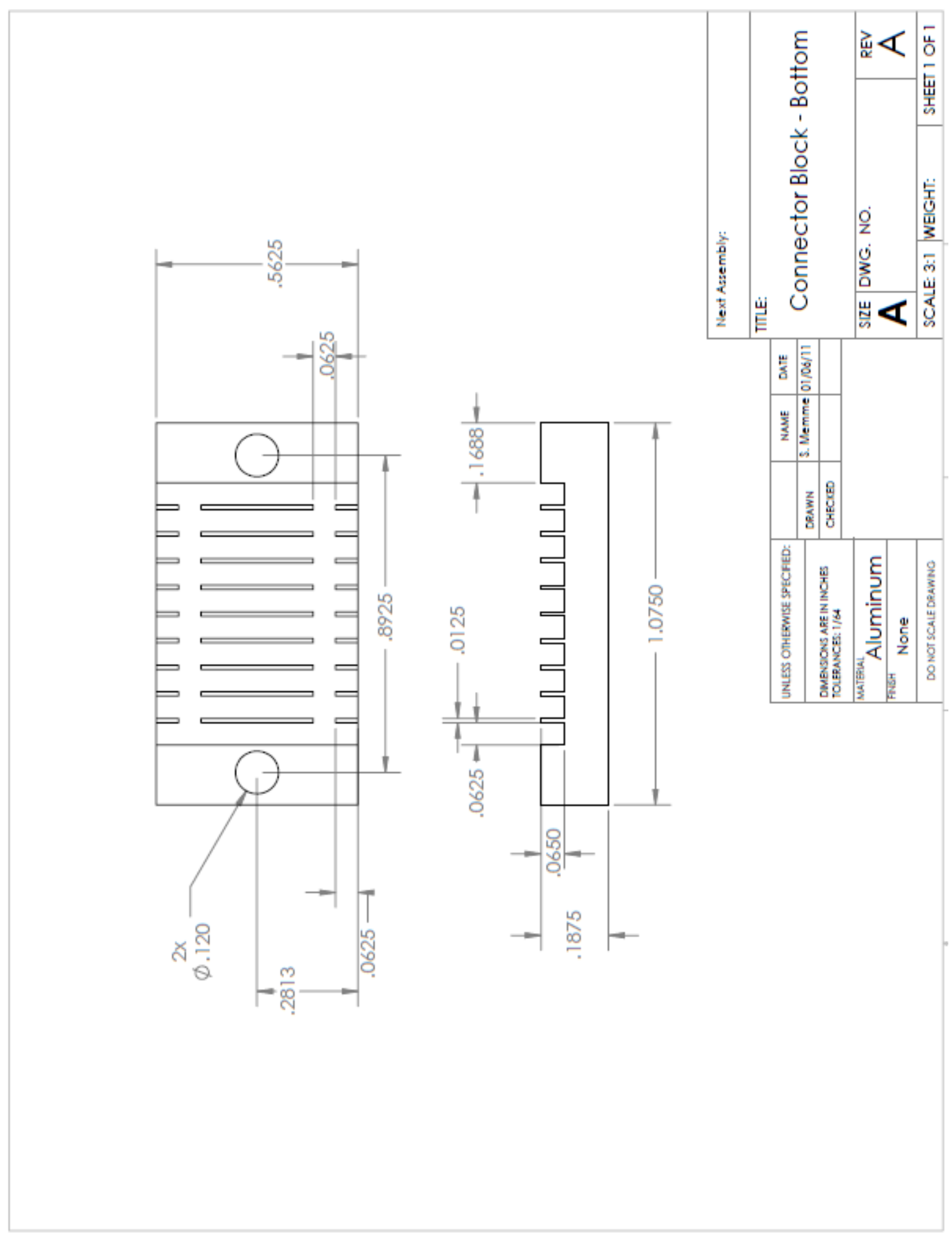

Figure B.5 - Connector Block - Bottom 


\section{Appendix C}

\section{Analog Filter Circuit Design}

Due to the inherently noisy test environment, previous attempts at making similar measurements had a great deal of difficulty obtaining meaningful instantaneous surface temperature measurements. The combinations of noise and low signal strength meant that the cycle-resolved temperature measurements could not be clearly deciphered from the temperature traces, resulting in the need for cycle averaging, and thus the loss of valuable information. An analog filtering circuit was designed to increase the signal-to-noise ratio of the high speed thermocouple signals used for this heat transfer analysis. In the following, a detailed outline of the circuit design and functionality will be given. 


\section{C.1 Design Objectives}

The purpose for designing the analog signal conditioning boards for the thermocouple signals was to increase the strength of the thermocouple signals while also reducing noise. Though various conditioning units are commercially available which amplify, filter and linearize thermocouple signals, they have two primary limitations. Since typical thermocouples usually have response times within the millisecond range, most signal conditioning circuits are limited to sampling speeds $<1000 \mathrm{~Hz}$, which was not sufficient for this experiment. Conditioning boards also typically only accept standard thermocouple metal pairings. Therefore, a custom circuit was designed to meet the specific needs of this experiment.

The primary design objectives for the circuit were to increase signal strength by amplifying it to the $\pm 10 \mathrm{~V}$ range of the NI 9215 module and thus maximize its 16-bit resolution. It was also desired to increase the signal-to-noise ratio of the thermocouple signals. The circuit should introduce as small a phase shift as possible and result in minimal distortion or attenuation of the temperature traces as a result of the filtering process.

\section{$\underline{\text { C.2 Circuit Design Features }}$}

The circuit board consists of three stages: initial amplification (AD8221), filtering (MAX274) and final amplification (AD797). Upon the analysis of the specifications for products from multiple integrated circuit (IC) manufacturers (Maxim, Analog Devices, National Semiconductor), the two amplifiers were selected due to their very low input voltage noise with respect to similar ICs in their respective categories. The filter selection process will be discussed based on the testing described in Section C.3. 
The circuit was designed to allow a gain of up to 40000. Tests conducted using uncoated plugs during the development of the circuit demonstrated that a gain of 10000 was sufficient to obtain temperature signals of greater than $2 \mathrm{Vp}$-p at typical engine operating conditions. The large gain settings were included in the circuit design to allow for sufficient signal strength during TBC-coated tests when temperature swings were greatly dampened.

In addition to the variable gain outputs, another key design feature of the circuit is the inclusion of a trim potentiometer which allows for the translation of the output signal between the rail voltages of the ICs. This ensures that the circuit output does not saturate when taking measurements at high gains. The ability to shift the output voltage is of particular importance during the calibration process of the thermocouples, as it acts as the zeroing/offset potentiometer of typical measurement circuitry (refer to Appendix D ).

\section{C.3 Circuit Development Testing Results}

Testing of the filtering circuit was conducted using both fixed frequency generator signals and through in-situ engine tests using a plug instrumented with surface thermocouples. After amplification through an AD8221 instrumentation amplifier, four different filtering IC and cut-off frequency combinations were tested simultaneously:

1) $\operatorname{MAX} 275 f_{c}=200 \mathrm{~Hz}$

2) $\operatorname{MAX} 275 f_{c}=1000 \mathrm{~Hz}$

3) MAX292 $f_{c}=333 \mathrm{~Hz}$

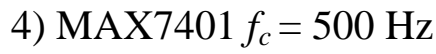

The signals measured during each test included the raw input signals, amplified signals (AD8221) and filtered signals to allow for comparison. MATLAB code was used to determine average noise level and phase shift in the signals. 


\section{$\underline{\text { C.4 Noise }}$}

During engine tests, average noise measurements were calculated as the mean peakto-peak voltage of five-point intervals (1 CAD) over 10 full engine cycles. Table C.1 below shows a sample of representative tests results at different engine operating conditions. The average noise values were translated to temperature using an approximate Seebeck coefficient of $40 \mathrm{uV} /{ }^{\circ} \mathrm{C}$ for the constantan-aluminum pairing as measured by Marr [113].

Table C.1 Samples Engine Test Noise Data (in Volts)

\begin{tabular}{|c|c|c|c|c|c|c|c|}
\hline $\begin{array}{l}\text { Speed } \\
\text { (rpm) }\end{array}$ & $\begin{array}{c}\text { Torque } \\
(\mathbf{N m})\end{array}$ & Raw TC & $\begin{array}{c}\text { AD8221 } \\
(G=100)\end{array}$ & $\begin{array}{c}\operatorname{MAX275} \\
\left(f_{c}=\right. \\
1000 \mathrm{~Hz})\end{array}$ & $\begin{array}{c}\text { MAX275 } \\
\left(f_{c}=\right. \\
200 \mathrm{~Hz}) \\
\end{array}$ & $\begin{array}{c}\text { MAX7401 } \\
\left(f_{c}=\right. \\
500 \mathrm{~Hz}) \\
\end{array}$ & $\begin{array}{c}\text { MAX292 } \\
\left(f_{c}=\right. \\
333 \mathrm{~Hz}) \\
\end{array}$ \\
\hline 1125rpm & 41 & $2.31 \mathrm{E}-04$ & $5.24 \mathrm{E}-04$ & $3.41 \mathrm{E}-04$ & $2.42 \mathrm{E}-04$ & $3.89 \mathrm{E}-04$ & $4.08 \mathrm{E}-04$ \\
\hline 1130rpm & 25 & 2.29E-04 & $5.22 \mathrm{E}-04$ & $2.71 \mathrm{E}-04$ & $2.10 \mathrm{E}-04$ & $4.11 \mathrm{E}-04$ & 4.13E-04 \\
\hline 1130rpm & 25 & $2.40 \mathrm{E}-04$ & $4.15 \mathrm{E}-04$ & $2.29 \mathrm{E}-04$ & $2.04 \mathrm{E}-04$ & $4.11 \mathrm{E}-04$ & $3.76 \mathrm{E}-04$ \\
\hline 1200rpm & Idle & 2.44E-04 & $3.76 \mathrm{E}-04$ & $2.04 \mathrm{E}-04$ & $1.86 \mathrm{E}-04$ & 3.09E-04 & 4.59E-04 \\
\hline 1125rpm & 41 & $2.70 \mathrm{E}-04$ & $5.97 \mathrm{E}-04$ & $3.33 \mathrm{E}-04$ & $3.35 \mathrm{E}-04$ & $4.95 \mathrm{E}-04$ & $3.78 \mathrm{E}-04$ \\
\hline 1125rpm & 41 & $2.31 \mathrm{E}-04$ & $5.24 \mathrm{E}-04$ & $3.41 \mathrm{E}-04$ & $2.42 \mathrm{E}-04$ & $3.89 \mathrm{E}-04$ & $4.08 \mathrm{E}-04$ \\
\hline 1130rpm & 25 & 2.29E-04 & $5.22 \mathrm{E}-04$ & $2.71 \mathrm{E}-04$ & $2.10 \mathrm{E}-04$ & $4.11 \mathrm{E}-04$ & 4.13E-04 \\
\hline 1250rpm & 22.4 & 2.23E-04 & $5.43 \mathrm{E}-04$ & $2.40 \mathrm{E}-04$ & $2.57 \mathrm{E}-04$ & $3.91 \mathrm{E}-04$ & $4.28 \mathrm{E}-04$ \\
\hline 1250rpm & 41 & 2.24 & 6.0 & 04 & 2.6 & 3.75 & $5.10 \mathrm{E}-04$ \\
\hline 1270rpm & 48 & $2.66 \mathrm{E}-04$ & $6.84 \mathrm{E}-04$ & $2.82 \mathrm{E}-04$ & $2.40 \mathrm{E}-04$ & $3.74 \mathrm{E}-04$ & $4.63 \mathrm{E}-04$ \\
\hline 1270rpm & 48 & $2.60 \mathrm{E}-04$ & $6.35 \mathrm{E}-04$ & $3.58 \mathrm{E}-04$ & $2.83 \mathrm{E}-04$ & $5.62 \mathrm{E}-04$ & $4.42 \mathrm{E}-04$ \\
\hline 1400rpm & 33.9 & 2.32E-04 & $4.96 \mathrm{E}-04$ & $3.73 \mathrm{E}-04$ & $2.39 \mathrm{E}-04$ & 4.43E-04 & $3.90 \mathrm{E}-04$ \\
\hline 1400rpm & 33.9 & $2.35 \mathrm{E}-04$ & $4.63 \mathrm{E}-04$ & $2.60 \mathrm{E}-04$ & $2.24 \mathrm{E}-04$ & $3.51 \mathrm{E}-04$ & $4.08 \mathrm{E}-04$ \\
\hline \multirow[t]{3}{*}{ 1450rpm } & 18.4 & $2.26 \mathrm{E}-04$ & $5.50 \mathrm{E}-04$ & $2.39 \mathrm{E}-04$ & $2.35 \mathrm{E}-04$ & $3.68 \mathrm{E}-04$ & $4.29 \mathrm{E}-04$ \\
\hline & Average & $2.38 \mathrm{E}-04$ & 5.34E-04 & $2.81 \mathrm{E}-04$ & $2.38 \mathrm{E}-04$ & $4.04 \mathrm{E}-04$ & $4.26 \mathrm{E}-04$ \\
\hline & $\begin{array}{l}{ }^{\circ} \mathrm{C} \text { of } \\
\text { Noise }\end{array}$ & 5.9489 & 0.1335 & 0.0703 & 0.0594 & 0.1010 & 0.1066 \\
\hline
\end{tabular}

Table C.1 clearly demonstrates the benefits of the filtering circuit at all engine operating conditions. The importance of the instrumentation amplifier is clear by comparing the average non-filtered raw thermocouple data to the signal after the first amplification stage. After amplifying the raw thermocouple signal by $100 \mathrm{X}$, the average peak-to-peak noise only doubles, thus increasing the signal-to-noise ratio by $50^{2}$ times. 
In comparing the effects of the different filtering ICs, it is clear that the most effective at reducing signal noise is the MAX275 with a cut-off frequency of $f_{c}=200 \mathrm{~Hz}$. However, due to the low cut-off, the signal was significantly attenuated in comparison to the non-filtered output of the instrumentation amplifier, thus resulting in the loss of critical temperature data and reducing the usefulness of this circuit configuration. The MAX275 with $f_{c}=1000 \mathrm{~Hz}$ thus proved to be the most effective at eliminating noise in comparison to the other options, with signals containing less than $0.1^{\circ} \mathrm{C}$ of noise on average, which is a reduction of $90 \%$ with respect to the pre-amplified signal. No signal attenuation was experienced with the MAX275 in this configuration. The MAX275 also provided one of the lower and most consistent phase shift ( 4 CAD) of the tested filtering circuits.

Another important factor in the selection of the MAX275 was its behaviour with respect to noise created by the engine spark plug. At ignition, an impulse response into the thermocouple signals during each firing cycle. Of the three filtering ICs tested, the MAX275 was least affected by this impulse, while the spark resulted in large distortions in the MAX292 and MAX7401 output signals.

The filtered signal was then amplified with the AD797 final amplification stage. Table C. 2 below shows the tests results using the full three-stage filtering circuit with a gain of 10000. Introducing the final amplification stage did not introduce any further noise into the signal, with an equivalent of only $0.07^{\circ} \mathrm{C}$ of noise being present in the final output signal after an applied gain of 10000 . 
Table C.2 - Filter Circuit Noise Data

\begin{tabular}{|c|c|c|c|c|}
\hline $\begin{array}{l}\text { Speed } \\
(\mathbf{r p m})\end{array}$ & $\begin{array}{c}\text { Torque } \\
(\mathrm{Nm})\end{array}$ & $\begin{array}{c}\text { AD8221 } \\
(\mathbf{G}=500) \\
\end{array}$ & $\begin{array}{c}\text { MAX275 } \\
\left(f_{c}=1000 H z\right)\end{array}$ & $\begin{array}{c}\text { AD797 } \\
\left(\mathbf{G}_{\text {final }}=\mathbf{1 0 0 0 0}\right) \\
\end{array}$ \\
\hline $1266 \mathrm{rpm}$ & 17.5 & $2.88 \mathrm{E}-03$ & $1.70 \mathrm{E}-03$ & $1.71 \mathrm{E}-02$ \\
\hline 1250rpm & 20.8 & $2.52 \mathrm{E}-03$ & $1.71 \mathrm{E}-03$ & $2.96 \mathrm{E}-02$ \\
\hline 1250rpm & 20.8 & $2.48 \mathrm{E}-03$ & $1.66 \mathrm{E}-03$ & $2.86 \mathrm{E}-02$ \\
\hline \multirow[t]{3}{*}{ 1250rpm } & 20.8 & $2.75 \mathrm{E}-03$ & $1.79 \mathrm{E}-03$ & 3.09E-02 \\
\hline & Average & $2.66 \mathrm{E}-03$ & $1.71 \mathrm{E}-03$ & $2.65 \mathrm{E}-02$ \\
\hline & $\begin{array}{l}{ }^{\circ} \mathrm{C} \text { of } \\
\text { Noise } \\
\end{array}$ & 0.1329 & 0.0857 & 0.0664 \\
\hline
\end{tabular}

A sample temperature trace obtained using an old instrumented plug showing the output signal after each of the three circuit stages is shown below in Figure C.1. It can be seen that the final output signal has a peak-to-peak signal of greater than $2 \mathrm{~V}$, with an inherent noise signal of only $0.0286 \mathrm{~V}$.

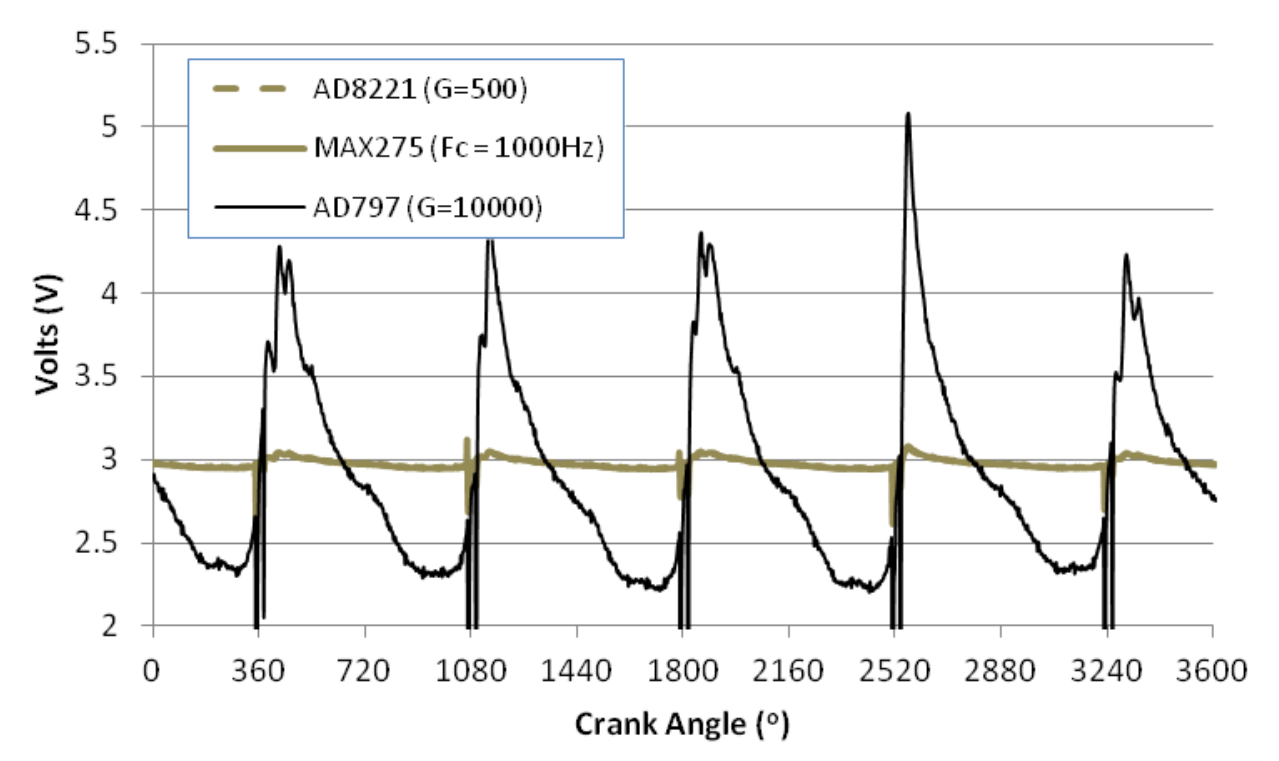

Figure C.1 - Example of Filtered Temperature Profile

\section{C.5 Phase Shift}

The filtering circuitry creates a phase shift in the output signal due to the inherent operating characteristics of the integrated circuits used. This phase shift must be accounted 
for during signal processing to ensure positional accuracy of the data throughout the cycle. It was measured for the final filtering circuit using a known input from a function generator.

In the function generator tests, a square wave was used to measure the delay induced by the circuit. By recording both the input and output of the circuit, the time delay was defined as the time difference between reaching the maximum values of the square wave in the input and output. On average, the measured time delay was $1.542 \mathrm{~ms}$, which was seen to be consistent at a range of input frequencies and circuit gains. Figure C.2b below shows the time delay of a filtered square wave.

Time delays were seen to vary when different waveforms were used as a result of the filter's interaction with the different harmonics which characterize each waveform. However, a square wave was deemed to be most representative of the combustion process.

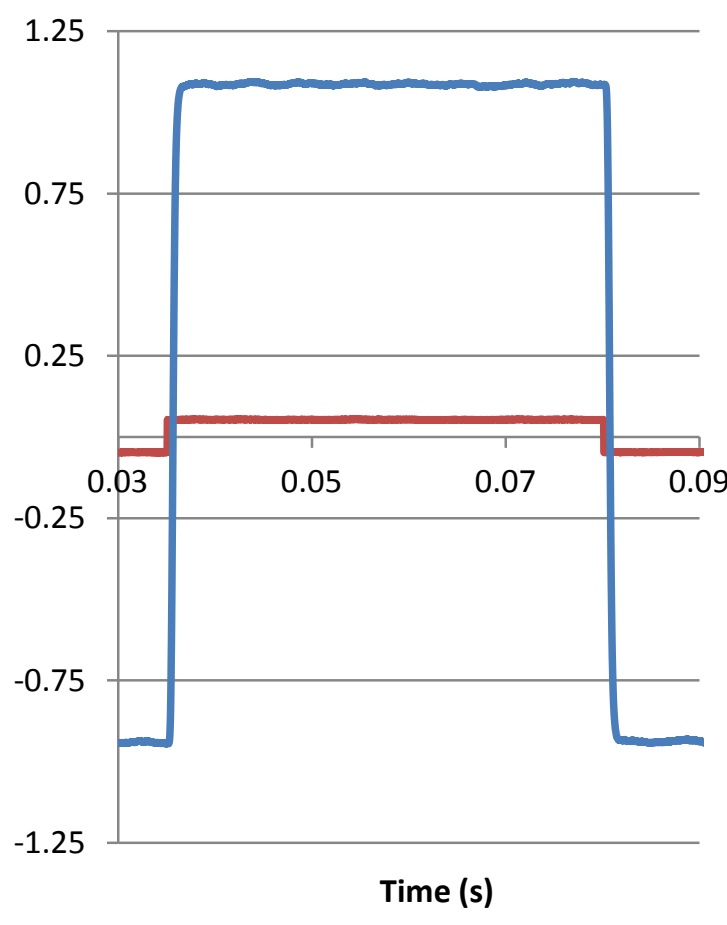

a)

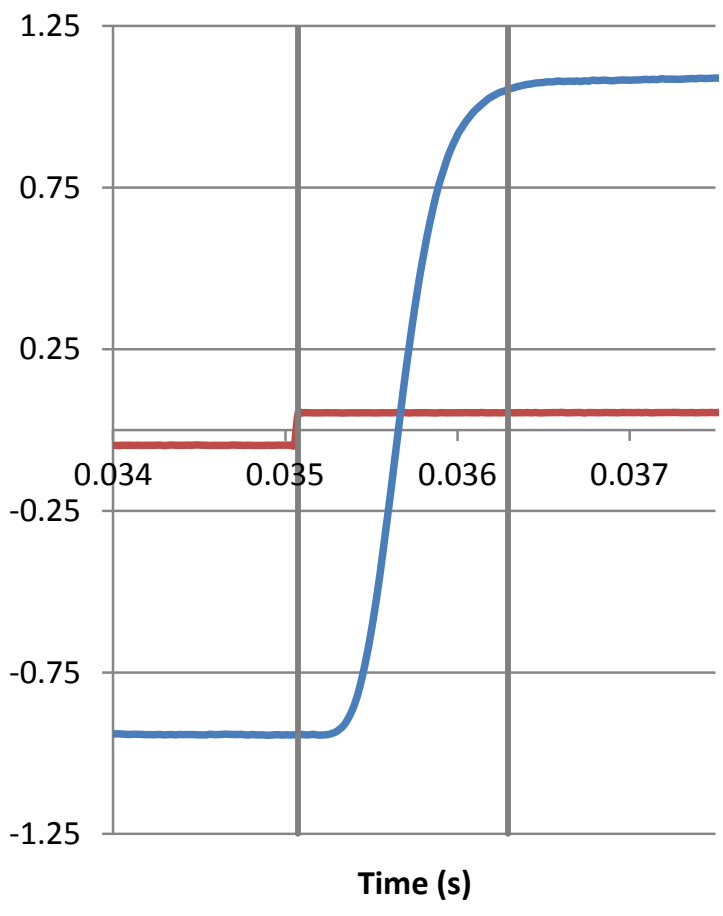

b)

Figure C.2 - Filter Circuit Time Delay a) Full cycle and b) Zoom Showing Time Delay 


\section{C.6 Circuit Gains}

Variations in resistor values and IC characteristics resulted in small deviation from the expected circuit gains. The gain at each of the available settings was verified using an input signal from a function generator. Table C.3 lists the measured gains for each of the available settings. Note that the gains at $500 \times 60$ and $500 \times 80$ could not be measured due to saturation of the circuit output.

Table C.3 - Measured Circuit Gains

\begin{tabular}{cc}
\hline Gain Setting & Measured Gain \\
\hline $\mathbf{1 0 0 x 1 0}$ & 999.4 \\
$\mathbf{1 0 0 x 2 0}$ & 2004.5 \\
$\mathbf{1 0 0 x 4 0}$ & 4010.3 \\
$\mathbf{1 0 0 x 6 0}$ & 6002.8 \\
$\mathbf{1 0 0 x 8 0}$ & 7991.5 \\
$\mathbf{5 0 0 x 1 0}$ & 4954.1 \\
$\mathbf{5 0 0 x 2 0}$ & 9867.0 \\
$\mathbf{5 0 0 x 4 0}$ & 19744.2 \\
\hline
\end{tabular}

\section{C.7 Circuit Layout}

The layout of the circuit board was completed using NI Multisim and Ultiboard 11.0. Refer to the accompanying DVD for the circuit Gerber and NC drill files.

To ensure maximum signal quality and reliability, the circuit boards were outsourced to be assembled. The circuit bare boards were manufactured by Gold Phoenix PCB Co., Ltd (Oakville, ON), and assembled by Mircroart Services, Inc (Markham, ON).

\section{$\underline{\text { C.8 Bill of Materials }}$}

Table C.4 below provides a list of the components used in the filtering circuit and their board designations. 
Table C.4 - Circuit Board Bill of Materials

\begin{tabular}{|c|c|c|}
\hline Component & \# & Board Designation \\
\hline AD8221BR-ND & 5 & AD8221-1, AD8221-2, AD8221-3, AD8221-4, AD8221-5 \\
\hline MAX274BCNG & 5 & MAX274-1, MAX274-2, MAX274-3, MAX274-4, MAX274-5 \\
\hline AD797BN & 5 & AD797 -1, AD797 -2, AD797 -3, AD797 -4, AD797 -5 \\
\hline LM7805CT & 1 & +V REG \\
\hline LM7905CT & 1 & -V REG \\
\hline $\begin{array}{c}\text { Screw } \\
\text { Terminal }\end{array}$ & 17 & $\begin{array}{l}\text { +15V MAIN, -15V MAIN, F OUT-1, F OUT-2, F OUT-3, F OUT-4, F } \\
\text { OUT-5, IN-1, IN-2, IN-3, IN-4, IN-5, OUT-1, OUT-2, OUT-3, OUT-4, } \\
\text { OUT-5 }\end{array}$ \\
\hline $\begin{array}{l}2 \text { POS DIP } \\
\text { Switch }\end{array}$ & 5 & IA GAIN-1, IA GAIN-2, IA GAIN-3, IA GAIN-4, IA GAIN-5 \\
\hline $\begin{array}{l}5 \text { POS DIP } \\
\text { Switch }\end{array}$ & 5 & $\begin{array}{l}\text { AMP GAIN-1, AMP GAIN-2, AMP GAIN-3, AMP GAIN-4, AMP } \\
\text { GAIN-5 }\end{array}$ \\
\hline Headers & 20 & $\begin{array}{c}+5 \mathrm{~V}-1,+5 \mathrm{~V}-2,+5 \mathrm{~V}-3,+5 \mathrm{~V}-4,+5 \mathrm{~V}-5,-5 \mathrm{~V}-1,-5 \mathrm{~V}-2,-5 \mathrm{~V}-3,-5 \mathrm{~V}-4,-5 \mathrm{~V}- \\
5,+15 \mathrm{~V}-1,+15 \mathrm{~V}-2,+15 \mathrm{~V}-3,+15 \mathrm{~V}-4,+15 \mathrm{~V}-5,-15 \mathrm{~V}-1,-15 \mathrm{~V}-2,-15 \mathrm{~V}-3 \\
-15 \mathrm{~V}-4,-15 \mathrm{~V}-5\end{array}$ \\
\hline JUMPER & 8 & $\mathrm{~J} 2, \mathrm{~J} 2, \mathrm{~J} 2, \mathrm{~J} 2, \mathrm{~J} 4, \mathrm{~J} 4, \mathrm{~J} 4, \mathrm{~J} 4$ \\
\hline TESTPOINT & 15 & $\begin{array}{l}\text { TP1, TP1, TP1, TP1, TP1, TP2, TP2, TP2, TP2, TP2, TP3, TP3, TP3, } \\
\text { TP3, TP3 }\end{array}$ \\
\hline $0.1 \mathrm{uF} 5 \%$ & 31 & $\begin{array}{c}\text { C1-1, C1-2, C1-3, C1-4, C1-5, C2-1, C2-2, C2-3, C2-4, C2-5, CA1-1, } \\
\text { CA1-2, CA1-3, CA1-4, CA1-5, CA2-1, CA2-2, CA2-3, CA2-4, CA2-5, } \\
\text { CF1+, CF1+1, CF1+2, CF1+3, CF1+4, CF1-, CF1-1, CF1-2, CF1-3, } \\
\text { CF1-4, CR2 }\end{array}$ \\
\hline $0.22 \mathrm{uF} 5 \%$ & 1 & CR1 \\
\hline 1.02MOhm 1\% & 5 & R2C-1, R2C-2, R2C-3, R2C-4, R2C-5 \\
\hline 1.1MOhm 1\% & 10 & $\begin{array}{l}\text { R2A-1, R2A-2, R2A-3, R2A-4, R2A-5, R2B-1, R2B-2, R2B-3, R2B-4, } \\
\text { R2B-5 }\end{array}$ \\
\hline 1MOhm 1\% & 25 & $\begin{array}{l}\text { R2D-1, R2D-2, R2D-3, R2D-4, R2D-5, R4A-1, R4A-2, R4A-3, R4A-4, } \\
\text { R4A-5, R4B-1, R4B-2, R4B-3, R4B-4, R4B-5, R4C-1, R4C-2, R4C-3, } \\
\text { R4C-4, R4C-5, R4D-1, R4D-2, R4D-3, R4D-4, R4D-5 }\end{array}$ \\
\hline 1kOhm 1\% & 5 & RA1-1, RA1-2, RA1-3, RA1-4, RA1-5 \\
\hline 1nF 5\% & 10 & $\mathrm{C} 3-1, \mathrm{C} 3-2, \mathrm{C} 3-3, \mathrm{C} 3-4, \mathrm{C} 3-5, \mathrm{C} 5-1, \mathrm{C} 5-2, \mathrm{C} 5-3, \mathrm{C} 5-4, \mathrm{C} 5-5$ \\
\hline $1 \mathrm{uF} 5 \%$ & 1 & CR4 \\
\hline $2.2 \mathrm{uF} 5 \%$ & 1 & CR3 \\
\hline $4.02 \mathrm{kOhm} 1 \%$ & 10 & R1-1, R1-2, R1-3, R1-4, R1-5, R2-1, R2-2, R2-3, R2-4, R2-5 \\
\hline $4.7 \mathrm{nF} 5 \%$ & 5 & C4-1, C4-2, C4-3, C4-4, C4-5 \\
\hline $5 p F 5 \%$ & 5 & CA3-1, CA3-2, CA3-3, CA3-4, CA3-5 \\
\hline 9kOhm 1\% & 5 & RG1-1, RG1-2, RG1-3, RG1-4, RG1-5 \\
\hline $10 u F 5 \%$ & 2 & $\mathrm{CP}+, \mathrm{CP}-$ \\
\hline 19kOhm 1\% & 5 & RG2-1, RG2-2, RG2-3, RG2-4, RG2-5 \\
\hline 39kOhm 1\% & 5 & RG3-1, RG3-2, RG3-3, RG3-4, RG3-5 \\
\hline 50k POT & 5 & V TRIM -1, V TRIM -2, V TRIM -3, V TRIM -4, V TRIM -5 \\
\hline $59 \mathrm{kOhm} 1 \%$ & 5 & RG4-1, RG4-2, RG4-3, RG4-4, RG4-5 \\
\hline 79kOhm 1\% & 5 & RG5-1, RG5-2, RG5-3, RG5-4, RG5-5 \\
\hline
\end{tabular}




\begin{tabular}{ccc}
\hline 100kOhm 1\% & 15 & R3A-1, R3A-2, R3A-3, R3A-4, R3A-5, R3B-1, R3B-2, R3B-3, R3B-4, \\
& & R3B-5, R3C-1, R3C-2, R3C-3, R3C-4, R3C-5 \\
$\mathbf{1 0 0 O h m ~ 1 \% ~}$ & 5 & RGI-2, RGI-3, RGI-5, RGI-7, RGI-9 \\
$\mathbf{2 0 0 k O h m ~ 1 \% ~}$ & 5 & R1D-1, R1D-2, R1D-3, R1D-4, R1D-5 \\
215kOhm 1\% & 25 & $\begin{array}{l}\text { R1A-1, R1A-2, R1A-3, R1A-4, R1A-5, R1B-1, R1B-2, R1B-3, R1B-4, } \\
\text { R1B-5, R1C-1, R1C-2, R1C-3, R1C-4, R1C-5, R3D-1, R3D-2, R3D-3, } \\
\text { R3D-4, R3D-5, RPOT-1, RPOT-2, RPOT-3, RPOT-4, RPOT-5 }\end{array}$ \\
& & RGI-1, RGI-4, RGI-6, RGI-8, RGI-10 \\
\hline 499Ohm 1\% & 5 & \\
\hline
\end{tabular}




\section{Appendix D}

\section{Thermocouple Calibration - Circuit Setup}

The analog filtering circuit was designed to allow for versatility in the thermocouple calibration process. The combination of the trim potentiometer and the variable output gains are used to maximize the resolution of the data acquisition system when small peak-to-peak temperature fluctuations are measured during TBC-coated tests. However, as the output gain is increased, the temperature range available for calibration is reduced. Also, due to the inherent DC offset of the ICs used, the trim pot must be used to shift the circuit output to the $\pm 10 \mathrm{~V}$ range read by the DAQ. As a result, a new thermocouple calibration must be completed at each gain setting.

To prepare the circuit for a calibration, a gain setting is selected based on the desired temperature range to be studied. The appropriate gain setting can be determined by using the thermocouple Seebeck coefficient of approximately $40 \mu \mathrm{V} /{ }^{\circ} \mathrm{C}$ and an available voltage range 
of $20 \mathrm{~V}$ on the DAQ. For example, if $\mathrm{G}=5000$, then a temperature range of approximately $20 \mathrm{~V} /\left(40 \mu \mathrm{V} /{ }^{\circ} \mathrm{C} * 5000\right)=100^{\circ} \mathrm{C}$ is available for calibration.

A desired temperature range across which to calibrate the thermocouples must then be selected. This is a function of the engine operating conditions and coating characteristics in which the thermocouples will be used. Surface temperature data from previous engine runs should be used as a reference. After determining the desired range, the thermocouple should be heated to the lower bound of the temperature range in the calibration apparatus (i.e. circulating bath, oven, etc) and the output of the analog circuit be set to $-10 \mathrm{~V}$ using the adjustment trim pot. The thermocouple can then be calibrated following the procedure outline in Section 6.2 (p.99).

Note that changing the trim pot position shifts the circuit output signal, voiding the calibration and thus must not be changed once the calibration is complete. Trim pot voltages should be recorded after calibration so that the calibration can be retained after the potentiometers have been moved.

It is suggested that if no information is available on the temperature ranges which can be expected during a particular engine test, a two stage calibration can be completed. First calibrate across a wide temperature range (i.e. low gain setting) using the method described above. This allows for a large window into which the in-cylinder temperatures may fall. A second calibration at a higher gain setting can then be completed to focus in on the desired temperature range and thus increase signal resolution. 


\section{Appendix E}

\section{Thermocouple Response Time Laser Test}

The following provides an in-depth overview of the results of the laser tests used to determine the thermocouple response time.

\section{$\underline{\text { E.1 Half Rise Time Technique }}$}

Analysis of the laser test data on a per-cycle basis, the thermocouple delay time was defined as the time needed to register the maximum surface temperature from the moment the laser was fired. Figure E.1 below shows a typical thermocouple response measured during the laser tests, with the vertical line in the figure indicating the point to which the circuit-thermocouple phase delay was defined. Using a pulse of energy of $120 \mathrm{~mJ}$, the time needed to register a temperature swing of $1.86^{\circ} \mathrm{C}$ (using the calibration slope of $2.156^{\circ} \mathrm{C} / \mathrm{V}$ ) was $2.057 \mathrm{~ms}$. Accounting for the time delay of the circuit, this translates to a thermocoupleonly delay of $495 \mu \mathrm{s}$. 
It was noted that there was a large degree of variance in the time the peak temperature was achieved from cycle to cycle, but the slope of the temperature responses during heating (for a given pulse energy) was relatively constant. The variation in the occurrence of the peak temperature was primarily attributed to noise within the signal and the response of the analog filtering circuit to this noise. Variation in the laser pulse energy from cycle-to-cycle was also believed to have been a contributor. In an attempt to obtain a more representative bound on the thermocouple response time, the delay time was defined as twice the time need to reach half of the maximum temperature in the cycle. This technique takes advantage of the relatively constant slope of the temperature trace during the heating process, and was seen to provide a much more consistent response. Figure E.2 compares the results of this technique using the same cycle presented in Figure E.1.

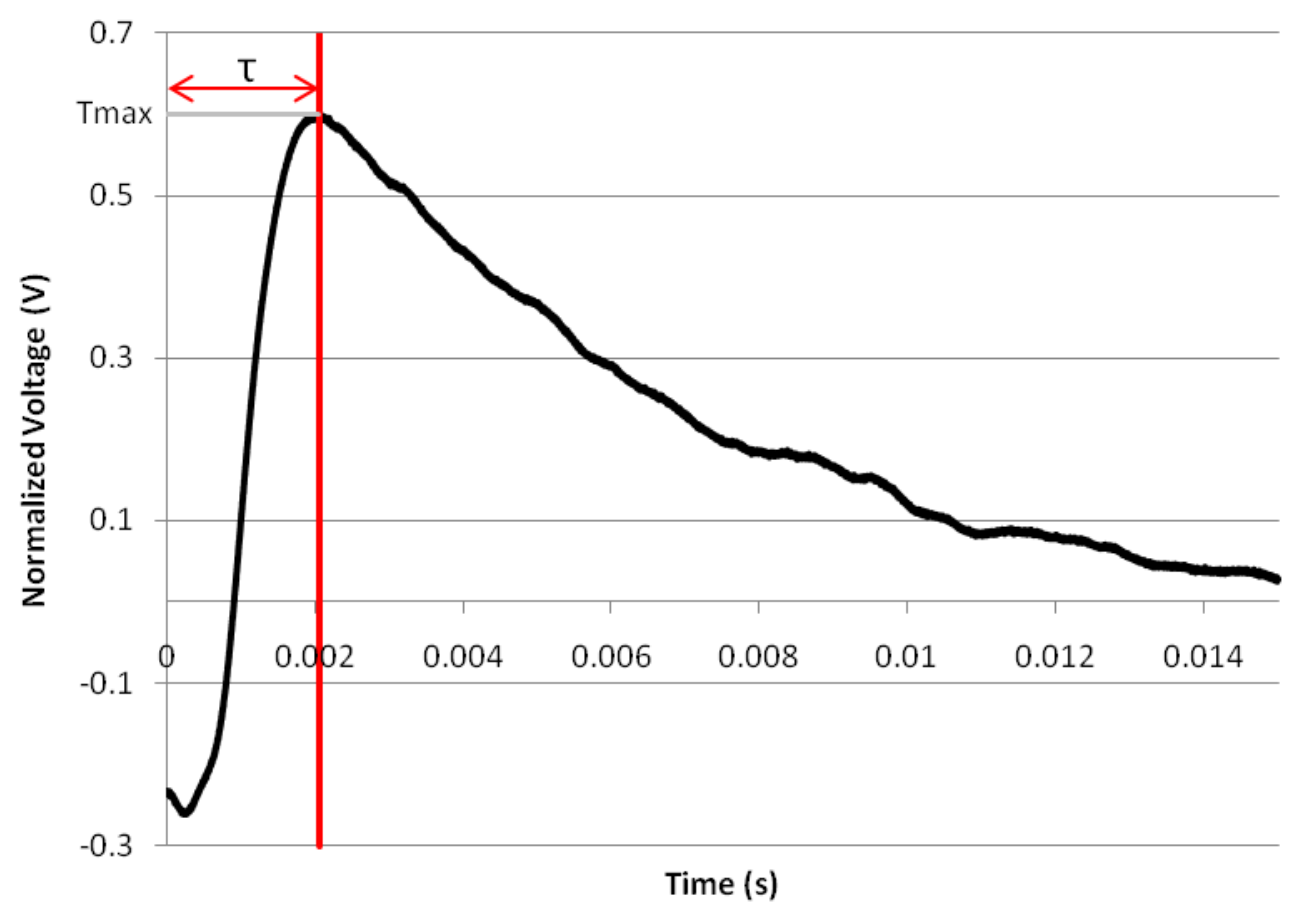

Figure E.1 - Surface Thermocouple Response to a Single 120mJ Laser Pulse 


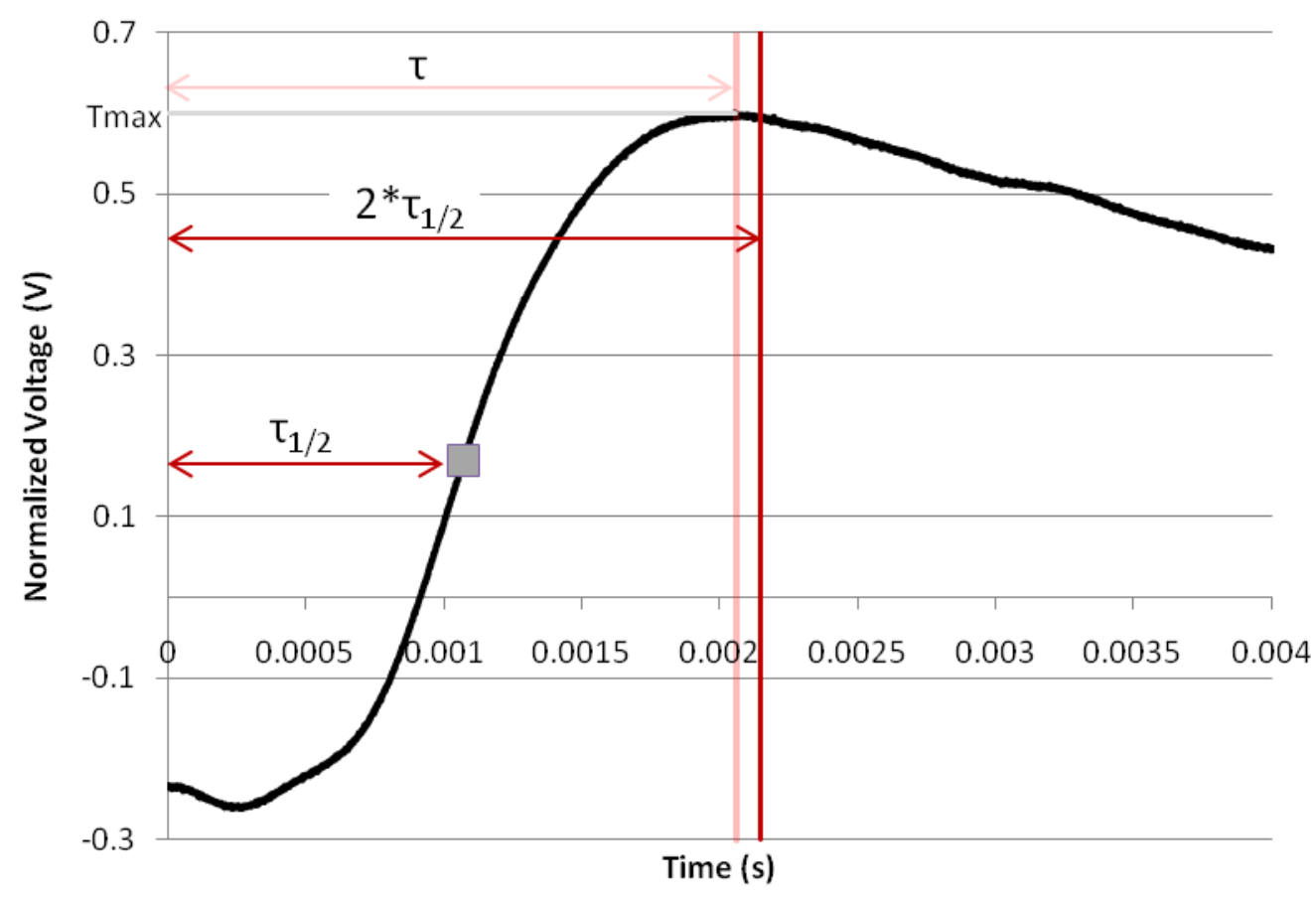

Figure E.2 - Half-Rise Time Method of Determining Thermocouple Response Time

Table E. 1 shows the average thermocouple response time and the associated standard deviation for each using both techniques. The effect of using the half-rise time method in calculating the response times is seen to greatly reduce the variation in the data and thus provide a more representative value of the thermocouple response, particularly for the case in which a low laser pulse energy was used. This is further brought to evidence when plotting the two sets of data, as seen in Figure E.3 and Figure E.4.

Table E.1 - Comparison of Techniques Used to Calculate Thermocouple Response Time

\begin{tabular}{ccccc}
\hline & \multicolumn{2}{c}{ Max Temp } & \multicolumn{2}{c}{ Half-Rise Time } \\
\hline Energy & $\tau_{\text {avg }}(\mathrm{s})$ & $\sigma$ & $\tau_{\text {avg }}(\mathrm{s})$ & $\sigma$ \\
$\mathbf{0 . 2 5} \boldsymbol{e}$ & $2.00 \mathrm{E}-03$ & $2.01 \mathrm{E}-04$ & $1.96 \mathrm{E}-03$ & $5.01 \mathrm{E}-05$ \\
$\mathbf{0 . 5} \boldsymbol{e}$ & $1.97 \mathrm{E}-03$ & $1.92 \mathrm{E}-04$ & $2.05 \mathrm{E}-03$ & $5.63 \mathrm{E}-05$ \\
$\mathbf{0 . 7 5} \boldsymbol{e}$ & $2.02 \mathrm{E}-03$ & $8.86 \mathrm{E}-05$ & $2.08 \mathrm{E}-03$ & $1.68 \mathrm{E}-05$ \\
$\boldsymbol{e}$ & $2.12 \mathrm{E}-03$ & $8.35 \mathrm{E}-05$ & $2.13 \mathrm{E}-03$ & $2.10 \mathrm{E}-05$ \\
\hline
\end{tabular}




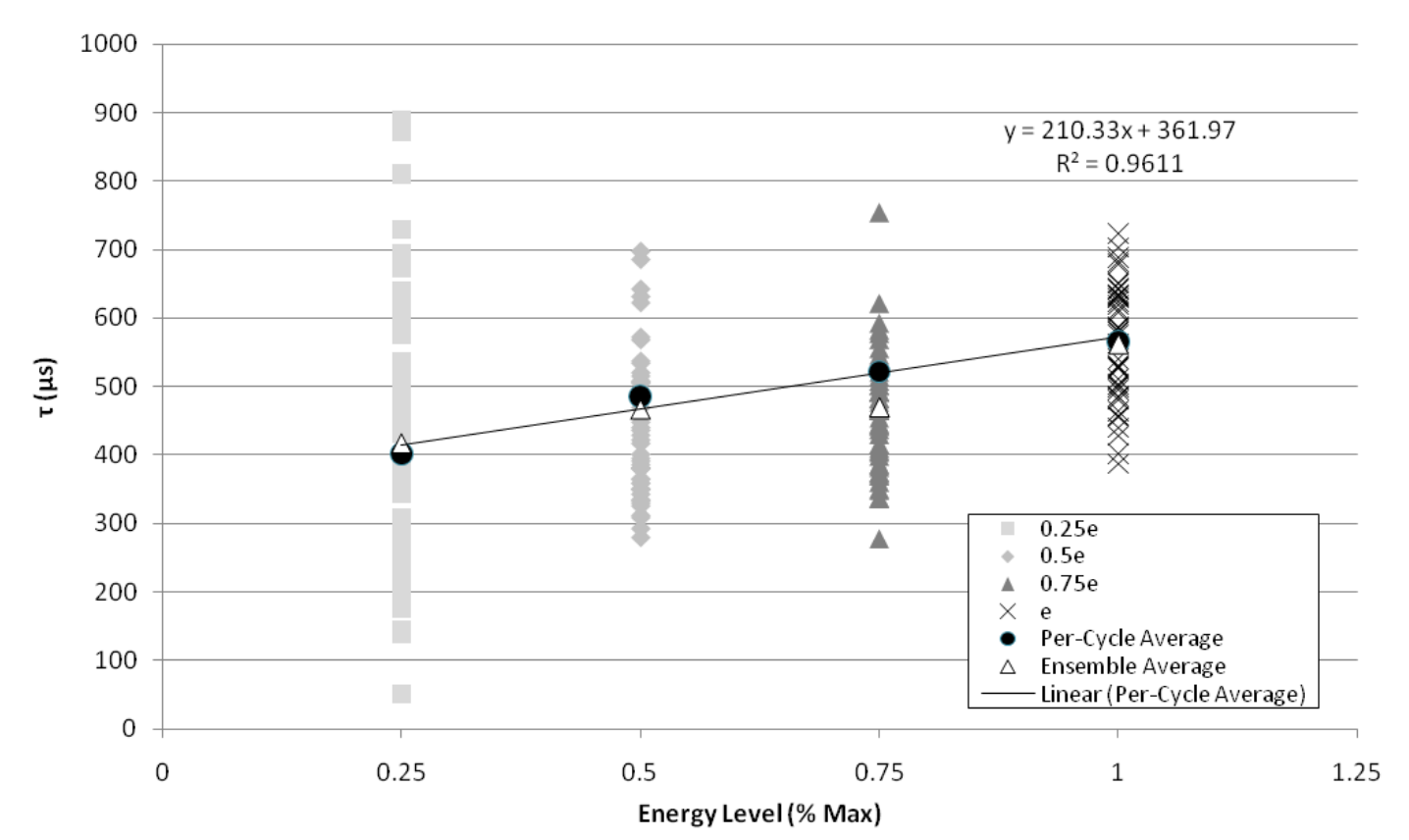

Figure E.3 - Thermocouple Time Delay Calculated at Cycle Maximum Temperature

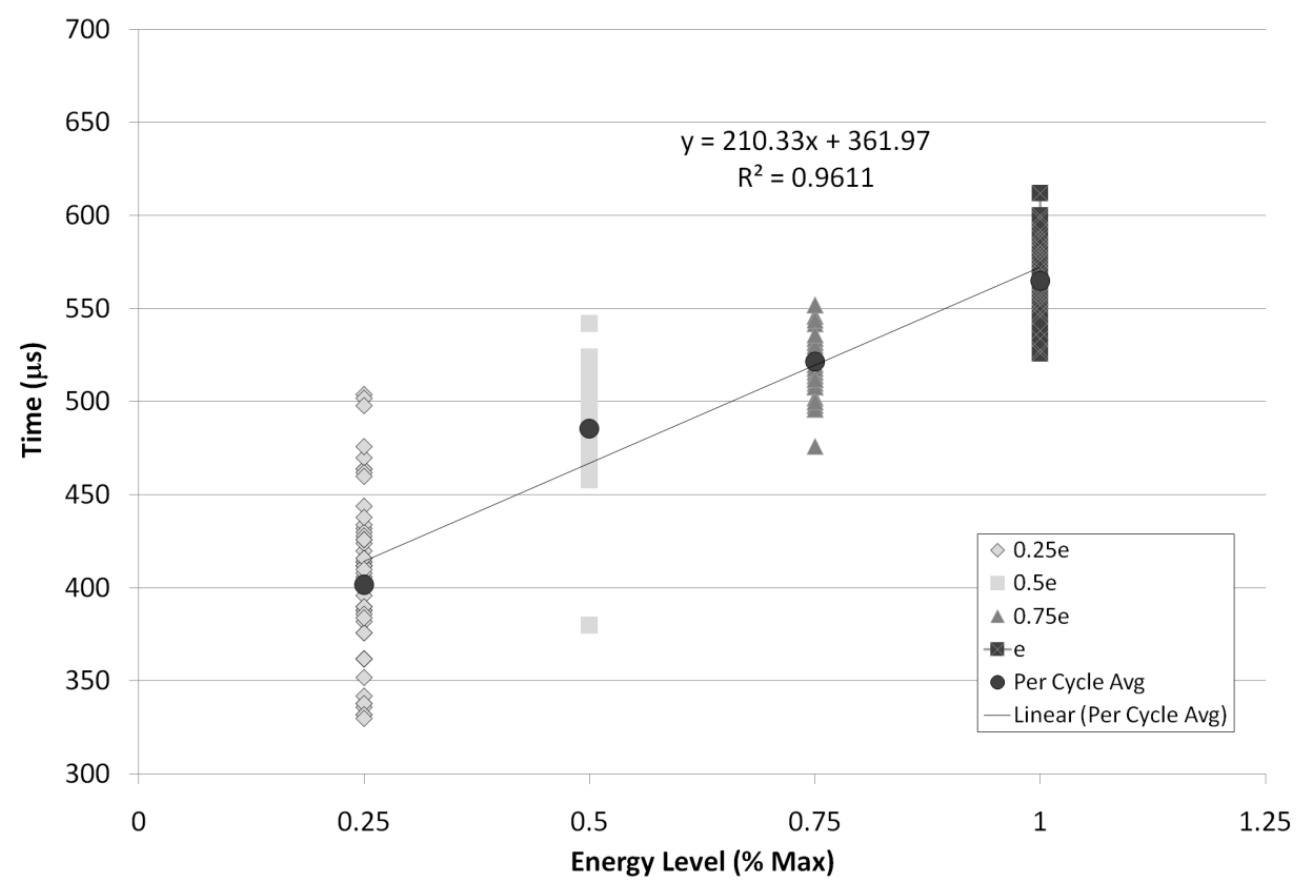

Figure E.4 - Thermocouple Time Delay Calculated Using Half Rise Time Method 


\section{Appendix F}

\section{MATLAB Code Descriptions}

The following section provides further detail on each of the MATLAB functions used in the processing of the collected data. Three types of data files are processed using these MATLAB programs: instantaneous thermocouple voltages, instantaneous in-cylinder pressure measurements and low speed control panel data (i.e. speed, torque, flow rates, emissions etc). All high speed temperature and pressure files contain 100 cycles of data measured at 3600 samples per engine cycle (1800 measurements per revolution). Note that the programs were written for the batch processing of multiple data files collected through a test run, but codes can also be modified to process individual data files. 
TempMain.m

Primary program file used to for the batch processing of the high speed temperature measurements. Requires user to select the directory containing the measurement files to be batch processed and the directory for the processed files to be saved. Contains function calls to TempPistonProcess.m, HeatFlux.m and TempSwing.m.

TempProcessPiston.m Converts the filtered high speed thermocouple voltage to temperature using the calibration coefficients for each individual thermocouple from a user selected txt file. Signals are shifted to account for the time delay introduced by the filtering circuit and inherent thermocouple delay. Also calculates the average measured temperature for each thermocouple. Outputs .txt files containing shifted temperature data (starting at TDC intake) vs. crank angle degree for each file and a single .txt file containing the average thermocouple temperatures for each of the processed files.

\section{HeatFlux.m}

Solves the one-dimensional, unsteady heat transfer equation through a semi-infinite wall to calculate the instantaneous and average heat flux through the piston crown based on the processed temperature measurements output by TempProcessPiston.m. Calls function AnBn.m for calculation of the Fourier coefficients. Outputs .txt files containing instantaneous heat flux measurements for each measurement file and a single .txt file containing the average and peak heat fluxes measured at the five measurement locations for each of the processed files.

AnBn.m

Calculates the Fourier coefficients used in the heat transfer calculation. Outputs a matrix containing the $\mathrm{A}$ and $\mathrm{B}$ coefficients whose size is dependent on the number of harmonics selected to represent the signal traces. 
TempSwing.m

CPMain.m

CPProcess.m

PressureMain.m
Calculates the peak-to-peak temperature for each cycle of instantaneous temperature data in a test measurement file and averages them over the 100 cycles collected. Maximum cycle temperatures and angle of occurrence are also calculated. Outputs two single .txt files for each batch of processed files that contain: the average temperature swings for each measurement file and the cycle-averaged peak measured temperatures/angle of occurrence.

Primary program file for the processing of the engine control panel data. Requires user to select the directory containing the measurement files to be batch processed and the directory for the processed files to be saved. Contains function call to CPProcess.m.

Averages the control panel data gathered at one second intervals over a test run. Uses the measured engine outputs to calculate average power, BMEP, BSFC and air fuel ratio. Function also eliminates the time delay in the emissions data. Writes a single .txt file containing the computed averages for each of the test runs in a batch of processed data files.

Primary program file for the processing of the in-cylinder pressure data. Requires user to select the directory containing the measurement files to be batch processed and the directory for the processed files to be saved. Contains function call to PressureProcess.m. 
PressureProcess.m Converts the measured voltages from the in-cylinder piezoelectric pressure transducer to pressure measurements using the transducer slope $(\mathrm{kPa} / \mathrm{V})$ and the intake pressure measurements. IMEP and COV are also calculated using Pressure traces are also analyzed for any traces of high frequency noise which are representative of abnormal combustion (i.e. knock). Program outputs a .txt files containing instantaneous intake and in-cylinder pressure measurements as a function of crank angle position. Outputs three single .txt files for each batch of processed files that contain: the average IMEP and COV, average knock intensity and cycle averaged peak pressure/angle of occurrence for each processed data file. 


\section{Appendix G}

\section{Piston Surface Temperature Measurement Overview}

The following section provides a brief overview of the piston surface temperature measurements which were successfully taken during multiple test runs. Photographs of wire failures at different locations along the routing path in the apparatus are also shown.

\section{G.1 Surface Temperature and Heat Flux Measurements}

The surface piston temperature measurements and the associated heat flux measurements were taken with a copper coated piston in the As-Sprayed condition at 1350rpm and four load conditions. The temperature measurements collected demonstrated that when wire integrity was maintained, the surface temperature measurements were highly satisfactory due to their high fidelity and excellent response. Figure G.1 shows a set of cycle resolved instantaneous thermocouple measurements taken at the four test conditions. The corresponding instantaneous heat flux values at the same conditions are shown in Figure G.2. 


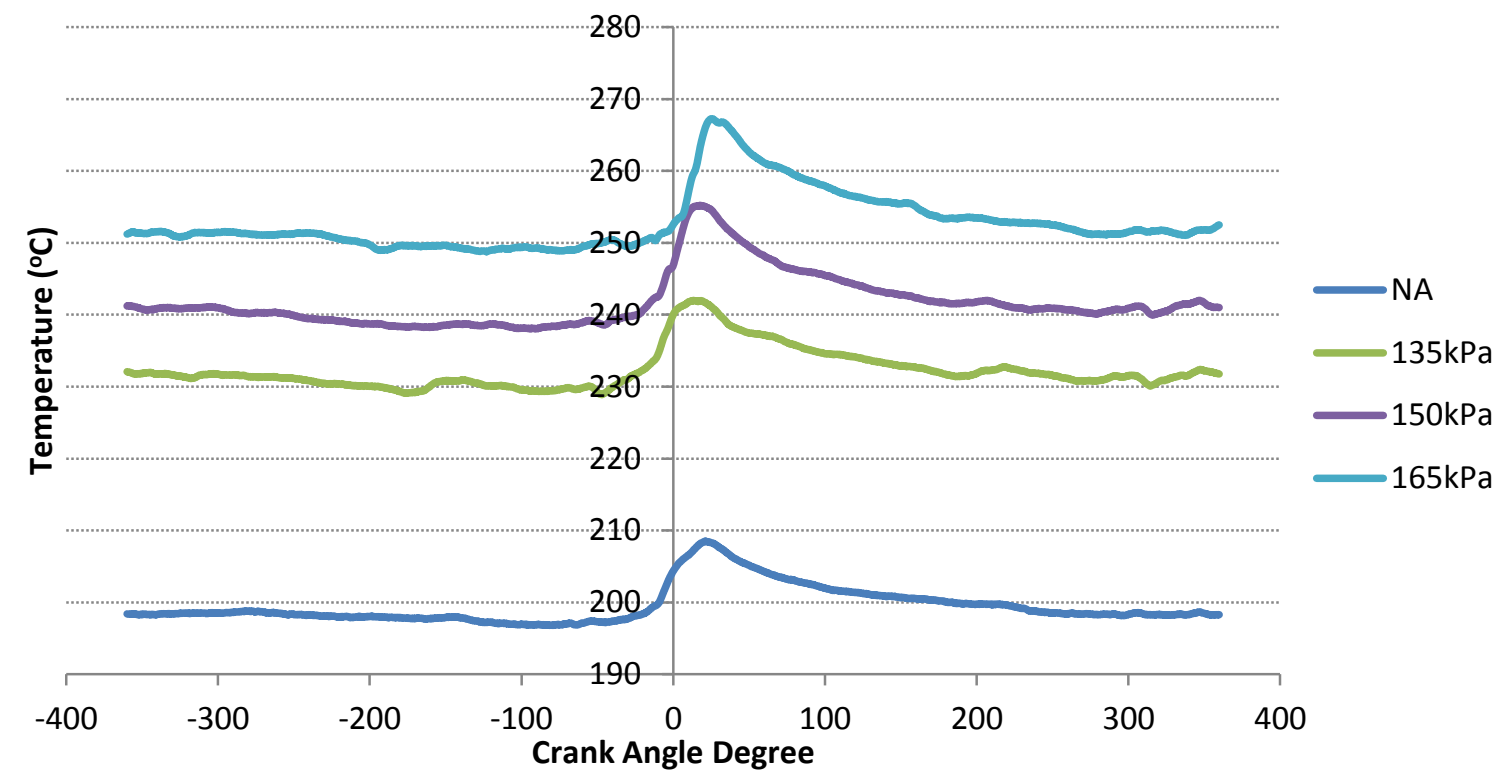

Figure G.1 - Instantaneous Surface Temperature Measurement

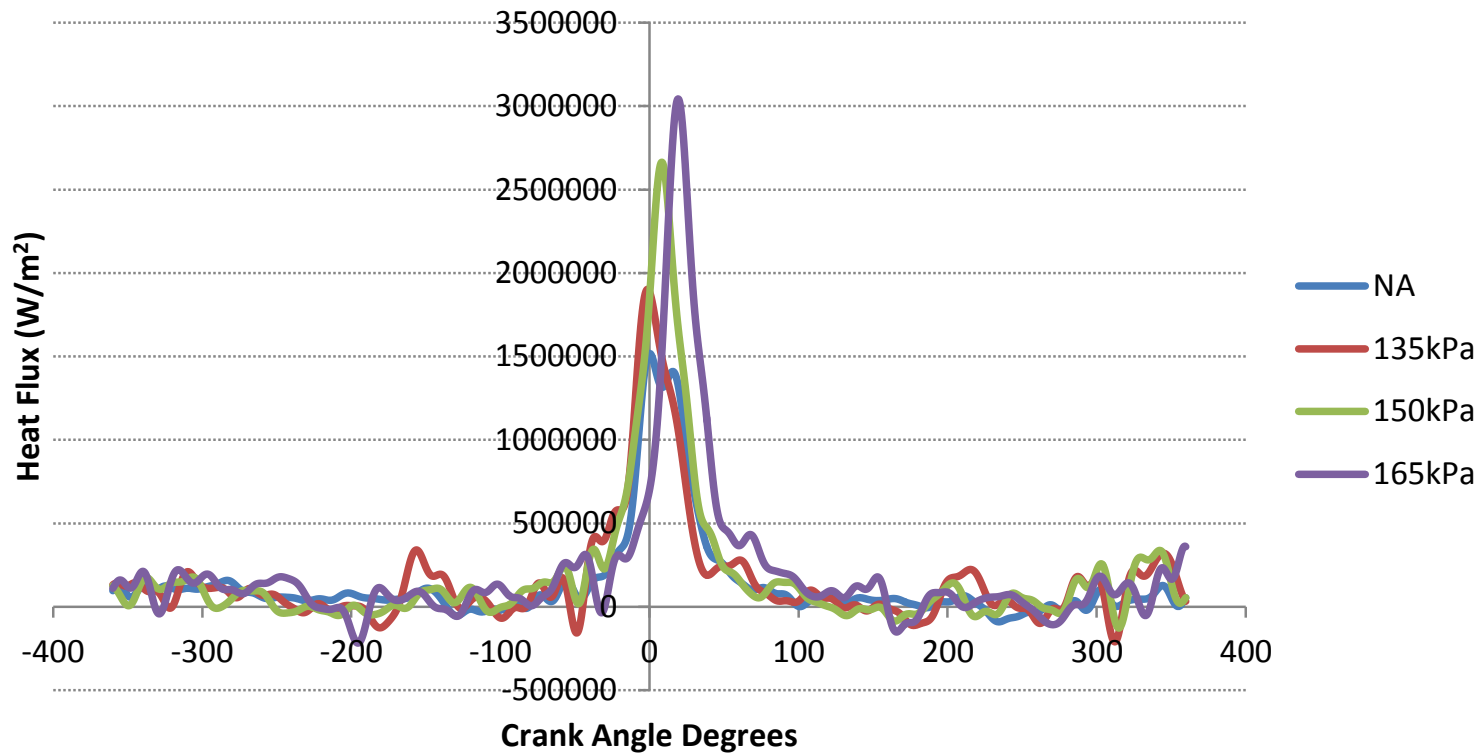

Figure G.2 - Instantaneous Heat Flux Measurements

The following figures are a compilation of the most significant results obtained during seven test runs in which wire integrity was maintained. While preliminary, the results demonstrate the functionality of the system and its potential to produce very meaningful data. 


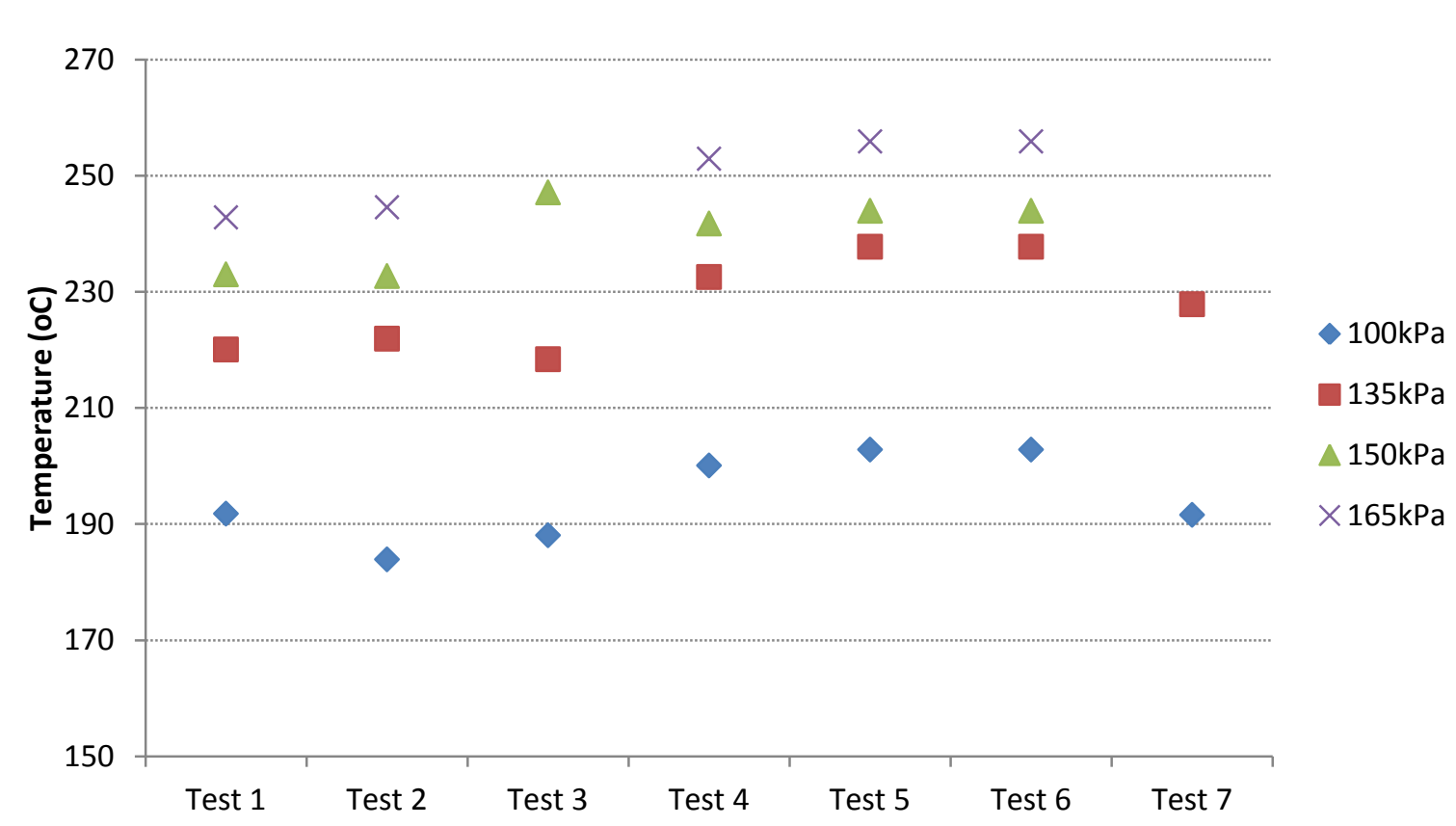

Figure G.3 - Average Piston Surface Temperature Measurements

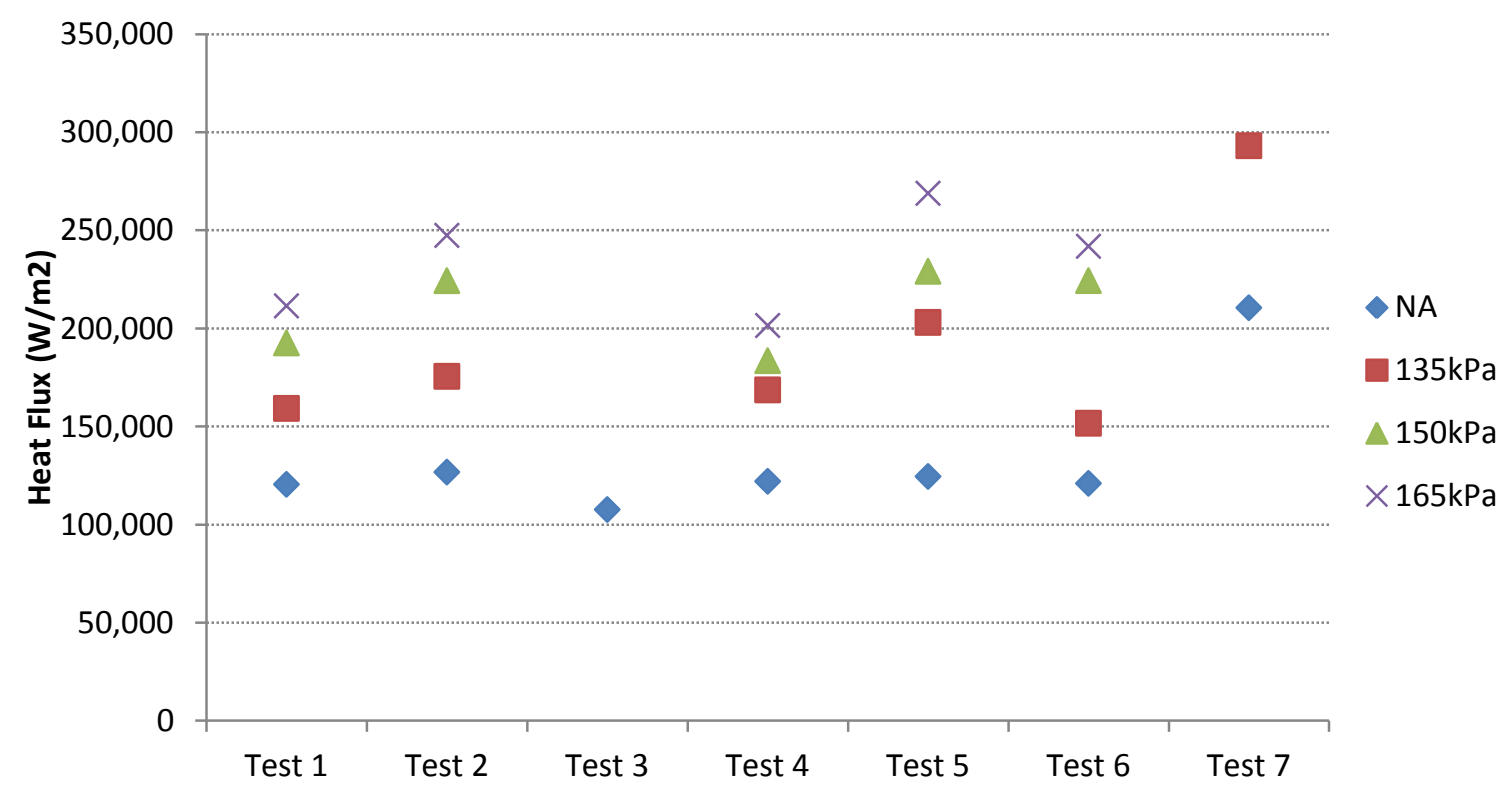

Figure G.4 - Average Flux Measurements 


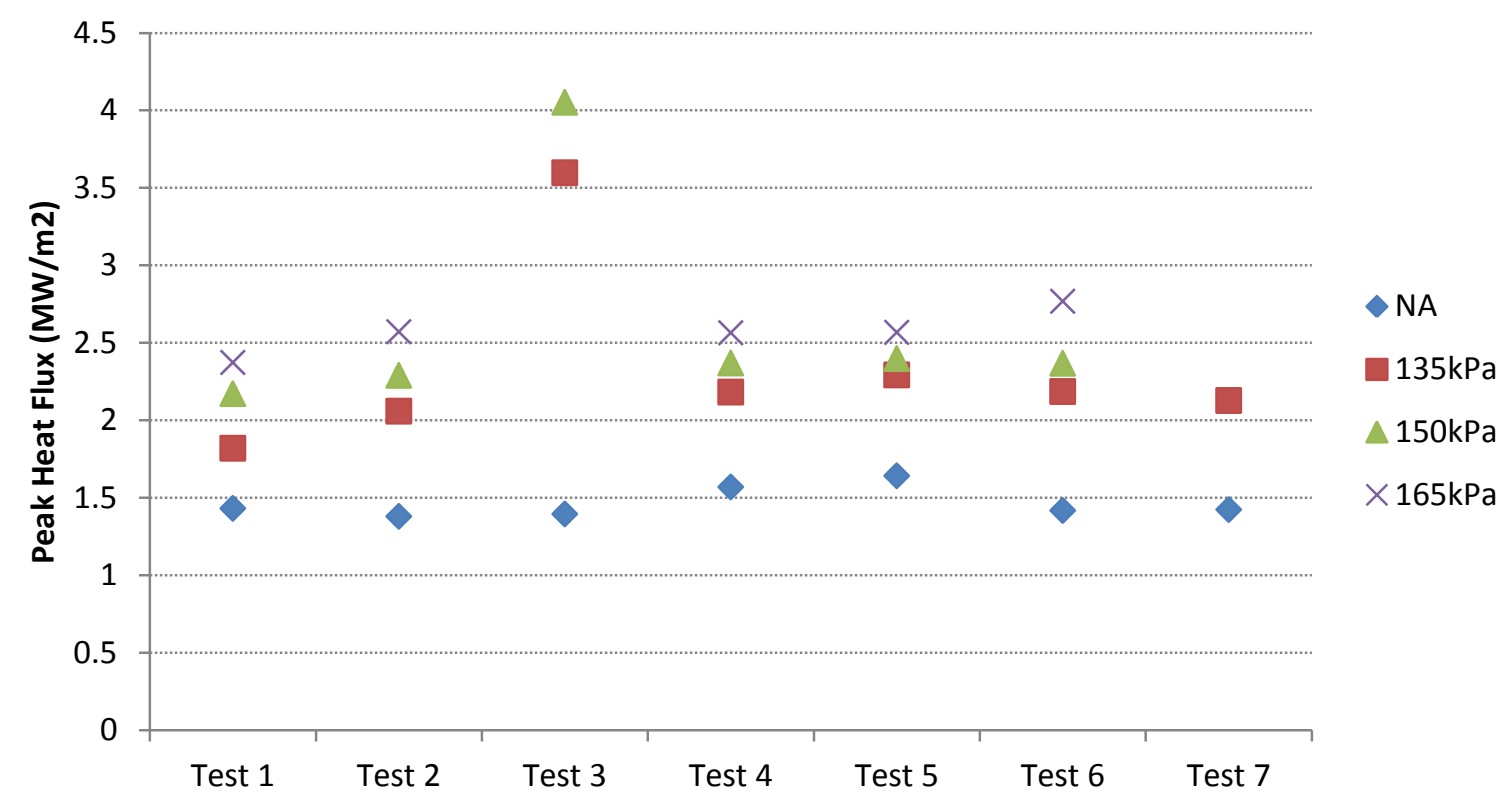

Figure G.5 - Peak Heat Flux Measurements

\section{G.2 Wire Failure Photographs}

The following are a collection of photographs documenting various wire failures which occurred along the thermocouple wire routing path during the testing regime. The metal strap seen in the photographs was determined to be the primary cause of the majority of the failures. It was later replaced with a $1 / 4$ in Teflon tube which maintained the integrity of the wires throughout the surface roughness testing described in Chapter 7. 

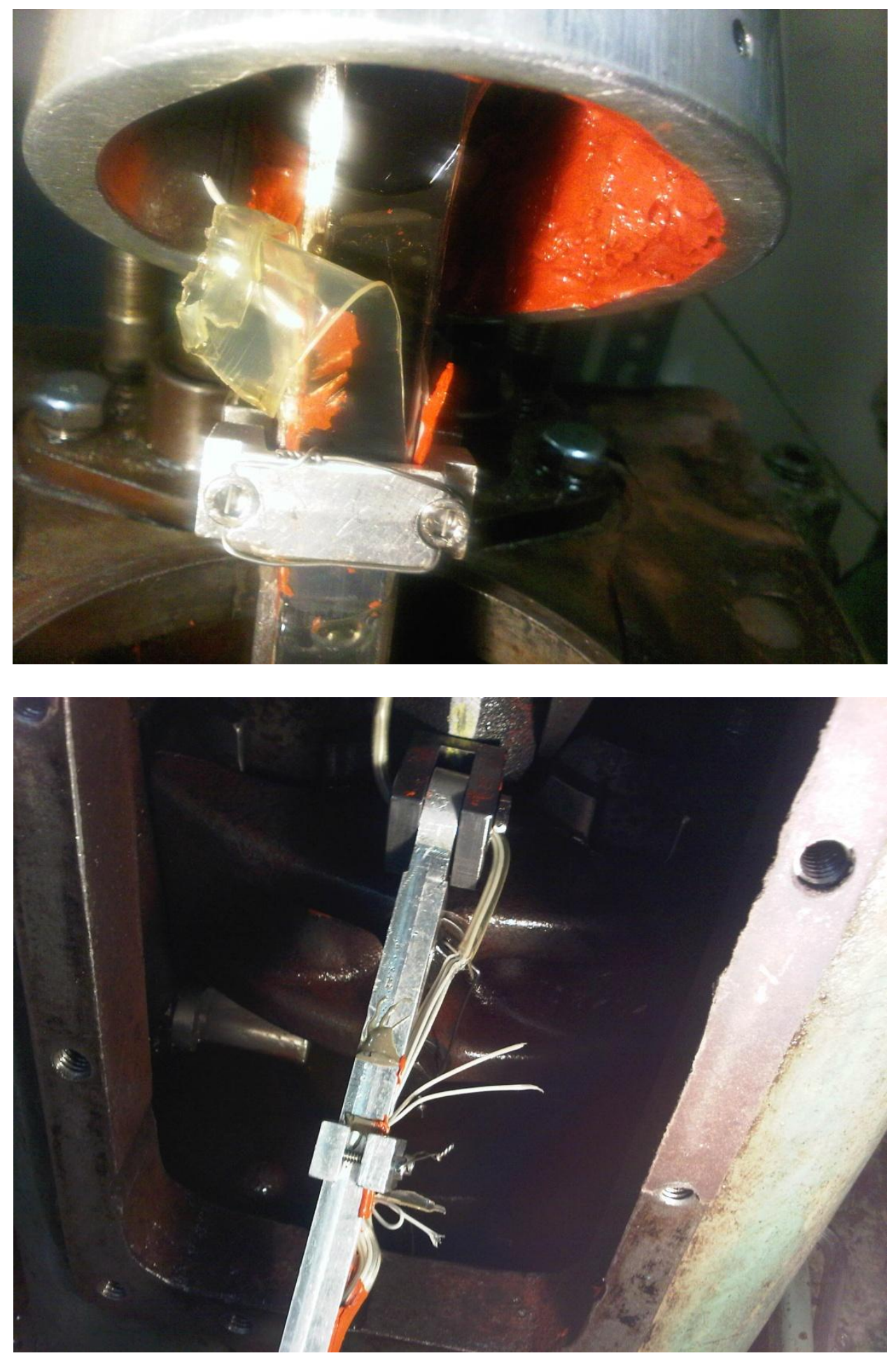

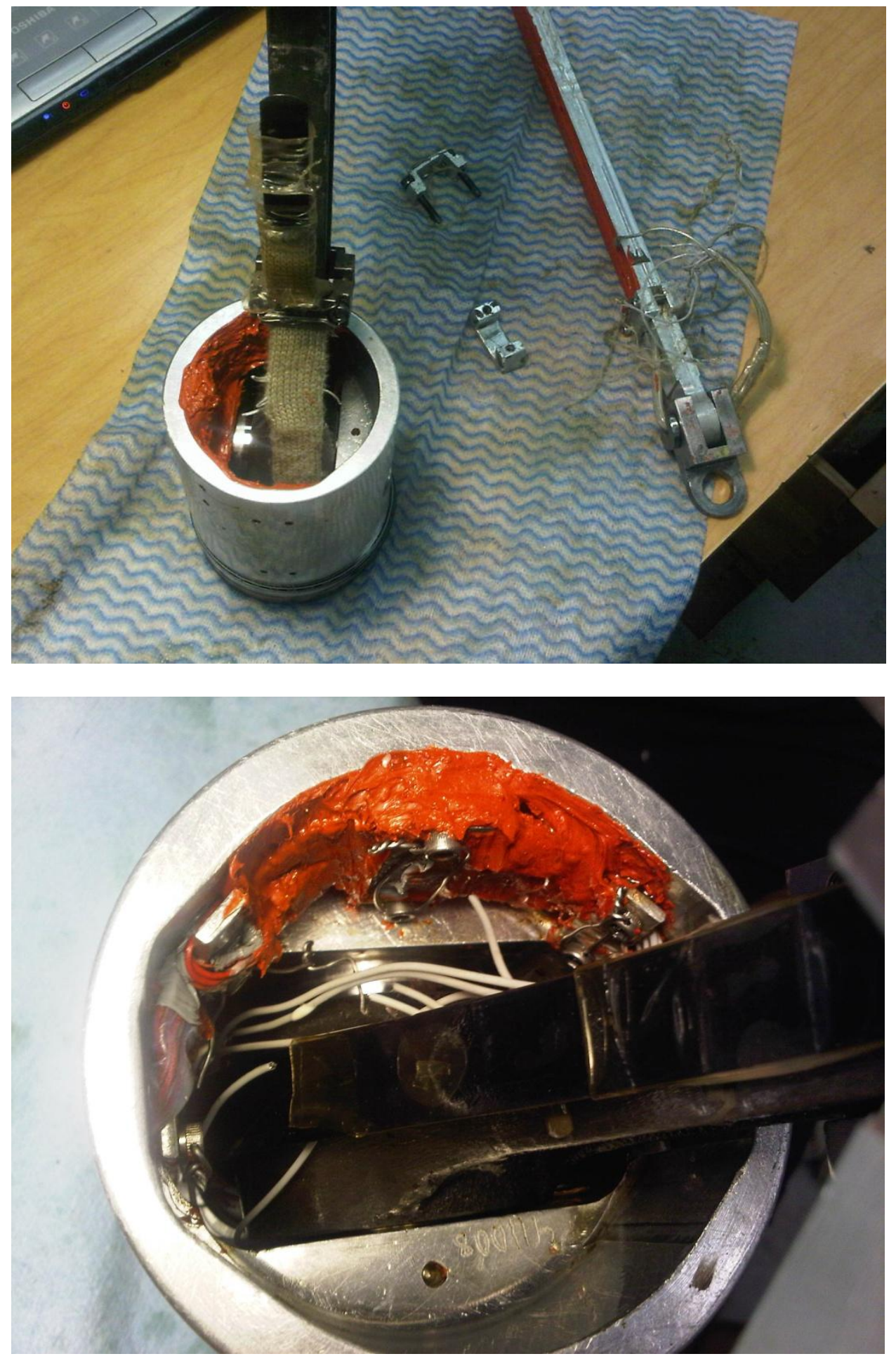


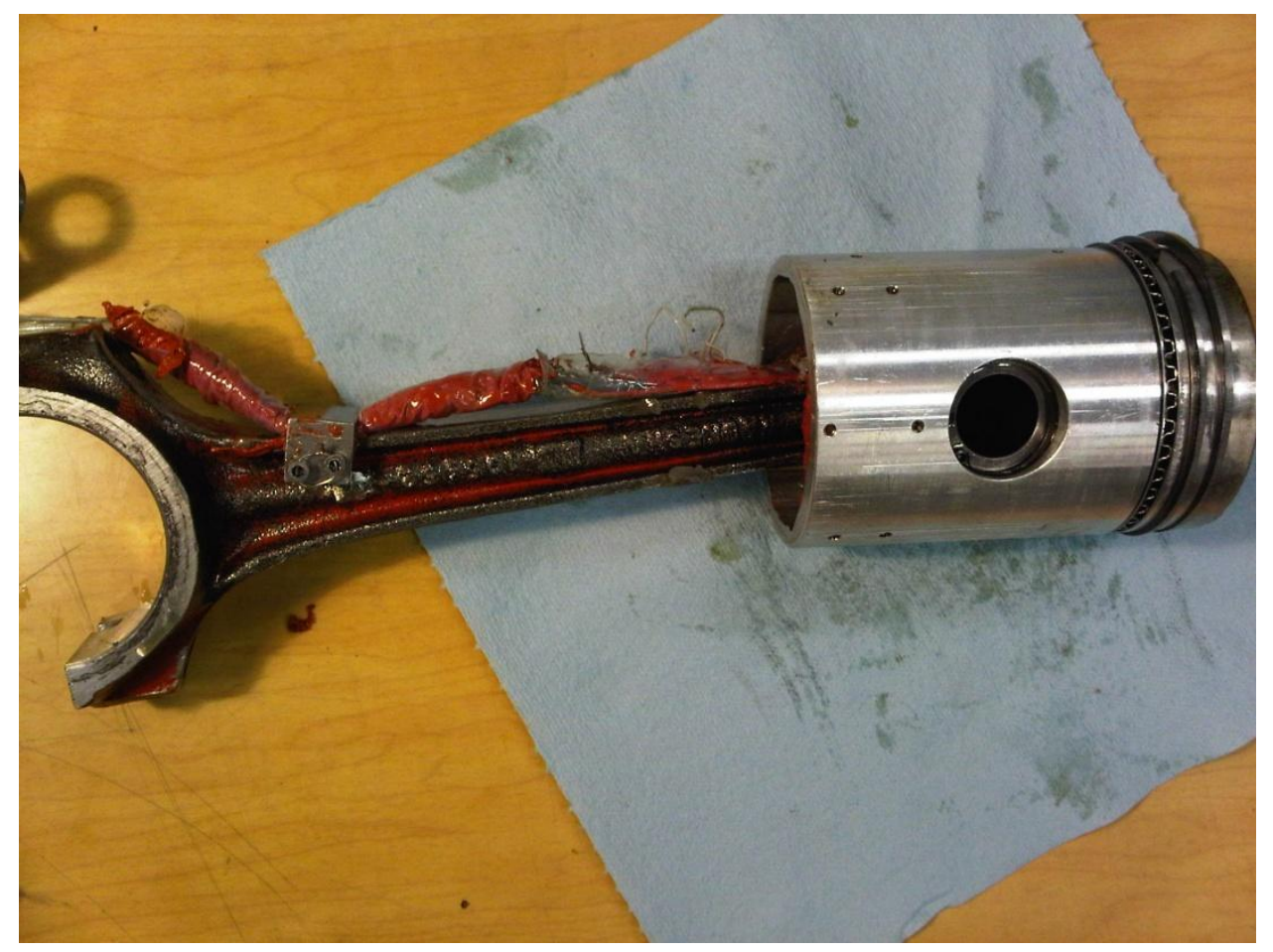

